\title{
Importance of CXCL12 and CXCR4 in radiotherapy of head and neck cancer, considering the association with HPV-infection
}

\section{Doctoral thesis}

In partial fulfillment of the requirements for the degree

"Doctor of Philosophy (PhD)"

in the Molecular Medicine Study Program

at the Georg-August University Göttingen

submitted by

Narges Tehrany

born in

Teheran, Iran

Göttingen, 2015 
Members of the Thesis Committee:

\section{Prof. Dr. Peter Burfeind}

Institute of Human Genetics, University Medical Center Göttingen

\section{Prof. Dr. Holger Reichardt}

Department of Cellular and Molecular Immunology, University Medical Center Göttingen

\section{PD. Dr. med. Hendrik A. Wolff}

Department of Radiotherapy and Radiation Oncology, University Medical Center Göttingen

Date of Disputation: $\quad 11.08 .2015$ 


\section{AFFIDAVIT}

Herewith I declare that my doctoral thesis entitled: "Importance of CXCL12 and CXCR4 in radiotherapy of head and neck cancer, considering the association with HPV-infection" has been written independently with no other sources and aids than quoted.

Göttingen,

Narges Tehrany 


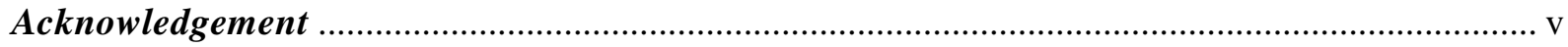

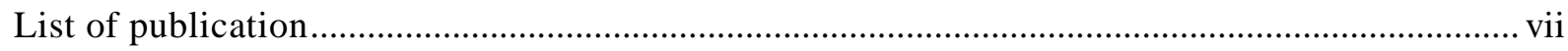

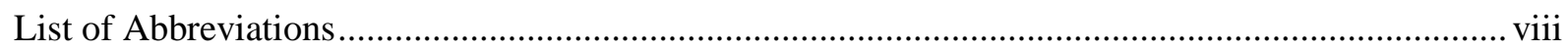

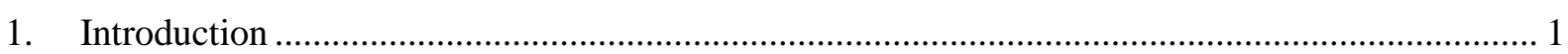

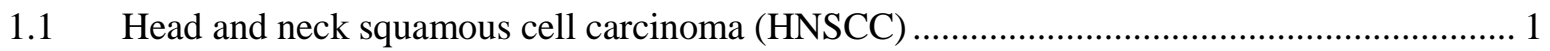

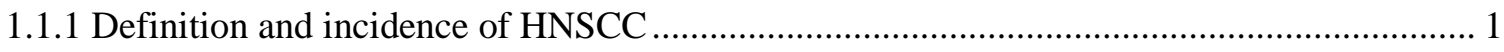

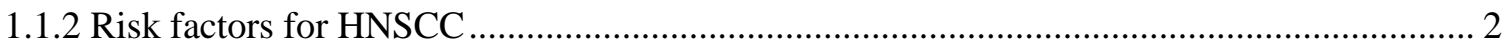

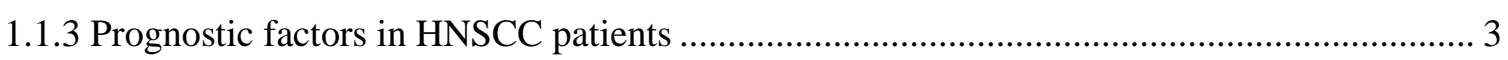

1.1.4 Survival of HNSCC patients and tumour recurrence …...................................................... 3

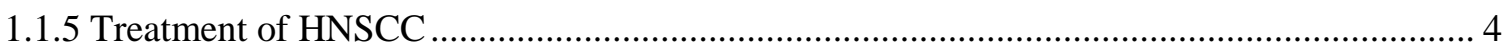

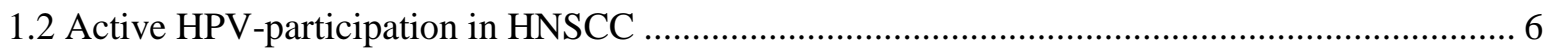

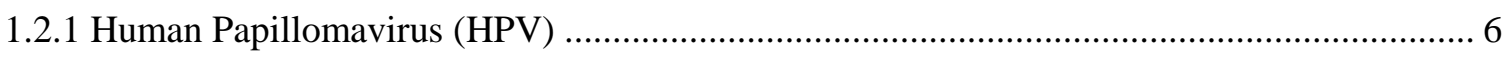

1.2.2 Molecular evidence for the role of HPV in HNSCC tumour progression .............................. 6

1.3 The role of the microenvironment in tumour development......................................................... 9

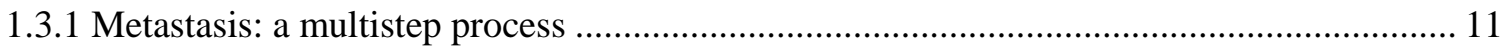

1.3.1.1 Three theories of seeding and colonisation in organ-specific metastasis ...................... 12

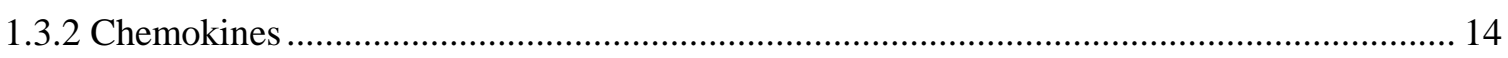

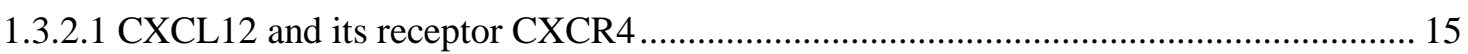

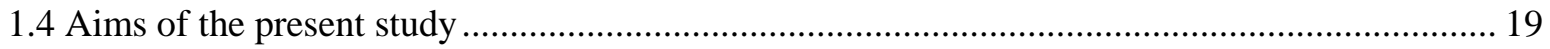

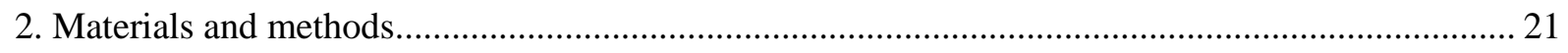

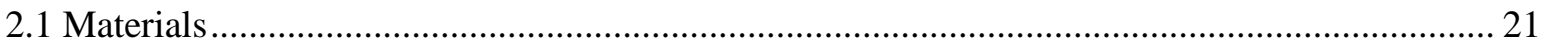

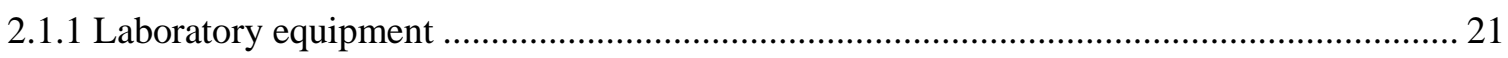

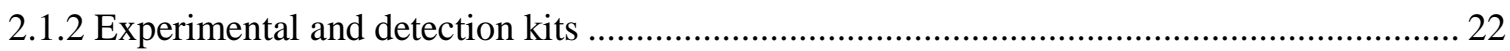

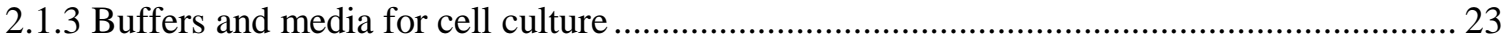

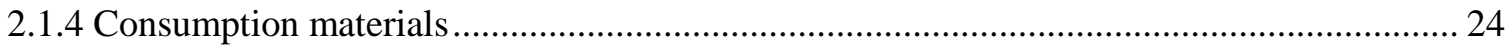

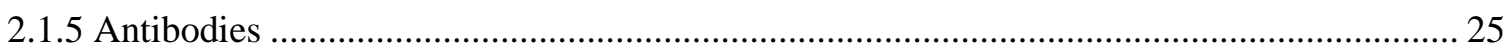

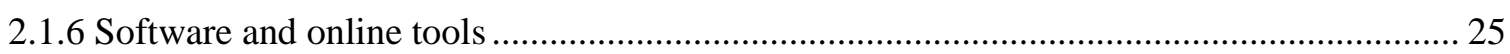

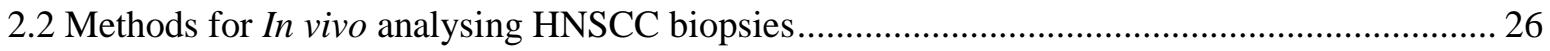

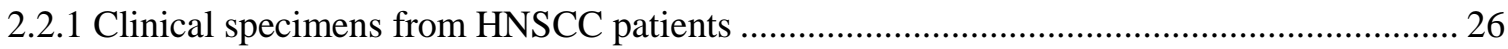

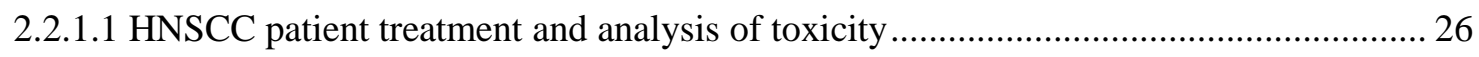

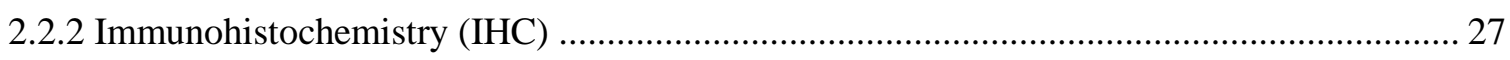

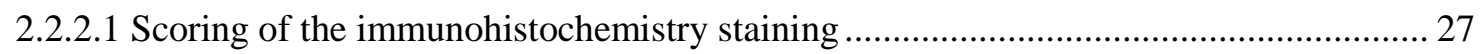

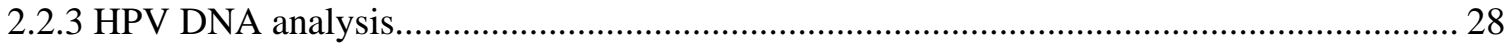

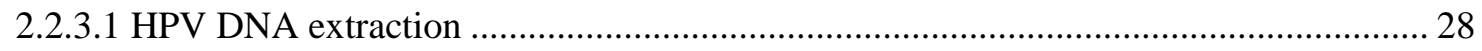

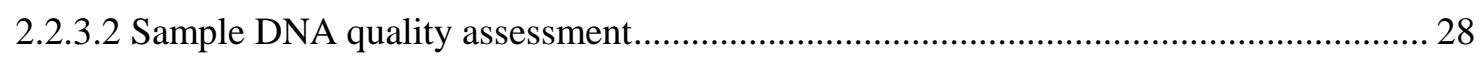

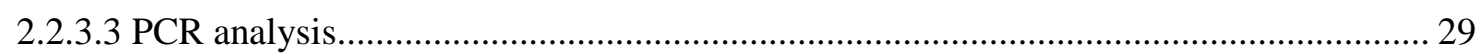




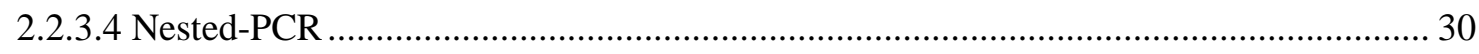

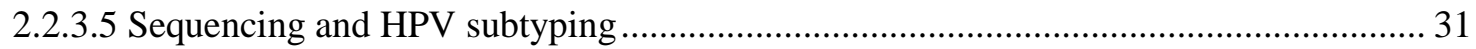

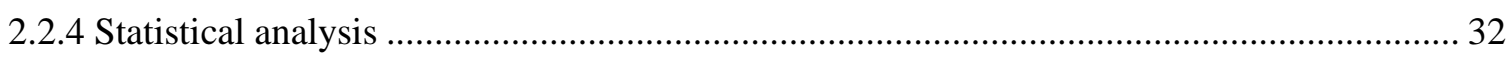

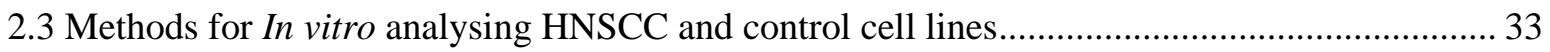

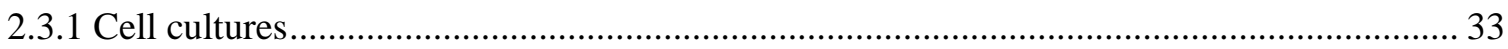

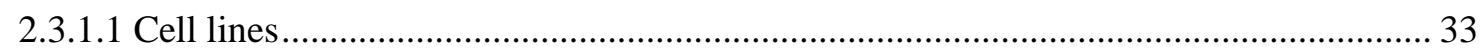

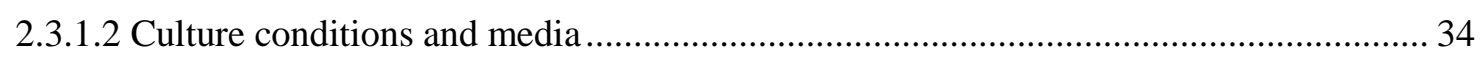

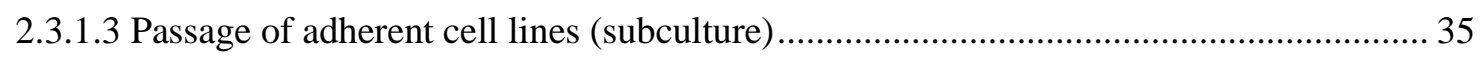

2.3.1.4 Counting cells with the Neubauer counting chamber................................................... 35

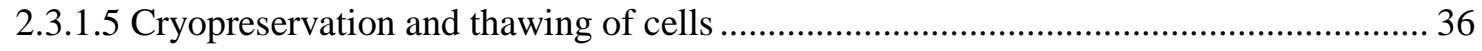

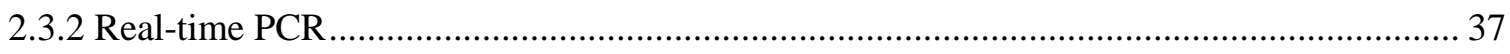

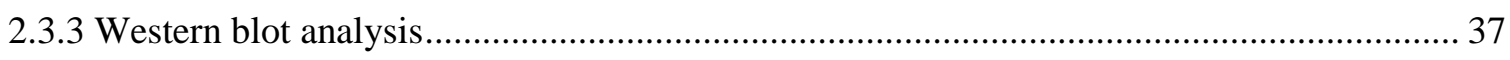

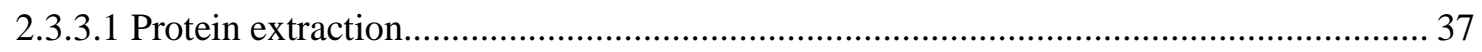

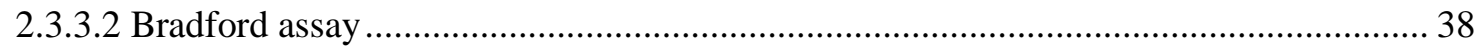

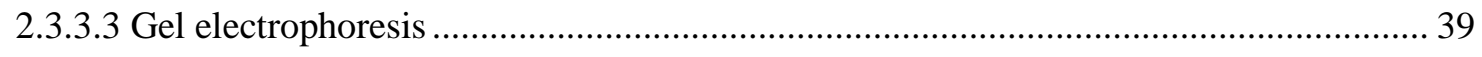

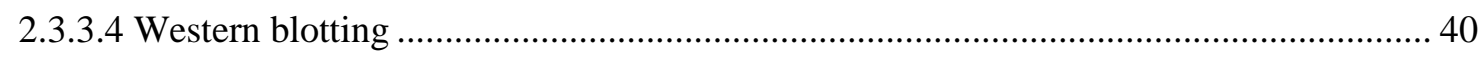

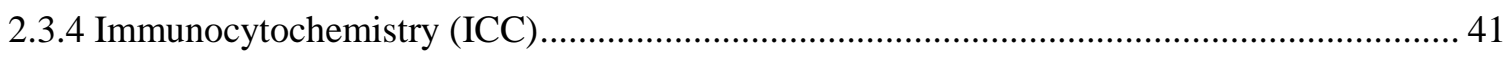

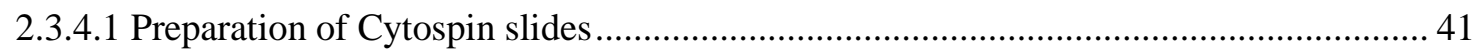

2.3.4.2 Immunocytochemical CXCL12 staining method ...................................................... 42

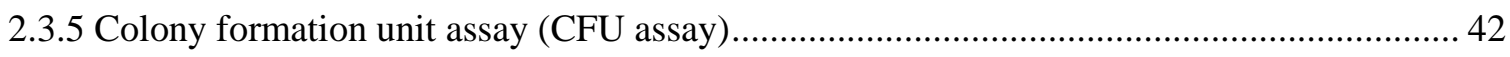

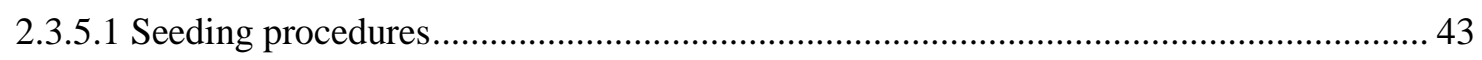

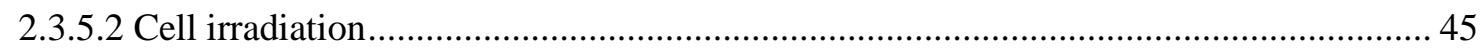

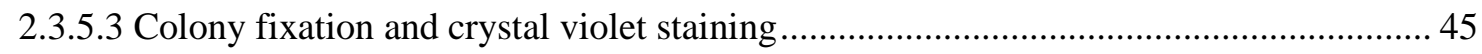

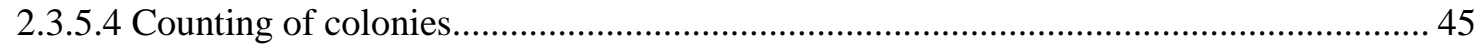

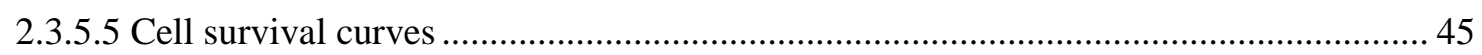

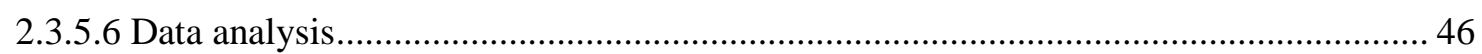

2.3.6 Cell viability assay - Cell Titer Blue ${ }^{\circledR}$ (CTB assay) ………………………………........... 46

2.3.6.1 Determination of optimal incubation time and radiation dose within CTB assay ......... 47

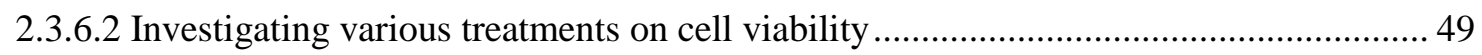

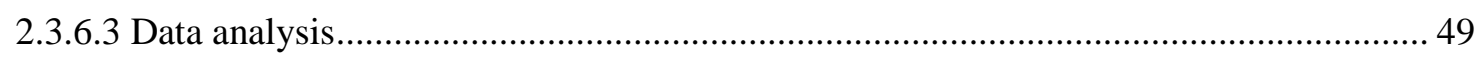

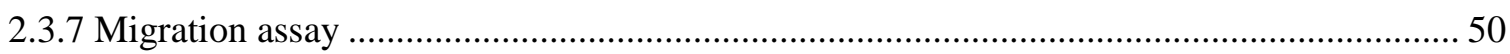

2.3.7.1 Determination of optimal concentrations of CXCL12 and AMD3100 ......................... 51

2.3.7.2 Influence of irradiation and CXCL12 on cell migration ............................................... 51

2.3.7.3 Influence of AMD3100 on CXCR4-positive migrating cells ........................................ 52

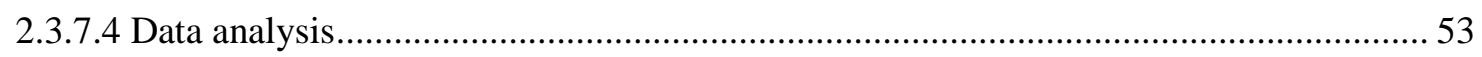

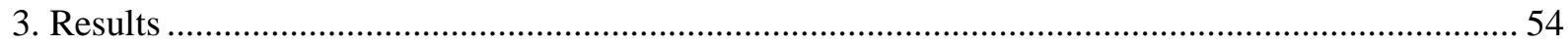

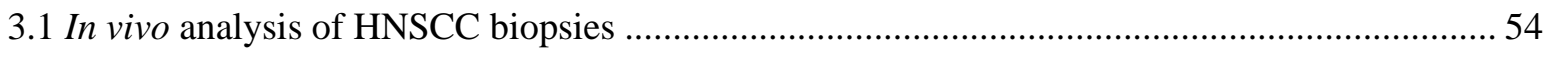

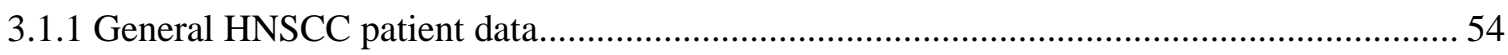


3.1.2 Analysis of CXCL12, CXCR4 and $\mathrm{p} 16^{\mathrm{INK} 4 \mathrm{~A}}$ expression at the protein level by immunohistochemical staining

3.1.2.1 Association of CXCL12, CXCR4 and p16 ${ }^{\mathrm{INK} 4 \mathrm{~A}}$ expression with pre-treatment parameters

3.1.2.2 Correlation between CXCL12, CXCR4 and $\mathrm{p} 16^{\mathrm{INK} 4 \mathrm{~A}}$ expression in HNSCC tumours 61

3.1.3. Correlation between $\mathrm{p} 16^{\mathrm{INK} 4 \mathrm{~A}}$ expression and HPV status in HNSCC tissue samples

3.1.4 Treatment outcome and high-grade acute organ and hematotoxicity in HNSCC patients ... 65

3.1.4.1 Correlation of cytoplasmic expression of CXCL12, CXCR4 and p16 ${ }^{\mathrm{INK} 4 \mathrm{~A}}$ with acute toxicity during treatment

3.1.5 Association of CXCL12, CXCR4 and $\mathrm{p} 16^{\mathrm{INK} 4 \mathrm{~A}}$ expression with survival data of HNSCC

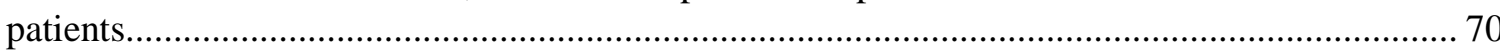

3.1.5.1 Impact of CXCL12 and CXCR4 expression on patient survival.................................. 70

3.1.5.2 Impact of $\mathrm{p} 16^{\mathrm{INK} 4 \mathrm{~A}}$ expression and the occurrence of HGAOT during $\mathrm{R}(\mathrm{C}) \mathrm{T}$ on HNSCC patient survival

3.2 The role of CXCL12 and CXCR4 in the migration of irradiated HNSCC and control cell lines

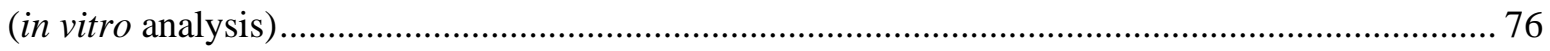

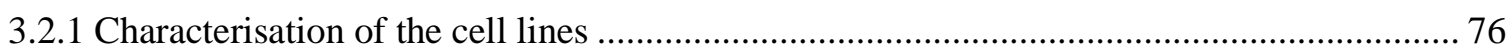

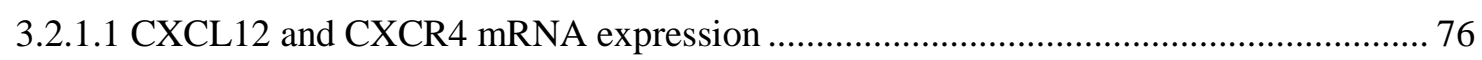

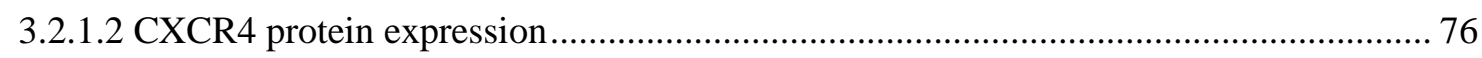

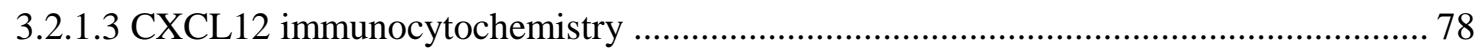

3.2.1.4 Investigation of the radiosensitivity of the cell lines ................................................... 79

3.2.1.5 Metabolic activity of the cell lines under different treatment conditions ...................... 82

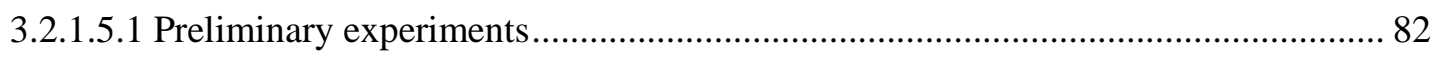

3.2.1.5.2 Main experiment: Analysis the cell viability of cells under different treatment

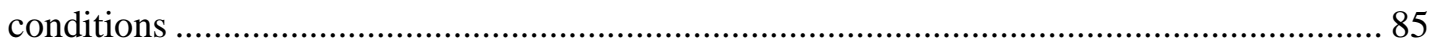

3.2.2 The role of CXCL12 and CXCR4 in the migration of HNSCC and control cells............... 87

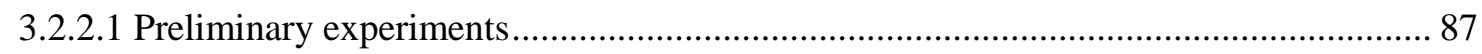

3.2.2.2 Migratory response of HNSCC and control cells with different level of CXCL12 and

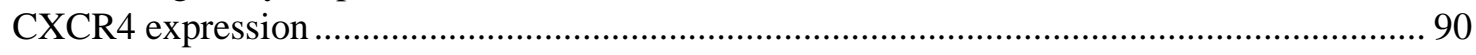

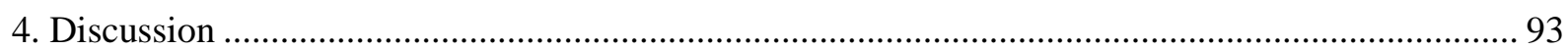

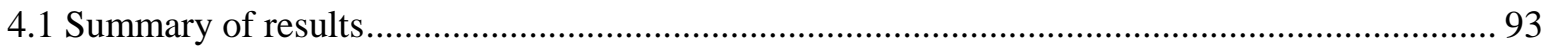

4.2 The crucial role of HPV/P16 $6^{\mathrm{INK} 4 \mathrm{~A}}$ in prognosis and survival of HNSCC patients ..................... 95

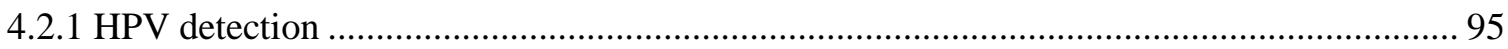

4.2.2 $\mathrm{HPV} / \mathrm{p} 16^{\mathrm{INK} 4 \mathrm{~A}}$-associated HNSCC and prognosis of patients ........................................... 98

4.2.3 Combined effect of $\mathrm{p} 16^{\mathrm{INK} 4 \mathrm{~A}}$ expression and the occurrence of HGAOT on patients'

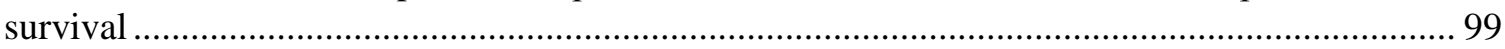

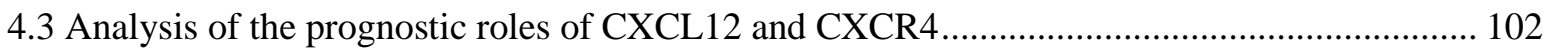

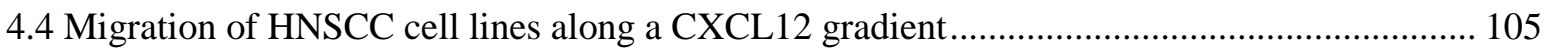

4.4.1 Characterisation of the employed cell lines.................................................................... 105

4.4.2 Effect of irradiation on the migration behaviour of HNSCC and control cell lines among a

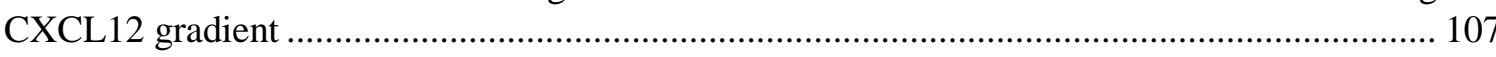




\section{Table of Contents}

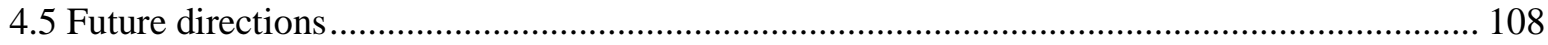

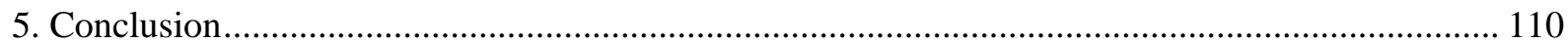

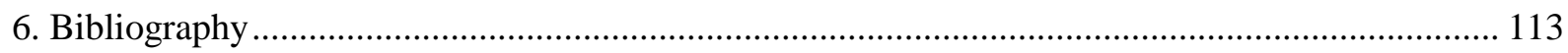

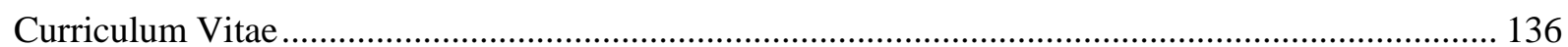


Completing a thesis is a scientific challenge. Without the generous guidance and the help of several individuals who in one way or another contributed and extended their valuable assistance in the preparation and completion of this study, it cannot be successfully done.

I am deeply grateful to Prof. Dr. Peter Burfeind, for his useful suggestion, aspiring guidance, encouragement, criticism and trust.

I also express my warm thanks to Prof. Dr. Holger Reichardt, for his scientific discussions and suggestions.

I gratefully acknowledged PD. Dr. med. Hendrik Wolff, for his personal attention, academic and financial support. For giving me the opportunity to perform such an important and also exciting research in his research group. He positively encouraged and constructively prodded me along, and for this, I am very thankful.

Special thanks go to laboratory leader Ms. Margret Rave-Fränk, for her constructive advices, valuable suggestion and patient correction of my thesis. Her expertise and advice were very beneficial for the progress of my project.

Thanks are also addressed to Dr. med. Julia Kitz and Dr. Li Li for collaborating with me and giving me the opportunity to do some of my experimental work in their laboratory, in the Department of Pathology. Dr. Li, I really appreciate the scientific discussion we had. Thank you to Dr. Kitz for our social and research conservation.

This research project would not have been possible without the support of members of the Radiotherapy and Radiation Oncology laboratories, for technical help and for sharing their time with me, and also for the friendship and constant support: Juliane Kasten-Krapp, Alexandra Bitter and Sandra Hoffmeister. In addition, the laboratory staffs of the Department of Pathology for the warm welcome help and support: Judith Wolf-Salgo and Anke Klages.

A special thanks to my parents, my sister and friends for supporting me through this endeavour; my father, for his support and interest in my work through all the time, my dear mother, no words will describe her importance in my life, who continuously inspired me and 


\section{Acknowledgement}

encourage me to go beyond my limit, and my sister for her endless love and persistent confidence in me.

Last but not least, I would like to thank my husband, for his faithful love, kindness, constant patience and support he has shown during the past three years, which has taken me to finalize this thesis. 


\section{List of publication}

\section{List of publication}

I. Narges Tehrany, Julia Kitz, Margret Rave-Fränk, Stephan Lorenzen, Li Li, Stefan Küffer, Clemens F. Hess, Peter Burfeind, Holger M. Reichardt, Martin Canis, Tim Beißbarth, Hendrik A. Wolff. "High-grade acute organ toxicity and p16 ${ }^{\mathrm{INK} 4 \mathrm{~A}}$ expression as positive prognostic factors in primary radio(chemo)therapy for patients with head and neck squamous cell carcinoma". Strahlentherapie und Onkologie, 2015; DOI 10.1007/s00066-014-0801-3 


\section{List of Abbreviations}

\begin{tabular}{|c|c|}
\hline${ }^{\circ} \mathrm{C}$ & Degree Centigrade \\
\hline A & Purinbase Adenin \\
\hline AJCC & The American Joint Committee on Cancer \\
\hline ATCC & The American Type Culture Collection \\
\hline bp & Base pair (s) \\
\hline BSA & Bovine serum albumin \\
\hline $\mathrm{C}$ & Pyrimidinbase Cytosine \\
\hline $\mathrm{CD}$ & Cluster of differentiation \\
\hline CFU assay & Colony-formation unit assay \\
\hline $\mathrm{CT}$ & Chemotherapy \\
\hline CTB assay & Cell Titer Blue ${ }^{\circledR}$ assay \\
\hline CTC & Common Toxicity Criteria \\
\hline DFS & Disease free survival \\
\hline DNA & Deoxyribonucleic acid \\
\hline DMF & The dose-modifying factor \\
\hline DMFS & Distant metastasis-free survival \\
\hline DMSO & Dimethyl sulphoxide \\
\hline dNTPs & Deoxynucleoside-5'-phosphate \\
\hline EDTA & Ethylenediamine tetraacetic acid \\
\hline EGFR & Epidermal growth factor receptor \\
\hline
\end{tabular}




\section{List of Abbreviations}

\begin{tabular}{|c|c|}
\hline ELISA & The enzyme-linked immunosorbent assay \\
\hline EMT & Epithelial-to-mesenchymal transition \\
\hline ERK & Extracellular signal-regulated kinases \\
\hline et al. & et alteres \\
\hline FCS & Fetal calf serum \\
\hline FFPE & Formalin fixed, paraffin embedded \\
\hline FFS & Failure-free survival \\
\hline $\mathrm{g}$ & Gram \\
\hline $\mathrm{G}$ & Purinbase Guanosin \\
\hline GDP & Guanosine diphosphate \\
\hline GPCRs & G-protein-coupled receptors \\
\hline Gy & Gray (unit of ionizing radiation dose) \\
\hline HGAHT & High-grade acute hematotoxicity \\
\hline HGAOT & High-grade acute organ toxicity \\
\hline HIF-1 & hypoxia-inducible factor-1 \\
\hline HIV-1 & Human immunodeficiency virus-1 \\
\hline HNSCC & Head and Neck Squamous Cell Carcinoma \\
\hline HR-HPV & High-risk human papilloma virus \\
\hline IFN- $\gamma$ & Interferon $\gamma$ \\
\hline $\mathrm{ICC}$ & immunocytochemistry \\
\hline IHC & immunohistochemistry \\
\hline IL-6 & Interleukin-6 \\
\hline ISH & in situ hybridization \\
\hline
\end{tabular}




\section{List of Abbreviations}

\begin{tabular}{|c|c|}
\hline $\mathrm{kDa}$ & Kilo Dalton \\
\hline $\mathrm{L}$ & litre \\
\hline LCR & Long control region \\
\hline LRC & Loco-regional control rates \\
\hline LRFS & Local recurrence-free survival \\
\hline HIF-1 & Hypoxia-inducible factor-1 \\
\hline HPV & Human Papilloma Virus \\
\hline $\mathrm{mA}$ & Milliampere \\
\hline MAPK & Mitogen-activated protein kinases \\
\hline $\min$ & Minute \\
\hline $\mathrm{ml}$ & Millilitre \\
\hline $\mathrm{mm}$ & Millimetre \\
\hline $\mathrm{mM}$ & Millimolar \\
\hline MMP & Matrix metalloproteinase \\
\hline mRNA & Messenger Ribonucleic acid \\
\hline ng & nanogram \\
\hline $\mathrm{nm}$ & Nanometre \\
\hline OD & Optical density \\
\hline OPSCC & Oropharyngeal squamous cell carcinoma \\
\hline ORF & Open reading frame \\
\hline OS & Overall survival \\
\hline OSCC & Oral squamous cell carcinoma \\
\hline PBS & Phosphate buffered saline \\
\hline
\end{tabular}




\section{List of Abbreviations}

\begin{tabular}{|c|c|}
\hline PCR & Polymerase chain reaction \\
\hline $\mathrm{RCT}$ & Radiochemotherapy \\
\hline PE & The plating efficiency \\
\hline $\mathrm{pH}$ & Negative decimal logarithm of the hydrogen ion concentration \\
\hline $\mathrm{pRb}$ & Retinoblastoma protein \\
\hline rpm & Rounds per minute \\
\hline RT & Radiotherapy \\
\hline SCC & Squamous cell carcinoma \\
\hline SDF-1 & Stromal cell-derived factor- 1 \\
\hline SDS & sodium dodecyl sulphate \\
\hline SE & Standard error \\
\hline SF & The surviving fraction \\
\hline $\mathrm{T}$ & Pyrimidinbase Thymidine \\
\hline TGF- $\beta 1$ & Transforming growth factor beta 1 \\
\hline TNF- $\alpha$ & Tumour necrosis factor- $\alpha$ \\
\hline TNM staging & Tumour, Node and Metastasis staging \\
\hline UICC & The Union Internationale Contre le Cancer \\
\hline $\mathrm{V}$ & Volt \\
\hline VEGF & Vascular endothelial growth factor \\
\hline vs. & versus \\
\hline WB & Western blot \\
\hline WHO & The World Health Organization \\
\hline$\mu$ & Micro $=10^{-6}$ \\
\hline
\end{tabular}




\section{Introduction}

\section{Introduction}

\subsection{Head and neck squamous cell carcinoma (HNSCC)}

\subsubsection{Definition and incidence of HNSCC}

Tumours of the head and neck region develop from the mucosal lining of the upper aerodigestive tract and include malignant tumours of the nasal cavity and the paranasal sinuses, the nasopharynx, the hypopharynx, the larynx, the trachea, the oral cavity and the oropharynx (Figure 1.1). Histologically, most of malignant tumours of the head and neck region are squamous cell carcinomas (SCC) (Epstein et al. 2008). The remainder are adenocarcinomas, adenoid cystic carcinomas, non-Hodgkin's lymphomas, melanomas and sarcomas (Böcker et al. 2004).

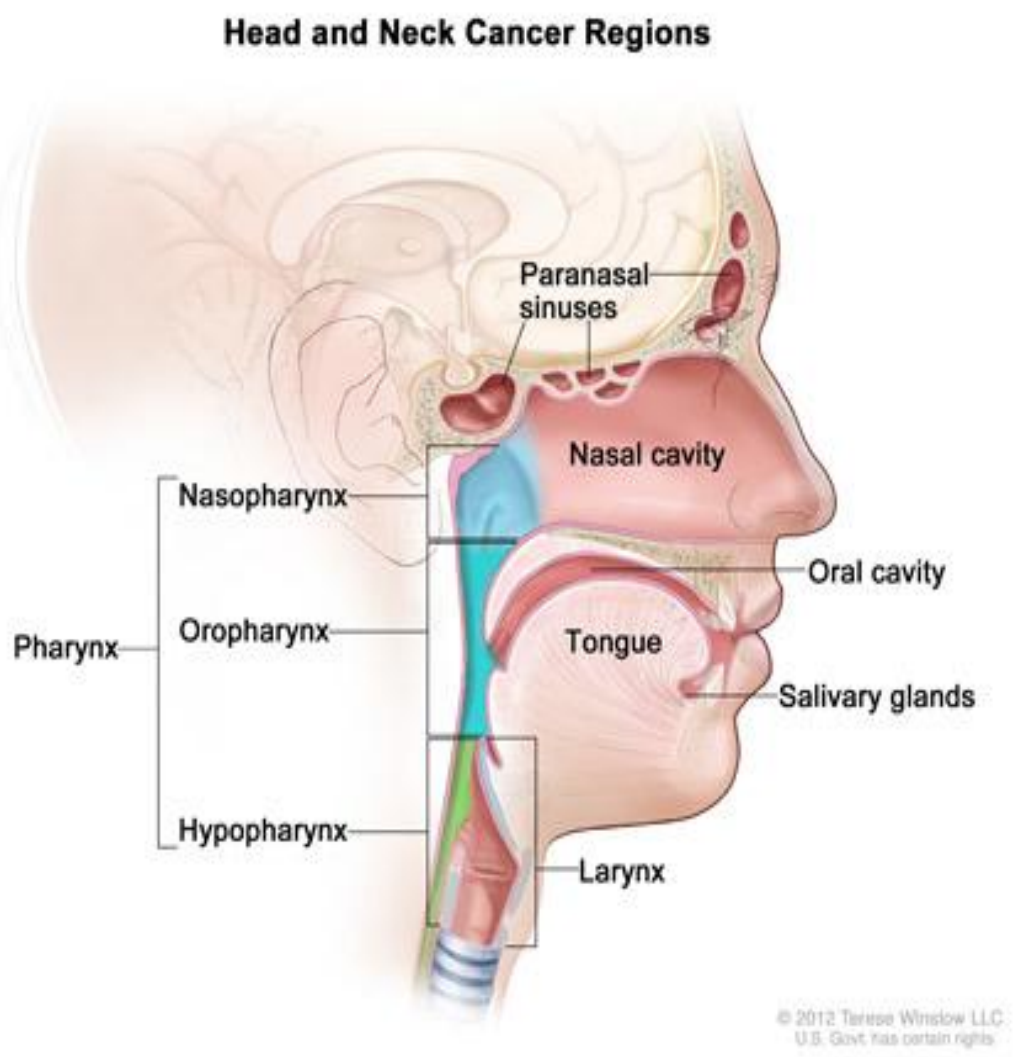

Figure 1.1: Anatomy of the head and neck illustrating the location of paranasal sinuses, nasal cavity, oral cavity, tongue, salivary glands, larynx, and pharynx (including nasopharynx, oropharynx, and hypopharynx). The Figure was taken From the National Cancer Institute www.cancer.gov/cancertopics/factsheet/Sites-Types/head-and-neck). 


\section{Introduction}

Head and Neck Squamous Cell Carcinoma (HNSCC) is the sixth most common carcinoma in the Western world (Ferlay et al. 2008). In 2002, the World Health Organization (WHO) estimated that there were about 600,000 new cases of head and neck cancer each year which affected primarily the oral cavity $(389,000$ cases), the larynx $(160,000)$ and the pharynx $(65,000)$ and 300,000 persons died from these cancers each year worldwide (Boyle and Levin 2008).

Recently, a marked increase in the prevalence of tonsillar and oropharyngeal carcinoma associated with human papillomavirus (HPV) has been observed. In a population-based study, the incidence of HPV-positive oropharyngeal squamous cell carcinoma (OPSCC) had increased by $225 \%$ between 1988 and 2004, while the incidence of HPV-negative oropharyngeal carcinoma had decreased by $50 \%$ in the same period (Chaturvedi et al. 2011).

\subsubsection{Risk factors for HNSCC}

HNSCC is primarily caused by exposure to alcohol and tobacco products. Tobacco-relatedproducts include cigarettes, cigars, and smokeless tobacco. The combination of both alcohol and tobacco increases the risk for HNSCC 13-fold compared with exposure to each agent alone (Gillison 2007). Smoking and alcohol have historically been the classic risk factors for approximately $42 \%$ of head and neck cancers. However, despite a shift in HNSCC epidemiology in recent decades, the incidence of oropharyngeal cancer has risen among younger persons with little or no history of smoking (Mehta et al. 2010, Cmelak 2012). It is now known that these tumours are caused by sexual transmitted HPV (Marur et al. 2010). HPV-associated oral cancers generally arise from the lingual and palatine tonsils in the oropharynx (Gillison 2004).

Besides sexual behaviour, exposure to marijuana was also strongly associated with the highrisk type of HPV infection, HPV-16 (Gillison et al. 2008). HPV infection in combination with alcohol and tobacco consumption may act synergistically to increase the HNSCC risk (Smith et al. 1998). Besides the above mentioned exogenous risk factors, oral hygiene (Guha et al. 2007), certain inherited disorders and also a more general genetic susceptibility may predispose to HNSCC (Hopkins et al. 2008). 


\subsubsection{Prognostic factors in HNSCC patients}

There are numerous factors which affect the prognosis of HNSCC. The primary site of tumour and the TNM (tumour, node, and metastasis) stage are the most important prognostic factors (Kowalski and Carvalho 2001). In addition, the infection with HPV has been known to be of significant prognostic importance and HPV-positive HNSCC patients showed a better prognosis (Gillison et al. 2008).

Molecular markers of prognosis have been studied but none has yet entered routine clinical reporting. Several candidates have been suggested. Based on a large study by Poeta et al., patients with tumour expressing wild-type p53 had better five-year overall survival (OS) compared to tumours which were positive for p53 mutation (Poeta et al. 2007). In a metaanalysis of 12 studies, the tumours with expression of vascular endothelial growth factor (VEGF) had twice the risk of specific cancer mortality (Kyzas et al. 2005). Some other studies showed that tumour hypoxia, in particular the increased expression of hypoxiainducible factor-1 $\alpha$ (HIF-1 $\alpha$ ), associated with adverse prognosis and local tumour aggressiveness (Aebersold et al. 2001, Yeo et al. 2004). Moreover, patients with high expression of epidermal growth factor receptor (EGFR) had poor prognosis and has also been linked to radiotherapy and drug resistance (Dai et al. 2005, Silva et al. 2007). The role of the CXCL12/CXCR4 axis in HNSCC has been investigated in some studies, and for the subgroup of oral squamous cell carcinoma (OSCC) a correlation between CXCR4 expression and OS was described (Salcedo et al. 1999, Katayama et al. 2005, Uchida et al. 2007), as well as a correlation between CXCR4 expression and lymph node or distant metastasis (Salcedo et al. 1999, Katayama et al. 2005, Ishikawa et al. 2006, Keeley et al. 2010, Ueda et al. 2010). CXCL12 expression was found to be higher in metastatic lymph nodes than in the primary tumour, and the intra-tumour CXCL12 levels correlated with the OS (Clatot et al. 2011). Although many biomarkers correlate with metastasis and mortality of HNSCC, none is appropriately independent or has prognostic value to be used routinely.

\subsubsection{Survival of HNSCC patients and tumour recurrence}

Despite improvements in surgical techniques, chemotherapy (CT) and radiotherapy (RT), the five-year survival rate for patients with HNSCC has remained relatively stable at less than $50 \%$ and has not changed since the 1960's (Forastiere et al. 2001, Bose et al. 2013). Low 


\section{Introduction}

survival rates are mainly due to a disease recurrence, which can lead to treatment failure and subsequent death. After tumour resection minimal leftover of tumour cells may remain adjacent to the lesion that are undetectable during histopathological assessment (van Houten et al. 2002) and cancer cells that were not removed are still present during post-treatment, which can lead to a recurrence of the disease.

Early detection of HNSCC is the most critical step in reducing morbidity and mortality. About one third of the patients present with stage I or stage II disease have a cure rate of up to $90 \%$ and $70 \%$, respectively (Argiris et al. 2008). After surgery, patients with late-stage disease often present with a local recurrence or a distant tumour (Argiris et al. 2008). In advanced HNSCC cases the tumour can metastasise to the lymph nodes causing cancer cell growth in the neck (Argiris et al. 2008). The survival rate of head and neck cancer patients decreases by at least $50 \%$ if lymph nodes positive for the tumour are detected (Sanderson and Ironside 2002). The most common anatomical sites of distant metastases are the lungs, followed by bones and the liver (Leon et al. 2000, Ferlito et al. 2001).

Most HNSCC patients present with cervical lymph node metastasis (Beasley et al. 2002). As an independent prognostic factor, cervical lymph node metastasis has a great impact on the OS of patients with HNSCC (Burusapat et al. 2015). Cervical metastasis is perhaps the most significant oncological factor in the prognosis of HNSCC, and if they are detected and treated early have a favourable prognosis (Burusapat et al. 2015). However, once distant metastases occur, the patients have an extremely poor prognosis. The mean survival time after the diagnosis of distant metastases is about six months and $90 \%$ of patients die within two years (Calhoun et al. 1994).

\subsubsection{Treatment of HNSCC}

The management of patients with HNSCC is currently a significant oncological challenge. The overall aim is to achieve increasingly higher survival rates. The consequences of treatment failure that often occur in late-stage disease such as facial disfigurement, loss of speech and impairment of the vital survival functions of swallowing and breathing can cause serious medical and psychosocial problems. Because of these psychosocial stress factors, the patients also are at risk of developing severe depression (Haddad et al. 2006). 


\section{Introduction}

The bases of treatment of HNSCC are surgery, RT, CT and to a lesser extent novel targeted therapies. Treatment modalities vary depending on the stage of the disease at the time of diagnosis and tumour histology (Chin et al. 2006). For early stage HNSCC without regional metastases, one treatment modality is sufficient, usually wide surgical excision or curative RT (Chin et al. 2006, Pai and Westra 2009). However, approximately 60\% of the patients are diagnosed in stage III. For late-stage primary tumours with or without regional metastases, treatment usually consists of a combination of surgery and post-operative RT or radiochemotherapy (RCT) (Chin et al. 2006, Perez-Ordonez et al. 2006, Pai and Westra 2009). However, when comparing the evidences available to determine the optimal therapeutic approach, it is clear that no single therapeutic approach offers a clear benefit over the others (Corvo 2007). Actually, ten percent of the patients presenting with metastases (Horner and Krapcho 2009) and about 50\% of the patients treated for advanced disease will have a recurrence (Clark et al. 2005, Boyle and Levin 2008).

Aside from the outcome, the quality of life is also influenced by the therapeutic approaches. The long-term side-effects affecting the quality of life vary depending on the treatment, i.e. RT, CT or both. For instance, irradiation frequently causes organ or hematotoxicity. In studies on patients with inoperable HNSCC without distant metastases Wolff et al. showed a significant connection between high-grade acute organ toxicity (HGAOT) during primary $\mathrm{R}(\mathrm{C}) \mathrm{T}$ and OS and locoregional tumour control, compared to patients undergoing these treatments without developing acute organ toxicity (Wolff et al. 2010a). The same significant correlation was also observed for patients with locally advanced HNSCC when were treated with adjuvant RCT (Wolff et al. 2011b). In a study on locally advanced rectal cancer Wolff and co-workers also reported a statistically significant correlation between HGAOT during preoperative RCT and complete tumour regression (Wolff et al. 2010b). Similar results were also observed in patients with breast cancer by Kuhnt et al. (Kuhnt et al. 1998). In addition, Wolff et al. showed a significant correlation between HGAOT and OS and locoregional control in patients with anal carcinoma (Wolff et al. 2010c). They reported that patients with HGAOT have a five-year OS rate of $97 \%$ compared to $30 \%$ for patients without HGAOT.

Although the differences in the biological and clinical characteristics of HPV-associated HNSCC and HPV-negative tumours have been known for several years, the treatment approaches have not taken this into account in the case of HPV-positive HNSCC patients. Some retrospective studies reported that patients with HPV-positive tumours have a better overall or disease-specific survival rate than those with HPV-negative tumours (Ringstrom et 


\section{Introduction}

al. 2002, Klussmann et al. 2003, Hafkamp et al. 2008) regardless of the employed therapy (Fakhry et al. 2008, Fallai et al. 2009, Lassen et al. 2009, Ang et al. 2010).

There are still no sufficient prospective clinical trials clarifying whether changes in treatment modalities, such as reducing the intensity of the therapy, can influence the quality of life of those patients with HPV-positive tumours and at the same time can maintain or further improve survival rates.

\subsection{Active HPV-participation in HNSCC}

\subsubsection{Human Papillomavirus (HPV)}

HPV are small, non-enveloped, epitheliotropic, circular double-stranded DNA viruses (Schiffman et al. 2007). There are more than 150 different known types of HPV (Bernard 2010) that can be divided into two groups according to their risk for humans, i.e. "high-risk" HPV types (potentially oncogenic) and "low-risk" HPV types (rarely or never oncogenic) (Chow et al. 2010). According to the literature the group of high-risk HPV types includes HPV-16, 18, 31, 33, 35, 39, 45, 51, 52, 56, 58 and 59 (IARC 2011). Particularly HPV-16 and 18 are known to cause malignant transformation of normal cervical epithelial cells (Clifford et al. 2003). Accordingly, some studies analysed the role of HPV as an aetiological agent in a subset of HNSCC (Kreimer et al. 2005, Strati and Lambert 2007, Allen et al. 2010). Based on currently available evidence, oral HPV infection is sexually transmitted to the upper aerodigestive tract, by oral genital contact (D'Souza et al. 2007). For instance, AnayaSaavedra et al. in a study of 62 patients and 248 controls showed that the presence of HPV DNA in the oral cavity was significantly related with a younger age of first sexual contact and increasing numbers of lifetime sexual partners (Anaya-Saavedra et al. 2008). In addition, HPV-6 and HPV-11 as low-risk HPV types have also been detected in some HNSCC patients, which may indicate that these low-risk HPV types are not truly benign (Kreimer et al. 2005).

\subsubsection{Molecular evidence for the role of HPV in HNSCC tumour progression}

The HPV genome is approximately $8 \mathrm{kbp}$ in length with eight open reading frames (ORFs), which encode the early genes (E1, E2, E4, E5, E6 and E7) and two late genes (L1 and L2) (Letian and Tianyu 2010). While the early expressed proteins are involved in replication, 


\section{Introduction}

transcription or the regulatory function of the HPV genome, the L1 and L2 genes convey the information for the capsid proteins. The transcription of the early and late genes is controlled by the non-coding LCR (long control region), which contains the origin of replication, promoters, binding sites for core transcription factors, enhancer and repressor proteins (Chow et al. 2010) (Fig. 1.2).

After entering the host cell, the E1 and E2 genes, which are required for the replication of viral DNA, are expressed (Motoyama and Ladines-Llave 2004, Zur Hausen 2006) to permit an episomal form of the viral genome to be maintained (Wilson et al. 2002). HPV E4 is expressed at a later phase of the viral life cycle, when the virus particles assembled (Zur

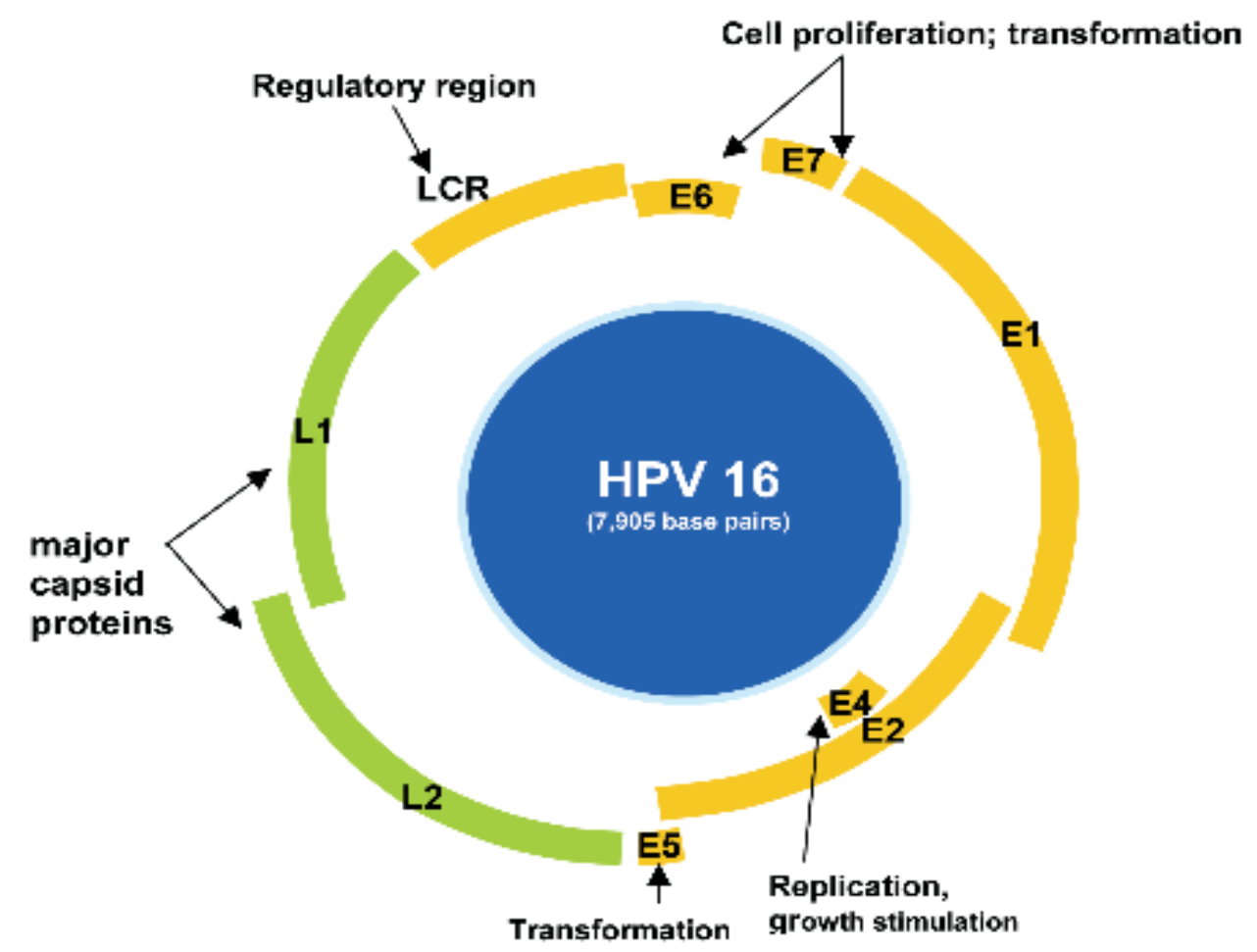

Figure 1.2: The organization of HPV-16. The HPV-16 DNA genome (7905 bp in size, circular double-stranded DNA) consists of two coding regions of early genes (E1-E7; yellow), which are expressed early in the viral life cycle and the late genes (L1 and L2; green) that encode the structural capsid proteins. Two important proteins, E6 and E7 are known as oncoproteins. The E6 protein promotes cell proliferation and also inhibits apoptosis. The E7 protein is the main cause of the transformational potential of special high-risk HPV types. The non-coding region, the long control region (LCR), is located between $\mathrm{L} 1$ and E6 ORFs, which is responsible for the regulation of DNA replication and transcription. The figure was taken from (Villa 2006). 


\section{Introduction}

Hausen 2006). The E6 and E7 proteins are the critical molecules in viral replication and both are the major mediators of carcinogenesis in the high-risk HPV types. The L1 and L2 proteins are expressed late in the infection cycle and spontaneously form an icosahedral virus capsid consisting of 72 capsomeres (Baker et al. 1991). Before this happens it comes to the conformation of the virions, and completed viruses are then released from the outer layer of the epithelium (Hummel and Hudson 1992).

The oncogenic E6 and E7 proteins are responsible for the progression of malignancy (Goia et al. 2010). The E6 protein of the high-risk HPV types, but not of the low-risk HPV types, has oncogenic potential. HNSCC with active HPV participation usually has an intact p53 gene(Balz et al. 2003). However, the synthesised protein is inactivated by the E6 oncoprotein. As a result, cell proliferation will be favoured and apoptosis inhibited. Carcinomas without HPV involvement, however, often show mutations in the p53 locus (Wiest et al. 2002, Braakhuis et al. 2004) and are associated to a greater degree with tobacco and alcohol consumption (Brennan et al. 1995). However, the inactivation of p53 in HNSCC have no distinct significance role for tumour progression and prognosis (Bosch et al. 2004).

Retinoblastoma protein (pRb), which is inactivated by the viral oncoprotein E7, also plays a central role in the carcinogenesis of HPV-associated HNSCC. However, a loss of function of the $\mathrm{Rb}$ gene, e.g. by mutation in HPV-negative HNSCC, is rare (Todd et al. 2002). If pRb is inactivated by HPV E7, the transcription factor E2F is permanently released to promote cell cycle progression (Dyson et al. 1989). This pathway is firmly regulated by a set of cyclindependent kinase inhibitors, among them $\mathrm{p} 16^{\mathrm{INK} 4 \mathrm{~A}}$. In addition, the Rb protein is important for the negative regulation of $\mathrm{p} 16^{\mathrm{INK} 4 \mathrm{~A}}$ (Reimers et al. 2007). In functionally inactivated $\mathrm{pRb}$ cells, p16 ${ }^{\mathrm{INK} 4 \mathrm{~A}}$ is also synthesised in large quantities without any intervention in the cell cycle inhibition (Figure 1.3). Overexpression of $\mathrm{p} 16^{\mathrm{INK} 4 \mathrm{~A}}$ has often been used as an important marker for HPV E7 activity, and increased expression of $\mathrm{p} 16^{\mathrm{INK} 4 \mathrm{~A}}$ is frequently found in HPV-associated HNSCC (Klussmann et al. 2003, Weinberger et al. 2006, Reimers et al. 2007, O'Regan et al. 2008). Since p16 ${ }^{\mathrm{INK} 4 \mathrm{~A}}$ overexpression is very seldomly seen in HPVnegative HNSCC and because of the functional inactivation of $\mathrm{pRb}$ by $\mathrm{E} 7$ that results in p $16^{\text {INK4A }}$ up-regulation, $\mathrm{p} 16^{\mathrm{INK} 4 \mathrm{~A}}$ positivity is considered to be a surrogate marker for HPVpositive HNSCC (Sano et al. 1998). 


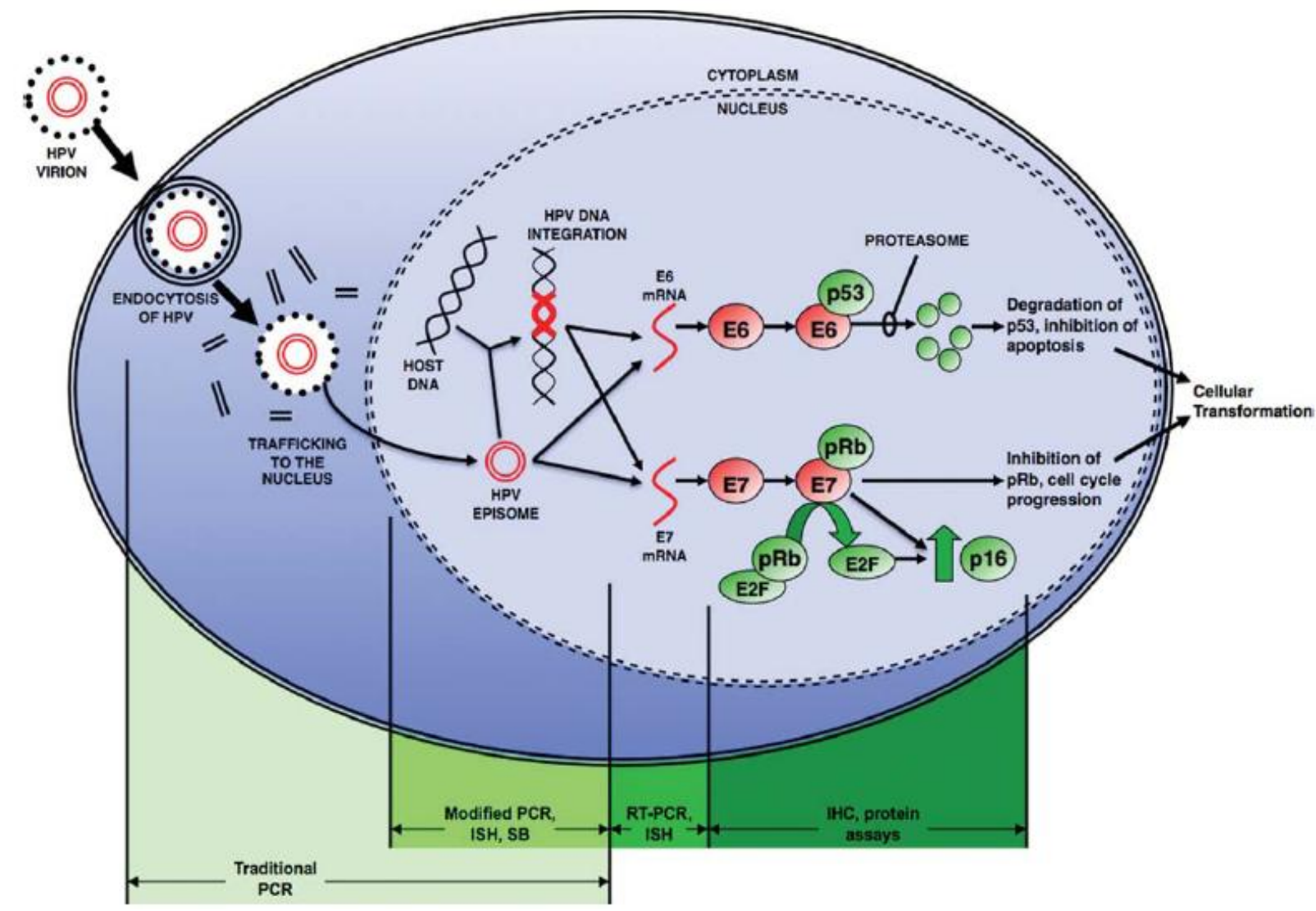

Figure 1.3: Schematic view of HPV infection of a mucosal cell. The human pathogenic virus enters the host cell by endocytosis, after which it causes a persisting infection as a viral episome or integrates into the genome of the host cell. From both forms of the viral DNA, viral oncoproteins such as E6 and E7 are expressed. This causes degradation of p53 and inhibition of pRb, respectively. E7 oncoprotein with dissociation of $\mathrm{pRb}$ and E2F causes a subsequent up-regulation of $\mathrm{p} 16^{\mathrm{INK} 4 \mathrm{~A}}$. Various methods are established to detect HPV DNA, E6 and E7 oncogene or p16 $6^{\mathrm{INK} 4 \mathrm{~A}}$ expression with regard to the stage of HPV biologic activity. The figure was taken from (Allen et al. 2010).

\subsection{The role of the microenvironment in tumour development}

It has become obvious that changes in the stromal microenvironment are important for the homeostasis of normal tissues and also for the progression, migration, invasion and metastasis of tumour cells (Bissell et al. 2002). Moreover, the secreted extracellular matrix that includes inhibitors, proteases, chemokines and growth factors affects both tumour and stromal cell behaviour (Mueller and Fusenig 2004). Interestingly, experiments by Polyak et al. have revealed that the initial modification leading to carcinoma development can occur either in epithelial cells or in adjacent stromal cells (Polyak et al. 2009). Furthermore, the stroma can both suppress and induce cancer progression (Bissell and Hines 2011). 


\section{Introduction}

The tumour microenvironment is composed of a non-cellular fraction consisting of collagen, elastin, fibronectin, fibrin, and a very heterogeneous cellular fraction. The latter mainly contains fibroblasts, epithelial cells and immune cells, which interact with each other and the adjacent tumour cells ( $\mathrm{Li}$ et al. 2007). The interaction between tumour cells and stroma occurs in various ways. Tumour cells can influence the stroma directly by changing the surrounding extracellular matrix or indirectly by modulating the metabolism of stromal cells (Zigrino et al. 2005). These direct or indirect effects are mediated by the release of soluble factors such as chemotactic factors by the tumour cells, which in consequence cause an active change in the cellular composition of the stroma (Zigrino et al. 2005). The stroma cells in turn affect the progression and the survival of the tumour cells by paracrine secretion. Furthermore, this cellular communication alters the cellular and molecular composition of a particular tumour microenvironment in a manner that supports cancer cell proliferation and increases the invasiveness and metastatic potential of tumour cells (Bhowmick and Moses 2005, Li et al. 2007, Itano et al. 2008). Some stroma-derived soluble cytokines, such as tumour necrosis factor- $\alpha$ (TNF- $\alpha$ ) and interleukin-6 (IL-6), may be exploited by the tumour cells in a manner that supports anti-apoptotic mechanisms and even fosters intratumoural angiogenesis, thus promoting local and systemic tumour dissemination or metastasis (Szlosarek et al. 2006, Knupfer and Preiss 2007).

The proportion of the stroma varies from tumour to tumour, but in any case it plays a crucial role in tumour progression, and significantly influences the growth, invasiveness, metastatic behaviour and also the sensitivity of the tumour to the various types of therapy (Fukumura and Jain 2007, Tse and Kalluri 2007). Fibroblasts and immune cells represent a significant portion of the tumour environment, which by producing a broad spectrum of growth factors and chemokines can directly stimulate tumour cell growth and even their own precursor cells, so that they themselves respond with abnormal growth and proliferation pattern (Li et al. 2007). It is also notable that the interstitial tissue of a solid tumour may exert an antitumourigenic influence on the tumour cells. Particularly, interferon- $\gamma$ (IFN- $\gamma$ ), a stromaderived soluble cytokine, is an example for reducing tumour mass formation by controlling inflammatory processes (Dranoff 2004). 


\subsubsection{Metastasis: a multistep process}

The important role of the stroma in the development of metastatic tumours was described towards the end of $20^{\text {th }}$ century. At that time the idea was established that tumours, depending on their nature, metastasise into some preferred organs. The conclusive role was ascribed to the microenvironment and can be read in Paget's "Seed and Soil" hypothesis (Paget 1989). To recognize the importance of the development of metastases in tumour progression, we have to bear in mind that $90 \%$ of deaths from cancers are due to metastases (Sporn 1996). Since metastasis is the foremost cause of cancer morbidity and mortality (Jemal et al. 2010), understanding the development of metastasis is important to improve the patients' survival rate.

Metastasis is a multistep process, which is based on the complex interaction of various molecular mechanisms and a highly organized, non-randomized and organ-specific process (Howell and Grandis 2005). In a first step, by changes in cell-cell contacts and loss of adhesion, some cells from the primary tumours succeed in evading from the solid structure (Chambers 2001). Later, the invasive tumour cells individually or in a cell assembly become motile and either penetrate the blood system or enter a lymphatic vessel, a process which is referred to intravasation (Chambers 2001, Bogenrieder and Herlyn 2003, Howell and Grandis 2005). In this step, proteolysis of the extracellular matrix and the directed migration/invasion of tumour cells play an essential role (Bogenrieder and Herlyn 2003). In a third step, the migrating tumour cells follow the routes of lymph or blood vessels until they reach a secondary organ, e.g. a lymph node, or lung or liver tissue, which they can invade (Figure 1.4). After successful extravasation in the target organ, the invasive capacity, proliferation and angiogenesis of those cancer cells are key processes for the development of a metastasis (Chambers 2001, Bogenrieder and Herlyn 2003, Howell and Grandis 2005). Subsequently, those tumour cells can start to colonize the new environment to form a secondary neoplasm, or they might deactivate the cell cycle for some time which causes a delayed metastatic relapse (Hedley and Chambers 2009). Importantly, effective colonisation by migrated primary tumour cells in target organs crucially depends on the interaction between the tumour cells and the microenvironment (soil) of the distant organs (Paget 1989). 


\section{Introduction}

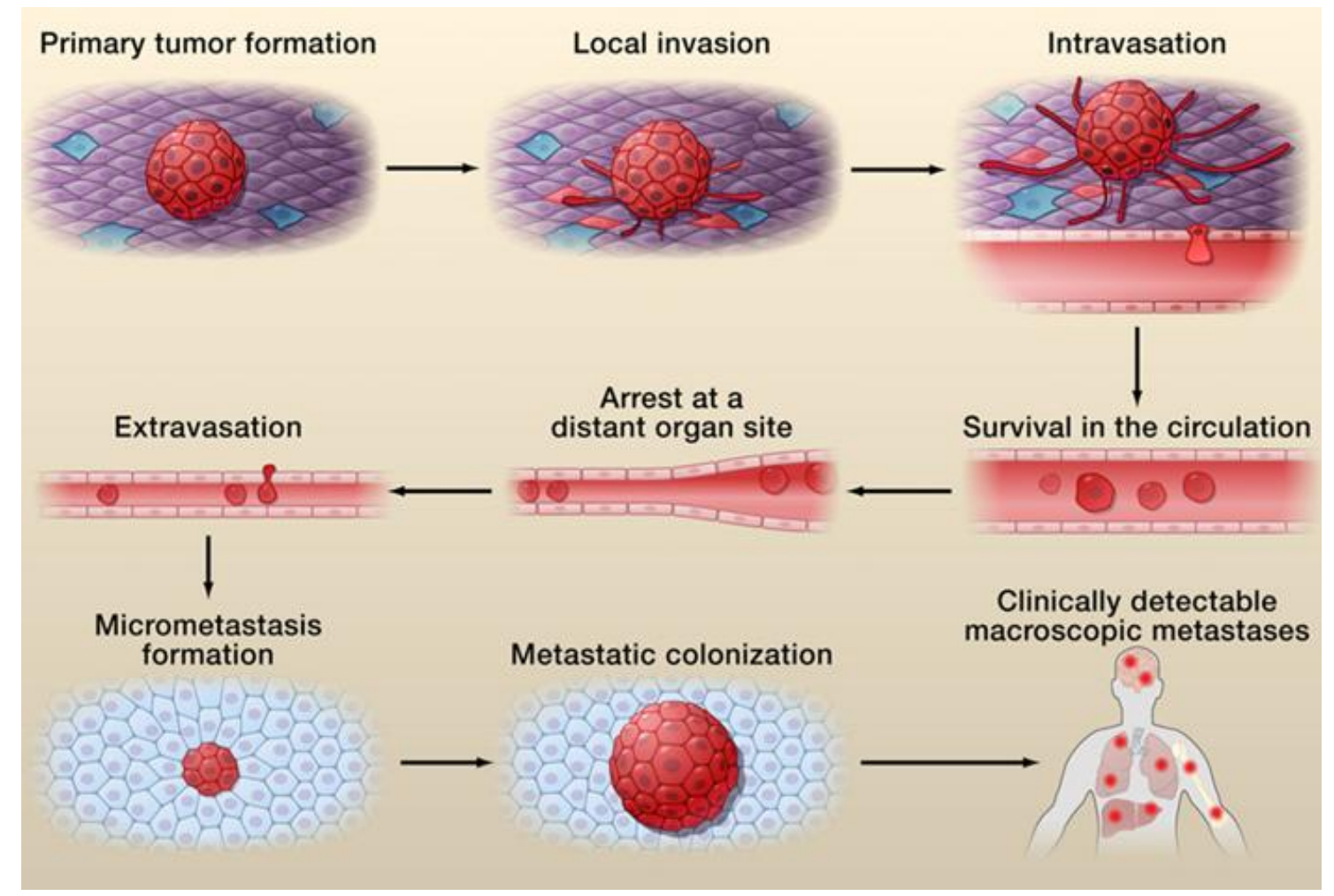

Figure 1.4: Schematic diagram of the metastatic cascade. Some malignant tumour cells break away from the primary tumour and leave their primary site of growth (local invasion, intravasation) followed by systemic translocation (survival in circulation, arrest at a distant organ site, extravasation) and last but not least adjust to survive in distant tissue (metastatic formation). This figure was taken from (Valastyan and Weinberg 2011).

Although a number of known physiological molecules are important for stimulating tumour cell motility and invasion, the exact molecular mechanisms that mediate the directed migration/metastasis of tumour cells into a specific organ are largely unknown (Bogenrieder and Herlyn 2003, Wong and Hynes 2006).

\subsubsection{Three theories of seeding and colonisation in organ-specific metastasis}

Organ selectivity of migrated primary tumour cells is recognised for seeding and colonisation. Breast cancer cells for instance prefer to metastasise to the bones, the lungs and the brain, whereas colorectal cancer cells commonly colonise the liver. Three different concepts have been proposed that attempt to explain organ-specific metastasis. 


\section{Introduction}

\section{Growth factor theory}

This theory assumes that tumour cells can theoretically "seed" into all organs via the circulation. However, they can only colonise such organs that provide them with the appropriate growth factors (Chambers 2001).

\section{Adhesion theory}

This theory states that the extravasation of tumour cells is controlled by certain adhesion molecules, which are expressed by the endothelium in an organ-specific manner (Qian et al. 2001).

\section{Chemoattractant theory}

This theory assumes that tumour cells can metastasise to certain organs on the basis of chemokine gradients, which means that the tendency for specific organs is determined by the local expression of chemoattractants (Figure 1.5) (Liotta 2001, Müller et al. 2001, Homey et al. 2002).

Chemokines can attract and activate various. For which reason migrating tumour cells that express special chemokine receptors are guided to the site of future metastasis formation as a consequence of chemokine gradients. For instance, breast cancer patients that express the chemokine receptor CXCR4 have a poor prognosis (Zlotnik 2008). It has been shown that CXCR4-positive tumour cells migrate to organs that naturally express high quantities of its ligand, CXCL12 (also known as SDF-1; stromal cell-derived factor-1), such as lung, liver and bones (Figure 1.5). Actin polymerization and also pseudopod formation are the results of CXCR4-mediated signalling and the cause of invasion of primary tumour cells (Müller et al. 2001). In addition, Müller et al. showed that in a xenograft mouse model neutralising CXCL12 or CXCR4 leads to a reduction of breast cancer metastasis (Müller et al. 2001). 


\section{Introduction}

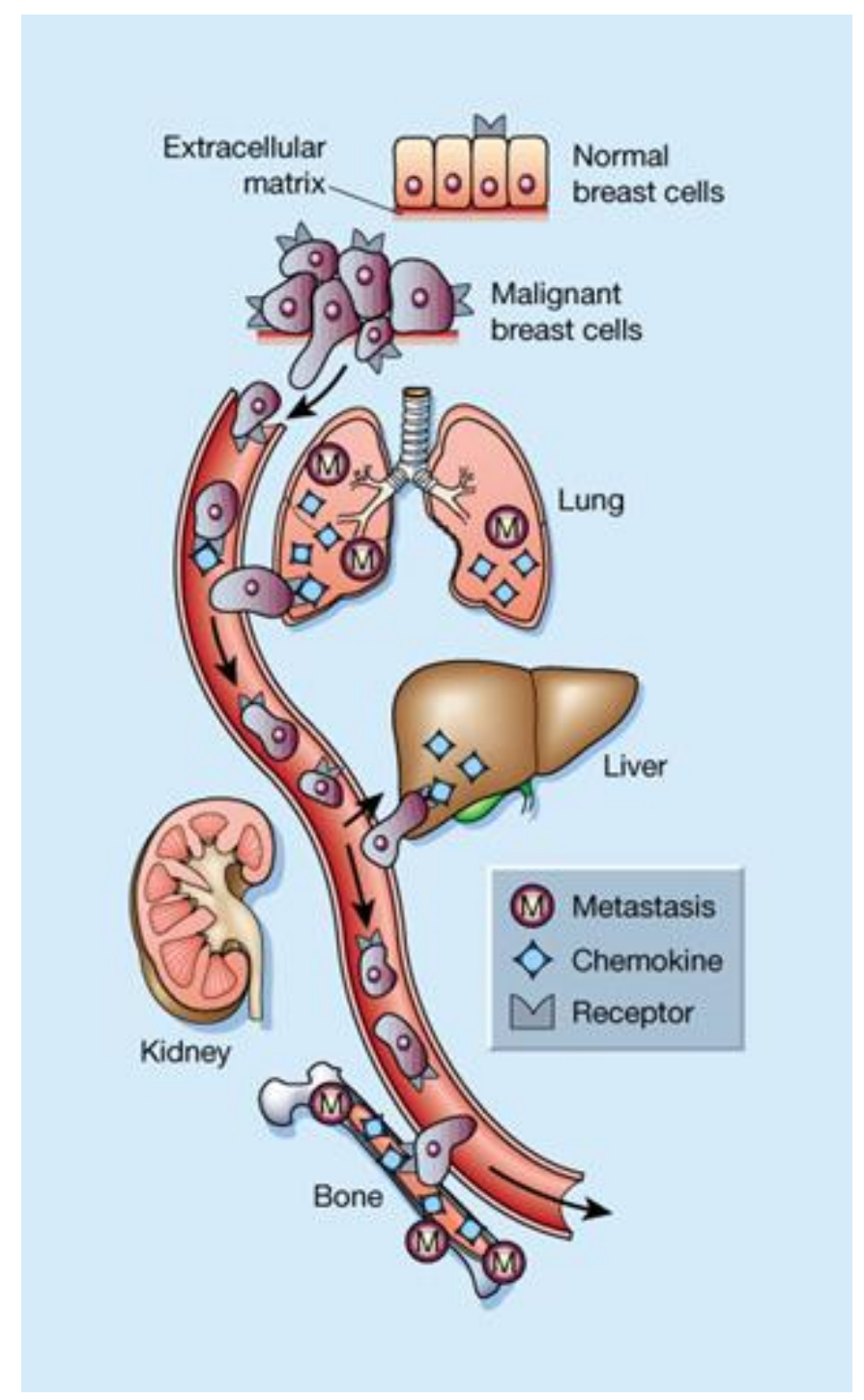

Figure 1.5: The functional relevance of chemokines and chemokine receptors in organ-specific metastasis according to the findings of Müller et al. (Müller et al. 2001). Malignantly transformed breast epithelial cells possess a highly chemokine receptor-enriched surface; such as CXCR4. Chemokines that bind to these kinds of receptors with a high affinity, e.g. CXCL12, are produced in high quantities only by certain organs such as bone marrow, liver and lung. Once malignant primary breast cancer cells locally invade the vascular and lymphatic system, they are attracted to organs producing high amounts of chemokines. This hypothesis reflects the relative organ-specific metastasis of malignant cells. The figure was taken from Nature (Liotta 2001).

\subsubsection{Chemokines}

Cytokines are 15 to $25 \mathrm{kDa}$ peptide mediators that are involved in paracrine and autocrine cell communication. Chemokines are small signal proteins with highly conserved threedimensional structures and members of the large family of chemotactic cytokines that can be synthesized by almost all cells in the human organism after stimulation. 


\section{Introduction}

Chemokines are categorized into four main families, CL, CCL, CXCL and CX ${ }_{3} \mathrm{CL}$, based on the number and location of cysteine residues at the $\mathrm{C}$-terminus end, where $\mathrm{X}$ represents any amino acid and L stands for ligand (Murphy 2002). According to the 2003 IUIS/WHO classification, the chemokines are designated corresponding to their subfamily as CCL1-28, CXCL1-17, XCL1-2 and CX ${ }_{3}$ CL1.

Chemokines mediate their biological effects through G-protein-coupled receptors (GPCRs), which belong to the group of seven-transmembrane domain receptors (Holmes et al. 1991). These chemokine receptors have a chain length of 340 to 370 amino acids. The N-terminus lies outside the cell membrane, three extracellular and three intracellular loops span the cell membrane and the C-terminus is located in the cytosol (Singh et al. 2007). Most chemokine receptors bind several chemokines of the same subfamily with different affinities. Some chemokine receptors such as CXCR4 interact with its ligand, in this case CXCL12, with high affinity (Bleul et al. 1996b).

The main function of chemokines and their corresponding receptors is to induce chemotaxis of blood cells, i.e. initiate the targeted migration of cells along a gradient to the site of the highest chemokine concentration (Zlotnik and yoshie 2000, Schier 2003). Chemokines are also known to be crucial regulators in the migration of other cell types. O'Harye et al. showed that chemokines play a key role in the progression of tumour development and also as an important chemoattractant aid in forming the tumour's microenvironment. Moreover, chemokines ensure survival and proliferation of metastasised cells ( $\mathrm{O}^{\prime}$ Harye et al. 2008). Furthermore, chemokines such as CXCL12 are essential for embryogenesis, organogenesis, haematopoiesis (Nagasawa et al. 1996, Ma et al. 1998, Zou et al. 1998, Bagri et al. 2002, Doitsidou et al. 2002), organ-specific metastasis (Müller et al. 2001) and (tumour) angiogenesis (Liang et al. 2007). The major focus of the present study is the chemokine receptor CXCR4 and its ligand CXCL12.

\subsubsection{CXCL12 and its receptor CXCR4}

CXCL12 (also known as SDF-1, stromal cell-derived factor-1) belongs to the CXC chemokine subfamily and was originally isolated from a stromal cell line of murine bone marrow (Tashiro et al. 1993). The gene encoding an $8 \mathrm{kDa}$ protein with 72 amino acids is located on chromosome 10. CXCL12 is the natural ligand for the two GPCRs; CXCR4 (Bleul et al. 1996b) and CXCR7 (Burns et al. 2006). CXCL12 is constitutively expressed by almost 


\section{Introduction}

all organs and tissues (Shirozu et al. 1995, Yu et al. 2006), including endothelial cells (Nagasawa et al. 1994, Imai et al. 1999, Ponomaryov et al. 2000, Ceradini et al. 2004), fibroblasts/osteoblasts, heart (Askari et al. 2003), brain (Zou et al. 1998) and kidney (Schrader et al. 2002). However, the highest concentration of CXCL12 is found in the bone marrow (Ponomaryov et al. 2000).

The main biological function of CXCL12 is the ability to induce processes, such as chemotaxis, adhesion, cell motility, and the secretion of MMPs (matrix metalloproteinases) and angiogenic factors (Kucia et al. 2004). Thus endothelial cells can be stimulated directly by CXCL12 to migrate and promote angiogenesis (Salcedo and Oppenheim 2003).

The receptor CXCR4 consists of 352 amino acids ( $40 \mathrm{kDa})$ and is highly conserved. The gene encoding CXCR4 is located on chromosome 2 (Horuk 2001). CXCR4 was discovered and cloned in leukocytes (Loetscher et al. 1994). In 1996 its role as cofactor for the absorption and penetration of HIV-1 (human immunodeficiency virus-1) was reported (Feng et al. 1996). In the same year it was found that it binds CXCL12 with high affinity, after which it was named CXCR4 (Bleul et al. 1996b). Many studies have shown that CXCR4 is expressed in almost all tissues and cell types as opposed to other chemokine receptors. In addition to cells of the haematopoietic system (Wang et al. 1998, Kowalska et al. 1999), CXCR4 is expressed in endothelial cells (Gupta et al. 1998, Tachibana et al. 1998, Volin et al. 1998, Murdoch et al. 1999a), epithelial cells (Murdoch et al. 1999b) and, in particular, in CD34 ${ }^{+}$progenitor cells (Aiuti et al. 1997) and also in tumour cells (Müller et al. 2001, Libura et al. 2002, Kucia et al. 2004, Hartmann et al. 2005). Even cells of the central nervous system and the gastrointestinal tract are positive for CXCR4 (Zou et al. 1998, Nagasawa 2001).

CXCR4 is responsible for a wide range of effects in a variety of cell types. This includes CXCL12-directed chemotaxis of monocytes, T-lymphocytes and haematopoietic stem cells (Bleul et al. 1996b, Aiuti et al. 1997, Kim and Broxmeyer 1998). In addition, CXCR4 plays a role in the pathogenesis of a number of diseases, such as arteriosclerosis and multiple sclerosis (Zernecke et al. 2005, Calderon et al. 2006). In breast cancers expressing CXCR4, tumour progression and metastasis are much faster than in CXCR4-negative tumours (Müller et al. 2001). Furthermore, it was shown that CXCR4 is involved in the invasion and angiogenesis of pancreatic cancer (Matsuo et al. 2009).

CXCL12 binding to CXCR4 leads to a conformational change of the chemokine receptor that can act as a nucleotide exchanger (a guanine nucleotide exchange factor) for the $G_{\alpha}$ protein, 


\section{Introduction}

which assists in the exchange of GDP (guanosine diphosphate) for GTP (guanosine triphosphate) on the $\mathrm{G}_{\alpha}$ subunit (Percherancier 2005). These events cause the activation of various signalling pathways (MEK1/2, MAPK, AKT), which eventually lead to increased IL6 and VEGF secretion and induction of chemotactic migration along a CXCL12 gradient in various cell types (Kucia 2005).

CXCR4 has been reported to be overexpressed in various types of cancers, including breast cancer (Müller et al. 2001), ovarian (Jiang et al. 2006), colorectal (Kim et al. 2005), and oral cancer (Almofti et al. 2004, Ishikawa et al. 2006). In colorectal cancer, the occurrence of lymphatic or distant metastases was significantly associated with CXCR4 expression (Ottaiano et al. 2006, Yoshitake et al. 2008). In OSCC patients, a statistically significant connection between CXCR4 expression and lymph node metastasis was reported, while treatment with CXCL12 increased the invasiveness of CXCR4-positive OSCC cells (Ishikawa et al. 2006). However, Zlotnik et al. noted that a CXCL12/CXCR4 gradient is correlated with distant metastatic spread rather than with lymph node metastasis (Zlotnik 2004).

There have been attempts to inhibit CXCR4 as a therapeutic target since the significance of this receptor in diverse disease entities was discovered. AMD3100 (Plerixafor ${ }^{\circledR}$ ) is a bicyclam molecule (Figure 1.6), which was originally developed as a specific antagonist of CXCR4 for the treatment of HIV infection by blocking the entry of HIV into target cells (CD4 ${ }^{+}$T-cells).

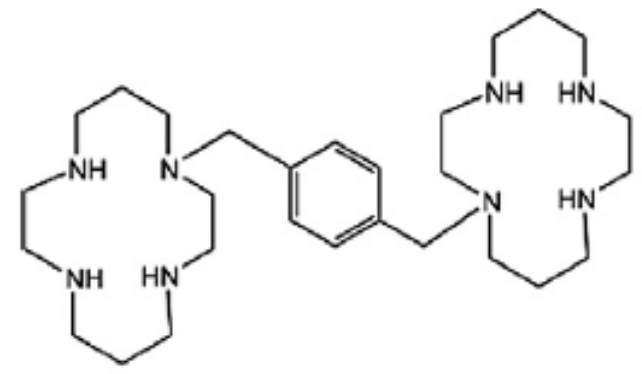

AMD3100

Figure 1.6: Chemical structure of the AMD3100 (Plerixafor). AMD3100 is a metal-chelating, bicyclic, reversible CXCR4 inhibitor that binds to CXCR4 and leads to allosteric modulation and effective blockade of CXCL12 binding (Wong et al. 2008). 


\section{Introduction}

AMD3100 inhibits the binding of CXCL12 to CXCR4 by activating a G-protein coupled with CXCR4 and thus acts as a partial CXCR4 agonist in vitro (Zhang et al. 2002). It binds with high affinity to CXCR4, independent of the cell type expressing CXCR4, but does not interact with other chemokine receptors (Hatse et al. 2002). In addition, AMD3100 prevents intracellular calcium signalling and chemotactic response caused by CXCL12 in various cell types (Schols et al. 1997, Donzella et al. 1998). Moreover, several studies have shown that AMD3100 decreased metastasis formation in mice (Smith et al. 2004) as well as the recurrence of glioblastoma in a mouse model after RT (Kioi et al. 2010). Uchida et al. also showed that subcutaneous administration of AMD3100 inhibited the formation of lymph node metastases after an HNSCC cell line expressing CXCR4 was inoculated into the masseter muscle of nude mice (Uchida et al. 2010). 
1. High-grade acute organ toxicity (HGAOT) as a potent prognostic marker for HNSCC patients and $\mathrm{p} 16^{\mathrm{INK} 4 \mathrm{~A}}$ overexpression as a known surrogate marker for HPV-positive HNSCC patients have been investigated. However, no studies have been performed to analyse both of them in combination. The aim of this part of the study was to analyse their combined impact on patient survival.

To analyse the prevalence of HPV infection by screening the HPV DNA status in tumour biopsies from 233 HNSCC patients treated between 1992 and 2011

To analyse the HPV subtype by nested-PCR-product sequencing

To analyse the expression of $\mathrm{p} 16^{\mathrm{INK} 4 \mathrm{~A}}$ in the 233 pre-treatment HNSCC biopsies by means of IHC staining in correlation with clinical outcomes and survival data

To analyse the impact of both HGAOT and HGAHT during/after R(C)T and $\mathrm{p} 16^{\mathrm{INK} 4 \mathrm{~A}}$ expression on the survival data of HNSCC patients

2. Some of the studies investigating CXCR4- and CXCL12-dependent tumour development and metastasis in lymph node and/or distant organs comprise only a small number of patients in the HNSCC collective. The second aim of this work was therefore to gain more reliable results by further investigating the impact of primary tumour levels of CXCL12 and CXCR4 expression in 233 pre-treatment HNSCC biopsies by means of immunohistochemistry staining.

* To analyse the impact of CXCL12 and CXCR4 expression on pre-treatment patient' data

* To analyse the impact of CXCL12 and CXCR4 expression on patient survival

* To analyse the impact of CXCL12 and CXCR4 expression on regional lymph node or distant metastasis 
3. Although migration of primary tumour cells is one of the most important components in the formation of metastases, little is known about the chemotactic effects of CXCL12-induced HNSCC cell migration under irradiated condition. Hence the aim of this part of the study was to analyse this effect in HNSCC cell lines with different CXCL12 and CXCR4 expression patterns.

To investigate, in three HNSCC and two control cell lines,

the expression profiles of CXCL12 and CXCR4 at the mRNA and protein levels

the radiosensitivity of cells using a colony-forming assay, including treatment with CXCL12 and AMD3100

the metabolic activity of cells by means of CellTiter ${ }^{\circledR}$-Blue cell viability assay after treatment with CXCL12, AMD3100 and radiation

To investigate the impact of CXCL12 on the migration of HNSCC and control cell lines by means of Boyden -chamber migration assay

To investigate the influence of different doses of radiation on cell migratory behaviour in cells with different patterns of CXCL12 and CXCR4 expression

To investigate the migration-inhibiting effect of AMD3100 in CXCR4expressing HNSCC cell lines 


\section{Materials and methods}

\subsection{Materials}

\subsubsection{Laboratory equipment}

Table 2.1: List of laboratory equipment used during the work

\section{Name of product}

Name of the company

(city or country of origin)

\section{Clean bench}

Incubator

Tube centrifuge

Heraeus (Hanau, Germany)

Refrigerator $\left(4-8^{\circ} \mathrm{C}\right)$

Freezer $\left(-20^{\circ} \mathrm{C}\right)$

Deep freezer $\left(-80^{\circ} \mathrm{C}\right)$

Sanyo (Osaka, Japan)

Light microscope

Carl Zeiss (Jena, Germany)

Light microscope with camera

Olympus BX40 (Japan)

Pipethelper "Pipetboy comfort" Integra Biosciences (Fernwald, Germany)

Wallec 1420 VICTOR ${ }^{\text {TM }}$ plate reader PerKinElmer (Turku, Finland)

Cytospin 4 cytocentrifuge Thermo Scientific (Rockford, USA)

Vortex shaker

Heidolph (Schwabach, Germany)

Luminometer

Tecan (Crailsheim, Germany)

Ice-machine

Ziega (Isernhagen, Germany)

Ultrasonic homogenizer

Bandelin (Berlin, Germany)

Small cup centrifuge

Thermomixer comfort

Eppendorf AG (Hamburg, Germany)

Unsterile clean bench

Norddeuche Laborbau (Kaltenkirschen, Germany)

Western Blot migration set Mini-

PROTEAN Tetra System 


\begin{tabular}{|lr|}
\hline $\begin{array}{l}\text { Electrophoresis power supply Power Pac } \\
300\end{array}$ & Bio-Rad (Hercules, USA) \\
\hline $\begin{array}{l}\text { Electroblotting transfer system Trans-Blot } \\
\text { Turbo }{ }^{\text {TM }}\end{array}$ & \\
\hline TGX ${ }^{\text {TM }}$ Transfer Gel & \\
\hline CoolCell ${ }^{\circledR}$ cell freezing container & Zeipel (Bovenden-Lenglern, Germany) \\
\hline Rotary shaker & Sartorius GmbH (Göttingen, Germany) \\
\hline Balance & Microm HM400(Walldorf, Germany) \\
\hline microtome & Ventana BenchMark (Tucson, USA) \\
\hline Automated slide stainer & Thermoscientific (Pittsburgh, USA) \\
\hline NanoDrop ND-2000 spectrophotometer & Qiagen (Hilden, Germany) \\
\hline $\begin{array}{l}\text { Automated capillary electrophoresis } \\
\text { QIAxcel }\end{array}$ \\
\hline Labcycler & SabelGuard cuvette, Implen (Munich, Germany) \\
\hline Real-time PCR machine & Star Lab (Korea) \\
\hline Spectrophotometer & \\
\hline Microcentrifuge for PCR tubes & \\
\hline
\end{tabular}

\subsubsection{Experimental and detection kits}

Table 2.2: List of experimental and detection kits used during the work

\begin{tabular}{|l|r|}
\hline Name of product & $\begin{array}{r}\text { Name of the company } \\
\text { (city or country of origin) }\end{array}$ \\
\hline CellTiter-Blue®Cell Viability Assay & Promega (Madison, USA) \\
\hline Bradford colorimetric protein assay & Bio-Rad (Hercules, USA) \\
\hline $\begin{array}{l}\text { Electrophoresis transfer pack Trans-Blot } \\
\text { Turbo }\end{array}$ & Bio-Rad (Hercules, USA) \\
\hline
\end{tabular}




\begin{tabular}{|lr|}
\hline $\begin{array}{l}\text { Western Blot immunodetection } \\
\text { WesternBreez® Chromogenic kit }\end{array}$ & Invitrogen (San Diego, USA) \\
\hline ZytoChem-Plus HRP Polymer-Kit & Zytomed Systems GmbH (Berlin, Germany) \\
\hline IHC- detection Kit & Qiagen (Hilden, Germany) \\
\hline QIAamp® DNA Mini Kit (250) & Bioron (Ludwigshafen, Germany) \\
\hline SuperHot Master Mix (2x) & Promega (Madison, USA) \\
\hline Wizard® SV Gel and PCR Clean-Up System & Greiner Bio-one (Frickenhausen, Germany) \\
\hline Transwell chamber assay & Medion Diagnostics (Düdingen, Switzerland) \\
\hline Diff-Quick kit & Qiagen (Hilden, Germany) \\
\hline RNeasy mini kit & Invitrogen (Carlsbad, California, USA) \\
\hline Super-Script II reverse transcriptase & USB (Cleveland, Ohio, USA) \\
\hline Recombinant RNase inhibitor & \\
\hline HotStart-IT SYBR Green qPCR-Master mix & \\
\hline
\end{tabular}

\subsubsection{Buffers and media for cell culture}

Table 2.3: List of used buffers and media for cell culture during the work

\begin{tabular}{|l|r|}
\hline Name of product & $\begin{array}{l}\text { Name of the company (city or country of } \\
\text { origin) }\end{array}$ \\
\hline $\begin{array}{l}\text { DMEM (Dulbecco's Minimum Essential } \\
\text { Medium) }\end{array}$ & Biochrom (Berlin, Germany) \\
\hline RPMI 1640 medium & Biochrom (Berlin, Germany) \\
\hline FCS (fetal calf serum) & Ratiopharm (Ulm, Germany) \\
\hline Ampicillin & Biochrom (Berlin, Germany) \\
\hline PBS & Biochrom (Berlin, Germany) \\
\hline Trypsin & SERVA (Heidelberg, Germany) \\
\hline Running buffer for SDS-PAGE &
\end{tabular}




\subsubsection{Consumption materials}

Table 2.4: List of consumption materials used during the work

\begin{tabular}{|c|c|}
\hline Name of product & $\begin{array}{l}\text { Name of the company (city or country of } \\
\text { origin) }\end{array}$ \\
\hline \multicolumn{2}{|l|}{ Freezing resistant plastic vials } \\
\hline Plastic sterile 15 and $50 \mathrm{ml}$ tubes & \multirow[t]{3}{*}{ Greiner Bio-One (Frickenhausen, Germany) } \\
\hline Sterile/unsterile 10 and 25 pipettes & \\
\hline Sterile 50 and $200 \mathrm{ml}$ flasks & \\
\hline Neubauer counting chamber & Paul Marienfeld (Lauda-Königshofen, Germany) \\
\hline Pipette & Eppendorf AG (Hamburg, Germany) \\
\hline \multicolumn{2}{|l|}{ Sterile pipette tips } \\
\hline Sterile 96-well black plates with clear bottom & Costar (New York, USA) \\
\hline Glass microscopic slide (superfrost plus) & Thermo Scientific (Braunschweig, Germany) \\
\hline Glass microscopic slide (cut edges frosted end) & Thermo Scientific (Braunschweig, Germany) \\
\hline Glass coverslips & Thermo Scientific (Braunschweig, Germany) \\
\hline Sterile cell scraper & Sarstedt (Newton, USA) \\
\hline Sterile insulin injections & Braun (Bad Arolsen, Germany) \\
\hline Sterile PCR tubes & Sarstedt (Germany) \\
\hline 96-well multiply PCR plate & Sarstedt (Germany) \\
\hline
\end{tabular}




\subsubsection{Antibodies}

Table 2.5: List of antibodies used during the work

\begin{tabular}{|c|c|c|}
\hline Name of product & Methods & $\begin{array}{l}\text { Name of the company } \\
\text { (city or country of origin) }\end{array}$ \\
\hline Anti-P53 & $\mathrm{IHC}$ & $\begin{array}{l}\text { monoclonal mouse anti-human p53 protein } \\
\text { Clone DO-7 Code Nr.: M7001 } \\
\text { DakoCytomation (Denmark) }\end{array}$ \\
\hline Anti-CXCL12 & IHC, ICC & $\begin{array}{l}\text { monoclonal mouse IgG1; Clone No.: } 79018 \\
\text { R\&D system (Abingdon, UK) }\end{array}$ \\
\hline Anti-CXCR4 & IHC, WB & $\begin{array}{l}\text { Rabbit monoclonal antibody; Ab } 2074 \\
\text { Abcam (Cambridge, UK) }\end{array}$ \\
\hline Anti-p16 ${ }^{\text {INK4A }}$ & IHC & $\begin{array}{l}\text { monoclonal mouse } \operatorname{IgG}_{2 \mathrm{a}} \text {; Clone: JC8 } \\
\text { SC-56330 } \\
\text { Santa Cruz Biotechnology (Texas, USA) }\end{array}$ \\
\hline Anti-actin & WB & $\begin{array}{l}\text { Monoclonal Anti- } \beta \text {-Actin antibody produced in } \\
\text { mouse ; Lot Nr: } 121 \mathrm{M} 4846 \\
\text { Sigma-Aldrich (Missouri, USA) }\end{array}$ \\
\hline
\end{tabular}

\subsubsection{Software and online tools}

Table 2.6: List of software and online tools used during the work

\begin{tabular}{|l|r|}
\hline Software & \multicolumn{1}{c|}{ Source } \\
\hline Microsoft Office Excel & Microsoft (Albuquerque) \\
\hline Kaleidergraph ${ }^{\circledR}$ Version 4.1 & Synergy Software (Reading, USA) \\
\hline Chromas Lite version 2.1.1. & Technelysium (Australia) \\
\hline ImageJ & National Institutes of Health (Bethesda, MD) \\
\hline STATISTICA 9 & StatSoft (Tulsa, USA) \\
\hline $\begin{array}{l}\text { Basic Local Alignment Search Tool } \\
\text { (Balermpas } \text { et al. } \text { ) }\end{array}$ & $\begin{array}{r}\text { NCBI (Bethesda, USA) } \\
\text { http://www.ncbi.nlm.nih.gov }\end{array}$ \\
\hline
\end{tabular}




\subsubsection{Clinical specimens from HNSCC patients}

A total of 233 patients with head and neck cancers were evaluated in this study. The histological diagnosis was SCC in all cases. All 233 tumour samples included in the study were fixed in formalin and embedded in paraffin (FFPE). The patients had been diagnosed with primary inoperable HNSCC without distant metastases. Tissue samples had been taken between 1992 and 2011 in the Department of Otorhinolaryngology of University Medical Centre Göttingen. The specimens and clinicopathological data were used with the approval of the local Ethics Committee. The clinical data of 183 patients have already been published (Wolff et al. 2010a), and these data were updated for this investigation. The clinicopathological data provide general patient information such as gender, age, site of primary tumour, diagnosis, histopathology, treatment, side-effects of therapy and follow-up data such as date and cause of death (Table 3.1).

\subsubsection{HNSCC patient treatment and analysis of toxicity}

The patients suffering from head and neck cancer evaluated in the current study were treated in accordance with respective clinical and technical standards. In the period from 06/1994 to 11/1999, 138 patients underwent a normofractionated definite (primary) RT (2 Gy/day, 5 times/week) as parallel-opposed lateral portals. In the period from 12/1999 to 10/2008, 45 patients were given a normofractionated (2 Gy/day, 5 times/week) 3-D conformal externalbeam RT with a total dose of $70 \mathrm{~Gy}$ in each case (Wolff et al. 2011b). Integrated intensitymodulated radiotherapy (IMRT) with single fractions of 2.2 Gy to the primary tumour and the involved lymph nodes up to a total of $66 \mathrm{~Gy}$ and single fractions of $1.8 \mathrm{~Gy}$ to the drainage sites on both sides of the neck up to a total of 54 Gy daily (5 times/week) (Tehrany et al. 2015) was applied to 50 patients, from 11/2008 to 11/2011. In addition to the RT a supplementary concomitant CT consisting of 5-fluorouracil plus mitomycin C or of cisplatin alone was administered to 171 patients.

Toxicity was monitored in the Department of Radiotherapy and Radiation Oncology of University Medical Centre Göttingen, weekly during treatment and every second week 


\section{Materials and Methods}

following the end of therapy until the disappearance of acute toxicity. Subsequently, chronic toxicity was monitored at least yearly. Toxicity was classified according to the CTC score for acute effects (Cox et al. 1995, Trotti et al. 2000, Trotti et al. 2003) and according to the "Late Effects on Normal Tissue" scoring system for chronic toxicity (Rubin et al. 1995, Hendry et al. 2006). Before data analysis, acute organ toxicity or acute hematotoxicity grade 3 or higher was chosen as the cut-off value for high-grade acute toxicity because patients with toxicity grade 3 or higher have a strongly impaired quality of life. For further analysis, acute toxicity was scored as high-grade acute organ toxicity (HGAOT) or high-grade acute hematotoxicity (HGAHT) if one or more items were scored as CTC grade 3 or higher. The acute organ toxicity items in this study were mucositis, skin reaction, dysphagia and nausea, while the acute hematotoxicity was observed as anaemia, leukopenia and thrombocytopenia.

\subsubsection{Immunohistochemistry (IHC)}

Immunohistochemical staining of CXCR4, CXCL12, p16 $6^{\mathrm{INK} 4 \mathrm{~A}}$ and $\mathrm{p} 53$ was performed on 2 $\mu \mathrm{m}$ slices of FFPE tissue samples from 233 pre-treatment HNSCC biopsies. Tissue sections were deparaffinized with three washes in xylene for five minutes each and rehydrated with distilled water through an ethanol series. Tissue antigens for CXCL12 and p16 ${ }^{\mathrm{INK} 4 \mathrm{~A}}$ were retrieved in boiled citrate buffer $(2.1 \mathrm{~g} / \mathrm{L}$ citric acid, $\mathrm{pH}$ 6.0) with incubation for 40 minutes. This step was not necessary for CXCR4 and p53. The tissue sections were then incubated in a blocking solution ( $2 \%$ BSA) to eliminate non-specific binding. The specimens were then incubated for two hours at room temperature with their specific primary antibodies (see listed antibodies in Table 2.5). Afterwards, the specimens were incubated for 20 minutes at room temperature with a biotinylated secondary antibody (Dako K5005). After extensive rinsing, they were developed using the streptavidin-biotin-peroxidase complex technique (Dako K5005). Negative control (absence of primary antibodies) and positive controls (FFPE human cell lines of known CXCR4, CXCL12 and p16 ${ }^{\mathrm{INK} 4 \mathrm{~A}}$ reactivity) were included for each staining. The quality of samples was confirmed by immunohistochemical staining for p53.

\subsubsection{Scoring of the immunohistochemistry staining}

The sections were examined microscopically by a pathologist and me without knowledge of the clinicopathologic data. The expression of targeted proteins was evaluated using a visual grading system based on the percentage of positive stained cells and the intensity of staining 


\section{Materials and Methods}

(graded on a scale of 0 to 3; 0: no staining; 1: weak staining; 2: moderate staining; 3: strong staining). The expression of targeted proteins was scored positive when more than $5 \%$ cells (cut-off) stained positively (Fregonesi et al. 2003). In addition, expression of p16 ${ }^{\mathrm{INK} 4 \mathrm{~A}}$ was separately graded as described: negative ( $0-5 \%$ of nuclei and cytoplasm positive), focal or patchy (5-30\% of nuclei and cytoplasm with weak and scattered positivity), and diffuse (>30\% of labelled cells with strong positivity). A weighted score was assumed to each case by multiplying the percentage of stained cells by the staining intensity scores (Xia et al. 2011).

\subsubsection{HPV DNA analysis}

\subsubsection{HPV DNA extraction}

The 233 FFPE tumour biopsies were analysed for the existence of HPV DNA. Seven $5 \mu \mathrm{m}$ scrolls were cut from each of the 233 FFPE biopsies. In the first step, these samples were deparaffinised following the existing protocol in the Department of Pathology of University Medical Centre Göttingen and the DNA was then extracted from the samples using the Nucleic Acid-Isolation Kit (QIAamp DNA Mini Kit) according to the manufacture's instruction.

\subsubsection{Sample DNA quality assessment}

The concentration of eluted DNA was measured with a NanoDrop ND-2000 Spectrophotometer. The purity of the DNA samples was determined by the ratio $\mathrm{A}_{260 \mathrm{~nm}} / \mathrm{A}_{280 \mathrm{~nm}}$. The $\mathrm{A}_{260} / \mathrm{A}_{280}$ ratio provided an estimate of the purity of the nucleic acid, with a value of 1.8-2.0 representing pure preparation (Sambrook et al. 1989). The samples were stored for further analysis at $-20^{\circ} \mathrm{C}$.

The quality of the DNA was confirmed by using $5 \mu 1$ aliquots of each DNA sample for PCR analysis of the human beta-globin gene with the PC04 and GH20 primers (see listed used primers in Table 2.7) using the same program described for primary PCR of nested-PCR (see Chapter 2.2.2.4). The amplified gene fragment was 268 bp in size and visualised on the automated capillary electrophoresis QIAxcel system. The primer sequences were synthesized by Eurofins MWG, Ebersberg, Germany (http://eurofinsgenomics.com). 


\subsubsection{PCR analysis}

The polymerase chain reaction (PCR) method allows the amplification of specific DNA sequences from small amounts of DNA-containing material. In repetitive cycles of DNA denaturation, primer annealing and elongation, the DNA sequences are amplified. The reaction is catalysed by a thermostable DNA polymerase and uses dNTPs and several or two oligonucleotide primers for primary and nested-PCR, respectively. To increase the sensitivity and/or specificity of PCR, nested-PCR was used in this study. Nested-PCR consists of twoPCR steps in sequence. Two different sets of PCR primers are used to amplify the same target sequence. The first primer mix (consist of 18 primer sequences) amplifies the target sequence as seen in any PCR experiment and the second pair of primers (nested-primers) bind within the first PCR product and produce a second PCR product that will be shorter than the first one. The logic behind this strategy is that nested-PCR offers an increase in sensitivity over the primary PCR.

Table 2.7: List of used primers for PCR assays

\begin{tabular}{|c|c|}
\hline PGMY 09/11 & \\
\hline PGMY 11-A & $5^{\prime}$ - GCA CAG GGA CAT AAC AAT GG -3' \\
\hline PGMY 11-B & $5^{\prime}-$ GCG CAG GGC CAC AAT AAT GG -3' \\
\hline PGMY 11-C & $5^{\prime}$ - GCA CAG GGA CAT AAT AAT GG -3' \\
\hline PGMY 11-D & $5^{\prime \prime}$ - GCC CAG GGC CAC AAC AAT GG -3' \\
\hline PGMY 11-E & 5'- GCT CAG GGT TTA AAC AAT GG -3' \\
\hline PGMY 09-F & $5^{\prime}-$ CGT CCC AAA GGA AAC TGA TC -3' \\
\hline PGMY 09-G & $5^{\prime}-$ CGA CCT AAA GGA AAC TGA TC -3' \\
\hline PGMY 09-H & 5'- CGT CCA AAA GGA AAC TGA TC -3' \\
\hline PGMY 09-I & $5^{\prime}-$ G CCA AGG GGA AAC TGA TC -3' \\
\hline PGMY09-J & $5^{\prime}-$ CGT CCC AAA GGA TAC TGA TC -3' \\
\hline PGMY 09-K & 5'- CGT CCA AGG GGA TAC TGA TC -3' \\
\hline PGMY 09-L & 5'- CGA CCT AAA GGG AAT TGA TC -3' \\
\hline
\end{tabular}




\begin{tabular}{|c|c|}
\hline PGMY 09-M & $5^{\prime}$ - CGA CCT AGT GGA AAT TGA TC -3' \\
\hline PGMY 09-N & $5^{\prime}$ - CGA CCA AGG GGA TAT TGA TC -3' \\
\hline PGMY 09-P & $5^{\prime}-$ G CCC AAC GGA AAC TGA TC -3' \\
\hline PGMY 09-Q & $5^{\prime}-$ CGA CCC AAG GGA AAC TGG TC -3' \\
\hline PGMY 09-R & $5^{\prime}$ - CGT CCT AAA GGA AAC TGG TC -3' \\
\hline HMB01 & $5^{\prime}$ - GCG ACC CAA TGC AAA TTG GT -3' \\
\hline \multicolumn{2}{|l|}{ GP5+/6+ } \\
\hline Gp5+ & $5^{\prime}$ - TTTGTTACTGTGGTAGATACTAC -3' \\
\hline GP6+ & $5^{\prime}$ - GAAAAATAAACTGTAAATCATATTC -3’ \\
\hline \multicolumn{2}{|l|}{ B-globin } \\
\hline PC04 & $5^{\prime}$ - CAACTTCATCCACGTTCACC -3' \\
\hline GH20 & 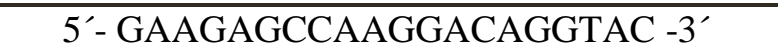 \\
\hline
\end{tabular}

\subsubsection{Nested-PCR}

To screen the presence of HPV in the samples, a nested-PCR consisting of the PGMY 09/11 primer mix (for the primary PCR) (Gravitt et al. 2000) and the GP5+/6+ primer set (for the secondary PCR) (de Roda Husman et al. 1995, Gravitt et al. 2000) targeting the L1-ORF of the HPV genome was used. The list of the primers used for nested-PCR and also $\beta$-globin PCR are summarised in Table 2.7.

\section{Primary PCR}

Briefly, the final $25 \mu \mathrm{l}$ PCR mixture containing $5 \mu \mathrm{l}$ DNA and $12.5 \mu \mathrm{l}$ of master mix (BIORON) was amplified with $2 \mu$ of the PGMY 09/11 primer mix (10 pmol each). Amplification was performed using the following cycling conditions: incubation at $94^{\circ} \mathrm{C}$ for three minutes followed by 40 cycles of one minute denaturation at $94^{\circ} \mathrm{C}$, one minute annealing at $54^{\circ} \mathrm{C}$, and one minute elongation at $72^{\circ} \mathrm{C}$. The last cycle was followed by a final extension for five minutes at $72^{\circ} \mathrm{C}$ and then storage at $4{ }^{\circ} \mathrm{C}$. 


\section{$\underline{\text { Secondary PCR (nested-PCR) }}$}

The end product of the first PCR was diluted 1:10, and one microliter of this sample and 7.5 $\mu 1$ of the master mix (BIORON) were used for the nested-PCR using $1.2 \mu 1$ GP5+/GP6+ primers in a $15 \mu \mathrm{l} \mathrm{PCR}$ mixture. The GP5+/GP6+ primers consisted of a fixed nucleotide sequence for each of the 18 primers of the first PCR and detected a wide range of HPV types by using a lower annealing temperature during PCR. The PCR cycling conditions were as follow: denaturing step at $95^{\circ} \mathrm{C}$ for five minutes, followed by 30 cycles of $95^{\circ} \mathrm{C}$ for one minute, then $40^{\circ} \mathrm{C}$ for two minutes and $72^{\circ} \mathrm{C}$ for one and half minutes. This last cycle was followed by a final extension period of ten minutes at $72^{\circ} \mathrm{C}$.

Positive (low-risk HPV-6 subtype) and negative (PCR-water (BIORON) instead of extracted DNA) controls were included during amplification. The amplified gene fragments of the primary and secondary PCRs were $450 \mathrm{bp}$ and $140 \mathrm{bp}$, respectively, and were visualised on the automated capillary electrophoresis QIAxcel system.

To avoid any contamination, the PCR mixture without DNA was pipetted in a room with an "air clean PCR workstation". DNA was extracted under sterile conditions in a separate laboratory. DNA was added to the PCR reaction mixture in a third laboratory room.

\subsubsection{Sequencing and HPV subtyping}

The PCR products from any samples positive for the primary and/or secondary PCR were purified using the Wizard® SV Gel and PCR Clean-Up System. The purified PCR products were then subjected to automated DNA sequencing based on Sanger sequencing method (Sequence Laboratories Göttingen GmbH, Germany, www.seqlab.de). The purified PCR product used for sequencing consisted of six microliters of the eluted PCR product and one microliter GP5+ primer.

Sequencing results were downloaded from the SeqLab website, and analysed using "Chromas Lite" software. Analysed sequences were compared to available databases, using the Basic Local Alignment Search Tool (Balermpas et al.) to determine approximate phylogenetic affiliations (NCBI, www.ncbi.nlm.nih.gov). 


\subsubsection{Statistical analysis}

Fisher's exact test was used to test differences between groups on categorical variables. The patient survival times were calculated from the day of the histological diagnosis to death for any reasons (OS), to local recurrence (local recurrence-free survival (LRFS)) or to the end of study. Kaplan-Meier analysis was used to estimate OS, LRFS, disease-free survival (DFS), loco-regional control rates (LRC) as the absence of local and/or regional recurrence or progression, and distant metastasis-free survival (DMFS).

Cox proportional hazards regression was used to analyse the impact of HPV infection, p $16^{\text {INK4A }}$ expression and HGOAT on OS. With $16^{\text {INK4A }}$ and HGAOT a multivariate Cox regression versus OS was computed including an interaction term. The impact of CXCR4 and CXCL12 expression on patient survival was analysed by univariate Cox proportional hazards regressions. In addition, to test whether the association between marker expression and survival was independent of other possible prognostic factors or factors that might influence treatment outcome and which could bias the univariate analysis, an additional multivariate analysis (multivariate Cox regression) was performed.

For the statistical tests the significance level was set as $\alpha=5 \%$. Statistical analyses were performed with free software (R, version 3.1; http: //www.r-project.org). 


\subsubsection{Cell cultures}

Three human HNSCC tumour cell lines and two control human cell lines were used for the in vitro experiments (see below). The cell lines were taken from stocks that were preserved in liquid nitrogen in the Department of Radiotherapy and Radiation Oncology at the University Medical Centre Göttingen.

\subsubsection{Cell lines}

\section{$\underline{\text { Tumour cell lines }}$}

\section{ZMK-1 cell line}

This cell line is a poorly differentiated (grade 2) SCC of an oropharyngeal tumour from a 47year-old male patient obtained during tumour resection performed in 1996 by the Department of Oral and Maxillofacial surgery, University Medical Centre Göttingen. Cells from this tumour were isolated and cultivated in the Department of Radiotherapy and Radiation Oncology at the University Medical Centre Göttingen (Rave-Frank et al. 1996).

\section{FaDu cell line}

FaDu-cells are human epithelial cells that were isolated in 1968 from a SCC of the hypopharynx of a 56-year-old male Hindu patient (Rangans 1972). The cells were obtained from the American Type Culture Collection (ATCC).

\section{GR-145 cell line}

This cell line is a moderately differentiated (grade 2) SCC of an oropharyngeal tumour from a 48-year-old male patient obtained during tumour resection performed in 1998 by the Department of Otorhinolaryngology at the University Medical Centre Göttingen. Cells from this tumour were isolated and cultivated in the Department of Radiotherapy and Radiation Oncology at the University Medical Centre Göttingen. 


\section{Control cell lines}

\section{HaCat cell line}

This spontaneously transformed epithelial cell line is an aneuploid, but highly differentiated, immortalized human keratinocyte cell line, which was gained from a histologically normal skin specimen. This skin specimen was obtained from a distant peripheral tissue of a malignant melanoma acquired in 1988 from a 62-year old male patient (Boukamp et al. 1988). This cell line was supplied by Cell Lines Service (CLS, www.cell-lines-service.de).

\section{DF-19 cell line}

Primary fibroblasts were obtained from a skin spindle taken from a healthy 30-year-old male. The cells were isolated and cultivated in 2003 in the Department of Radiotherapy and Radiation Oncology at the University Medical Centre Göttingen.

\subsubsection{Culture conditions and media}

To prevent contamination of the cell cultures with bacteria or fungi, all used materials such as Eppendorf reaction tubes and pipette tips were autoclaved for 15 minutes at $121^{\circ} \mathrm{C}$. Devices not autoclaved were regularly cleaned with $70 \%$ ethanol. All solutions, i.e. all growth media, cell culture additives and other reagents, were supplied sterile by the manufacturers and were only opened and used under the sterile hood.

The cell lines were cultured in sterile culture flasks with two different capacities, 50 or $250 \mathrm{ml}$ at $37^{\circ} \mathrm{C}$ and in an atmosphere containing $5 \% \mathrm{CO}_{2}$. A volume of cell medium of $10 \mathrm{ml}$ for the $50 \mathrm{ml}$ flasks and $20 \mathrm{ml}$ for the $250 \mathrm{ml}$ flasks was sufficient to cover the cells growing adherently in a monolayer. Depending on the cell line, every three to five days the cell medium was changed. After reaching a confluency of 80 to $90 \%$ cells were dissociated by trypsinisation, and were subcultured and reseeded in new culture flasks. The compositions and contents of each cell line-related medium are itemized in the following Table 2.8.

Reagents and media were stored at $4^{\circ} \mathrm{C}$. Fetal calf serum (FCS), trypsin and antibiotics were kept at $-20^{\circ} \mathrm{C}$ for long term storage. All reagents and media were warmed slowly to $37{ }^{\circ} \mathrm{C}$ before use. 
Table 2.8: Culture mediums used for the cell lines

FaDu

Ampicillin $(0.5 \mathrm{~g} / 10 \mathrm{ml})$

GR-145

HaCat

DMEM including $10 \%$ inactivated FCS and $1 \mathrm{ml}$ Ampicillin $(0.5 \mathrm{~g} / 10 \mathrm{ml})$

DF-19

\subsubsection{Passage of adherent cell lines (subculture)}

The cell cultures were passaged by trypsinisation when required. The culture medium was drained from the flasks and residual medium was removed by rinsing with $2-3 \mathrm{ml}$ of Phosphate Buffered Saline (PBS) without calcium and magnesium. The cell layer was slowly covered with 1-2 ml trypsin-EDTA solution (0.5\% trypsin; $0.2 \%$ EDTA in PBS), and the flask was returned to the incubator for 5 to 10 minutes. The HaCat cells were more strongly attached to the bottom of the culture flask and required a second step in dissociation. The HaCat cells were washed additionally with $1 \mathrm{ml}$ EDTA solution after the PBS wash. One ml of trypsin-EDTA solution was then added and incubated as described above. At the end of the incubation time the flasks were removed and shaken gently by hand to dislodge the cells.

The flasks were inspected under the microscope to determine whether all cells had been detached from the flask bottom. The cells were then resuspended in fresh growth medium.

\subsubsection{Counting cells with the Neubauer counting chamber}

A Neubauer chamber is a four millimetres thick, 30 by $70 \mathrm{~mm}$ crystal slide with a counting grid. There are single or double chamber slides. Only double chamber slides with separate counting areas were used in this study; the upper and the lower chamber.

A glass cover slip was placed over the grid of the chambers, and ten microlitre of cell suspension was pipetted into the chambers. Once both chambers were filled, the slide was placed under the light microscope. The number of viable cells in each of the 25 small squares 
of the central square is counted in both chambers. The average number of cells is calculated and multiplied $1 \times 10^{4}$ to give the number of cells in one millilitre of our cell suspension.

\subsubsection{Cryopreservation and thawing of cells}

\section{Cryopreservation}

Cryopreservation is the best method to store mammalian cells. Cryoprotectants are added to the cell suspension to prevent the formation of Intra- and extracellular ice crystal that would cause cell death. Dimethyl sulphoxide (DMSO) is the standard cryoprotectant. Cultures that had reached 80 to $90 \%$ confluency were harvested by trypsinisation. The cell suspension was centrifuged at $1200 \mathrm{rpm}$ for ten minutes, and the cell pellet was resuspended in freezing medium (culture medium containing 9\% DMSO). Two millilitre aliquots of cell suspension containing $1 \times 10^{6}$ viable cells per $\mathrm{ml}$ were put into $2 \mathrm{ml}$ plastic cryovials. These were frozen in a CoolCell ${ }^{\circledR}$ container at $-80^{\circ} \mathrm{C}$ for four hours before transferring them to long-term archive storage at $-150^{\circ} \mathrm{C}$.

\section{Thawing of frozen cells}

Frozen cell vials were thawed in a $37^{\circ} \mathrm{C}$ water bath, until a liquid film had formed and the remaining solid block could be transferred to a flask containing ten millilitres of the appropriate medium, and the cells were allowed to attach. To remove residual DMSO, the medium was changed after approximately four hours or on the following day. 


\subsubsection{Real-time PCR}

The cells $\left(1 \times 10^{6}\right.$ cells $\left./ \mathrm{ml}\right)$ were washed in PBS before storing them in lysis buffer at $-80^{\circ} \mathrm{C}$. To extract and isolate RNA from our used cells for real-time PCR, RNeasy mini kit (Qiagen) was used according to the manufacturer's instructions. The RNA amounts were then measured by a spectrophotometric method. Super-Script II reverse transcriptase was used to carry out reverse transcription to complementary DNA with $1 \mu \mathrm{g}$ total RNA for one hour, under inhibition of RNase by adding 20 units recombinant RNase inhibitor per each samples. In a real-time PCR machine, the quantification of transcript numbers of target and reference genes was determined relatively by using HotStart-IT SYBR Green qPCR-Master Mix (USB). The amplification condition of the PCR was composed of 40 to 50 cycles (dependent on expression level). The annealing step lasted $20 \mathrm{~s}$ accomplished at $60^{\circ} \mathrm{C}$ and the elongation step was performed for $40 \mathrm{~s}$ at $72^{\circ} \mathrm{C}$ for each primer pair (Wolff et al. 2011a).

The primer sequences were synthesized by MWG, Ebersberg, Germany (primer sequences given in Table 2.9). Data were normalized to weighted mean expression of HPRT1 using as reference gene (Wolff et al. 2011a).

Table 2.9: primer pairs used for the analysis of CXCL12 and CXCR4 transcript expression

\begin{tabular}{|c|c|c|}
\hline Gen & \multicolumn{2}{|c|}{ Primer sequences } \\
\hline & Forward primer & Reverse primer \\
\hline CXCL12 & 5'- GGT CGT GGTCGTGCTGGT -3’' & $5^{\prime}$-CGG GCT ACA ATC TGA AGG G -3' \\
\hline CXCR4 & $5^{\prime}-\mathrm{TAC}$ ACC GAG GAA ATG GGC TCA -3' & 5'- AGA TGA TGG AGT AGA TGG TGG G-3' \\
\hline HPRT1 & $5^{\prime}$-TGA CAC TGG CAA AAC AAT GCA -3' & 5'-GGT CCT TTT CAC CAG CAA GCT -3' \\
\hline
\end{tabular}

\subsubsection{Western blot analysis}

\subsubsection{Protein extraction}

All steps of protein extraction were performed at $4^{\circ} \mathrm{C}$. For cell lysis, growth medium was removed and the cells were washed twice with $5 \mathrm{ml}$ cold PBS to remove all residual medium. 


\section{Materials and Methods}

The cells were then scraped off the flask bottom with a cell scraper and resuspended in PBS. This suspension was centrifuged at $1200 \mathrm{rpm}$ for eight minutes at $4^{\circ} \mathrm{C}$. After the centrifugation, the PBS supernatant was removed.

$500 \mu 1$ of lysis buffer (see the composition of the lysis buffer in Table 2.10) was added to the cell sediment and stirred carefully. Ultrasound was used to facilitate cell lysis and protein release with the following parameters: four times with duration of 0.9 seconds and $42 \%$ intensity.

Table 2.10: Composition of the lysis buffer

\begin{tabular}{|c|c|c|}
\hline Substrate & Molecular weight (MW) & Dilutions \\
\hline $20 \mathrm{mM}$ Tris $\mathrm{HCl}(\mathrm{pH}=7.5)$ & 157.60 & $0.0315 \mathrm{~g} / 100 \mathrm{ml}$ water \\
\hline $150 \mathrm{mM} \mathrm{NaCl}$ & 58.60 & $0.0876 \mathrm{~g} / 100 \mathrm{ml}$ water \\
\hline $1 \mathrm{mM} \mathrm{MgCl}_{2}$ & 203.30 & $0.002 \mathrm{~g} / 100 \mathrm{ml}$ water \\
\hline $1 \mathrm{mM} \mathrm{CaCl}_{2}$ & 147.02 & $0.0014 \mathrm{~g} / 100 \mathrm{ml}$ water \\
\hline $1 \% \mathrm{NP}-40$ & - & $1 \mathrm{ml} / 100 \mathrm{ml}$ water \\
\hline $10 \%$ glycerol & - & $10 \mathrm{ml} / 100 \mathrm{ml}$ water \\
\hline \multicolumn{3}{|c|}{$10 \mathrm{ml}$ lyse buffer } \\
\hline \multicolumn{3}{|c|}{ + 1 pill of Mini, EDTA-free, protein inhibitor } \\
\hline
\end{tabular}

The cell-buffer suspension was incubated on ice for ten minutes in order to let the foam subside. A series of five to six passages through a fine insulin cannula was done manually to increase protein release. This step was repeated after ten minutes. After the final passage, the suspension from each tube was transferred into a nonsterile, $1.5 \mathrm{ml}$ plastic cup and centrifuged at $6000 \mathrm{rpm}$ for ten minutes at $4{ }^{\circ} \mathrm{C}$.

The lysate was transferred to a fresh $1.5 \mathrm{ml}$ cup for Bradford assay and western blot. Lysates were kept on ice until use or at $-80^{\circ} \mathrm{C}$ for long-term storage.

\subsubsection{Bradford assay}

Protein concentrations in the samples, were determined by Bradford assay (Bradford 1976). Bovine serum albumin (BSA) was used to prepare a standard curve (with 0 to $2 \mathrm{mg} / \mathrm{ml}$ protein 


\section{Materials and Methods}

concentration range). First a standard curve was prepared, by defining the standard absorbance values on the $\mathrm{y}$-axis and their concentrations in $\mathrm{mg} / \mathrm{ml}$ on the $\mathrm{x}$-axis, in order to determine unknown protein concentrations. One millilitre Bradford solution (Bio-Rad) was added to each vial and mixed by inversion. The blank sample was $20 \mu$ sterile water in one millilitre of Bradford solution. The absorbance of the prepared standard concentration samples were measured at $595 \mathrm{~nm}$ and the standard curve was drawn. For samples with unknown protein concentration, $20 \mu \mathrm{l}$ of the samples was added to one millilitre Bradford solution and the absorbance was measured. The values were entered into the standard curve to obtain the protein concentration of the sample.

The measurements were performed in duplicate to improve the accuracy of the determination. The results corresponded to the protein concentration in $20 \mu 1$ of lysate. The amount of lysate required for loading the electrophoresis gel was calculated by dividing $20 \mu 1$ of lysate volume by the concentration. In order to reach a final volume of $20 \mu 1$, we calculated the volume of sodium dodecyl sulphate (SDS) buffer that had to be added (see the SDS buffer consistence in Table 2.11).

\subsubsection{Gel electrophoresis}

Purified proteins were separated on precast 10-well polyacrylamide gels (TGX-gel). The gels were placed in the migration set that consisted of a tank, lid, and an electrode assembly. The separated proteins were further processed for western blotting using a Trans-Blot Turbo ${ }^{\mathrm{TM}}$ system.

Adequate volumes of the protein lysate and SDS buffer-mercaptoethanol solution (see Table 2.11) were mixed together. These mixtures were centrifuged for a few seconds by rapid acceleration. Afterwards they were incubated for five minutes at $95{ }^{\circ} \mathrm{C}$.

Samples were loaded into wells of the TGX-gel and run against protein standards. The gel electrophoresis was performed at $200 \mathrm{~V}$ and $30 \mathrm{~mA}$. Once migration was over, the proteins were transferred from the gel onto a nitrocellulose membrane. 
Table 2.11: SDS buffer consistence

\begin{tabular}{|l|l|}
\hline SDS buffer (pH= 7.4) & $\begin{array}{l}30 \mathrm{mM} \text { Tris-Base } \\
9 \% \text { SDS } \\
15 \% \text { glycerine } \\
0.04 \% \text { bromphenol blue Na-salt } \\
10 \% \text { 2-mercaptoethanol }\end{array}$ \\
\hline
\end{tabular}

\subsubsection{Western blotting}

After the proteins had been separated by electrophoresis, they were transferred by electroblotting to a nitrocellulose membrane. In electroblotting an electric current is used to propel the proteins from the gel onto the nitrocellulose membrane while maintaining their pattern.

Electroblotting was done with the Trans-Blot Turbo ${ }^{\mathrm{TM}}$ Transfer system following the manufacture's instruction using a transfer time of three minutes. The protein-loaded membranes were then stained with the sodium salt of a diazo dye. The loading and transfer efficiency was analysed with this procedure. The dye was later washed out with water.

Western blotting of the nitrocellulose membrane was performed after protein transfer. Prior to incubating the protein-loaded membranes with the primary antibody, the membrane-blocking step is crucial to avoid non-specific primary antibody binding in protein in free spaces. For this purpose a WesternBreez ${ }^{\circledR}$ Chromogenic Western blot immunodetection kit was used. The membrane was blocked with blocking solution for 30 minutes on a rotatory shaker followed by two washes of five minutes with distilled water.

Following this, the primary antibody was incubated on the membrane for one hour at room temperature or over-night at $4^{\circ} \mathrm{C}$. For the present study, rabbit anti-CXCR4 monoclonal antibody (see Table 2.5) was used.

Beta-actin, as a ubiquitous structural protein, was used to confirm equal loading of the protein lysates. Due to an almost identical molecular weight of the two targeted proteins (molecular weights of CXCR4 and $\beta$-actin proteins were approximately 40 and $42 \mathrm{kDa}$, respectively), western blotting was performed to detect each protein separately on two individual 


\section{Materials and Methods}

membranes. For this purpose monoclonal mouse anti- $\beta$-actin antibody was applied as primary antibody (Table 2.5). The primary antibodies were diluted in five millilitres of blocking solution in order to obtain the dilutions recommended by the manufacturers. For anti-CXCR4 a dilution of 1:500 and for anti- $\beta$-actin a dilution of $1: 10000$ was used.

An incubation time of one hour was kept. After the membranes had been washed three times for five minutes each in ten millilitres of antibody wash to remove residual primary antibody, the membranes were re-incubated for 30 minutes in five millilitres of the secondary antibody solution. The choice of the secondary antibody depended on the primary antibody (i.e. mouse or rabbit). In order to remove residual secondary antibody the membranes were washed three times for five minutes followed by a final wash procedure of three two-minute washes with distilled water.

In the last step, the membranes were incubated with $5 \mathrm{ml}$ of chromogenic substrate for one to 60 minutes without agitation. With our antibodies, 15 minutes were enough to visualise the bands.

The membranes were then washed for a final three times in ten millilitres of distilled water for two minutes before placing them on a clean filter paper to dry in the open air at room temperature.

The stained bands were visually compared to those of the marker loaded during electrophoresis to estimate size. The process was performed with the above mentioned $\beta$-actin protein-loaded membrane. Beta-actin was therefore also useful in detecting eventual errors such as incomplete transfers.

\subsubsection{Immunocytochemistry (ICC)}

The expression of CXCL12 in the studied cell lines was determined by immunocytochemical staining. The detection procedure consisted of cytocentrifugation prior to the staining itself.

\subsubsection{Preparation of Cytospin slides}

Cell staining began with preparation of the enriched suspension. To avoid stromal CXCL12 in background, the cells were starved in medium without FCS for 24 hours. After 24 hours, the 


\section{Materials and Methods}

medium was discarded, and the cells were washed with PBS and incubated with trypsin. Then cells were transferred to a fresh Falcon ${ }^{\circledR}$-tube with fresh medium. An appropriate cellular suspension was prepared and the cells were counted according to the procedure described in Chapter 2.3.1.4. For our purpose, $3 \times 10^{4}$ cells $/ \mathrm{ml}$ were needed for the preparation of each superfrost glass slide.

The centrifuge consists of 12 "Cytospin-sample chambers". For each superfrost glass slide, $100 \mu \mathrm{l}$ of each cellular suspension was added. The cells $\left(3 \times 10^{3}\right.$ cells $\left./ \mathrm{ml}\right)$ were centrifuged for five minutes at $1500 \mathrm{rpm}$ using program 1 (predefined for this purpose according to the manufacturer's protocol). After the cells had been centrifuged the slides were removed from the centrifuge and examined under a light microscope to confirm homogenous separation. Afterwards the slides were dried at room temperature over-night.

\subsubsection{Immunocytochemical CXCL12 staining method}

In order to prepare the glass slides with the cellular monolayer for the immunochemical staining procedure, they were fixed in $-20^{\circ} \mathrm{C}$ acetone for 10 minutes and then washed in a Wash-Buffer for a few minutes. The samples were incubated for 45 minutes at room temperature with the primary monoclonal mouse anti-CXCL12 antibody (Table 2.5) diluted 1:2000. After washing, the enhancement reagent "PostBlock" was applied and incubated at room temperature for 20 minutes. A second wash was followed by the application of the "HRP-polymer" with 30 minutes incubation at room temperature. Any excess of unbound HRP-polymer was thoroughly washed off after incubation. The addition of the chromogenic substrate started the enzymatic reaction of the peroxidase, which led to colour precipitation wherever the primary antibody was bound.

For the final visualisation, a 20-power Olympus light microscope equipped with a camera was used to obtain photographic documentation of the observed images. If cells expressed CXCL12 this was seen as a red-brown staining either of the cell surface, cytoplasm or both.

\subsubsection{Colony formation unit assay (CFU assay)}

The colony-forming unit (CFU) assay is the basic method of tumour radiobiology to determine the clonogenicity of irradiated cells by their ability to form a colony in a defined growth environment. It is the "gold standard" for in vitro studies (Joiner and Kogel 2009). 


\section{Materials and Methods}

In general, the in vitro $\mathrm{CFU}$ assay for radiosensitivity is based on seeding cells, irradiating them, and then after a suitable period of incubation counting the number of colonies. The plating efficiency (PE) is calculated by dividing the number of colonies by the number of seeded cells.

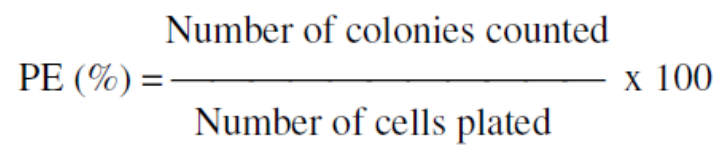

Following determination of PE, the fraction of cells surviving a given treatment (SF) was calculated by normalizing PE after a given dose to that of the control non-irradiated plates:

$$
\mathrm{SF}(\%)=\frac{\text { PE of treated sample }}{\text { PE of control }} \times 100
$$

The cytotoxic effect of radiation on cells is commonly described by a cell survival curve. The survival curves were evaluated for three tumour and one control cell lines irradiated in a range of doses from 0 to 4 or $6 \mathrm{~Gy}$. Since the number of colonies became too low for trustworthy quantification, higher doses of irradiation could not be used. Because the number of seeded cells is not directly proportional to the number of resulting colonies, even in control samples, increase in number of seeded cells failed to overcome this dose limitation. The survival fraction as a function of dose was plotted on a logarithmic scale (y axis), against dose on a linear scale (x axis), resulting in a survival curve.

\subsubsection{Seeding procedures}

A single-cell suspension was prepared for each cell line (except for DF-19 cell line because of its poor colony forming capacity and the tendency to differentiate during the incubation period) following the procedure described above (see Chapter 2.3.1.4). Depending on the different radiation doses to be tested the single-cell suspension was divided into aliquots. One group of cells was defined as a control for the assay and was kept without irradiation and eventually without any kind of particular treatment. For treatment with CXCL12 or 


\section{Materials and Methods}

AMD3100, appropriated concentrations of CXCL12 or AMD3100 solution were prepared in the medium of each cell lines (see Table 2.8).

Suspensions with the desired total number of cells were prepared in $15 \mathrm{ml}$ sterile plastic tubes. The cells underwent subsequent X-ray irradiation in the laboratory. The doses were previously defined as $0.5,2,4$, or $6 \mathrm{~Gy}$ with a dose rate of $1 \mathrm{~Gy} / \mathrm{min}$. The control cells were not irradiated.

After irradiation, the cell suspensions were dispensed in $50 \mathrm{ml}$ culture flasks in quadruplicate for each treatment condition. Depending on the employed radiation dose, 300 to 3000 cells were seeded per flask.

\section{Treatment with CXCL12}

When treated with CXCL12, the cells were incubated for two hours in a medium lacking FCS and were then trypsinised. Suspensions of $2 \times 10^{5}$ cells $/ \mathrm{ml}$ were prepared in medium lacking FCS. The cells were irradiated ( 0 to $6 \mathrm{~Gy}$ ) and 500 microlitres of each cell suspension was incubated in 48-well plates. Each well, except the control well (cells in medium), was treated with $100 \mathrm{ng} / \mathrm{ml} \mathrm{CXCL12} \mathrm{(cells} \mathrm{in} \mathrm{medium} \mathrm{with} \mathrm{CXCL12).} \mathrm{The} \mathrm{plate} \mathrm{was} \mathrm{incubated} \mathrm{for} 48$ hours at $37^{\circ} \mathrm{C}$ in a $5 \% \mathrm{CO}_{2}$-atmosphere. After the incubation period, the cells were trypsinised and counted and 300 to 3000 cells/flask were seeded in a quadruplicate for each treatment condition.

\section{$\underline{\text { Treatment with CXCR4 antagonist (AMD3100) }}$}

For treatment with AMD3100, we used two CXCR4-positive cell lines, ZMK-1 and FaDu. The cells were first incubated for two hours in medium lacking FCS and then trypsinised. Suspensions of $2 \times 10^{5}$ cells $/ \mathrm{ml}$ were prepared in medium lacking FCS. The cells, except the control cells, were treated with $5 \mu \mathrm{g} / \mathrm{ml}$ AMD3100 for 30 minutes and then incubated at $37^{\circ} \mathrm{C}$ and $5 \% \mathrm{CO}_{2}$. The cells were irradiated ( 0 to $\left.4 \mathrm{~Gy}\right)$ and $1 \mathrm{ml}$ of each cell suspension was incubated in a 48 -well plate for 26 hours at $37^{\circ} \mathrm{C}$ and $5 \% \mathrm{CO}_{2}$. After incubation, the cells were trypsinised and counted and 300 to 2000 cells/flask were seeded in a quadruplicate for each treatment condition.

After seeding into the culture flasks, cells were incubated at $37^{\circ} \mathrm{C}$ and $5 \% \mathrm{CO}_{2}$ for a period between 8 to 14 days depending on the cell growth capacity of each line. All plates were 


\section{Materials and Methods}

regularly observed under the microscope and colony growth was evaluated. The colonies were then fixed and stained as described in Chapter 2.3.5.3.

\subsubsection{Cell irradiation}

A RS 225 X-ray Research System (Gulmay Medical Systems, Camberley, Surrey, UK) was used for irradiation. The cells were irradiated with a tube voltage of $200 \mathrm{kV}$ and a current of $15 \mathrm{~mA}$ filtered by a $0.5 \mathrm{~mm}$ thick copper sheet at a temperature of 22 to $24{ }^{\circ} \mathrm{C}$. The table height, defined as a distance between the table and the radiation source, was altered according to the preferred dose rate. This height was $500 \mathrm{~mm}$ and $351 \mathrm{~mm}$ for a dose rate of $1 \mathrm{~Gy} / \mathrm{min}$ and $2 \mathrm{~Gy} / \mathrm{min}$, respectively.

\subsubsection{Colony fixation and crystal violet staining}

After the cell culture medium was removed from the culture flasks, four millilitres of $70 \%$ ethanol were pipetted into each flask and left there for 20 minutes. The ethanol was removed and the flasks were dried in an incubator over-night. The fixed cells were stained with $0.1 \%$ crystal violet solution. Four millilitres of the crystal violet solution were added to each flask. After 20 minutes the solution was removed and excess stain was washed away with water. This procedure made the colonies visible and easily counted. Sterile conditions were not required for fixation and staining.

\subsubsection{Counting of colonies}

Plates with stained colonies were examined under the light microscope. A cluster of bluestained cells was considered a colony if it comprised at least 50 cells. It was important to keep this cut-off constant to avoid variations between experiments. All the cells of the colony were the progeny of a single cell.

\subsubsection{Cell survival curves}

To establish cell survival curves, the fixed and stained colonies were counted and the values of the surviving fraction for each treatment condition were calculated as described above. Each experiment and different treatment condition was repeated three times and the cells from 


\section{Materials and Methods}

each were seeded in quadruplicate. Afterwards mean values (expressed as points in the curves) were calculated and standard errors (SE) were plotted as error bars. If the error bars are not visible on the graph, they are smaller than the size of the point. Using Kaleidagraph ${ }^{\circledR}$ (version 4.1) the calculated surviving fractions were transformed graphically into a semilogarithmic scale representation. The abscissa represents the radiation doses on a linear scale, and the ordinate represents the surviving fractions on a logarithmic scale. The shape of the survival curve is unique for each cell line helping to evaluate cell behaviour under different irradiation conditions associated with or without other treatment regimens.

\subsubsection{Data analysis}

Survival curves, each referring to its specific control, were fitted to the data points using a linear-quadratic approach with:

$$
\ln (S F)=-\left(\alpha D+\beta D^{2}\right)
$$

where $\mathrm{D}$ represents the applied radiation dose and $\alpha$ and $\beta$ are proportionality factors. The dose-modifying factor (DMF) was calculated by the ratio of the radiation dose in the absence or presence of CXCL12 and AMD3100 to achieve the same cell survival rate.

\subsubsection{Cell viability assay - Cell Titer Blue ${ }^{\circledR}$ (CTB assay)}

The CTB assay is a cell viability assay that provides a homogeneous, fluorometric method to monitor cell viability and cell metabolic activity in multiwell plates. The assay is based on a redox reaction. Viable, metabolically active cells, can convert resazurin (dark blue with little intrinsic fluorescence activity) into its highly fluorescent product, resorufin (pink, highly fluorescent molecule) (Promega, Technical Bulletin, revised 6/09, Figure 2.1). The intensity of the fluorescence is proportional to the number of viable cells and their metabolic activity. Sterile 96-well black plates with clear bottoms were used for analysis. 


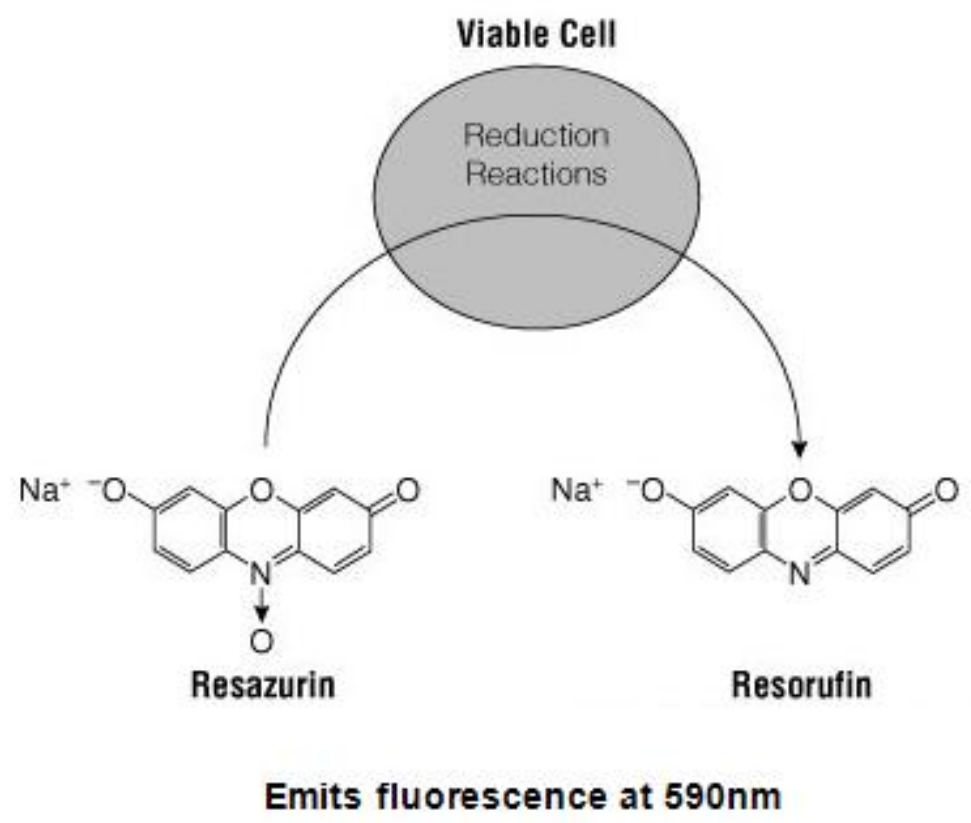

Figure 2.1: Conversion of resazurin with little fluorescence activity to resorufin with highly fluorescence activity by viable cells. The intensity of the fluorescence produced is proportional to the number of viable cells and their metabolic activities. (The figure was taken from Promega productguide-page: www.promega.de/resources/product-guides-and-selectors/protocols-and-applicationsguide/cell-viability)

2.3.6.1 Determination of optimal incubation time and radiation dose within CTB assay

\section{Test 1: Optimal incubation time}

Before setting up the 96-well plates for the cell viability assay, four different incubation times (26, 48, 72, and 96 hours) were tested to find the best possible incubation time. This experiment was performed only for control cell line HaCat and tumour cell line ZMK-1.

First, a suspension of HaCat and ZMK-1 cells was prepared and maintained in a $15 \mathrm{ml}$ plastic tube. One tube contained a suspension of the control cells without irradiation; after preparing the cell suspension, the second tube was irradiated. The irradiation was performed as described in Chapter 2.3.5.2. A total dose of $4 \mathrm{~Gy}$ was delivered with a dose rate of $1 \mathrm{~Gy} / \mathrm{min}$. After the irradiation the cells were seeded into wells; 5000 cells per well for HaCat and 6000 cells per well for ZMK-1 (see Table 2.12, green area). 
Table 2.12: Schematic representation of a 96-well plate seeded with cells and medium

\begin{tabular}{|c|c|c|c|c|c|c|c|c|c|c|c|c|}
\hline & 1 & 2 & 3 & 4 & 5 & 6 & 7 & 8 & 9 & 10 & 11 & 12 \\
\hline A & $\mathrm{M}$ & $\mathrm{M}$ & $\mathrm{M}$ & $\mathrm{M}$ & $\mathrm{M}$ & $\mathrm{M}$ & $\mathrm{M}$ & $\mathrm{M}$ & $\mathrm{M}$ & $\mathrm{M}$ & M & $\mathrm{M}$ \\
\hline B & $\mathrm{M}$ & \multirow{3}{*}{1} & \multirow{3}{*}{2} & \multirow{3}{*}{3} & \multirow{3}{*}{4} & \multirow{3}{*}{5} & \multirow{3}{*}{6} & \multirow{3}{*}{7} & \multirow{3}{*}{8} & \multirow{3}{*}{9} & \multirow{3}{*}{10} & $\mathrm{M}$ \\
\hline $\mathrm{C}$ & $\mathrm{M}$ & & & & & & & & & & & $\mathrm{M}$ \\
\hline $\mathrm{D}$ & $\mathrm{M}$ & & & & & & & & & & & $\mathrm{M}$ \\
\hline$E$ & $\mathrm{M}$ & \multirow{3}{*}{11} & \multirow{3}{*}{12} & \multirow{3}{*}{13} & \multirow{3}{*}{14} & \multirow{3}{*}{15} & \multirow{3}{*}{16} & \multirow{3}{*}{17} & \multirow{3}{*}{18} & \multirow{3}{*}{19} & \multirow{3}{*}{20} & $\mathrm{M}$ \\
\hline $\mathrm{F}$ & $\mathrm{M}$ & & & & & & & & & & & $\mathrm{M}$ \\
\hline $\mathrm{G}$ & $\mathrm{M}$ & & & & & & & & & & & $\mathrm{M}$ \\
\hline $\mathrm{H}$ & $\mathrm{M}$ & $\mathrm{M}$ & $\mathrm{M}$ & $\mathrm{M}$ & $\mathrm{M}$ & $\mathrm{M}$ & $\mathrm{M}$ & $\mathrm{M}$ & $\mathrm{M}$ & $\mathrm{M}$ & $\mathrm{M}$ & $\mathrm{M}$ \\
\hline
\end{tabular}

\section{Test 2: Optimal radiation dose}

Suspensions containing the necessary number of cells were prepared and maintained in $15 \mathrm{ml}$ plastic tubes. One tube contained cells for the control group (no irradiation); the other tubes were irradiated. After delivering with a dose rate of $2 \mathrm{~Gy} / \mathrm{min}$ total doses of 2, 4, 6, 8, 10 and 12 Gy the cells were seeded into wells, with 5000 cells/well for HaCat and 6000 cells/well for ZMK-1 (see Table 2.12, green area).

\section{Test 3: Combination of optimal incubation time and radiation dose}

Due to non-optimal incubation times for observing the effect of irradiation on cell viability, the assay was repeated for all five cell lines with a longer incubation time, i.e. for one week. For this test, a radiation dose of $8 \mathrm{~Gy}$ was selected as the optimal dose. For observing the effect of irradiation on cell viability, we decided to reduce the cell density to 2000 cells per well. In this last test, the cells were seeded in wells and the plate was then irradiated. Two plates were prepared; one 8 Gy irradiated plate, and one non-irradiated plate.

With the purpose of completing and homogenizing the volume per well, a total volume of 100 $\mu 1$ of each cell suspension per well was added to each well. The outer wells on all sides were loaded with cell-free medium (cell-free medium: M, Table 2.12). The contents of the wells in the first column (column 1, blue area B1-G1) were used as blank samples to determine background fluorescence. The green area represents the different conditions investigated. For each experiment and condition the test was done in triplicate (Table 2.12). 


\section{Materials and Methods}

The prepared plates (irradiated and non-irradiated) were incubated for one week under standard incubation conditions $\left(37^{\circ} \mathrm{C}\right.$ and $\left.5 \% \mathrm{CO} 2\right)$. At the end of the incubation period, the plate was removed from the incubator, $20 \mu 1$ of CTB Reagent was added cells in culture as well as 6 wells in the column 1 (Blank wells) following the manufacturer's guides, and the plate incubated again for one hour at $37^{\circ} \mathrm{C}$ before reading the 96 -well plate on a fluorometer at $560 \mathrm{~nm}$ excitation and $590 \mathrm{~nm}$ emission.

\subsubsection{Investigating various treatments on cell viability}

The notion of optimal radiation dose and incubation time permits to optimise the experimental process. If more treatment combinations are required in the same experiment, e.g. irradiation, CXCL12 and/or AMD3100, one plate is not irradiated and the other is irradiated allowing each treatment condition to be analysed with and without irradiation.

To begin with, a cell suspension containing $2 \times 10^{4}$ cells $/ \mathrm{ml}$ was prepared and divided in four $15 \mathrm{ml}$ plastic tubes. The first tube was treated with $100 \mathrm{ng} / \mathrm{ml}$ of CXCL12, a second tube with $5 \mu \mathrm{g} / \mathrm{ml}$ of AMD3100, a third tube with both of them. The last tube did not contain any drug. All tubes were incubated for 30 minutes at $37^{\circ} \mathrm{C}$ and $5 \% \mathrm{CO}_{2}$. From each tube $100 \mu$ of the cell suspension (2000 cells/well) was pipetted in two sterile 96-well black plates with clear bottoms; each experimental condition was performed in triplicate. One of this 96-well-plate was irradiated. A total dose of $8 \mathrm{~Gy}$ was delivered with a dose rate of $2 \mathrm{~Gy} / \mathrm{min}$.

After a one-week incubation time, the plates were removed from the incubator and CellTiterBlue ${ }^{\circledR}$ Reagent was added to the wells. The plates were gently shaken for ten seconds and returned to the incubator for one more hour at $37{ }^{\circ} \mathrm{C}$ for one hour. The experiment was performed twice for each cell line and the data were analysed following the procedure described below (see following Chapter 2.3.6.3).

\subsubsection{Data analysis}

The fluorescence analysis was performed with a Wallec1420 VICTOR ${ }^{\mathrm{TM}}$ plate reader. The dye was excited with a $560 \mathrm{~nm}$ wavelength and the emissions measured at $590 \mathrm{~nm}$. The obtained data were imported into Microsoft Office and the following calculations were performed: background fluorescence was subtracted from the raw fluorescence results of all 
wells. The averages and the standard deviations of the triplicate determinations were calculated.

\subsubsection{Migration assay}

One of the most commonly used migration assays is the Boyden chamber/Transwell assay (Figure 2.2). This method is used to quantify the migration of cells exposed to chemoattractants such as chemokines. The chamber includes two compartments separated by a microporous filter $(8 \mu \mathrm{m})$ through which the cells migrate.

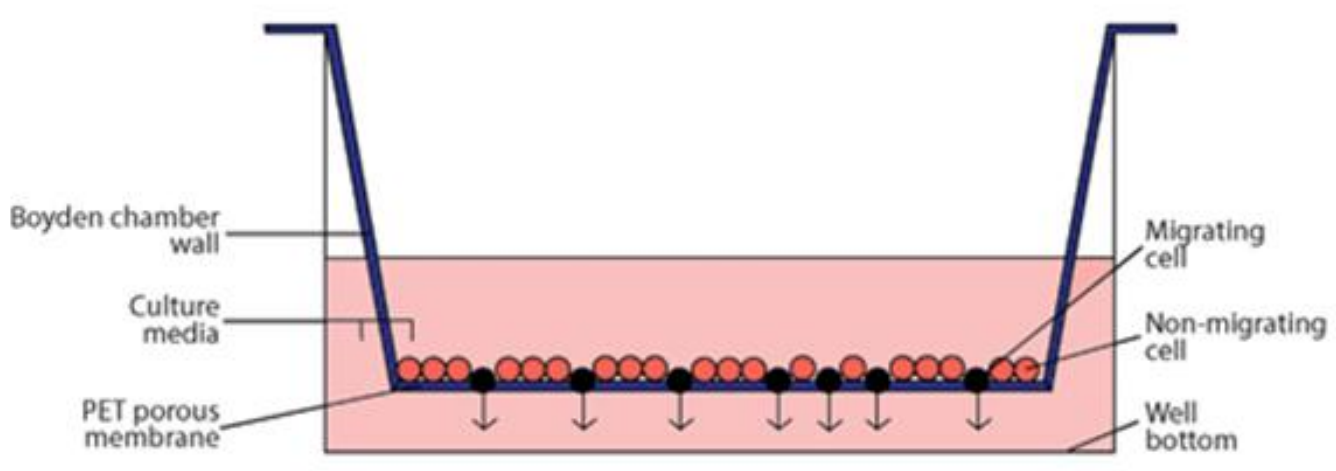

Figure 2.2: A ThinCertTM cell culture insert is placed in the well of a multiwell cell culture plate, thus forming a migration chamber. The migration chamber consists of an upper and lower compartment with a porous PET membrane in-between. Cells may actively migrate from the upper to the lower compartment. The figure was taken and modified from (Oppegard et al. 2010).

The relevant chemoattractant solution is placed in the lower chamber to create a chemotactic gradient while the cells to be tested are incubated in the upper chamber. After an appropriate incubation time, the upper surface of the filter is scraped twice with cotton swabs to remove non-migrating cells. Migrated cells on the lower surface of the membrane are fixed and stained by Diff-Quick ${ }^{\circledR}$ kit. Five to seven random photographs were taken of each membrane with an Olympus light-microscope coupled with a camera, and the cells in each photograph were counted and quantified using the "ImageJ" software. 


\section{$\underline{\text { Best concentration of CXCL12 }}$}

This experiment was performed with the CXCR4-positive tumour cell line (ZMK-1). $8 \times 10^{4}$ cells were seeded into the insert. CXCL12 as chemoattractant was added to the lower chamber in the concentrations $0,25,50$ and $100 \mathrm{ng} / \mathrm{ml}$. The cells were allowed to migrate for 26 hours at $37^{\circ} \mathrm{C}$ and $5 \% \mathrm{CO}_{2}$.

\section{Best concentration of AMD3100}

This experiment was also performed with ZMK-1 cell line. The cells were incubated with six different concentrations of AMD3100, i.e. $0,1,5,12.5,25$ and $50 \mu \mathrm{g} / \mathrm{ml}$ for 26 hours at $37^{\circ} \mathrm{C}$ and $5 \% \mathrm{CO}_{2}$. At the end of the incubation time $8 \times 10^{4}$ cells were seeded into the insert. CXCL12 (100 ng/ml, optimal concentration determined in the experiment described above) was added to the lower chambers. The cells were allowed to migrate for 26 hours at $37^{\circ} \mathrm{C}$ and $5 \% \mathrm{CO}_{2}$.

\subsubsection{Influence of irradiation and CXCL12 on cell migration}

Cells were initially starved of serum for two hours. A cell suspension containing $16 \times 10^{4}$ cells was prepared and kept in four $15 \mathrm{ml}$ plastic tubes. One tube contained cells for the control group (non-irradiated cells); the second tube was irradiated at $0.5 \mathrm{~Gy}$; the third and fourth tubes were irradiated at 2 and $4 \mathrm{~Gy}$, respectively. $500 \mu \mathrm{l}$ cell suspensions aliquots from each tube $\left(8 \times 10^{4}\right.$ cells $)$ were seeded into serum-free medium in the two inserts. To investigate the influence of CXCL12 on cell migration, $100 \mathrm{ng} / \mathrm{ml}$ of CXCL12 was added to the one of the lower chambers (see Table 2.13, A1-A4, purple area). The remaining lower chambers were CXCL12-free (Table 2.13, B1-B4, green area).

The cells were allowed to migrate for 26 hours at $37^{\circ} \mathrm{C}$ and $5 \% \mathrm{CO} 2$. The experiments were repeated in duplicate for all cell lines. The results are expressed as the mean number of migrated cells \pm standard deviation. Statistical differences were determined by Student's ttest. A value of $\mathrm{p}<0.05$ was considered to indicate a statistically significant difference. 
Table 2.13: Schematic illustration of a 24 -well transwell plate seeded with irradiated and non-irradiated cells. $100 \mathrm{ng} / \mathrm{ml}$ of CXCL12 was added in the lower chamber of purple area, which was not available in green area.

\begin{tabular}{|c|c|c|c|c|c|c|}
\hline & $\mathbf{1}$ & $\mathbf{2}$ & $\mathbf{3}$ & $\mathbf{4}$ & $\mathbf{5}$ & $\mathbf{6}$ \\
\hline $\mathbf{A}$ & $\begin{array}{c}\text { Non-irradiated } \\
\text { cells } \\
\text { +CXCL12 }\end{array}$ & $\begin{array}{c}0.5 \text { Gy irradiated } \\
\text { cells } \\
\text { +CXCL12 }\end{array}$ & $\begin{array}{c}2 \text { Gy irradiated } \\
\text { cells } \\
\text { +CXCL12 }\end{array}$ & $\begin{array}{c}\text { 4Gy irradiated } \\
\text { cells } \\
\text { +CXCL12 }\end{array}$ & & \\
\hline $\mathbf{B}$ & $\begin{array}{c}\text { Non-irradiated } \\
\text { cells }\end{array}$ & $\begin{array}{c}0.5 \text { Gy irradiated } \\
\text { cells }\end{array}$ & $\begin{array}{c}2 \text { Gy irradiated } \\
\text { cells }\end{array}$ & $\begin{array}{c}\text { 4Gy irradiated } \\
\text { cells }\end{array}$ & & \\
\hline $\mathbf{C}$ & & & & & & \\
\hline $\mathbf{D}$ & & & & & & \\
\hline
\end{tabular}

\subsubsection{Influence of AMD3100 on CXCR4-positive migrating cells}

This experiment was only performed with the CXCR4-positive tumour cell lines (ZMK-1 and $\mathrm{FaDu}$ ). Cells were initially starved of serum for two hours. A cell suspension containing $16 \mathrm{x}$ $10^{4}$ cells was prepared and maintained in eight $15 \mathrm{ml}$ plastic tubes. Two tubes contained cells for the non-irradiated control group. For each radiation dose $(0.5,2$ and $4 \mathrm{~Gy})$ two tubes were prepared, i.e. for each dose one tube was treated with AMD3100 $(5 \mu \mathrm{g} / \mathrm{ml})$ for 30 minutes at $37^{\circ} \mathrm{C}$ and $5 \% \mathrm{CO}_{2}$ and the other tube was untreated (see Table 2.14, purple area: treated and green area: untreated cells). To control for AMD3100 influence on non-irradiated cells one of the control tubes was also treated with AMD100 (see Table 2.14, blue area).

Table 2.14: Schematic illustration of a 24-well transwell plate seeded with irradiated and non-irradiated cells. $100 \mathrm{ng} / \mathrm{ml}$ of CXCL12 was added in all lower chambers except A1 for control. Irradiated cells in the purple area were treated with $5 \mu \mathrm{g} / \mathrm{ml}$ of AMD3100. However, irradiated cells in the green area were untreated.

\begin{tabular}{|c|c|c|c|c|c|c|}
\hline & 1 & 2 & 3 & 4 & 5 & 6 \\
\hline $\mathbf{A}$ & $\begin{array}{l}\text { Non-irradiated } \\
\text { cells }\end{array}$ & $\begin{array}{c}\text { Non-irradiated } \\
\text { cells } \\
\text { +CXCL12 }\end{array}$ & $\begin{array}{c}\text { Non-irradiated } \\
\text { cells } \\
\text { +CXCL12 } \\
\text { +AMD3100 } \\
\end{array}$ & $\begin{array}{c}0.5 \text { Gy irradiated } \\
\text { cells } \\
\text { +CXCL12 } \\
\text { +AMD3100 } \\
\end{array}$ & $\begin{array}{c}2 \text { Gy irradiated } \\
\text { cells } \\
\text { +CXCL12 } \\
\text { +AMD3100 } \\
\end{array}$ & $\begin{array}{c}\text { 4Gy irradiated } \\
\text { cells } \\
\text { +CXCL12 } \\
\text { +AMD3100 } \\
\end{array}$ \\
\hline B & & & & $\begin{array}{c}0.5 \text { Gy irradiated } \\
\text { cells } \\
\text { +CXCL12 }\end{array}$ & $\begin{array}{l}2 \text { Gy irradiated } \\
\text { cells } \\
+ \text { CXCL12 }\end{array}$ & $\begin{array}{l}\text { 4Gy irradiated } \\
\text { cells } \\
\text { +CXCL12 }\end{array}$ \\
\hline C & & & & & & \\
\hline D & & & & & & \\
\hline
\end{tabular}




\section{Materials and Methods}

After the six treated cell suspensions had been irradiated, $500 \mu 1$ cell suspension $\left(8 \times 10^{4}\right.$ cells) aliquots from all nine tubes were seeded into serum-free medium. To investigate the inhibitory effect of AMD3100 on cell migration, $100 \mathrm{ng} / \mathrm{ml}$ of CXCL12 was added to all lower chambers except one control chamber (see Table 2.14, A1). The cells were allowed to migrate for 26 hours at $37^{\circ} \mathrm{C}$ and $5 \% \mathrm{CO}_{2}$. The experiments were repeated in triplicate.

\subsubsection{Data analysis}

The measurements and numbers of migrated cells were determined in duplicate to analyse the impact of the CXCL12 gradient on cell migration. The experiments on the inhibitory effect of AMD3100 on CXCR4-positive cell lines were repeated three times. The results are expressed as the mean number of migrated cells \pm standard deviation. The differences between two groups were compared by Student's t-test. One-way ANOVA was used to compare three or more groups. A value of $\mathrm{p}<0.05$ was considered to indicate a statistically significant difference. 
Results

\section{Results}

\subsection{In vivo analysis of HNSCC biopsies}

\subsubsection{General HNSCC patient data}

In the patient collective, both genders were included. The numbers of men and women were $197(85 \%)$ and $36(15 \%)$, respectively, which correspond to a male-to-female ratio of 5.7:1 (Table 3.1). Four different primary tumour sites were present in the patients. These were oral cavity, oropharynx, hypopharynx and larynx. Oropharyngeal carcinomas were the most common ones (99 cases, $42.5 \%$ ), followed by oral cavity (63 cases, 27\%) and hypopharyngeal carcinomas (45 cases, 19.3\%) (Table 3.1).

\begin{tabular}{|c|c|}
\hline Characteristic & Patientsn (\%) \\
\hline \multicolumn{2}{|l|}{ Gender } \\
\hline - $\quad$ Male & $197(85)$ \\
\hline - $\quad$ Female & $36(15)$ \\
\hline \multicolumn{2}{|l|}{ Tumour localization } \\
\hline - Oral cavity & $63(27)$ \\
\hline - Oropharynx & $99(42.5)$ \\
\hline - Hypopharynx & $45(19.3)$ \\
\hline - $\quad$ Larynx & $26(11.2)$ \\
\hline \multicolumn{2}{|l|}{ UICC stage } \\
\hline - II & $7(3.0)$ \\
\hline - III & $16(6.9)$ \\
\hline - IV A/B & $189 / 21(90.1)$ \\
\hline \multicolumn{2}{|l|}{ T-status } \\
\hline - 1 & $7(3.0)$ \\
\hline - 2 & $17(7.3)$ \\
\hline - 3 & $39(16.7)$ \\
\hline - 4 & $170(73)$ \\
\hline \multicolumn{2}{|l|}{ N-status } \\
\hline - $\mathbf{0}$ & $35(15)$ \\
\hline $\begin{array}{ll} & 1\end{array}$ & $27(11.6)$ \\
\hline
\end{tabular}




\section{Results}

\begin{tabular}{|c|l|}
\hline$\bullet \mathbf{2}$ & $149(64)$ \\
\hline$\bullet \mathbf{3}$ & $22(9.4)$ \\
\hline Histological grading & \\
\hline$\bullet \mathbf{1}$ & $11(4.7)$ \\
\hline$\bullet \mathbf{2}$ & $187(80.3)$ \\
\hline$\bullet \mathbf{3}$ & $35(15)$ \\
\hline
\end{tabular}

Previously untreated tumours were staged according to the current classification of the Union Internationale Contre le Cancer (UICC) and the American Joint Committee on Cancer (AJCC) (Brandwein-Gensler and Smith 2010). All tumours were also staged according to the TNM staging system (Sobin and Compton 2010). The pathologic stage, tumour diameter, and nodal status were obtained from the primary pathology reports.

The distribution of the histopathological tumour grades was: Grade 1: 11 patients; Grade 2: 187 patients; and Grade 3: 35 patients (Table 3.1).

\subsubsection{Analysis of CXCL12, CXCR4 and $\mathrm{p} 16^{\mathrm{INK} 4 \mathrm{~A}}$ expression at the protein level by immunohistochemical staining}

In order to investigate the in vivo relevance of the expression of CXCL12, CXCR4 and p16 ${ }^{\mathrm{INK} 4 \mathrm{~A}}$, immunohistochemical analyses were performed on 233 primary HNSCC tumour tissue samples. The individual results of the staining are expressed as a score for each patient and each marker (see Chapter 2.2.2.1). This has the advantage that the evaluations of the
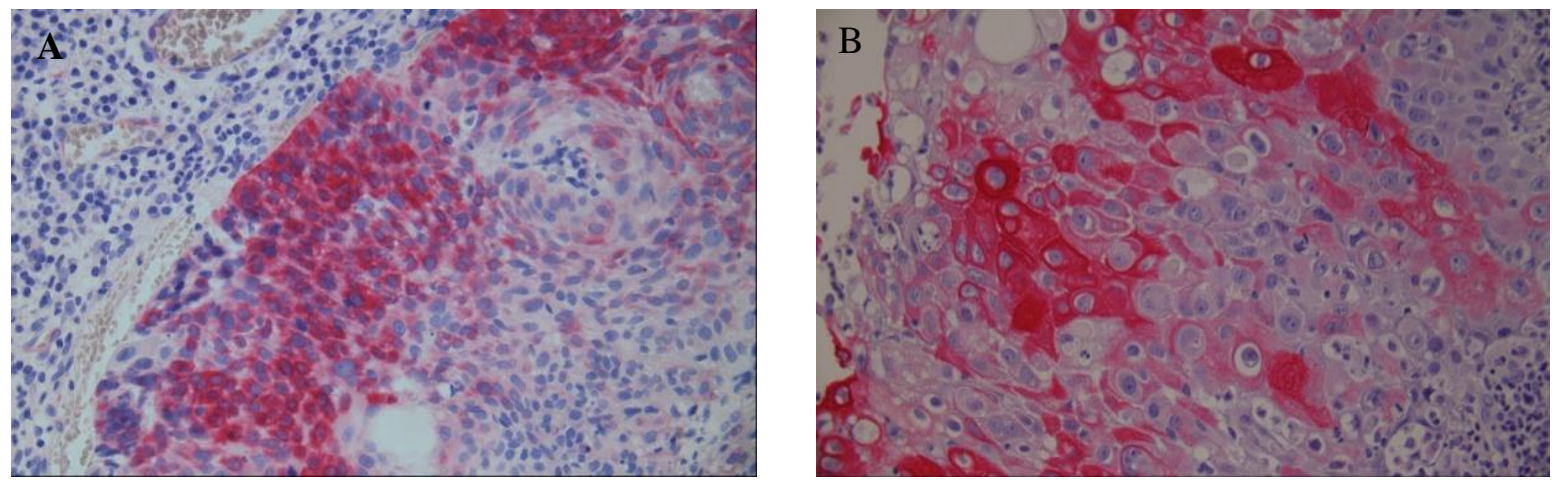

Figure 3.1: Representative IHC staining of CXCL12 and CXCR4 in HNSCC tumour specimens. In this staining system, the CXCL12 and CXCR4 are stained red and the nuclei are stained blue A) CXCL12 was expressed in the cytoplasm and/or in the nucleus. B) CXCR4 was also expressed in the cytoplasm and/or in the nucleus. The blue staining presents the nucleus of cells (Magnification 40x). 


\section{Results}

analysis could be directly and simply compared with other parameters that were generated in this study. First of all, the expression of the three markers was correlated with the patient's pre-treatment data.

The analyses were able to detect expression of CXCR4 and CXCL12 in 233 and 229 patients, respectively (Figure 3.1). For 4 patients there was not enough material for CXCL12 staining. The scores for the expression intensity of CXCR4 ranged from 0 to 210. Absent or very low expression with a score $\leq 10$ was found in about one third of the patients $(n=79,33.9 \%)$. For further analysis, the data were divided into three groups: a score between 15 and 70 represented a medium expression $(\mathrm{n}=79$ patients, 33.9\%) and a score $>70$ a high expression ( $\mathrm{n}=75$ patients, $32.2 \%)$. CXCL12 expression was observed less frequently, as 132 patients (56.7\%) were negative for the marker. In the CXCL12 expression analyses we only differentiated between negative and positive samples.

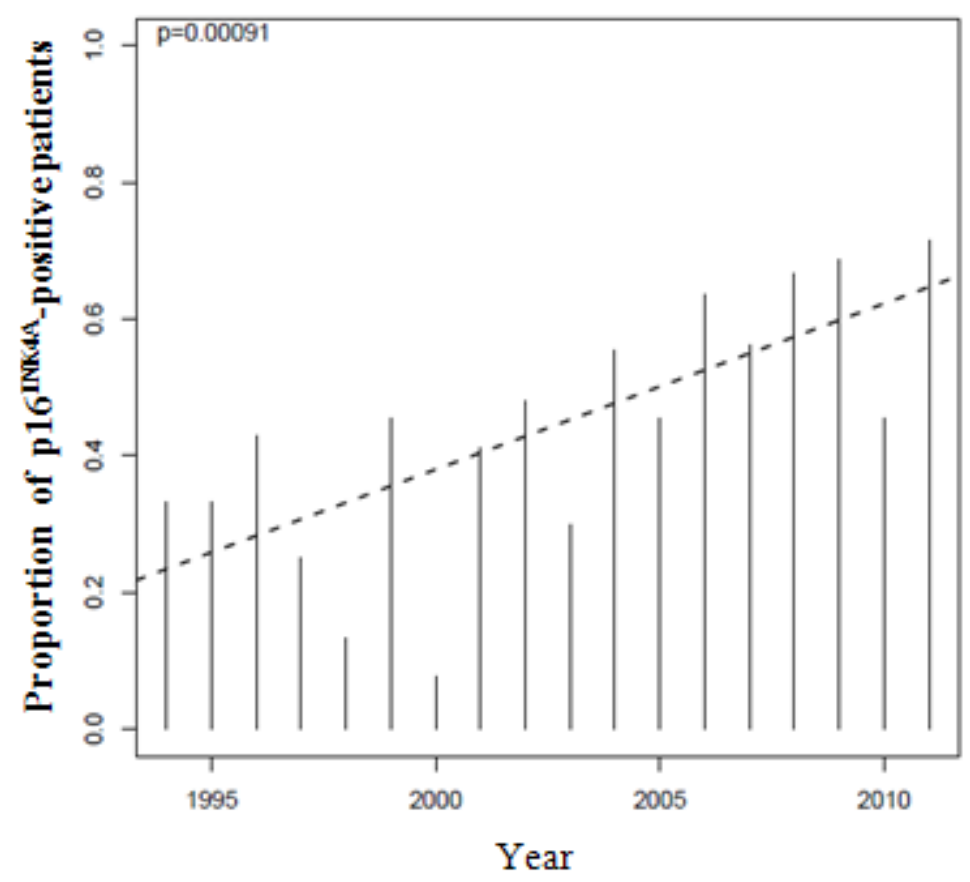

Figure 3.2: A significant increase of positive p16 ${ }^{\text {INK4A }}$ expression in HNSCC patients from 1992 to 2011 .

The analysis of $\mathrm{p} 16^{\mathrm{INK} 4 \mathrm{~A}}$ expression showed that 102 of the 233 (44\%) samples had cytoplasmic and/or nuclear staining. Interestingly, there was a significant increase in p16 ${ }^{\mathrm{INK} 4 \mathrm{~A}}$-positive HNSCC patients in this cohort study over the period from 1992 to 2011 (Figure 3.2, $\mathrm{p}=0.00091$ ). 


\section{Results}
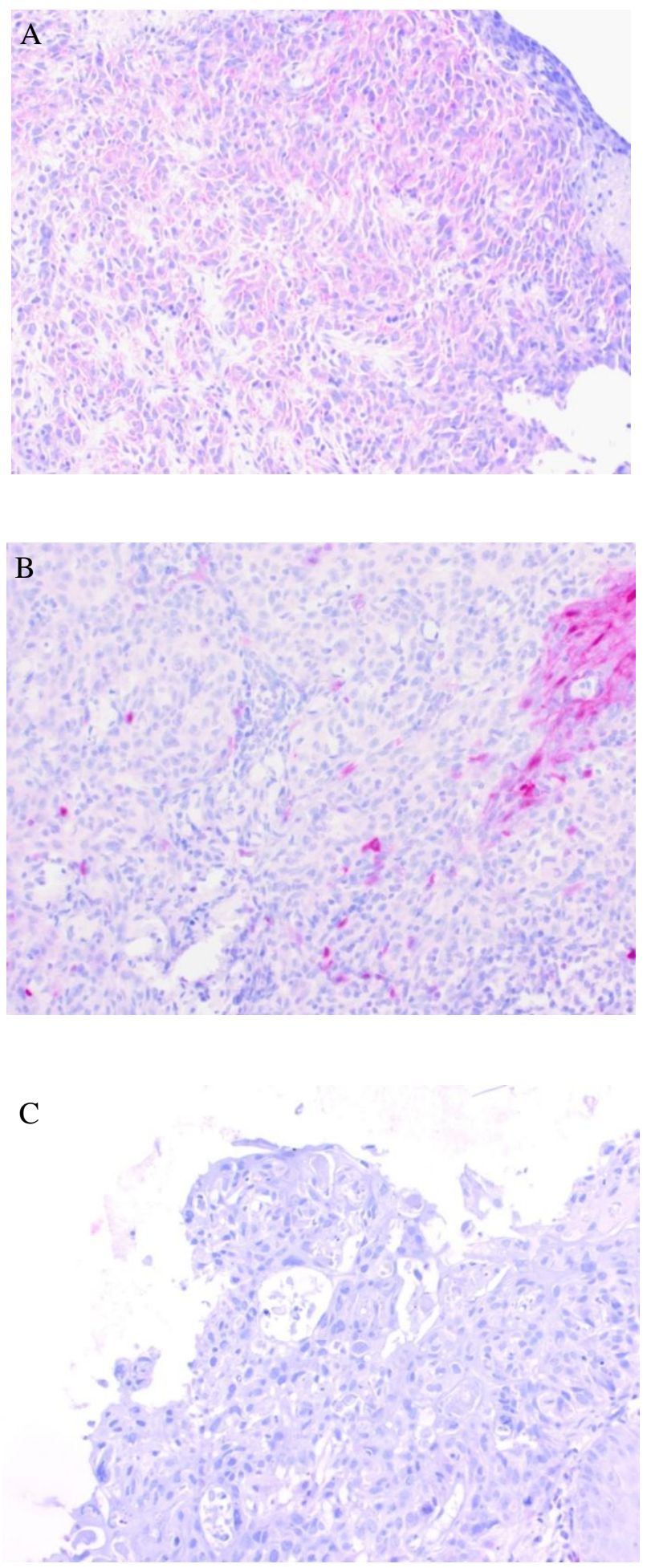

Figure 3.3: Representative IHC staining of $\mathbf{p 1 6}^{\mathrm{INK} 4 \mathrm{~A}}$ in HNSCC tumour specimens. In this staining system, the $\mathrm{p} 16^{\mathrm{INK} 4 \mathrm{~A}}$ is stained red and the nuclei are stained blue. Tumours were classified as: A) continuous and diffuse cytoplasmic and/or nuclear staining, B) weak and focal (patchy) cytoplasmic and/or nuclear staining and C) negative staining (Magnification 20x) 


\section{Results}

Based on the evaluation, there were three different phenotypes for $\mathrm{p} 16^{\text {INK4A }}$ immunoreactivity (Figure 3.3 A-C), namely diffuse positive cytoplasmic and/or nuclear staining (Figure $3.3 \mathrm{~A}$ ), weak and focal (patchy) positive cytoplasmic and/or nuclear staining (Figure 3.3 B), and negative staining (Figure 3.3 C). Diffuse positive staining was found in 62 of the $233(27 \%)$ samples. Forty of the $233(17 \%)$ samples had weak focal positive staining. The remaining 135 samples were negative for the $\mathrm{p} 16^{\mathrm{INK} 4 \mathrm{~A}}$ expression.

\subsubsection{Association of CXCL12, CXCR4 and $\mathrm{p} 16^{\mathrm{INK} 4 \mathrm{~A}}$ expression with pre-treatment} parameters

The association of CXCR4, CXCL12 and p16 ${ }^{\mathrm{INK} 4 \mathrm{~A}}$ expression with clinicopathological characteristics is shown in Table 3.2 and Table 3.3.

\section{$\underline{\text { CXCR4 }}$}

The expression of CXCR4 was positively and significantly associated with the patients' age; patients older than the median age of the cohort showed a significant increase in CXCR4 positivity $(\mathrm{p}=0.0035)$. However, the expression of this protein did not show any statistically relevant correlation with other pre-treatment parameters, such as gender, primary tumour localisation, T/N status or UICC stage.

Table 3.2: Association of CXCL12 and CXCR4 expression with clinicopathological characteristics of 233 Patients with inoperable HNSCC

\begin{tabular}{|c|c|c|c|c|c|c|c|c|}
\hline \multirow[t]{3}{*}{ Characteristics } & \multicolumn{4}{|c|}{ Number of patients (\%) } & $\begin{array}{c}\text { p- } \\
\text { value }\end{array}$ & \multicolumn{2}{|c|}{$\begin{array}{c}\text { Number of patients } \\
\qquad(\%)\end{array}$} & $\begin{array}{c}\text { p- } \\
\text { value }\end{array}$ \\
\hline & Total & \multicolumn{3}{|c|}{ CXCR4 expression } & & \multicolumn{2}{|c|}{ CXCL12 expression } & \\
\hline & & $\begin{array}{l}\text { low } \\
\leq 10 \\
10\end{array}$ & $\begin{array}{l}\text { median } \\
>10-70 \\
\end{array}$ & $\begin{array}{l}\text { high } \\
>70 \\
\end{array}$ & & $\begin{array}{c}\text { negative } \\
0\end{array}$ & $\begin{array}{c}\begin{array}{c}\text { positive } \\
>0\end{array} \\
\end{array}$ & \\
\hline Total & $n=233$ & $\begin{array}{c}79 \\
(33.9)\end{array}$ & $\begin{array}{c}79 \\
(33.9)\end{array}$ & $\begin{array}{c}75 \\
(32.2)\end{array}$ & & $\begin{array}{c}132 \\
(56.7)\end{array}$ & $\begin{array}{c}97 \\
(41.6)\end{array}$ & \\
\hline Age & & & & & 0.0035 & & & 0.90 \\
\hline - < Median & $\begin{array}{c}116 \\
(49.7)\end{array}$ & $\begin{array}{c}53 \\
(45.7)\end{array}$ & $\begin{array}{c}31 \\
(26.7)\end{array}$ & $\begin{array}{c}32 \\
(27.6)\end{array}$ & & $\begin{array}{c}64 \\
(56.1)\end{array}$ & $\begin{array}{c}50 \\
(43.9)\end{array}$ & \\
\hline - $\quad>$ Median & $\begin{array}{c}117 \\
(50.2)\end{array}$ & $\begin{array}{c}26 \\
(22.2)\end{array}$ & $\begin{array}{c}48 \\
(41.0)\end{array}$ & $\begin{array}{c}43 \\
(36.8)\end{array}$ & & $\begin{array}{c}68 \\
(59.1)\end{array}$ & $\begin{array}{c}47 \\
(40.9)\end{array}$ & \\
\hline
\end{tabular}


Results

\begin{tabular}{|c|c|c|c|c|c|c|c|c|}
\hline Gender & & & & & 0.65 & & & 0.83 \\
\hline - $\quad$ Male & $\begin{array}{c}197 \\
(84.7)\end{array}$ & $\begin{array}{c}67 \\
(34.0)\end{array}$ & $\begin{array}{c}69 \\
(35.0)\end{array}$ & $\begin{array}{c}61 \\
(31.0)\end{array}$ & & $\begin{array}{c}110 \\
(57.0)\end{array}$ & $\begin{array}{c}83 \\
(43.0)\end{array}$ & \\
\hline - $\quad$ Female & $\begin{array}{c}36 \\
(15.3)\end{array}$ & $\begin{array}{c}12 \\
(33.3)\end{array}$ & $\begin{array}{c}10 \\
(27.8)\end{array}$ & $\begin{array}{c}14 \\
(38.9)\end{array}$ & & $\begin{array}{c}22 \\
(61.1)\end{array}$ & $\begin{array}{c}14 \\
(38.9)\end{array}$ & \\
\hline Tumour localization & & & & & 0.76 & & & $<0.001$ \\
\hline Oropharynx & $\begin{array}{c}99 \\
(42.5)\end{array}$ & $\begin{array}{c}36 \\
(36.4)\end{array}$ & $\begin{array}{c}33 \\
(33.3)\end{array}$ & $\begin{array}{c}30 \\
(30.3)\end{array}$ & & $\begin{array}{c}46 \\
(48.4)\end{array}$ & $\begin{array}{c}49 \\
(51.6)\end{array}$ & \\
\hline Hypopharynx & $\begin{array}{c}44 \\
(18.9)\end{array}$ & $\begin{array}{c}13 \\
(29.5)\end{array}$ & $\begin{array}{c}17 \\
(38.6)\end{array}$ & $\begin{array}{c}14 \\
(31.8)\end{array}$ & & $\begin{array}{c}18 \\
(40.9)\end{array}$ & $\begin{array}{c}26 \\
(59.1)\end{array}$ & \\
\hline Larynx & $\begin{array}{c}27 \\
(11.6)\end{array}$ & $\begin{array}{c}10 \\
(37.0)\end{array}$ & $\begin{array}{c}10 \\
(37.0)\end{array}$ & $\begin{array}{c}7 \\
(25.9)\end{array}$ & & $\begin{array}{c}15 \\
(55.6)\end{array}$ & $\begin{array}{c}12 \\
(44.4)\end{array}$ & \\
\hline Oral cavity & $\begin{array}{c}63 \\
(27.0)\end{array}$ & $\begin{array}{c}20 \\
(31.7)\end{array}$ & $\begin{array}{c}19 \\
(30.2)\end{array}$ & $\begin{array}{c}24 \\
(38.1)\end{array}$ & & $\begin{array}{c}53 \\
(84.1)\end{array}$ & $\begin{array}{c}10 \\
(15.9)\end{array}$ & \\
\hline Histological grading & & & & & 0.33 & & & 0.075 \\
\hline - $\quad$ G1 & $\begin{array}{c}11 \\
(4.7)\end{array}$ & $\begin{array}{c}3 \\
(27.3)\end{array}$ & $\begin{array}{c}3 \\
(27.3)\end{array}$ & $\begin{array}{c}5 \\
(45.5)\end{array}$ & & $\begin{array}{c}10 \\
(90.9)\end{array}$ & $\begin{array}{c}1 \\
(9.1)\end{array}$ & \\
\hline - $\quad$ G2 & $\begin{array}{c}187 \\
(80.3)\end{array}$ & $\begin{array}{c}62 \\
(33.2)\end{array}$ & $\begin{array}{c}63 \\
(33.7)\end{array}$ & $\begin{array}{c}62 \\
(33.2)\end{array}$ & & $\begin{array}{c}104 \\
(56.8)\end{array}$ & $\begin{array}{c}79 \\
(43.2)\end{array}$ & \\
\hline - $\quad$ G3 & $\begin{array}{c}35 \\
(15.0)\end{array}$ & $\begin{array}{c}14 \\
(40.0)\end{array}$ & $\begin{array}{c}13 \\
(37.1)\end{array}$ & $\begin{array}{c}8 \\
(22.9)\end{array}$ & & $\begin{array}{c}18 \\
(51.4)\end{array}$ & $\begin{array}{c}17 \\
(48.6)\end{array}$ & \\
\hline T-status & & & & & 0.88 & & & 0.51 \\
\hline - 1 & $\begin{array}{c}7 \\
(3.0)\end{array}$ & $\begin{array}{c}3 \\
(42.9)\end{array}$ & $\begin{array}{c}2 \\
(28.6)\end{array}$ & $\begin{array}{c}2 \\
(28.6)\end{array}$ & & $\begin{array}{c}3 \\
(42.9)\end{array}$ & $\begin{array}{c}4 \\
(57.1)\end{array}$ & \\
\hline - 2 & $\begin{array}{c}17 \\
(7.3)\end{array}$ & $\begin{array}{c}3 \\
(17.6)\end{array}$ & $\begin{array}{c}10 \\
(58.8)\end{array}$ & $\begin{array}{c}4 \\
(58.8)\end{array}$ & & $\begin{array}{c}12 \\
(70.6)\end{array}$ & $\begin{array}{c}5 \\
(29.4)\end{array}$ & \\
\hline - 3 & $\begin{array}{c}39 \\
(16.7)\end{array}$ & $\begin{array}{c}15 \\
(38.5)\end{array}$ & $\begin{array}{c}14 \\
(35.9)\end{array}$ & $\begin{array}{c}10 \\
(35.9)\end{array}$ & & $\begin{array}{c}22 \\
(56.4)\end{array}$ & $17(43.6)$ & \\
\hline - 4 & $\begin{array}{c}170 \\
(73.0)\end{array}$ & $\begin{array}{c}58 \\
(34.1)\end{array}$ & $\begin{array}{c}53 \\
(31.2)\end{array}$ & $\begin{array}{c}59 \\
(31.2)\end{array}$ & & $\begin{array}{c}95 \\
(57.2)\end{array}$ & $\begin{array}{c}71 \\
(42.8)\end{array}$ & \\
\hline $\mathrm{N}$-status & & & & & 0.78 & & & 0.025 \\
\hline - $\mathbf{0}$ & $\begin{array}{c}35 \\
(15.0)\end{array}$ & $\begin{array}{c}10 \\
(28.6)\end{array}$ & $\begin{array}{c}15 \\
(42.9)\end{array}$ & $\begin{array}{c}10 \\
(28.6)\end{array}$ & & $\begin{array}{c}26 \\
(74.3)\end{array}$ & $\begin{array}{c}9 \\
(25.7)\end{array}$ & \\
\hline
\end{tabular}




\section{Results}

\begin{tabular}{|c|c|c|c|c|c|c|c|c|}
\hline - 1 & $\begin{array}{c}27 \\
(11.6)\end{array}$ & $\begin{array}{c}11 \\
(40.7)\end{array}$ & $\begin{array}{c}8 \\
(29.6)\end{array}$ & $8(29.6)$ & & $\begin{array}{c}19 \\
(70.4)\end{array}$ & $\begin{array}{c}8 \\
(29.6)\end{array}$ & \\
\hline - 2 & $\begin{array}{l}149 \\
(64)\end{array}$ & $\begin{array}{c}48 \\
(32.2)\end{array}$ & $\begin{array}{c}51 \\
(34.2)\end{array}$ & $\begin{array}{c}50 \\
(33.6)\end{array}$ & & $\begin{array}{c}76 \\
(52.4)\end{array}$ & $\begin{array}{c}69 \\
(46.6)\end{array}$ & \\
\hline - 3 & $\begin{array}{c}22 \\
(9.4)\end{array}$ & $\begin{array}{c}10 \\
(45.5)\end{array}$ & $\begin{array}{c}5 \\
(22.7)\end{array}$ & $\begin{array}{c}7 \\
(31.8)\end{array}$ & & $\begin{array}{c}11 \\
(50.0)\end{array}$ & $\begin{array}{c}11 \\
(50.0)\end{array}$ & \\
\hline UICC stage & & & & & 0.53 & & & 0.30 \\
\hline - $\quad$ II & $\begin{array}{c}7 \\
(3.0)\end{array}$ & $\begin{array}{c}1 \\
(14.3)\end{array}$ & $\begin{array}{c}4 \\
(57.1)\end{array}$ & $\begin{array}{c}2 \\
(28.6)\end{array}$ & & $\begin{array}{c}4 \\
(57.1)\end{array}$ & $\begin{array}{c}3 \\
(42.9)\end{array}$ & \\
\hline • $\quad$ III & $\begin{array}{c}16 \\
(6.9)\end{array}$ & $\begin{array}{c}4 \\
(25.0)\end{array}$ & $\begin{array}{c}6 \\
(37.5)\end{array}$ & $\begin{array}{c}6 \\
(37.5)\end{array}$ & & $\begin{array}{c}12 \\
(75.0)\end{array}$ & $\begin{array}{c}4 \\
(25.0)\end{array}$ & \\
\hline - $\quad$ IV A/B & $\begin{array}{c}189 / 21 \\
(90.1)\end{array}$ & $\begin{array}{c}74 \\
(35.2)\end{array}$ & $\begin{array}{c}69 \\
(32.9)\end{array}$ & $\begin{array}{c}67 \\
(31.9)\end{array}$ & & $\begin{array}{c}116 \\
(56.1)\end{array}$ & $\begin{array}{c}90 \\
(43.9)\end{array}$ & \\
\hline
\end{tabular}

\section{CXCL12}

The expression of CXCL12 was significantly correlated with tumour localisation $(\mathrm{p}<0.001)$. Tumours of the oral cavity were predominantly CXCL12-negative (84.1\% negative vs. $15.9 \%$ positive, Table 3.2). In contrast, tumours located either in the oropharynx, the hypopharynx or the larynx showed nearly similar proportions of CXCL12-positive and negative samples. It also observed that the expression of CXCL12 in tumours is linked to an increasing N-status $(\mathrm{p}=0.025)$.

$\mathrm{p16}^{\mathrm{INK4A}}$

p $16^{\mathrm{INK} 4 \mathrm{~A}}$ expression was not significantly associated neither with age at diagnosis, gender, tumour localization, histological tumour grade nor UICC stage. There were no statistically significant differences in these parameters between patients with and without $\mathrm{p} 16^{\mathrm{INK} 4 \mathrm{~A}}$ expression (Table 3.3). 


\section{Results}

Table 3.3: Correlation between $\mathrm{p} 16^{\mathrm{INK} 4 \mathrm{~A}}$ expression and clinicopathological characteristics of 233 patients with inoperable HNSCC (reproduced from (Tehrany et al. 2015))

\begin{tabular}{|c|c|c|c|c|}
\hline \multirow[t]{3}{*}{ Characteristics } & \multirow{3}{*}{$\begin{array}{c}\text { Patients (\%) } \\
\text { Total }\end{array}$} & \multicolumn{2}{|c|}{ Number of patients $(\%)$} & \multirow[t]{3}{*}{ p-value } \\
\hline & & \multicolumn{2}{|c|}{ P16 INK4A expression } & \\
\hline & & $\begin{array}{c}\text { negative } \\
0 \\
\end{array}$ & $\begin{array}{c}\text { positive } \\
>0\end{array}$ & \\
\hline Total & $n=233$ & $131(56.2)$ & $102(43.8)$ & \\
\hline Age & & & & 0.146 \\
\hline - $\quad<$ Median & $116(49.7)$ & $71(61.2)$ & $45(38.8)$ & \\
\hline - $\quad>$ Median & $117(50.2)$ & $60(51.3)$ & $57(48.7)$ & \\
\hline Gender & & & & 0.586 \\
\hline - $\quad$ Male & $197(84.7)$ & $109(55.3)$ & $88(44.7)$ & \\
\hline - $\quad$ Female & $36(15.3)$ & $22(61.1)$ & $14(38.9)$ & \\
\hline Tumour localization & & & & 0.066 \\
\hline Oropharynx & $99(42.5)$ & $50(50.5)$ & $49(49.5)$ & \\
\hline Hypopharynx & $44(18.9)$ & $21(47.7)$ & $23(52.3)$ & \\
\hline Larynx & $27(11.6)$ & $17(63.0)$ & $10(37.0)$ & \\
\hline Oral cavity & $63(27.0)$ & $43(68.3)$ & $20(31.7)$ & \\
\hline Histological grading & & & & 0.203 \\
\hline - $\quad$ G1 & $11(4.7)$ & $6(54.6)$ & $5(45.4)$ & \\
\hline - $\quad$ G2 & $187(80.3)$ & $110(58.8)$ & $77(41.2)$ & \\
\hline - $\quad$ G3 & $35(15.0)$ & $15(42.9)$ & $20(57.1)$ & \\
\hline UICC stage & & & & 0.08 \\
\hline - II & $7(3.0)$ & $1(14.3)$ & $6(85.7)$ & \\
\hline - III & $16(6.9)$ & $9(56.2)$ & $7(43.8)$ & \\
\hline - $\quad$ IV A/B & $189 / 21(90.1)$ & $121(57.6)$ & $88(42.4)$ & \\
\hline
\end{tabular}

\subsubsection{Correlation between CXCL12, CXCR4 and $\mathrm{p} 16^{\mathrm{INK} 4 \mathrm{~A}}$ expression in HNSCC} tumours

In HNSCC tumour samples, for which the expression of CXCL12, CXCR4 and p16 ${ }^{\mathrm{INK} 4 \mathrm{~A}}$ was evaluated by immunohistochemical staining, the correlation among CXCL12, CXCR4 and p $16^{\mathrm{INK} 4 \mathrm{~A}}$ expression was investigated. There was a significant positive correlation between 


\section{Results}

p16 ${ }^{\mathrm{INK} 4 \mathrm{~A}}$ expression and CXCL12 and CXCR4 expression. However, no significant association between CXCL12 expression and CXCR4 was seen. Additionally, as shown in Figure 3.4, the degree of CXCR4 expression and positivity for CXCL12 correlate significantly with positive expression of $\mathrm{p} 16^{\mathrm{INK} 4 \mathrm{~A}}$ (Figure 3.4).

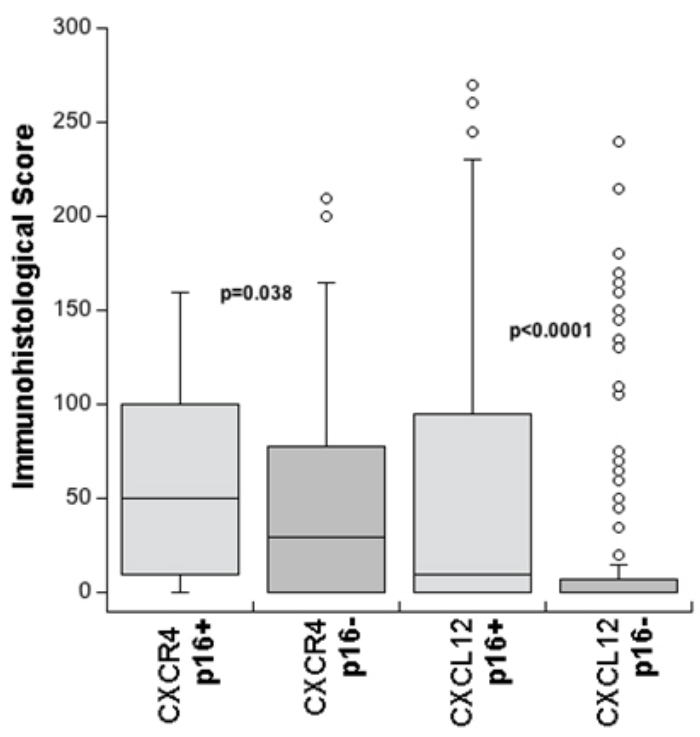

Figure 3.4: Correlation between $16^{\mathrm{INK} 4 \mathrm{~A}}$ positivity and CXCL12 and CXCR4 expression. In the box-plots the immunohistological scores for CXCR4 and CXCL12 stratified by $16^{\text {INK4A }}$ positivity are summed. 


\section{Results}

\subsubsection{Correlation between $\mathrm{p} 16^{\mathrm{INK} 4 \mathrm{~A}}$ expression and HPV status in HNSCC tissue samples}

Next, 233 HNSCC tissue samples were examined for the presence of HPV DNA using broad spectrum PCR and nested-PCR to determine whether HPV detection differs when different primer sets are used. First of all, the two major consensus primer sets used for PCR amplification of HPV DNA were compared, the PGMY 09/11 primer sets and the GP5+/GP6+ primers. To monitor DNA quality, the specimens were also amplified with the Bglobin primers PC04 and GH20 (268 bp in size) (Figure 3.5 A). Fifty-four of the 233 (23\%) samples showed either only weak signals or no amplification of the $\beta$-globin. However, to avoid missing samples that contain HPV DNA, we decided to subject these 54 samples to nested-PCR as well. Furthermore, the fragments of $450 \mathrm{bp}$ and $140 \mathrm{bp}$ in size were amplified in all samples using PGMY 09/11 and GP5+/GP6+ primers, respectively (Figure $3.5 \mathrm{~B}$ and C). In this study the PGMY 09/11 and GP5+/GP6+ consensus primer sets showed a completely different sensitivity, as defined by the ability to detect HPV DNA. Although 44 (19 \%) specimens were HPV DNA positive in PCR experiments using the GP5+/GP6+ primers, no sample showed HPV DNA positivity in PCR experiments using the PGMY 09/11 primers except for the positive control with a high concentration of HPV-6 DNA.

Of note, we did not observe multiple infections. Furthermore, we sequenced the positive nested amplicons to confirm correct HPV genotype amplification (see methods Chapter 2.2.2.5).

Nested-PCR was performed to validate the IHC-based detection of $\mathrm{p} 16^{\mathrm{INK} 4 \mathrm{~A}}$ expression. The correlation between immunohistochemical analysis of p16 ${ }^{\mathrm{INK} 4 \mathrm{~A}}$ expression and HPV subtypes is summarized in Table 3.4.

Although the FFPE samples were old, we were able to detect HPV DNA (L1 consensus) in 44 (19\%) samples (42 samples were sequenced as HPV-16 and 2 samples as either HPV-6 or HPV-11). Based on the immunohistochemical analysis cytoplasmic and nuclear p16 ${ }^{\mathrm{INK} 4 \mathrm{~A}}$ expression was detected in 102 of 233 (44\%) samples. 


\section{Results}

$\begin{array}{lllllllllllll}A & 51 & \$ 2 & \$ 3 & \$ 4 & 55 & \text { S6 } & \text { S7 } & \$ 8 & \text { S9 } & \text { S10 } & \text { S11 } & \$ 12\end{array}$

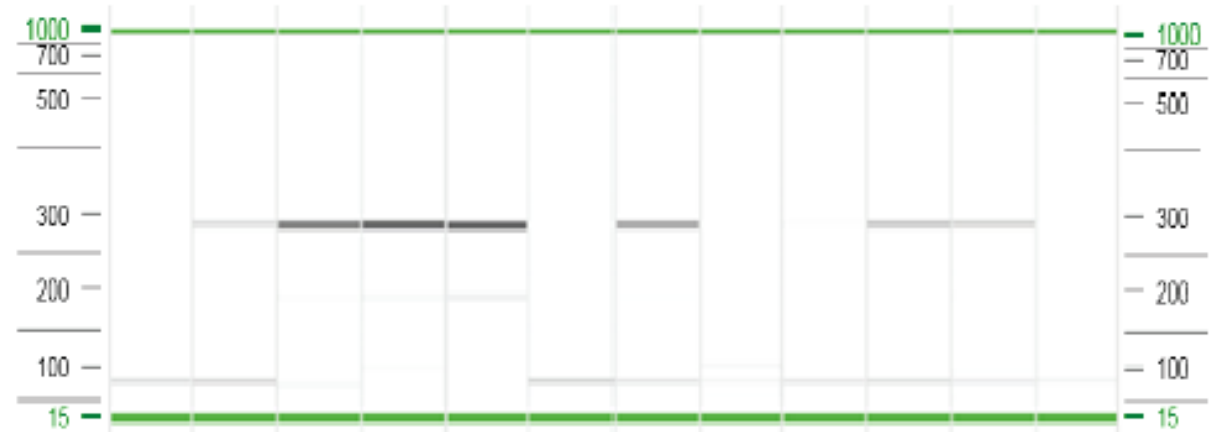

B $\begin{array}{llllllllllll}\text { S1 } & \text { S2 } & \text { S3 } & \text { S4 } & \text { S5 } & \text { S6 } & \text { S7 } & \text { S8 } & \text { PC } & \text { NC } & \text { B } & \text { B }\end{array}$
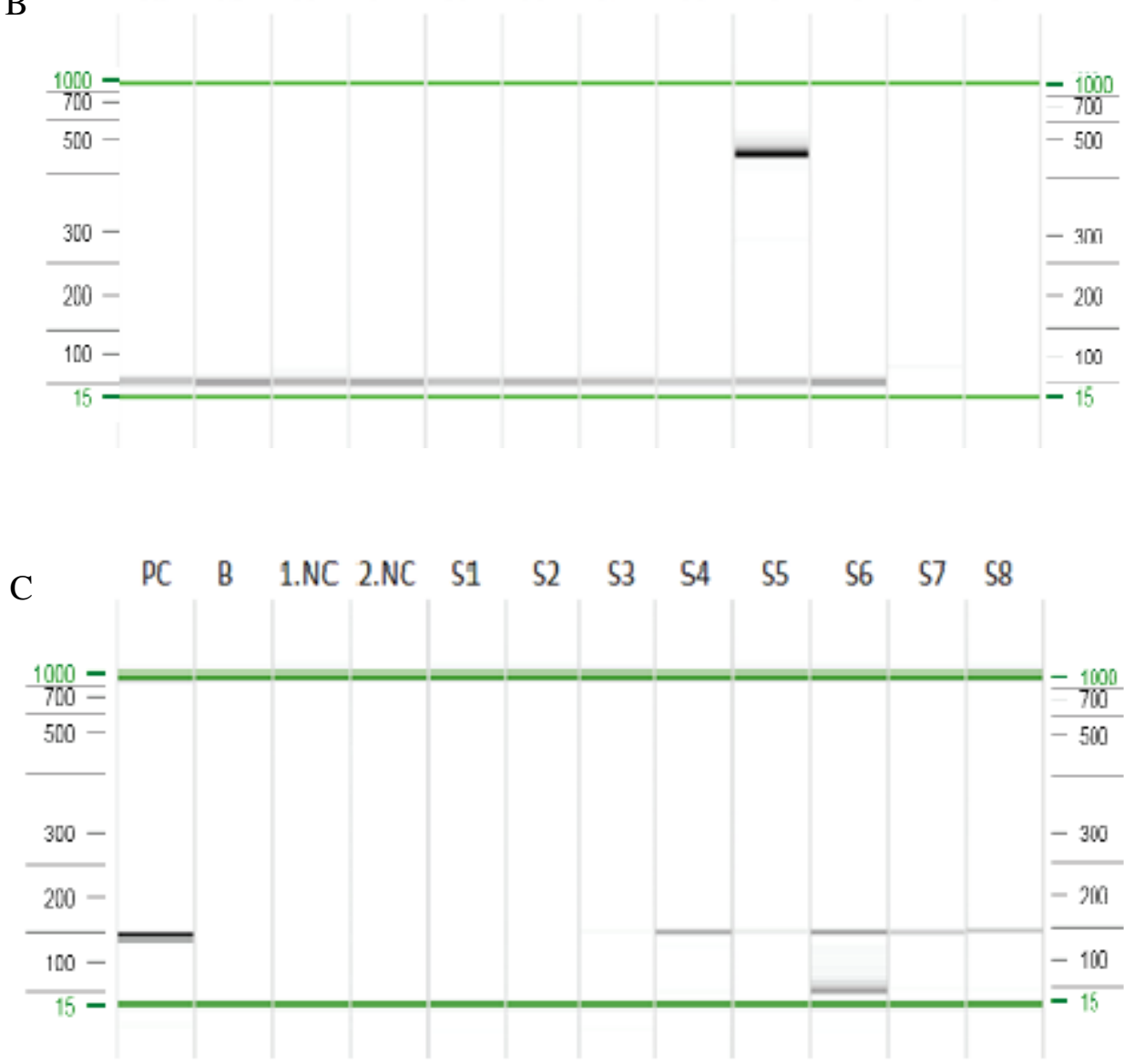

Figure 3.5: PCR results with 3 primer sets on HNSCC specimens. A) PCR with PC04 and GH20 Bglobin primers to monitor DNA quality (expected size of $268 \mathrm{bp}$ in size). B) Board spectrum PCR amplification yield with PGMY 09/11 primer sets for the L1 region of HPV genome (expected size of $450 \mathrm{bp}$ in size). C) nested-PCR with GP5+/GP6+ primers as nested-PCR (expected size of $140 \mathrm{bp}$ in size); PC: positive control; NC: negative control; S: sample; B: blank. 


\section{Results}

The correlation between $\mathrm{p} 16^{\mathrm{INK} 4 \mathrm{~A}}$ expression and HPV DNA in the tumour cells was highly significant $(\mathrm{p}<0.01)$, and 41 of $42(98 \%)$ samples positive for HPV-16 (a high-risk HPV subtype) showed $\mathrm{p} 16^{\mathrm{INK} 4 \mathrm{~A}}$ immunoreactivity. However, in one sample there was no p16 ${ }^{\mathrm{INK} 4 \mathrm{~A}}$ immunoreactivity despite HPV-16 DNA being detected (details given in Table 3.4). There were also two low-risk HPV subtypes (HPV-6 and HPV-11) that one of them was positive for $\mathrm{p} 16^{\mathrm{INK} 4 \mathrm{~A}}$.

Table 3.4: HPV detection and P16 ${ }^{\mathrm{INK} 4 \mathrm{~A}}$ expression (reproduced from (Tehrany et al. 2015))

\begin{tabular}{|cc|ccc|}
\hline & Total & Diffuse & Focal & Negative \\
\hline HPV-16 & 42 & 31 & 10 & 1 \\
\hline HPV-6/11 & 2 & 1 & 0 & 1 \\
\hline HPV negative & 189 & 30 & 30 & 133 \\
\hline \hline Total & 233 & 62 & 40 & 135 \\
\hline
\end{tabular}

\subsubsection{Treatment outcome and high-grade acute organ and hematotoxicity in HNSCC patients}

In this study, the response to treatment was classified as complete remission (126 patients, $54.1 \%$ ), partial remission (48 patients, $20.6 \%$ ), no change (19 patients, $8.2 \%$ ), and progression (20 patients, $8.6 \%$ ). Twenty patients $(8.6 \%)$ were lost during follow-up, and no data are available concerning the state of disease at the end of therapy.

At the end of the study, 185 patients (79.4\%) had died due to tumour-related causes (132 patients) or from other intercurrent disease (53 patients). Loco-regional reoccurrence were seen in 66 of the 233 patients (28.3\%), and distant metastases occurred in 29 of 233 patients (12.5\%) during follow-up. At the end of the study, 48 patients $(20.6 \%)$ were still alive. The three- and five-year OS rates were $27.1 \%$ and $23.2 \%$, respectively.

In addition to treatment outcome, treatment-related acute organ toxicity and hematotoxicity were evaluated in all patients (details given in Table 3.5). 


\section{Results}

Table 3.5: Incidence and grading of acute organ and hematotoxicity (reproduced from (Tehrany et al. 2015))

\begin{tabular}{|c|l|l|l|l|l|}
\hline \multicolumn{7}{|c|}{ Number of patients (\%) } \\
\hline Type & None & Grade 1 & Grade 2 & Grade 3 & Grade 4 \\
\hline Acute organ toxicity & & & & & \\
\hline$\bullet \quad$ Mucositis & $2(0.9)$ & $58(24.9)$ & $131(56.2)$ & $42(18.0)$ & $0(0.0)$ \\
\hline$\bullet \quad$ Skin reaction & $1(0.4)$ & $82(35.2)$ & $135(57.9)$ & $15(6.4)$ & $0(0.0)$ \\
\hline$\bullet \quad$ Dysphagia & $37(15.9)$ & $92(27.8)$ & $70(30.0)$ & $34(14.6)$ & $0(0.0)$ \\
\hline$\bullet \quad$ Nausea & $182(78.1)$ & $36(15.5)$ & $15(6.4)$ & $0(0.0)$ & $0(0.0)$ \\
\hline Acute hematotoxicity & & & & & \\
\hline$\bullet \quad$ Anaemia & $122(52.4)$ & $41(17.6)$ & $59(25.3)$ & $11(4.7)$ & $0(0.0)$ \\
\hline$\bullet \quad$ Leukopenia & $123(52.8)$ & $35(15.0)$ & $42(18.0)$ & $26(11.2)$ & $7(3.0)$ \\
\hline$\bullet \quad$ Thrombocytopenia & $203(87.1)$ & $19(8.1)$ & $7(3.0)$ & $3(1.3)$ & $1(0.4)$ \\
\hline
\end{tabular}

Acute organ toxicity occurred during $\mathrm{R}(\mathrm{C}) \mathrm{T}$ as follows and is summarized in table $3.5 ; 231$ of the 233 patients developed mucositis (58x grade 1; 131x grade 2; 42x grade 3), a skin reaction was seen in 232 patients ( $82 x$ grade $1 ; 135 x$ grade $2 ; 15 x$ grade 3 ), dysphagia was noted in 196 patients (92x grade 1; 70x grade 2; 34x grade 3) and nausea was seen in 51 patients (36x grade $1 ; 15 x$ grade 2$)$.

Acute hematotoxicity during $\mathrm{R}(\mathrm{C}) \mathrm{T}$ appeared as follows: anaemia grade 1 was seen in 41 , grade 2 in 59, and grade 3 in 11 patients; leukopenia grade 1 was observed in 35, grade 2 in 42, grade 3 in 26, and grade 4 in 7 patients; thrombocytopenia grade 1 was noted in 19, grade 2 in 7 , grade 3 in 3 patients and grade 4 in one patient (Table 3.5).

3.1.4.1 Correlation of cytoplasmic expression of CXCL12, CXCR4 and p16 ${ }^{\mathrm{INK} 4 \mathrm{~A}}$ with acute toxicity during treatment

Figure 3.6 illustrates the correlation between the expression of the three investigated proteins (CXCL12, CXCR4 and p16 ${ }^{\mathrm{INK} 4 \mathrm{~A}}$ ) and high-grade toxicity during $\mathrm{R}(\mathrm{C}) \mathrm{T}$. Acute organ toxicity and hematotoxicity were evaluated weekly for the entire duration of $\mathrm{R}(\mathrm{C}) \mathrm{T}$. The evaluation was continued every second week after the end of therapy until acute toxicity according to the scoring system (Common Toxicity Criteria, CTC) was no longer detectable. For this analysis, due to a significantly impaired of quality of life, acute toxicity was scored as HGAOT or 


\section{Results}

HGAHT if one or more of the acute toxicity items were graded as CTC $>2$. HGAOT of grade III ensued in 77 of the 233 cases (33\%). Additionally, HGAHT of grade III-IV occurred in 42 of the 233 cases (18\%) (Figure 3.6).

There was no significant correlation between HGAHT and the expression of any of the three proteins with $\mathrm{p}=0.55, \mathrm{p}=0.97$ and $\mathrm{p}=0.46$ for CXCL12, CXCR4 and $\mathrm{p} 16^{\mathrm{INK} 4 \mathrm{~A}}$, respectively (Figure 3.6 A, C, E). Moreover, HGAOT also showed no association with CXCL12 and CXCR4 status with $\mathrm{p}=0.34$ and $\mathrm{p}=0.49$ for CXCL12 and CXCR4, respectively (Figure 3.6 B, D). In contrast, the expression of $\mathrm{p} 16^{\mathrm{INK} 4 \mathrm{~A}}$ was significantly associated with the occurrence of HGAOT during $\mathrm{R}(\mathrm{C}) \mathrm{T}$ (Figure 3.6-F, $\mathrm{p}=0.011$ ). The correlation between HGAOT and $\mathrm{p} 16^{\mathrm{INK} 4 \mathrm{~A}}$ expression is summarized in Table 3.6.
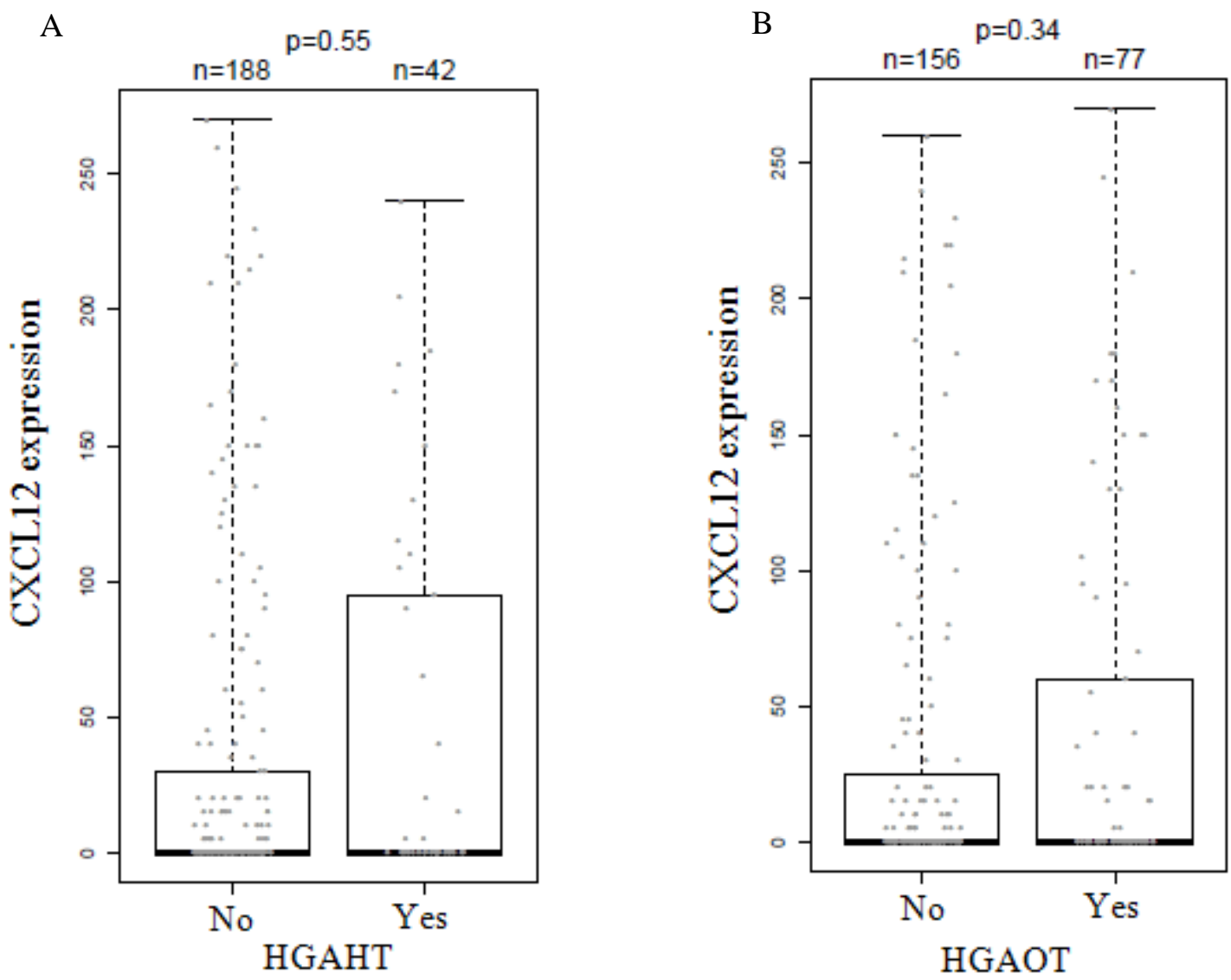

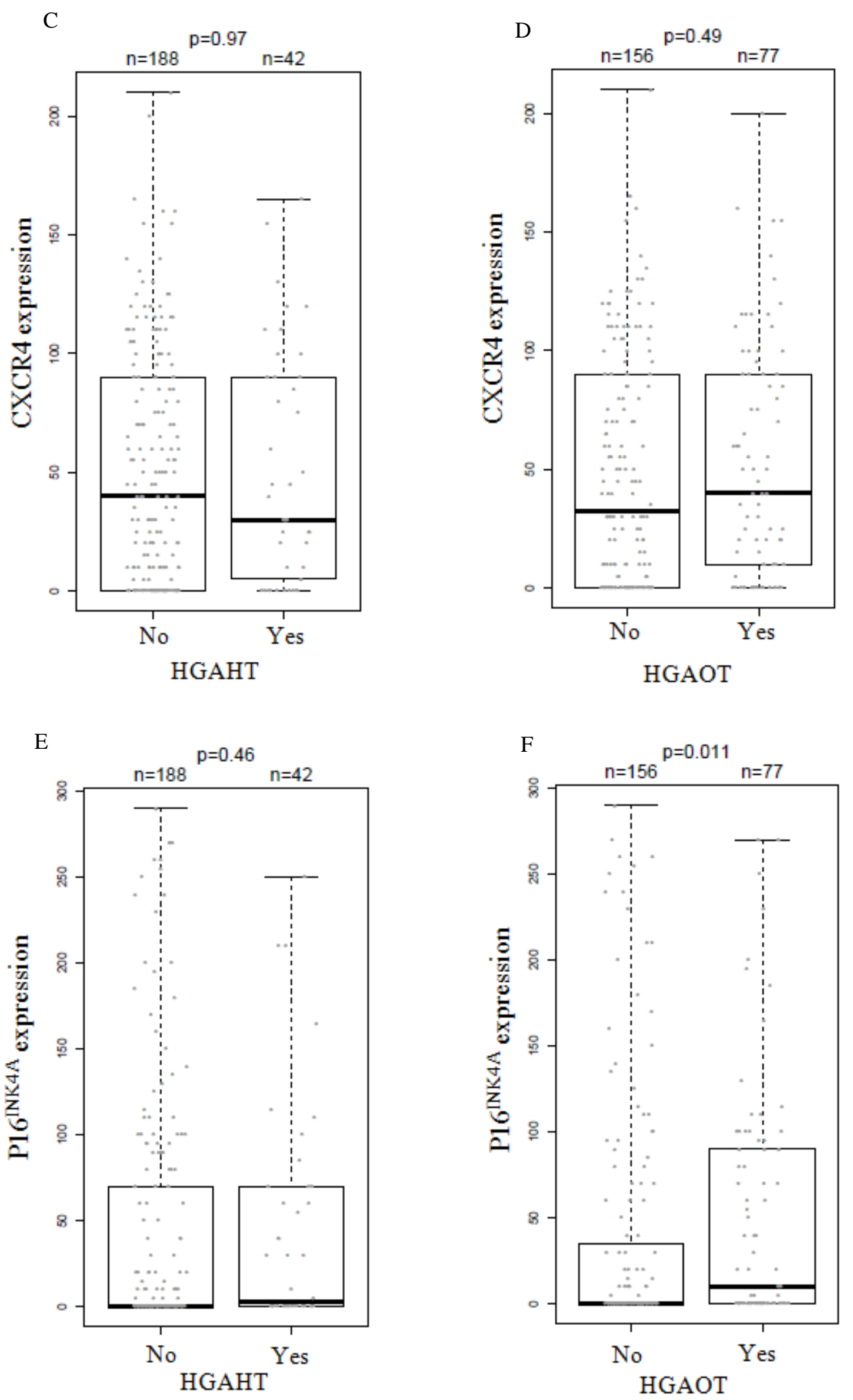


\section{Results}

Figure 3.6: Correlation between cytoplasmic expression of CXCL12, CXCR4 and p16 ${ }^{\mathrm{INK} 4 \mathrm{~A}}$ and HGAOT and HGAHT during R(C)T. Expression of these three proteins did not correlate with HGAHT (A, C, E). Only for p $16^{\mathrm{INK} 4 \mathrm{~A}}$ expression there was a statistically significant correlation with HGAOT $(\mathrm{p}=0.011)$ during $\mathrm{R}(\mathrm{C}) \mathrm{T}(\mathbf{F})$. No significant correlation between expression of CXCL12 and CXCR4 with HGAOT was noted (B, D). HGAHT: high-grade acute hematotoxicity, HGAOT: highgrade acute organ toxicity, $n$ : number of patients with positive or negative occurrence of HGAOT or HGAHT.

The distribution of acute toxicity symptoms in patients with positive or negative expression of p16 ${ }^{\mathrm{INK} 4 \mathrm{~A}}$ during $\mathrm{R}(\mathrm{C}) \mathrm{T}$ was as follows: out of the 77 patients with higher than grade 2 acute organ toxicity, 43 patients $(42.2 \%)$ expressed $\mathrm{p} 16^{\mathrm{INK} 4 \mathrm{~A}}(\mathrm{p}=0.011)$.

Table 3.6: Organ toxicity in relation to $\mathrm{p} 16^{\mathrm{INK} 4 \mathrm{a}}$ expression (reproduced from (Tehrany et al. 2015))

\begin{tabular}{|c|c|c|c|c|}
\hline \multirow{2}{*}{ Type } & \multicolumn{3}{|c|}{ Number of patients (\%) } & \multirow[t]{2}{*}{ P-value } \\
\hline & Total & P16 $^{\text {INK4a }}$ ex & & \\
\hline & & Negative & Positive & \\
\hline Mucositis & & & & 0.609 \\
\hline$\leq$ grade 2 & $191(82.0)$ & $109(83.2)$ & $82(80.1)$ & \\
\hline$>$ grade 2 & $42(18.0)$ & $22(16.8)$ & $20(19.9)$ & \\
\hline Skin reaction & & & & 0.592 \\
\hline$\leq$ grade 2 & $218(93.6)$ & $124(94.7)$ & $94(92.2)$ & \\
\hline$>$ grade 2 & $15(16.4)$ & $7(5.3)$ & $8(7.8)$ & \\
\hline Dysphagia & & & & 0.001 \\
\hline$\leq$ grade 2 & $199(85.4)$ & $121(92.4)$ & $78(76.4)$ & \\
\hline$>$ grade 2 & $34(14.6)$ & $10(7.6)$ & $24(23.6)$ & \\
\hline Nausea & & & & 0.524 \\
\hline grade 0 & $182(78.1)$ & $100(76.3)$ & $82(80.1)$ & \\
\hline$\geq$ grade 1 & $51(21.9)$ & $31(23.7)$ & $20(19.9)$ & \\
\hline Organ toxicity & & & & 0.011 \\
\hline$\leq$ grade 2 & $156(67.0)$ & $97(74.1)$ & $59(57.8)$ & \\
\hline$>$ grade 2 & $77(33.0)$ & $34(25.9)$ & $43(42.2)$ & \\
\hline
\end{tabular}

Overall, 20 of the 42 patients with higher than grade 2 mucositis during $R(C) T$ were positive for $\mathrm{p} 16^{\mathrm{INK} 4 \mathrm{~A}}$ expression (Table 3.6, $\mathrm{p}=0.609$ ). Of the 15 patients with a higher than grade 2 skin reaction, eight patients expressed $\mathrm{p} 16^{\mathrm{INK} 4 \mathrm{~A}}$ (Table 3.6, $\mathrm{p}=0.592$ ). Dysphagia higher than grade 2 was observed in 34 patients, of whom 24 patients were p16 ${ }^{\mathrm{INK} 4 \mathrm{~A}}$ positive. 


\section{Results}

Furthermore, expression of $\mathrm{p} 16^{\mathrm{INK} 4 \mathrm{~A}}$ showed a strong correlation with dysphagia (Table 3.6, $\mathrm{p}=0.001)$. There were no patients with higher than grade 2 nausea.

\subsubsection{Association of CXCL12, CXCR4 and p16 ${ }^{\mathrm{INK} 4 \mathrm{~A}}$ expression with survival data of HNSCC patients}

We analysed the patient survival data to determine whether expression of CXCL12, CXCR4, and $\mathrm{p} 16^{\mathrm{INK} 4 \mathrm{~A}}$ in head and neck tumours as well as the occurrence of HGAOT during $\mathrm{R}(\mathrm{C}) \mathrm{T}$ had any prognostic relevance.

\subsubsection{Impact of CXCL12 and CXCR4 expression on patient survival}

In this analysis, no relationship was found between CXCL12 expression, disease free survival (DFS), local recurrence-free survival (LRFS), and distant metastasis-free survival (DMFS) (Table 3.7). In contrast, Kaplan-Meier analysis of the survival data indicated that patients with a tumour expressing CXCL12 had a better OS than those who were CXCL12-negative (Figure 3.7, $\mathrm{p}=0.036$ ). The survival rates were $17 \%$ vs. $26 \%$, and $12 \%$ vs. $20 \%$ (positive vs. negative) at 5 years and 10 years, respectively. 


\section{Results}

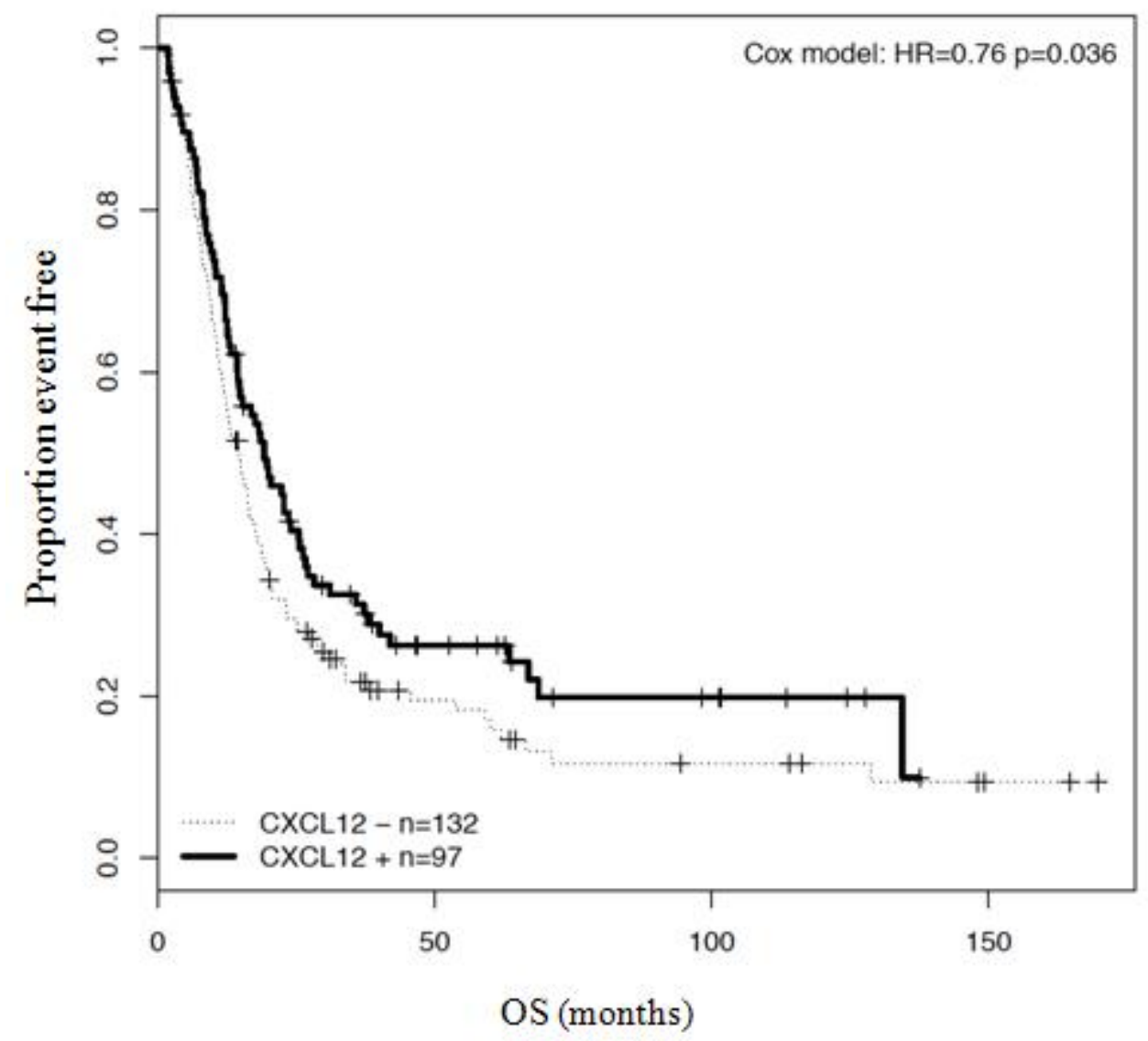

Figure 3.7: Overall survival (OS) related to CXCL12 expression in tumour cells of pre-treatment biopsies of patients with HNSCC by Kaplan-Meier analysis. Patients were divided into two groups based on CXCL12 expression in the tumour, i.e. CXCL12 + $(\mathrm{n}=97)$ vs. CXCL12 - $(\mathrm{n}=132)$ HNSCC patients.

Univariate Cox regression analyses showed that CXCR4 expression was not significantly associated with either OS ( $\mathrm{p}=0.32$, Table 3.7) or LRFS ( $\mathrm{p}=0.42$, Table 3.7). However, a reduced DMFS was significantly associated with a high CXCR4 expression ( $\mathrm{p}=0.034$, Figure 3.8-B, Table 3.7). In addition, a borderline statistically significant correlation was found between high CXCR4 expression and decreased DFS ( $\mathrm{p}=0.057$, Figure 3.8-A, Table 3.7). The association between expression of CXCL12 and CXCR4 and survival data of patients is summarized in Table 3.7. 


\section{Results}
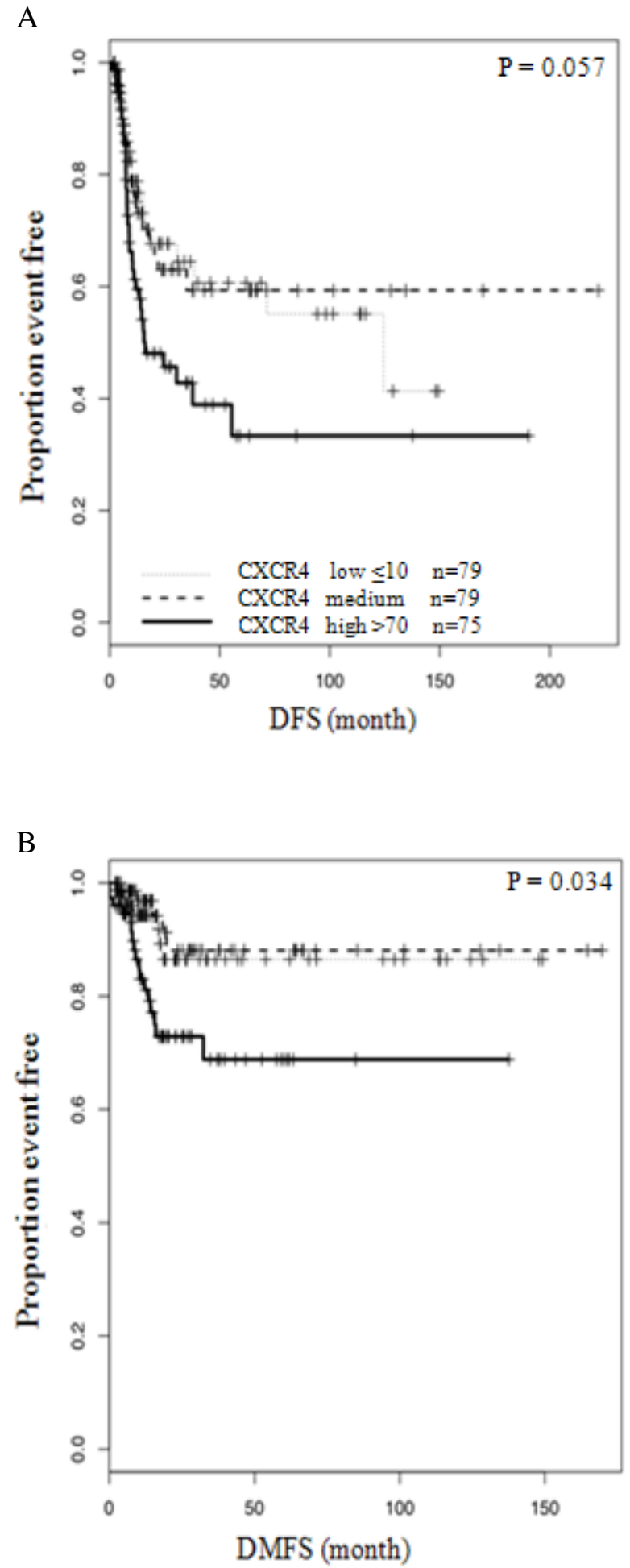

Figure 3.8: Correlation between survival data, and low, medium and high CXCR4 expression in pre-treatment biopsies of patients with HNSCC receiving radio(chemo)therapy. A) disease free survival, (DFS); B) distant metastasis-free survival (DMFS). The Cox proportional hazard model demonstrated that CXCR4 expression was significantly correlated with DMFS $(p=0.034)$. Although an association between CXCR4 expression and DFS was also observed, these correlation was not statistically significant $(\mathrm{p}=0.057)$. 


\section{Results}

Table 3.7: Survival data in relation to CXCL12 and CXCR4 expression

\begin{tabular}{|c|c|c|c|c|c|c|c|c|}
\hline \multirow[t]{3}{*}{ Characteristics } & \multicolumn{4}{|c|}{ Number of patients (\%) } & p- & \multicolumn{2}{|c|}{ Number of patients (\%) } & \multirow{3}{*}{$\begin{array}{c}\text { p- } \\
\text { value }\end{array}$} \\
\hline & Total & \multicolumn{3}{|c|}{ CXCR4 expression } & & \multicolumn{2}{|c|}{ CXCL12 expression } & \\
\hline & & $\begin{array}{l}\text { low } \\
\leq 10\end{array}$ & $\begin{array}{c}\text { median } \\
>10-70\end{array}$ & $\begin{array}{l}\text { high } \\
>70\end{array}$ & & $\begin{array}{c}\text { negative } \\
0\end{array}$ & $\begin{array}{c}\text { positive } \\
>0\end{array}$ & \\
\hline Total & $\mathrm{n}=\mathbf{2 3 3}$ & 79 (33.9) & $79(33.9)$ & $75(32.2)$ & & $132(56.7)$ & $97(41.6)$ & \\
\hline RT schedule & & & & & 0.001 & & & 0.53 \\
\hline Classic & $183(78.5)$ & $73(39.9)$ & $59(32.2)$ & $51(27.9)$ & & $104(58.1)$ & 75 (41.9) & \\
\hline $\begin{array}{l}\text { Intensity- } \\
\text { modulated }\end{array}$ & $50(21.5)$ & $6(12.0)$ & $20(40.0)$ & $24(48.0)$ & & $28(56.0)$ & $22(44.0)$ & \\
\hline Chemotherapy & & & & & 0.44 & & & 0.023 \\
\hline No & $62(26.6)$ & $18(29.0)$ & $26(41.9)$ & $18(29.0)$ & & $42(68.9)$ & $19(31.1)$ & \\
\hline Yes & $171(73.4)$ & $61(35.7)$ & $53(31.0)$ & $53(31.0)$ & & $90(53,6)$ & $78(46.4)$ & \\
\hline $\begin{array}{l}\text { Loco-regional } \\
\text { recurrence }\end{array}$ & & & & & 0.42 & & & 0.87 \\
\hline \#Events & 66 & 21 & 18 & 27 & & 33 & 32 & \\
\hline 60 month survival & 0.60 & 0.64 & 0.69 & 0.46 & & 0.55 & 0.64 & \\
\hline $\begin{array}{l}120 \text { month } \\
\text { survival }\end{array}$ & 0.57 & 0.58 & 0.69 & 0.46 & & 0.55 & 0.53 & \\
\hline Distant metastases & & & & & 0.034 & & & 0.52 \\
\hline \# Events & 29 & 7 & 5 & 17 & & 17 & 12 & \\
\hline 60 month survival & 0.81 & 0.87 & 0.88 & 0.69 & & 0.79 & 0.81 & \\
\hline $\begin{array}{l}120 \text { month } \\
\text { survival }\end{array}$ & 0.81 & 0.87 & 0.88 & 0.69 & & 0.79 & 0.81 & \\
\hline DFS & & & & & 0.057 & & & 0.89 \\
\hline \# Events & 81 & 23 & 22 & 36 & & 44 & 36 & \\
\hline 60 month survival & 0.51 & 0.61 & 0.59 & 0.33 & & 0.46 & 0.55 & \\
\hline $\begin{array}{l}120 \text { month } \\
\text { survival }\end{array}$ & 0.48 & 0.55 & 0.59 & 0.33 & & 0.46 & 0.50 & \\
\hline OS & & & & & 0.32 & & & 0.036 \\
\hline \# Events & 185 & 68 & 62 & 55 & & 110 & 72 & \\
\hline 60 month survival & 0.22 & 0.17 & 0.25 & 0.24 & & 0.17 & 0.26 & \\
\hline $\begin{array}{l}120 \text { month } \\
\text { survival }\end{array}$ & 0.15 & 0.15 & 0.14 & 0.11 & & 0.12 & 0.20 & \\
\hline
\end{tabular}




\section{Results}

3.1.5.2 Impact of $\mathrm{p} 16^{\mathrm{INK} 4 \mathrm{~A}}$ expression and the occurrence of HGAOT during $\mathrm{R}(\mathrm{C}) \mathrm{T}$ on HNSCC patient survival

For this cohort we considered the demographic and clinicopathologic characteristics of age at diagnosis, gender, tumour stage, and tumour grade (Table 3.3). With regard to these characteristics, there was no statistically significant difference between patients with p $16^{\text {INK4A }}$-positive HNSCC and those with $\mathrm{p} 16^{\mathrm{INK} 4 \mathrm{~A}}$-negative HNSCC. We also examined survival outcome differences based on $\mathrm{p} 16^{\mathrm{INK} 4 \mathrm{~A}}$ expression status in patients with HNSCC tumours. We observed that patients with $\mathrm{p} 16^{\mathrm{INK} 4 \mathrm{~A}}$ overexpression in their tumours had a significantly better OS ( $\mathrm{p}=0.002$, Figure 3.9$)$.

A

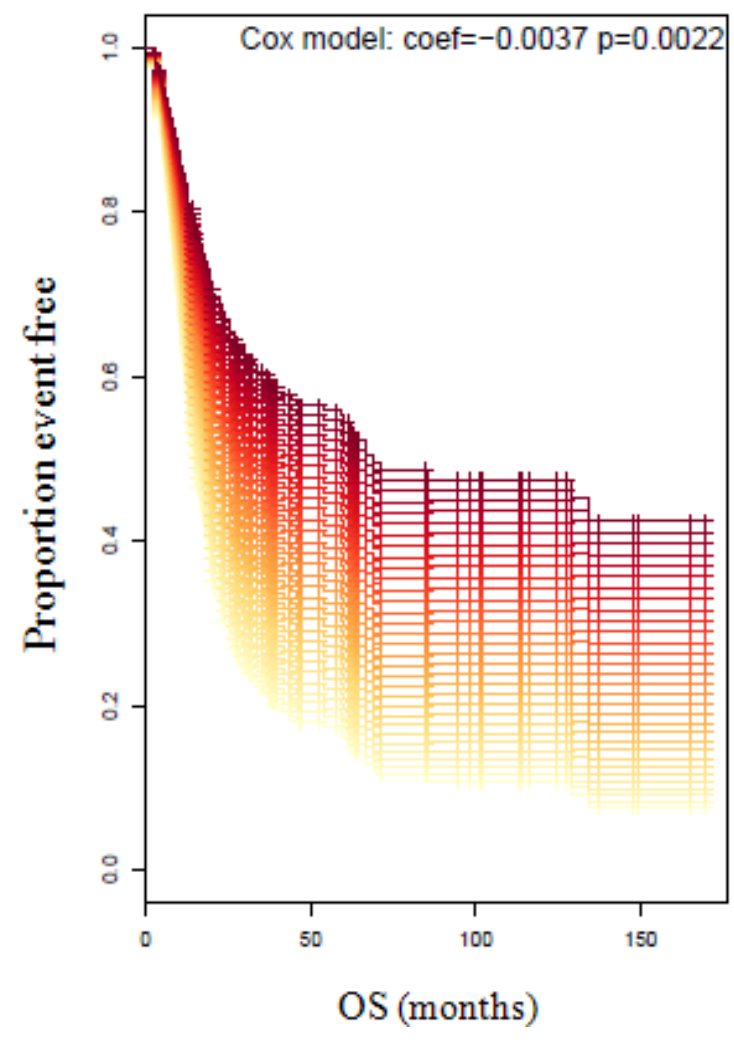

B

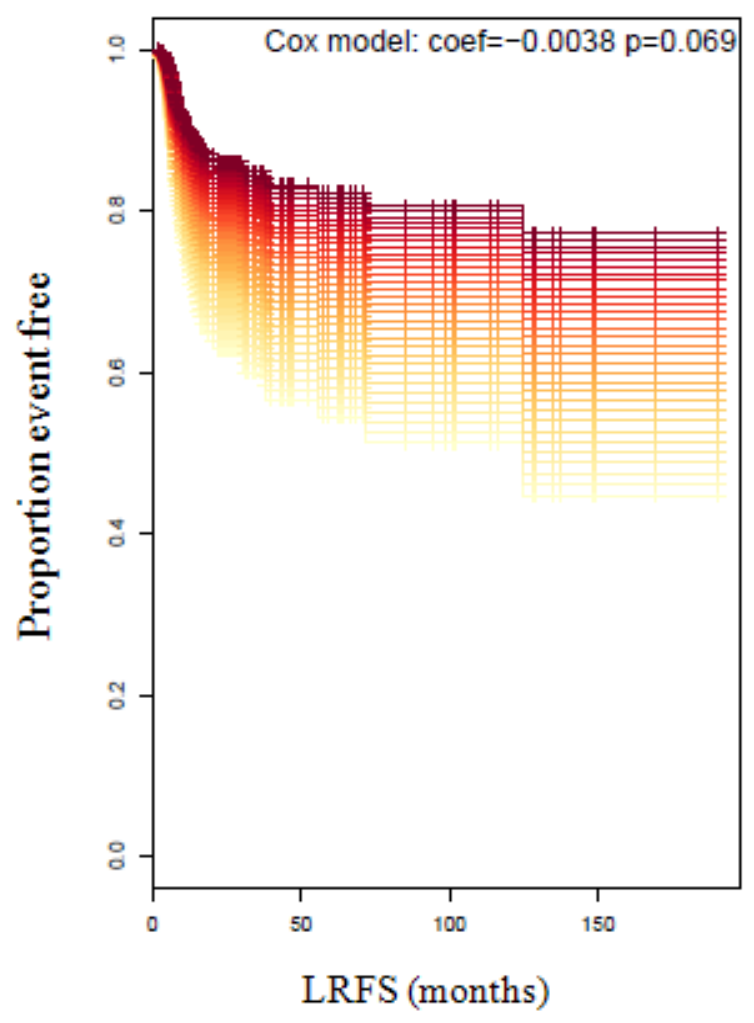

Figure 3.9: Correlation between cytoplasmic $16^{\mathrm{INK} 4 \mathrm{~A}}$ expression and overall survival (OS) and local recurrence-free survival (LRFS). A) The Cox proportional hazard model demonstrated that cytoplasmic $\mathrm{p} 16^{\mathrm{INK} 4 \mathrm{~A}}$ expression was significantly associated with OS in this group of patients $(\mathrm{p}=0.0022)$. B) The trend towards improved LRFS in the patients with positive $\mathrm{p} 16^{\mathrm{INK} 4 \mathrm{~A}}$ expression was not statistically significant $(\mathrm{p}=0.069)$. 


\section{Results}

Moreover, we evaluated the impact of $\mathrm{p} 16^{\mathrm{INK} 4 \mathrm{~A}}$ expression on OS of our HNSCC study cohort after therapy and the analysis of acute organ toxicity. It is known that patients with HGAOT (CTC >2) including one or more of the items mucositis, skin reaction or dysphagia had better OS and locoregional control rates than patients without such reactions (Wolff et al. 2010a).

Figure 3.10 shows the Kaplan-Meier plots for patients positive and negative for $\mathrm{p} 16^{\mathrm{INK} 4 \mathrm{~A}}$ expression, and with and without the occurrence of HGAOT. These four patient subgroups significantly differed in their five-year OS rates. Patients with $\mathrm{p} 16^{\mathrm{INK} 4 \mathrm{~A}}$ expression and HGAOT had a five-year OS rate of 47\%. With only HGAOT, the five-year OS rate was $42 \%$, while in patients with $\mathrm{p} 16^{\mathrm{INK} 4 \mathrm{~A}}$ expression it was only $20 \%$. The five-year OS rate in patients without $\mathrm{p} 16^{\mathrm{INK} 4 \mathrm{~A}}$ expression or HGAOT was $10 \%$. In addition, a borderline statistically significant correlation was found between P16 ${ }^{\mathrm{INK} 4 \mathrm{~A}}$ expression and LRFS (Figure 3.9, $\mathrm{p}=0.069)$.

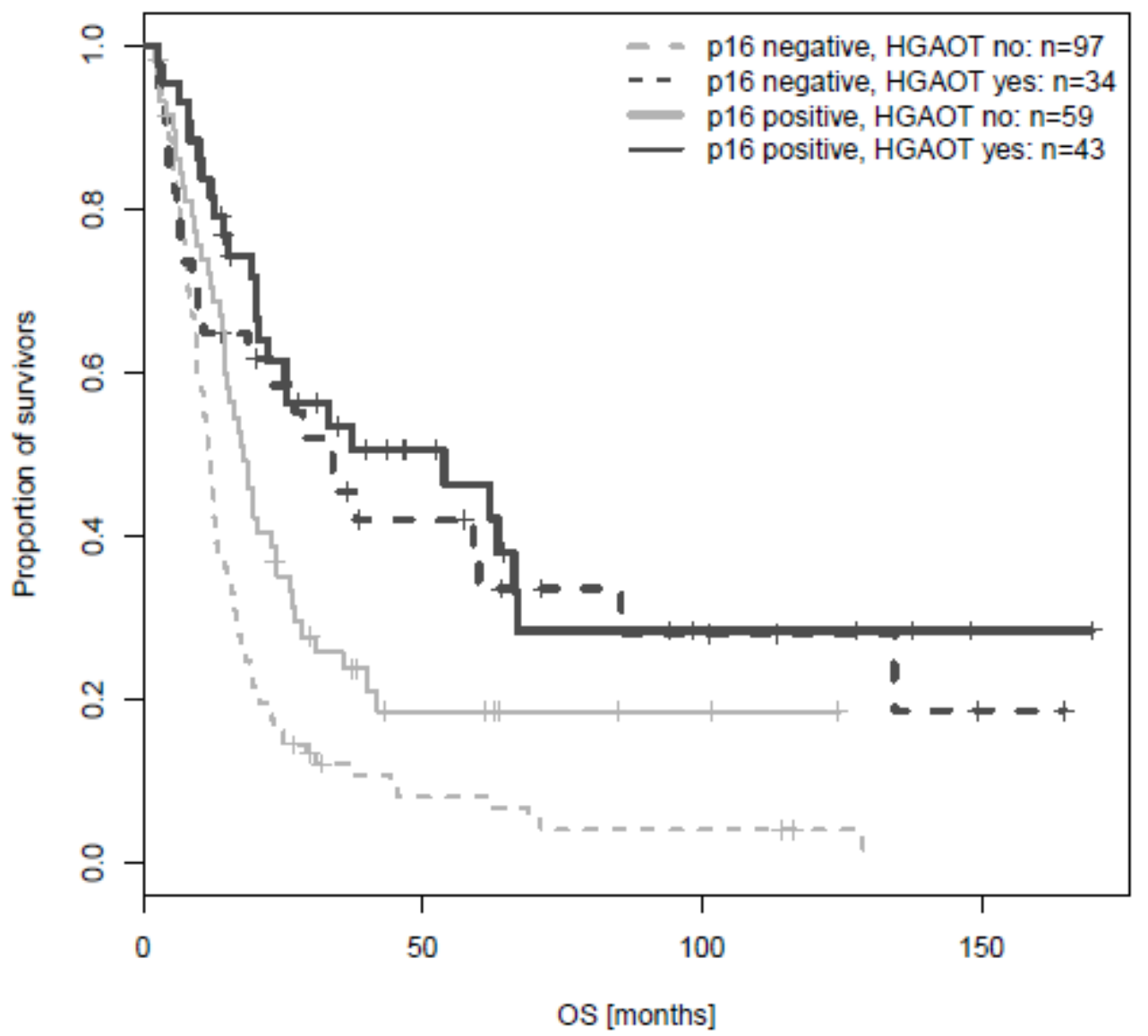

Figure 3.10: Kaplan-Meier plots for patients tested positive and negative for p16 $^{\mathrm{INK} 4 \mathrm{~A}}$ expression, and with and without HGAOT. These four patient subgroups significantly differed in their five-year OS rates; Patients with $16^{\mathrm{INK} 4 \mathrm{~A}}$ expression and HGAOT showed better five-year OS rates than patients with $\mathrm{p} 16^{\mathrm{INK} 4 \mathrm{~A}}$ expression or HGAOT alone. The five-year OS rates in patients without $16^{\mathrm{INK} 4 \mathrm{~A}}$ expression and HGAOT was $10 \%\left(\mathrm{n}=\right.$ number of patients, $\mathrm{p} 16: \mathrm{p} 16^{\mathrm{INK} 4 \mathrm{~A}}$, yes: occurrence of HGAOT, no: without HGAOT) (reproduced from (Tehrany et al. 2015)). 


\section{Results}

3.2 The role of CXCL12 and CXCR4 in the migration of irradiated HNSCC and control cell lines (in vitro analysis)

\subsubsection{Characterisation of the cell lines}

The characterisation of three HNSCC and two control cell lines for the expression of CXCL12 and CXCR4, and their radiosensitivity and metabolic activity under diverse conditions were prerequisite for all subsequent analyses.

\subsubsection{CXCL12 and CXCR4 mRNA expression}

Expression of CXCL12 and CXCR4 in the cell lines FaDu, ZMK-1, GR-145 (HNSCC tumour cell lines), DF-19 and HaCat (control cell lines) under non-irradiated and irradiated conditions has already been determined by real-time PCR at the mRNA level (Wolff et al. 2011a). The positivity or negativity of CXCL12 and CXCR4 expression was reconfirmed in the present study (Table 3.8).

Table 3.8: CT values of target genes (CXCL12 and CXCR4) and the housekeeping gene (HPRT1) by real-time PCR

\begin{tabular}{|lccc|}
\hline Cell line & CXCL12 & CXCR4 & HPRT1 \\
\hline DF-19 & 21.47 & Not expressed & 25.47 \\
\hline FaDu & Not expressed & 31.30 & 23.47 \\
\hline GR-145 & 27.35 & Not expressed & 25.01 \\
\hline HaCat & Not expressed & Not expressed & 24.79 \\
\hline ZMK-1 & Not expressed & 22.95 & 22.58 \\
\hline
\end{tabular}

We examined, whether HNSCC tumour cells or control cells revealed characteristic CXCL12 and CXCR4 patterns at protein levels. For this purpose, we performed western blot analysis and immunocytochemical staining.

3.2.1.2 CXCR4 protein expression

Western blot analysis was performed to assess CXCR4 protein expression in HNSCC and control cell lines. Protein was extracted and its concentration measured. Equal amounts of 


\section{Results}

protein for each cell line were transferred from the TGX gels onto nitrocellulose membranes and incubated with primary antibodies specific for each protein of interest (CXCR4 and $\beta$ actin). Appropriate secondary antibodies were used to detect specific binding of the primary ones. Due to the nearly identical molecular weight of CXCR4 and $\beta$-actin an extra blot was probed for $\beta$-actin as an internal control to ensure equivalent protein loading and also protein integrity (see Chapter 2.3.3).

Western blot analysis of $\beta$-actin showed positive bands for all cell lines, indicating sufficient amounts of protein and successful transfer. As shown in Figure 3.11, the expression of CXCR4 was confirmed in two tumour cell lines, ZMK-1 and FaDu, with strong bands at a molecular weight of about $40 \mathrm{kDa}$, while GR-145, HaCat and DF-19 cell lines showed no CXCR4 positive staining (Figure 3.11, Table 3.9).

$40 \mathrm{kDa}$
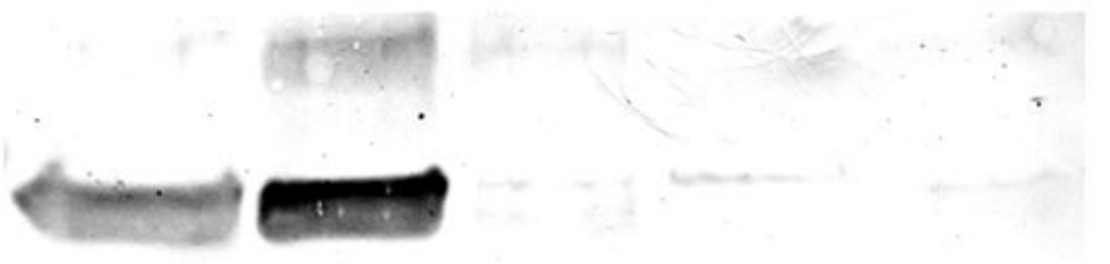

$\underline{\text { CXCR4 }}$

ZMK-1 FaDu GR-145 HaCat $\quad$ DF-19

$42 \mathrm{kDa}$
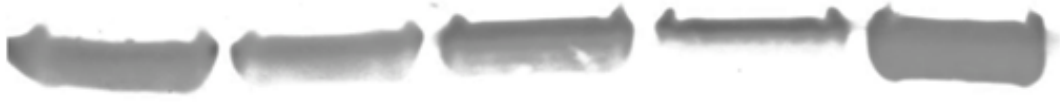

$\underline{\text { B-actin }}$

ZMK-1

FaDu

GR-145

HaCat

DF-19

Figure 3.11: Protein expression analysis of CXCR4 and $\beta$-actin (as internal control) in three HNSCC tumour and two control cell lines by western blotting. These two blots were produced using TGX-gel. The gel was run at $200 \mathrm{~V}$ and $30 \mathrm{~mA}$ before being transferred to a nitrocellulose membrane following an appropriate transfer protocol for 3 minutes. Whole cell lysate probed against CXCR4 and $\beta$-actin showing lower CXCR4 expression in ZMK-1 cells than in FaDu cells, while GR-145, HaCat and DF-19 cell lines were negative. $\beta$-actin serves to control for equal protein loading, and is observed in all cell lines tested. 


\section{Results}

The presence of CXCL12 in the cells was studied by immunocytochemical staining. Figure 3.12 shows the results obtained for each cell line that was studied in this work.
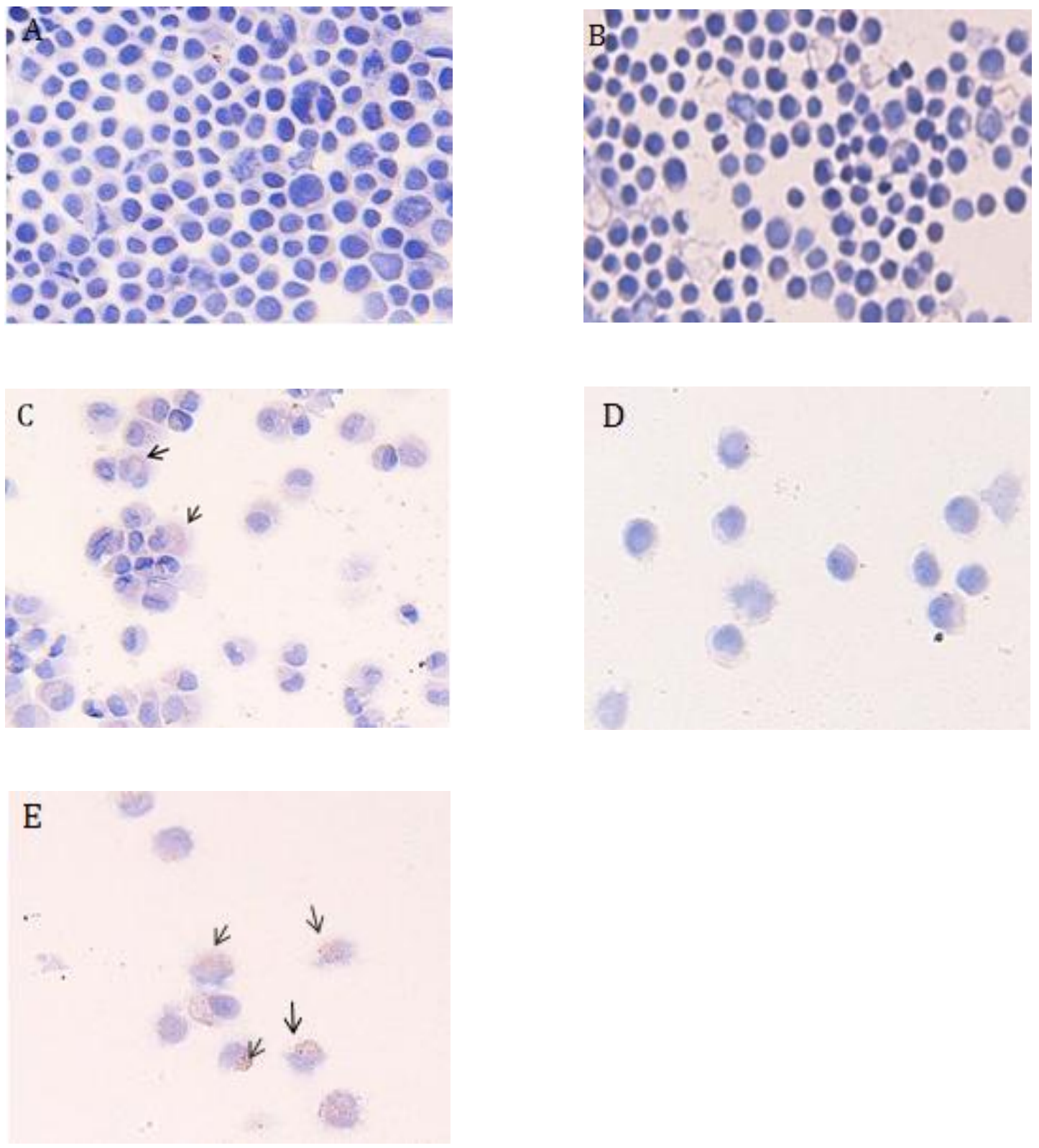

Figure 3.12: Cells stained by ICC method to detect CXCL12 in three HNSCC tumour and two control cell lines. Red staining correlates to the presence of CXCL12 and the nuclei are stained blue. Tumour cells of ZMK-1 (A) and FaDu (B) were CXCL12-free. Other tumour cell line, GR-145 (C) showed a weak cytoplasmic staining. From two control cell lines, HaCat cells (D) were CXCL12-free, while DF-19 cells (E) expressed CXCL12 in the cytoplasm. (40x magnification and 2x zoom) 


\section{Results}

Red staining correlates to the presence of CXCL12. Chemokine-free cells i.e. HaCat, FaDu and ZMK-1 show only blue stained nuclei. It can be seen that DF-19 cells expressed more CXCL12 in the cytoplasm, while a weak cytoplasmic staining in GR-145 cells was also observed (Figure 3.12, Tab. 3.9).

The results of the PCR analysis, western blotting, and immunocytochemical staining are summarized in Table 3.9.

Table 3.9: Review of CXCL12 and CXCR4 expression in each cell lines

\begin{tabular}{|l|l|l|}
\hline Cell line & CXCR4 & NXCL12 \\
\hline ZMK-1 & Positive (PCR, WB) & Positive (PCR, ICC) \\
\hline GR-145 & Negative (PCR, WB) & Negative (PCR, ICC) \\
\hline FaDu & Positive (PCR, WB) & Negative (PCR, ICC) \\
\hline HaCat & Negative (PCR, WB) & Positive (PCR, ICC) \\
\hline DF-19 & Negative (PCR, WB) & \\
\hline
\end{tabular}

3.2.1.4 Investigation of the radiosensitivity of the cell lines

A colony-forming assay was performed to examine and compare the radiosensitivity of HNSCC tumour and control cells. Using the Kaleidagraph ${ }^{\circledR}$ software, the surviving fractions (SF) of irradiated and treated/untreated cells in all performed experiments were determined and the means and standard deviations of the SF were calculated. In the colony-forming assay, the cell survival curve describes the correlation between the radiation dose and the fraction of cells still dividing. The response of all cell lines to increasing radiation doses is shown in Figure 3.13 A-D. The survival curves for the irradiated cells alone show that for all four cell lines exposure to increasing doses of radiation induces a proportional decrease in clonogenic cell survival (Figure 3.13 A-D, solid lines).

The impact of CXCL12 and AMD3100 on the radiosensitivity of the cell lines was measured using a colony-forming assay as described in Chapter 2.3.4 (Figure 3.13 A-D, and Figure 3.14). 


\section{Results}

A
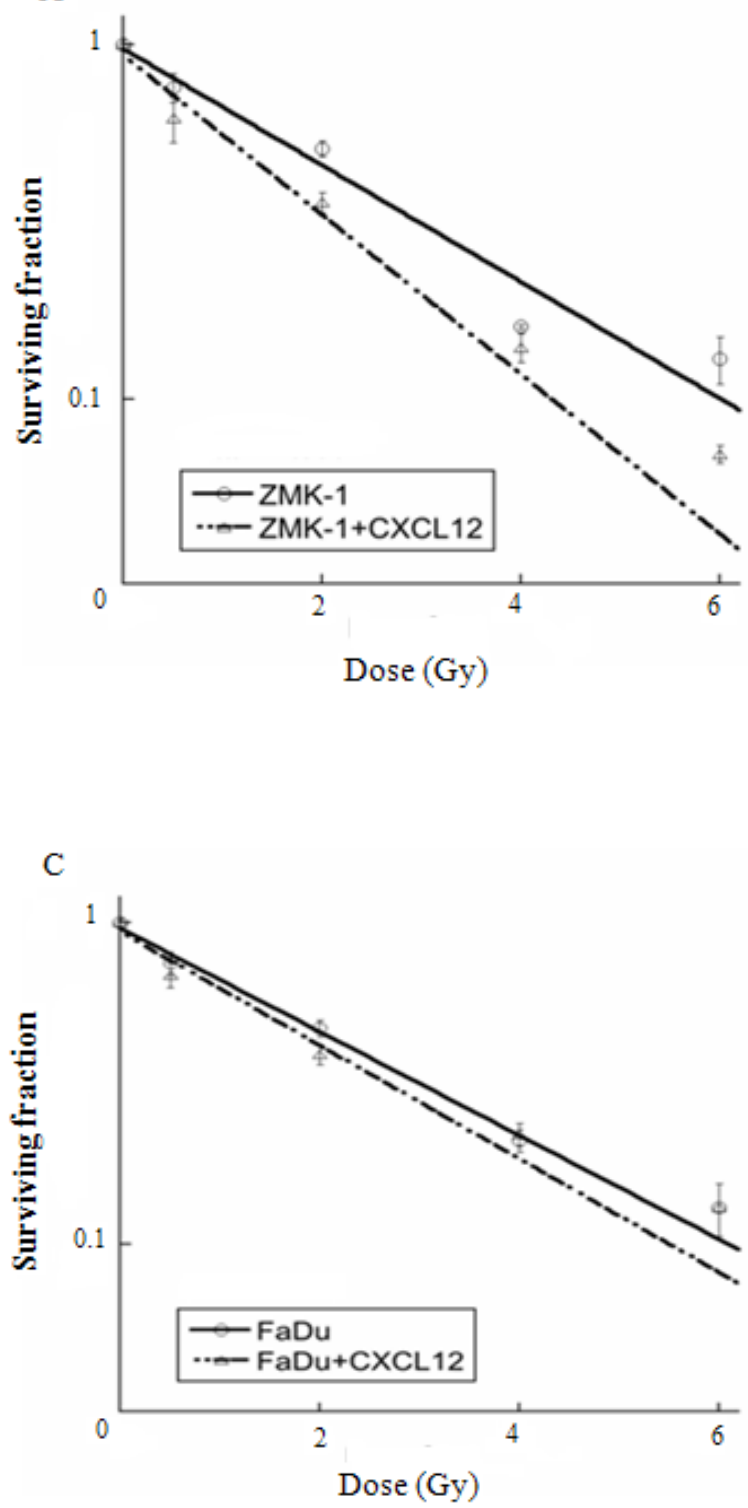
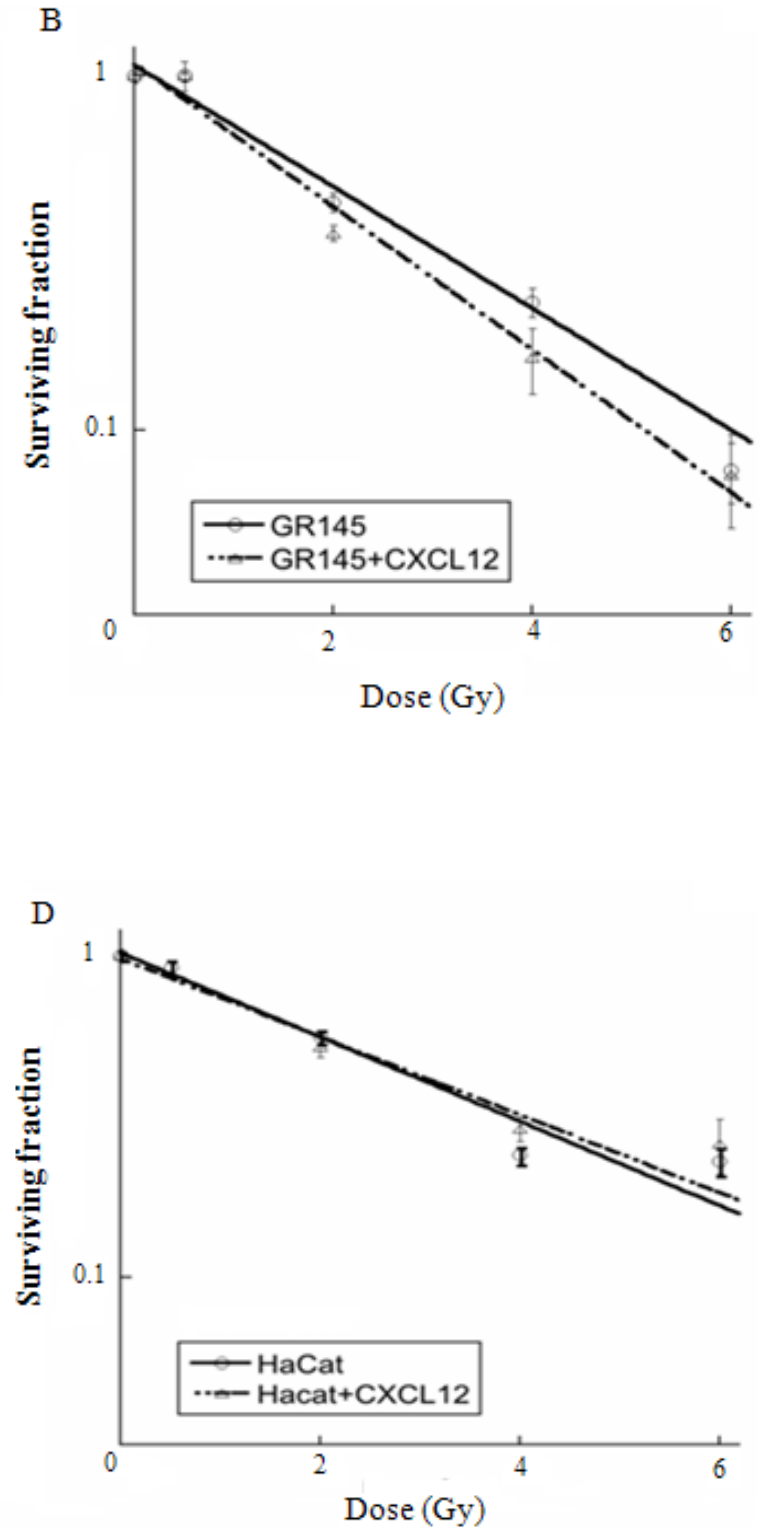

Figure 3.13: Surviving fraction of three HNSCC tumour and one control cell lines after irradiation alone or a combined treatment with $100 \mathrm{ng} / \mathrm{ml}$ CXCL12 after 0.5, 2, 4 and 6 Gy of radiation. After about 10 days, colonies were fixed and stained with $0.1 \%$ crystal violet solution. Colonies were counted and the surviving fraction was normalised to the surviving fraction of the corresponding control. In all tumour and control cell lines, irradiation reduced cell survival in a dosedependent manner. The ZMK-1 cell line (A) (one of the CXCR4-positive cell lines) showed a significantly enhanced radiosensitivity in response to CXCL12 treatment, while GR-145 (B) and FaDu (C) cells showed a weak enhanced sensitizing effect of CXCL12. HaCat cells (D) were not affected by CXCL12. Data are presented as the mean \pm standard errors of three independent experiments. 


\section{Results}

The radiosensitivity with a dose-modifying factor (DMS) of 1.44 was significantly increased in the ZMK-1 cell line, the tumour cell line that is negative for CXCL12 and has the high CXCR4 expression, when treated for 26 hours with CXCL12 (Figure 3.13-A). GR-145 cells and $\mathrm{FaDu}$ cells showed a slightly enhanced sensitizing effect of CXCL12 in the culture medium (Figure 3.13-B, C). However, HaCat cells were not affected by the addition of CXCL12 at all (Figure 3.13-D). Data were derived from three independent experiments and error bars show the standard error of the mean survival following exposure to $0.5,2,4$, and 6 Gy radiation.

To determine the impact of the CXCR4 inhibitor, AMD3100, on the radiosensitivity of CXCR4-positive cell lines, cells were incubated with $5 \mu \mathrm{g} / \mathrm{ml}$ AMD3100 for 26 hours. After incubation, the colony-forming assay was performed (see Chapter 2.3.5.1). The data shown are the means and standard deviations of three independent experiments following exposure to $0.5,2$ and 4 Gy of radiation. FaDu and ZMK-1 cells were not affected by the addition of AMD3100 to the cell culture medium indicating that AMD3100 has no effect on the radiosensitivity of these CXCR4-positive tumour cell lines (Figure 3.14).

A

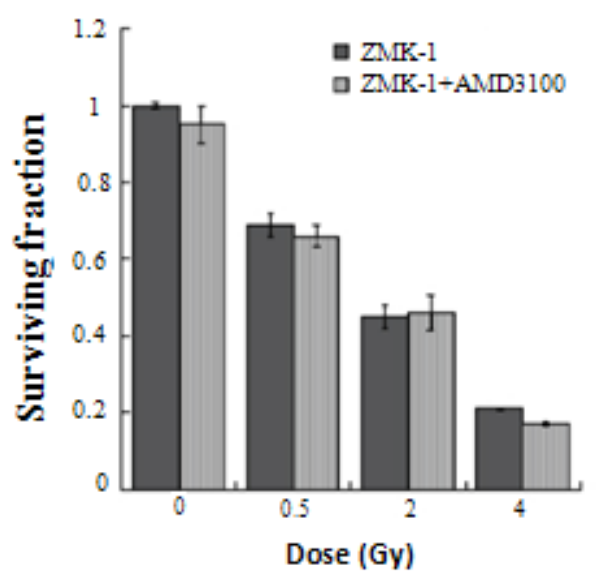

B

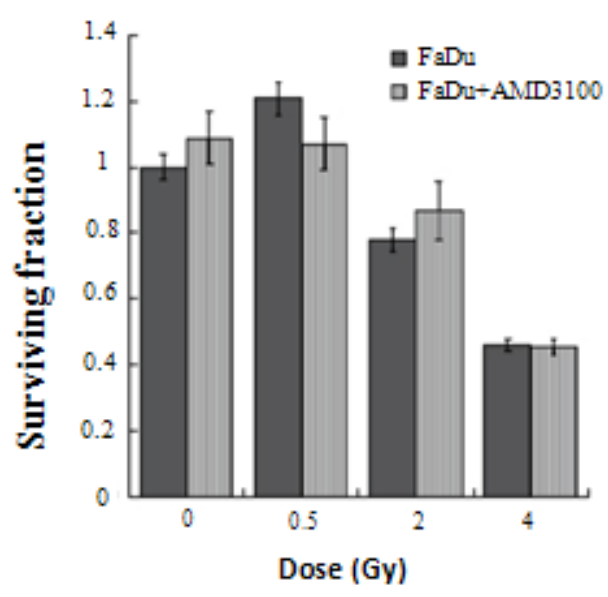

Figure 3.14: Surviving fraction of two CXCR4-positive HNSCC tumour cell lines after irradiation alone or combined with $5 \mu \mathrm{g} / \mathrm{ml} \mathrm{AMD3100}$ after $0.5,2$ and $4 \mathrm{~Gy}$ of radiation. A) AMD3100 showed no effect on radiosensitivity of ZMK-1 (CXCR4-positive) tumour cell lines. B) FaDu cells (also CXCR4-positive tumour cells) were not affected by the addition of AMD3100 to the cell culture. 


\section{Results}

\subsubsection{Metabolic activity of the cell lines under different treatment conditions}

\subsection{Preliminary experiments}

\section{First preliminary experiment}

In order to determine the optimal incubation times and effective radiation doses for all planned experiments the preliminary CTB assay procedure was performed as described in Chapter 2.3.6.1. First preliminary experiments were performed with incubation times of 26, 48, 72 and 96 hours for ZMK-1 and HaCat cell lines (Figure 3.15). The viable cells can convert resazurin into resorufin, a highly fluorescent product. This intensity of the fluorescence is proportional to the number of viable cells that are able to perform this redox reaction.
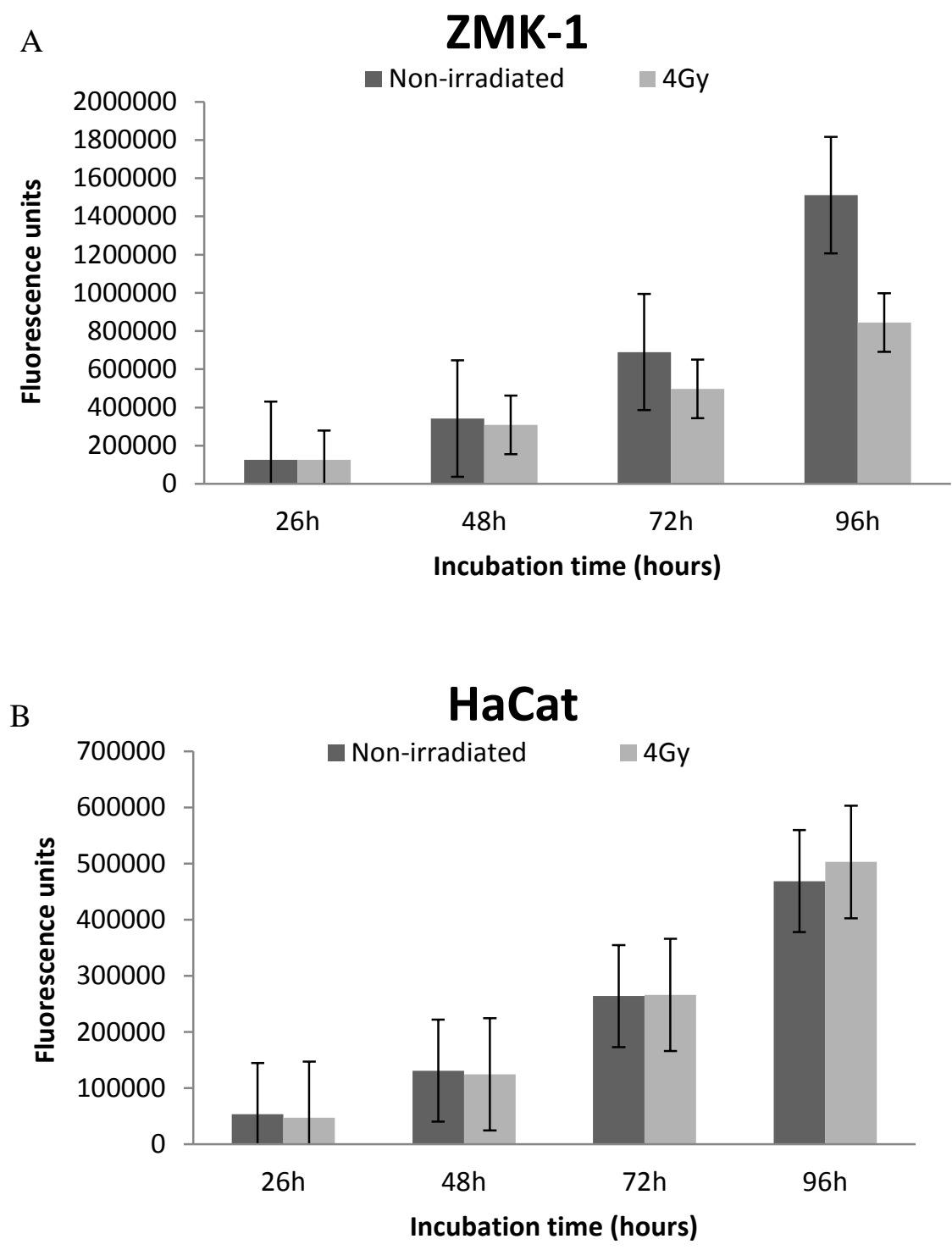


\section{Results}

Figure 3.15: First preliminary CTB assay experiments with 26, 48, 72 and 96 hours incubation time for ZMK-1 and HaCat cell lines. The incubation time, after which difference between the irradiated and non-irradiated cells was observable, was chosen as an optimal incubation time. A) In the ZMK-1 cell line a difference of metabolic activity of irradiated and non-irradiated cells was observed after 96 hours. B) In the HaCat cell line no impact of irradiation on cell viability was detected even after 96 hours incubation time. Each experimental condition was performed in triplicate. A total dose of $4 \mathrm{~Gy}$ was delivered with a dose rate of $2 \mathrm{~Gy} / \mathrm{min}$.

Figure 3.15 shows that a reduced viability of 4 Gy-irradiated ZMK-1 cells can been seen after a 96-hour incubation time, while HaCat cells would probably require a longer incubation time or a higher radiation dose to show alterations in metabolic activity.

\section{Second preliminary experiment}

A second preliminary experiment was performed to determine the optimal radiation dose. The incubation time for this second preliminary test was set at 72 hours after irradiation (see Chapter 2.3.6.1.).

A

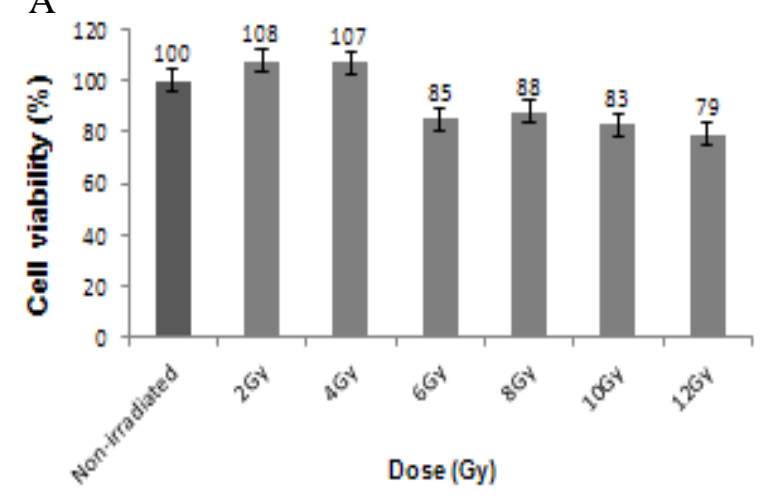

C

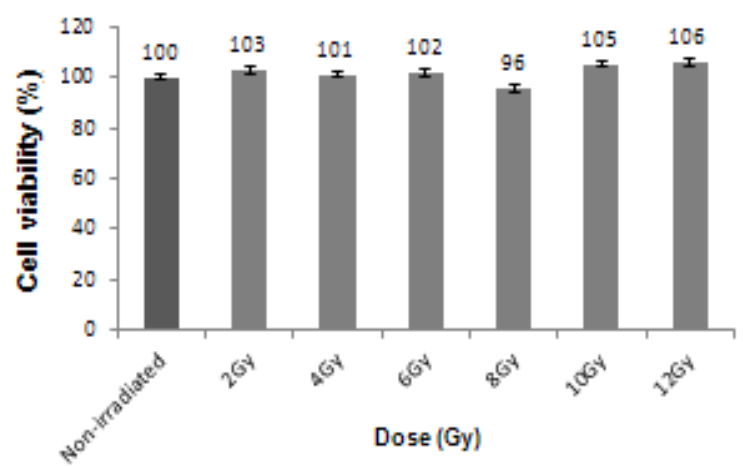

B

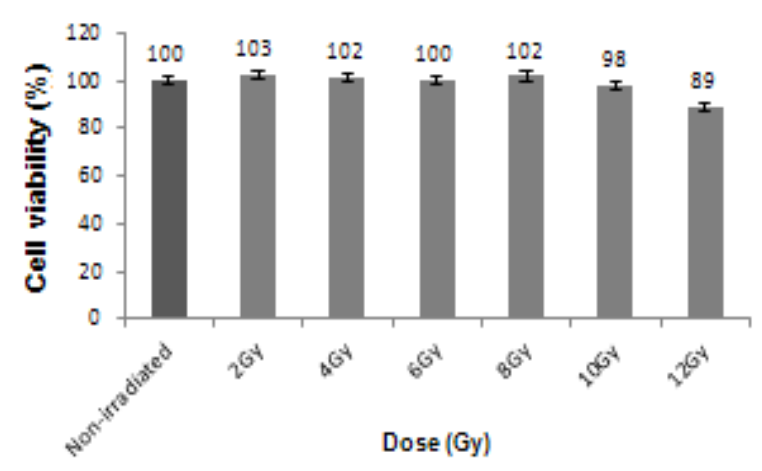

$\mathrm{D}$

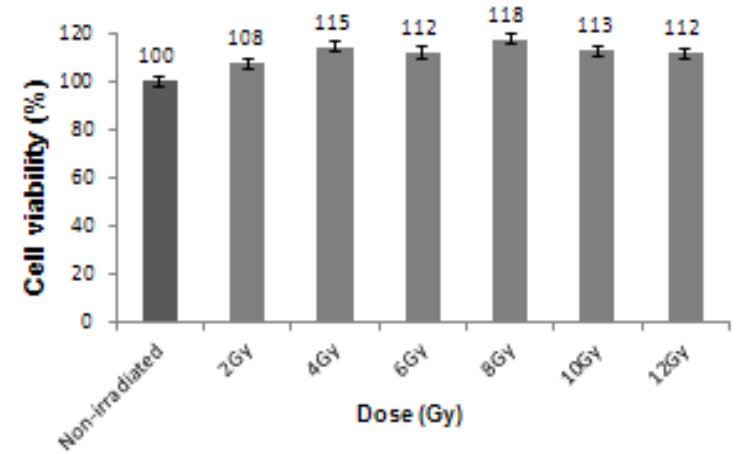




\section{Results}

Figure 3.16: Second preliminary CTB assay experiment with different radiation doses. Cells were incubated for 72 hours. A) The tumour cell line FaDu (at 6 to 12 Gy) showed reduced cell viability compared to non-irradiated control cells after irradiation. B) The control DF-19 cell line showed reduced metabolic activity after $12 \mathrm{~Gy}$ radiation. C) The tumour GR-145 cell line showed reduced cell viability compared to non-irradiated control cells after irradiation (only with 8Gy). D) In the HaCat cell line even after $12 \mathrm{~Gy}$ radiation, the metabolic activity of the cells was still efficient. Each experimental condition was performed in triplicate. A total dose of 2, 4, 6, 8, 10 and 12 Gy was delivered with a dose rate of $2 \mathrm{~Gy} / \mathrm{min}$.

Figure 3.16 illustrates that for the diverse radiation doses, no clear difference in cell viability of control cell lines, HaCat and DF-19, can be observed. The tumour cell line FaDu showed reduced metabolic activity following 6, 8, 10 and 12 Gy radiation, while the tumour cell line GR-145 showed slightly decreased cell viability only with 8 Gy irradiation (Figure 3.16).

\section{Third preliminary experiment}

In the final experiment, the number of cells in each well was reduced from 5000-6000 cells to 2000 cells. The incubation time was prolonged to one week (168 hours) to analyse the cell viability in an expanded period of time and a radiation dose of $8 \mathrm{~Gy}$ was used. The results are summarised in Figure 3.17. There was only a non-significant reduction in the fluorescence

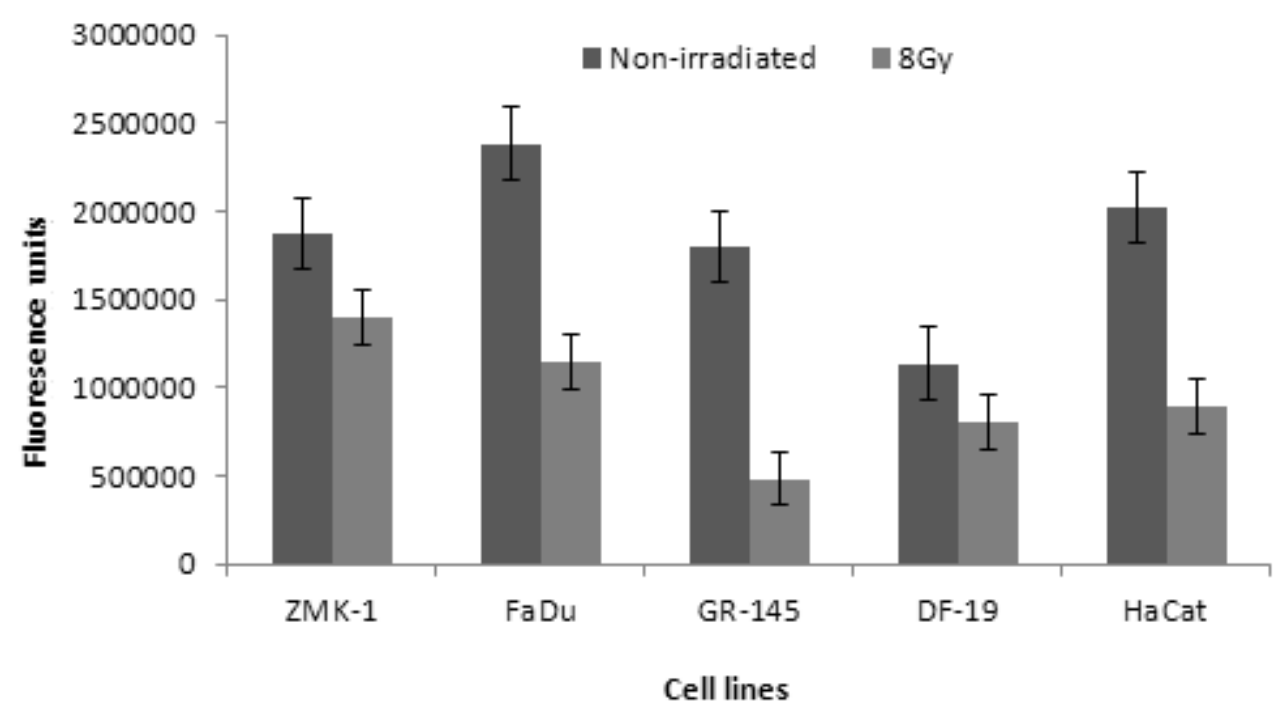

Figure 3.17: Optimising incubation time, radiation dose and cell densities in all used cell lines. The cells were irradiated with $8 \mathrm{~Gy}$ and after one week incubation time, the cell viability was measured. Each cell line except DF-19 demonstrates reduced metabolic activity following irradiation. Each experimental condition was performed in triplicate. A total dose of $8 \mathrm{~Gy}$ was delivered with a dose rate of $2 \mathrm{~Gy} / \mathrm{min}$. 


\section{Results}

intensity in the DF-19 cells, while a notable reduction of fluorescence was detected in the other cell lines (Figure 3.17). In addition, between non-irradiated cells, the FaDu cells after one week incubation time showed more cell viability in compare to DF-19 cells.

After optimising the parameters for analysing cell viability the results suggested that the $8 \mathrm{~Gy}$ irradiation dose with a one-week incubation time should be used to detect the impact of irradiation on cell viability.

\subsection{Main experiment: Analysis the cell viability of cells under different treatment conditions}

This aforementioned irradiation dose and incubation time (Figure 3.15-17) was used in the following CTB assay to determine the impact of CXCL12 and AMD3100 on the metabolic activity of each cell line.

To this end, cell suspensions were prepared and the cells incubated with $100 \mathrm{ng} / \mathrm{ml} \mathrm{CXCL12,}$ $5 \mu \mathrm{g} / \mathrm{ml}$ AMD3100 or both for 30 minutes at $37^{\circ} \mathrm{C}$ and $5 \% \mathrm{CO} 2$. The cells were pipetted in two 96-well plates (2000 cells/well). One of two plates was irradiated at $8 \mathrm{~Gy}$. The cell viability of each cell line under the different treatment conditions was analysed after one week. The non-irradiated or untreated cells were compared using the t-test, and $\mathrm{p}<0.05$ was regarded significant. In each group the cell viability in the presence of CXCL12, AMD3100 or both compounds was compared with untreated cells. In addition, cells treated with CXCL12, AMD3100 or both and irradiated with 8 Gy were compared with non-irradiated cells to study the impact of irradiation on cell viability. Data are presented as mean differences \pm standard deviations. Results are taken from two independent experiments, always performed in triplicate (Figure 3.18).

Of all cell lines, tumour cell lines $\mathrm{ZMK}-1, \mathrm{FaDu}$ and GR-145 were rather radiosensitive, and irradiation reduced viability as shown by the results of the colony-forming assays (Figure 3.18 A-C). However, the metabolic activity of the control cell lines, DF-19 and HaCat, was not significantly reduced by irradiation (Figure $3.18 \mathrm{D}-\mathrm{E}$ ).

As seen in Figure 3.18, the tumour cell lines, ZMK-1, FaDu and GR-145 as well as the control cell line DF-19 showed unchanged cell viability following treatment with CXCL12, AMD3100 or both compounds. However, when HaCat cells were treated with CXCL12, 


\section{Results}

AMD3100 or even both together, there was a significant increase of metabolic cell activity compared to the untreated control cells.

A

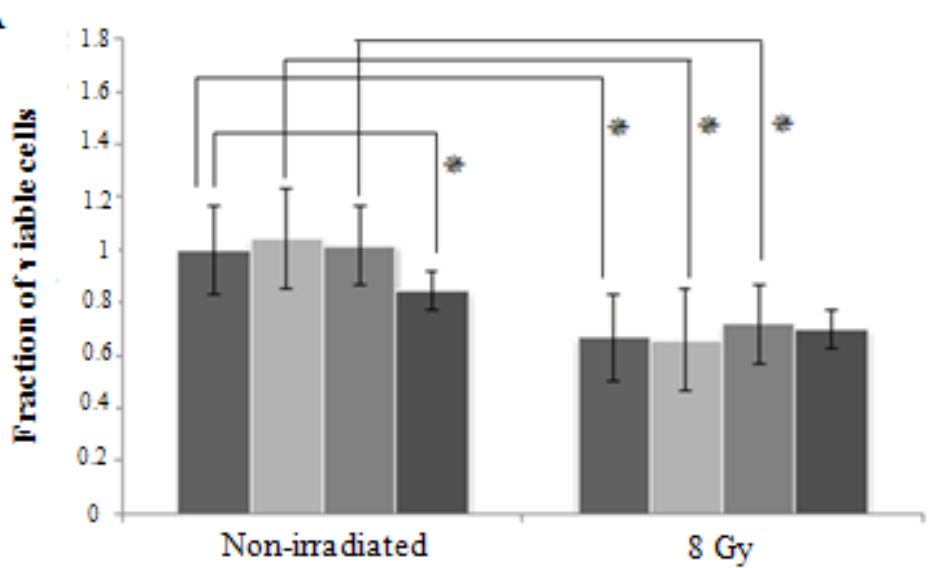

$=\mathrm{ZMR}-1$

$=\mathrm{ZaR}-1+\mathrm{CXCL} 12$

$=\mathrm{ZMK}-1+\mathrm{AMD} 3100$

$=\mathrm{ZMK}-1+\mathrm{CXCL} 12+\mathrm{AND} 3100$

B

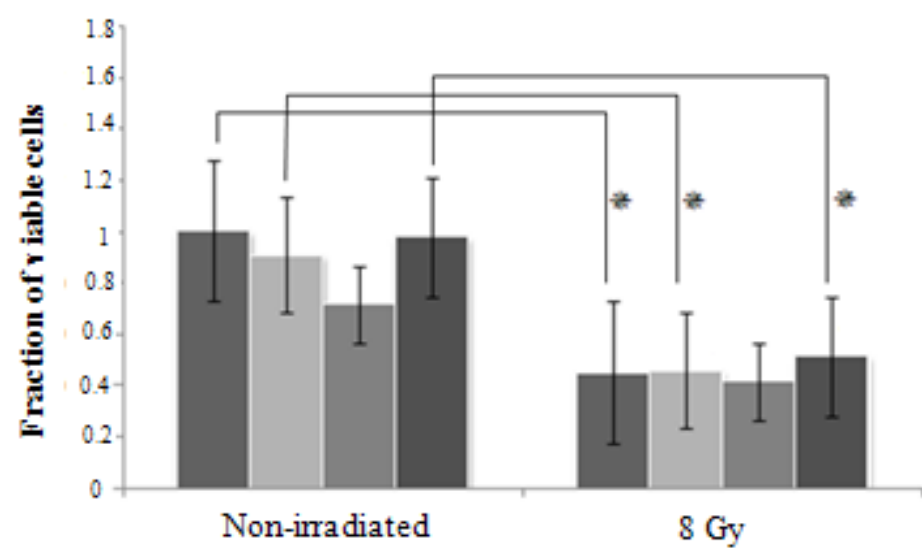

EaDu

$=\mathrm{FaDu}+\mathrm{CXCL} 12$

a FaDu+AMD 3100

= FaDu+CXCL 12+AND3100

$\mathrm{C}$

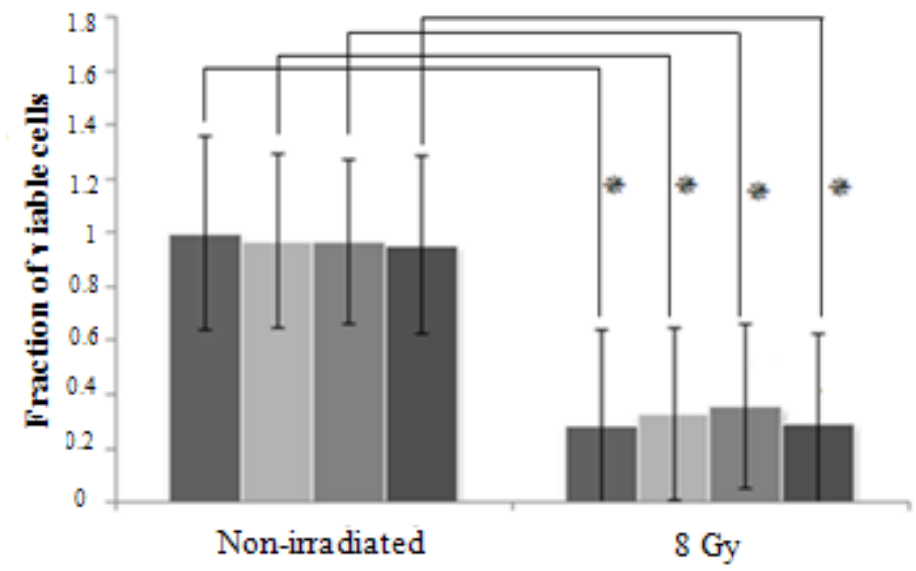

$=$ GR-145

$=$ GR-145+CXCL 12

= GR-145+AND3100

$=$ GR-145+CXCL $12+$ AND 3100 


\section{Results}

D

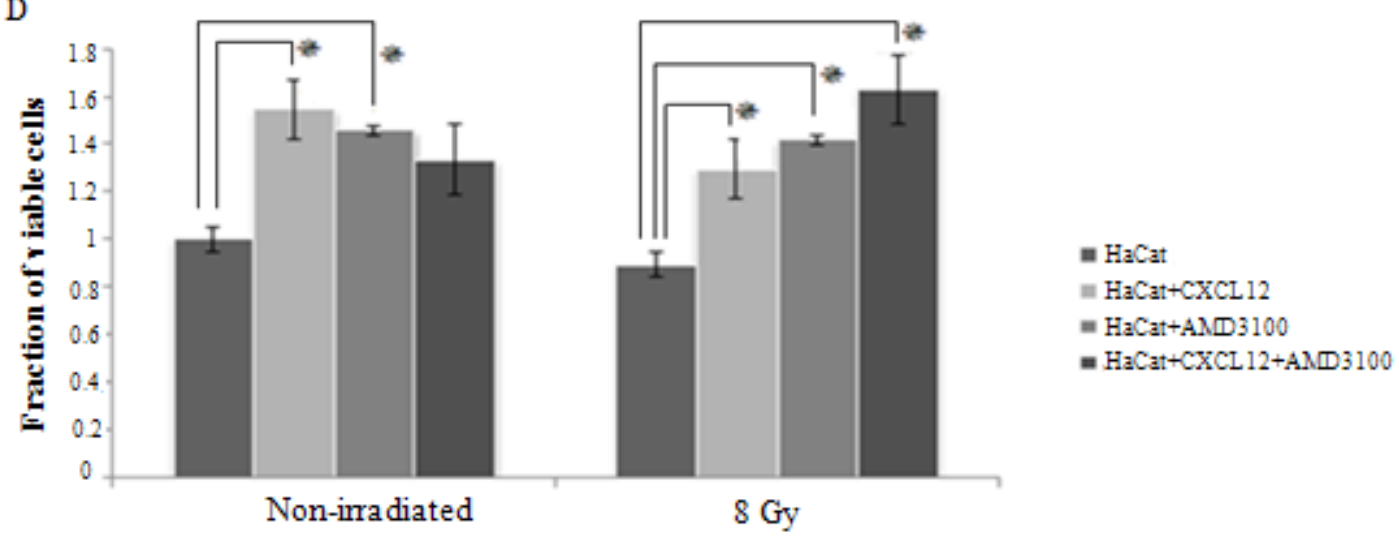

E

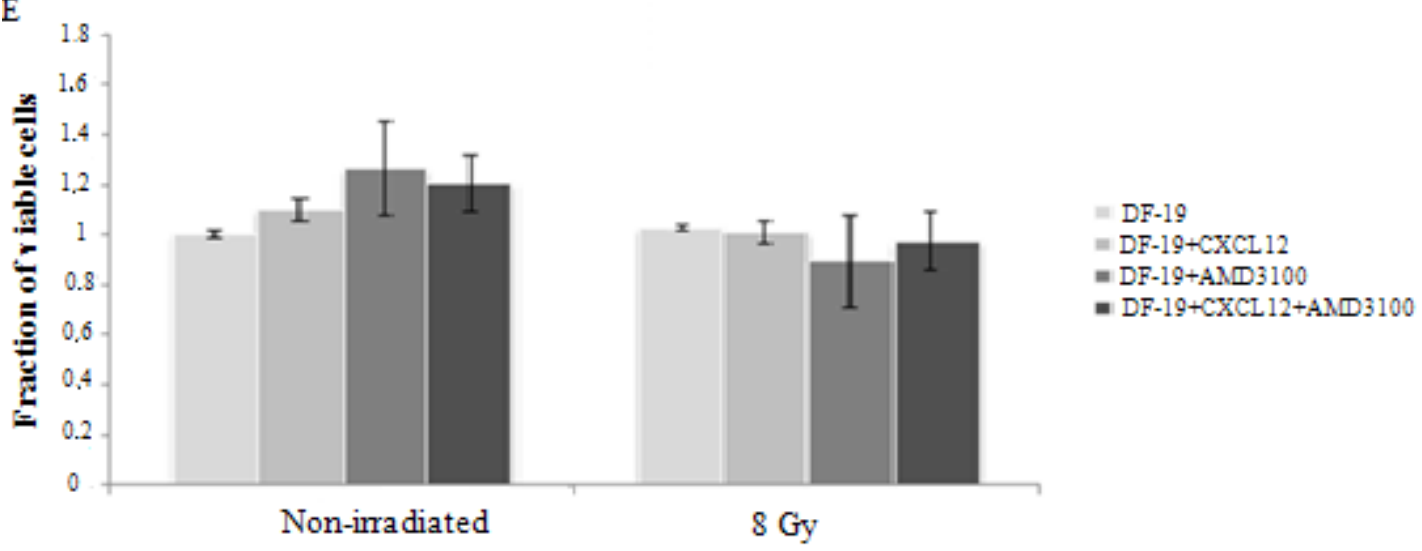

Figure 3.18: Mean fraction of viable cells of non-irradiated and 8 Gy irradiated cells. The cells were additionally pre-treated with either $100 \mathrm{ng} / \mathrm{ml} \mathrm{CXCL12,} \mathrm{or} 5 \mu \mathrm{g} / \mathrm{ml}$ AMD3100 or both compounds. A) ZMK-1 cells were radiosensitive and the metabolic activity of cells following treatment with CXCL12, AMD3100 or both compounds was not changed. B) FaDu cells were also radiosensitive and treatment with CXCL12, AMD3100 or both compounds was not changed the metabolic activity of cells. C) Irradiation reduced also viability of GR-145 cells. Cells showed unchanged metabolic activity following treatment with CXCL12, AMD3100 or both compounds. D) The metabolic activity of HaCat cells was not reduced by irradiation. However, treatment with CXCL12, AMD3100 or both compounds showed an increased cell metabolic activity compared to the untreated control cells. E) Irradiation and treatment with CXCL12, AMD3100 or both compounds have no effect of metabolic activity of DF-19 cells. Student's t-test was used in all experiments: $*=p<0.05$. The results were compared to nontreated cells from each cell line. Data are obtained as mean differences \pm standard deviation. Results are taken from two independent experiments, performed in triplicate.

\subsubsection{The role of CXCL12 and CXCR4 in the migration of HNSCC and control cells}

\subsubsection{Preliminary experiments}

To determine the best concentration of CXCL12 for the lower chamber in the migration assay, three CXCL12 concentrations were tested. The CXCL12 concentrations in the lower 


\section{Results}

chamber were 25, 50 and $100 \mathrm{ng}$ per ml, respectively. After incubation, the migrated cells were stained, quantified, and the results compared to controls without addition of CXCL12.

We observed a significant CXCL12-related stimulation of migration for ZMK-1 cells with concentrations of $25 \mathrm{ng}$ and $100 \mathrm{ng}$ per $\mathrm{ml}$ with $160 \%$ and $180 \%$ increase of cell migration compared to controls (Figure 3.19). For the main migration assay experiments, the $100 \mathrm{ng} / \mathrm{ml}$ CXCL12 concentration was chosen.

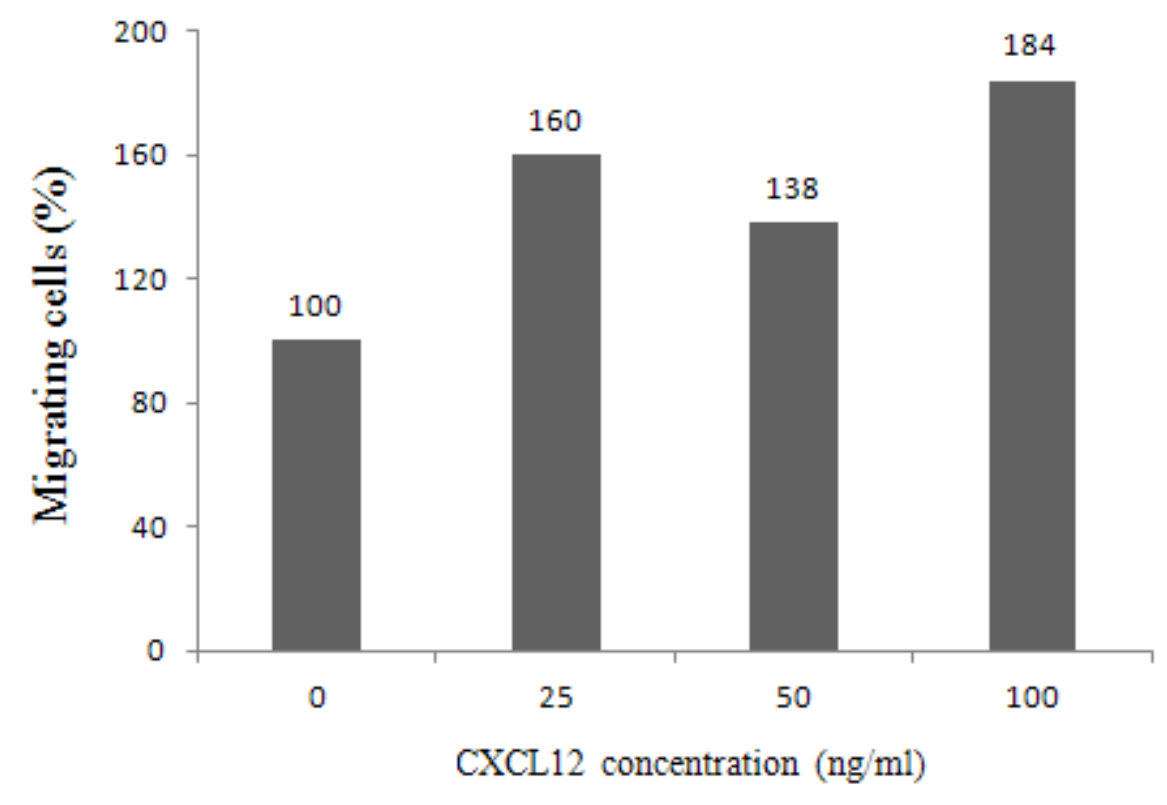

Figure 3.19: Concentration-dependent migration of ZMK-1 cells along a CXCL12 gradient. The highest percentage of migrating ZMK-1 cells compared to the control with $0 \mathrm{ng} / \mathrm{ml}$ CXCL12 was seen at a concentration of $100 \mathrm{ng} / \mathrm{ml}$. The experiment was performed one time.

In the next step, to determine the best concentration of AMD3100, two preliminary tests were performed. First, the cells were incubated with AMD3100 at different concentrations. They were then pipetted into the upper chambers, while $100 \mathrm{ng} / \mathrm{ml} \mathrm{CXCL12}$ was added to all lower chambers except for control chamber (Figure 3.20-A). After incubation, the migrated cells were stained, numerated, and the results compared with control cells.

Figure 3.20-A shows that after AMD3100 treatment, the migratory capacity of ZMK-1 cells was reduced in a concentration-dependent manner up to $25 \mu \mathrm{g} / \mathrm{ml}$ AMD3100. The inhibition rate with AMD3100 at 1, 5, 12.5 and $25 \mu \mathrm{g} / \mathrm{ml}$ was $89 \%, 64 \%, 58 \%$, and 58\%, respectively. However, at the high concentration of AMD3100 $(50 \mu \mathrm{g} / \mathrm{ml})$, the inhibitory effect of 


\section{Results}

AMD3100 on the migratory response of non-irradiated cells was partially abolished (Figure 3.20-A).

A

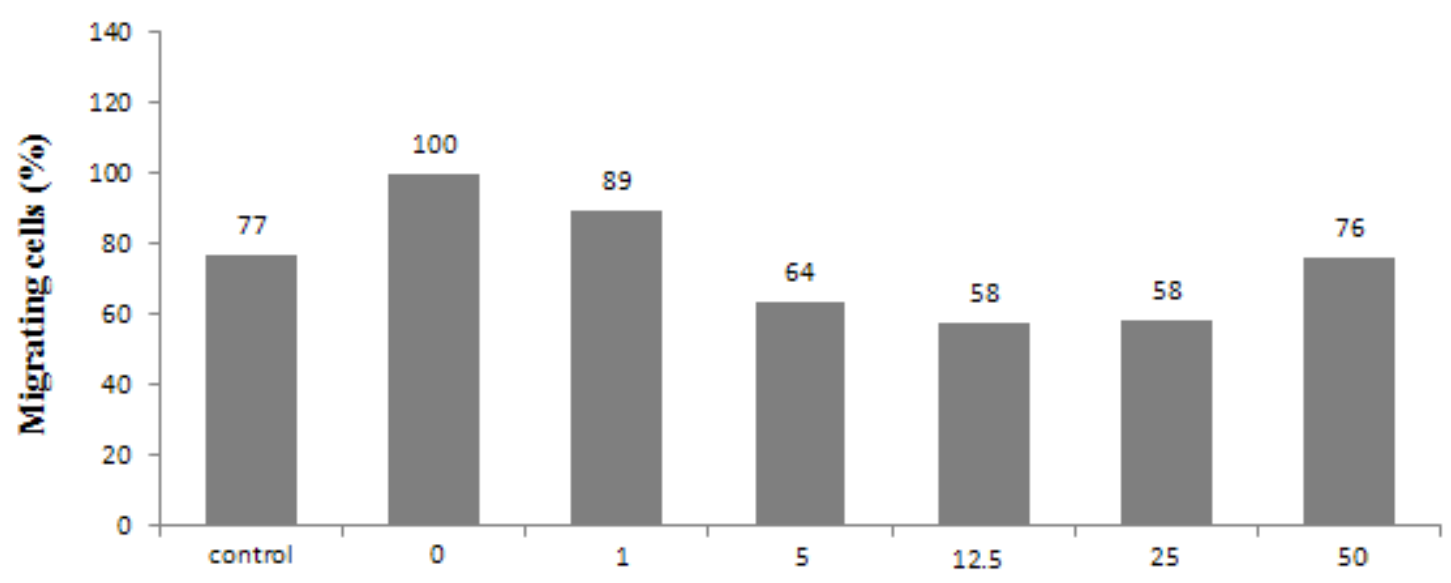

AMD3100 concentration $(\mu \mathrm{g} / \mathrm{ml})$

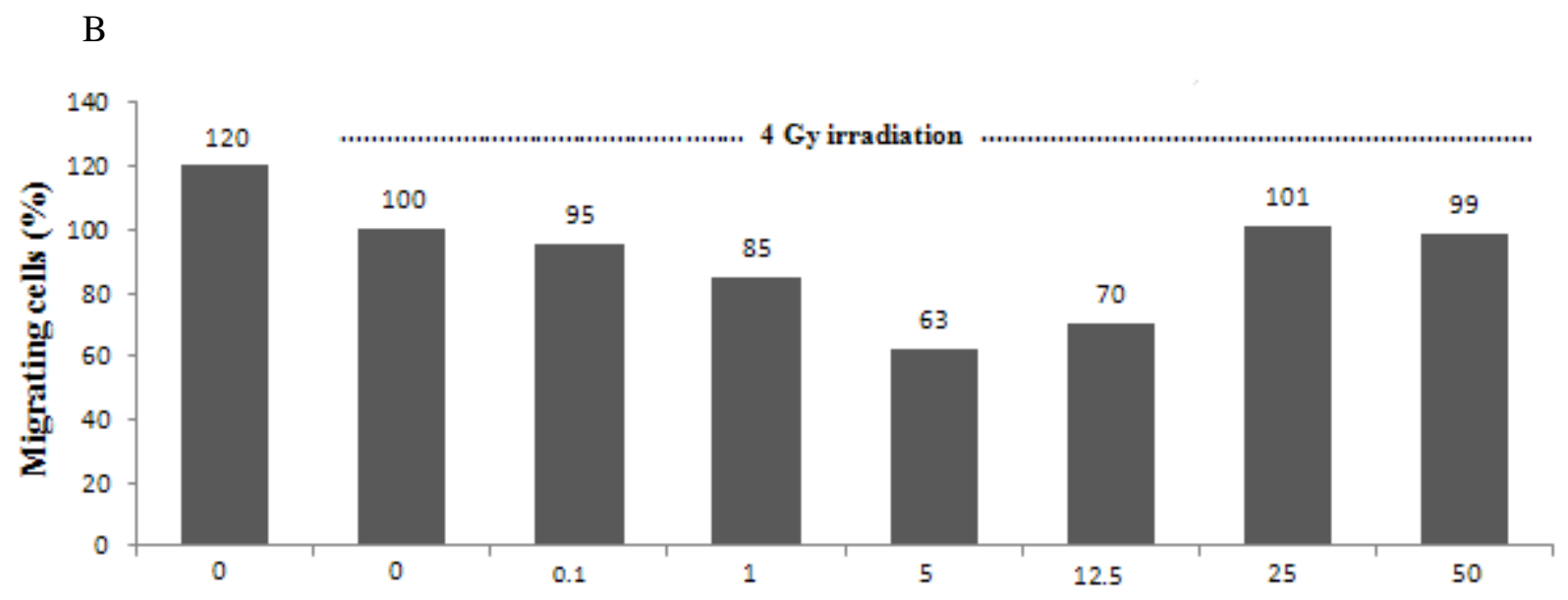

AMD3100 concentration $(\mu \mathrm{g} / \mathrm{ml})$

Figure 3.20: Concentration-dependent effects of AMD3100 on cell migration. Percentage of migrated ZMK-1 cells compared to a control with $100 \mathrm{ng} / \mathrm{ml}$ CXCL12 and 4 Gy-irradiated cells. A) Inhibitory effect on migration with different concentrations of AMD3100 in non-irradiated ZMK-1 cells. CXCL12 $(100 \mathrm{ng} / \mathrm{ml})$ was added to all lower chambers except for control chamber. The migration of ZMK-1 cells was reduced in a concentration-dependent manner up to $25 \mu \mathrm{g} / \mathrm{ml}$ AMD3100. B) Inhibitory effect on migration with different concentrations of AMD3100 in 4 Gy-irradiated ZMK-1 cells. CXC12 $(100 \mathrm{ng} / \mathrm{ml})$ was added to all lower chambers. The migration of irradiated ZMK-1 cells was reduced in a dose-dependent manner up to $5 \mu \mathrm{g} / \mathrm{ml}$. These experiments were performed one time. 


\section{Results}

To analyse the inhibitory effect of different concentrations of AMD3100 on irradiated cells, ZMK-1 cells were incubated with different concentrations of AMD3100, then the cells were irradiated at 4 Gy. After seeding, the cells were incubated. Migrated cells were stained, the number of migrated cells was determined and the results were compared with control cells irradiated at $4 \mathrm{~Gy}$, which had been exposed to $100 \mathrm{ng} / \mathrm{ml} \mathrm{CXCL12} \mathrm{but} \mathrm{not} \mathrm{treated} \mathrm{with}$ AMD3100. Figure 3.20-B shows that after AMD3100 treatment, the chemotactic activity of irradiated ZMK-1 cells was reduced in a concentration-dependent manner up to $5 \mu \mathrm{g} / \mathrm{ml}$. However, the inhibitory effect of AMD3100 on the migratory response of irradiated cells decreased at higher concentrations of AMD3100 (25 and $50 \mu \mathrm{g} / \mathrm{ml})$. For the main experiments, a concentration of $5 \mu \mathrm{g} / \mathrm{ml}$ of AMD3100 was used.

\subsubsection{Migratory response of HNSCC and control cells with different level of} CXCL12 and CXCR4 expression

The CXCR4-positive cell lines, $\mathrm{ZMK}-1$ and $\mathrm{FaDu}$, migrated uniformly in response to CXCL12 with an optimal response at $100 \mathrm{ng} / \mathrm{ml}$. For these cells, the CXCL12-mediated migration could be abolished by pre-treatment with the CXCR4-antagonist AMD3100. As expected, CXCL12 had no significant effect on the migration activity of the CXCR4-negative GR-145 and HaCat cell lines. The data are summarized in Figure $3.21 \mathrm{~A}-\mathrm{E}$ and a representative picture of $\mathrm{FaDu}$ cells that migrated across the transwell membrane to the other side of the filter is shown in Figure 3.22 A-C.

Pre-treating the CXCR4-positive cell lines in upper chamber with AMD3100 resulted in a significant decrease in relative migration. As shown in Figure 3.21-A and B in ZMK-1 and FaDu cell lines, respectively, AMD3100 effectively blocked CXCL12-induced migratory response in a dose-dependent manner.

Non-irradiated and irradiated cells exhibited comparable migration patterns with a decrease at higher radiation doses (Figure 3.21 A-D), the radiation effect being less pronounced than the effect of CXCL12 and AMD3100. DF-19 cells, which are CXCR4-negative and express and secrete large quantities of CXCL12 served as controls. The results showed no change in their migratory activities towards CXCL12, and reduced migration ability was found after irradiation at $4 \mathrm{~Gy}$ (Figure 3.21 E). 


\section{Results}

A
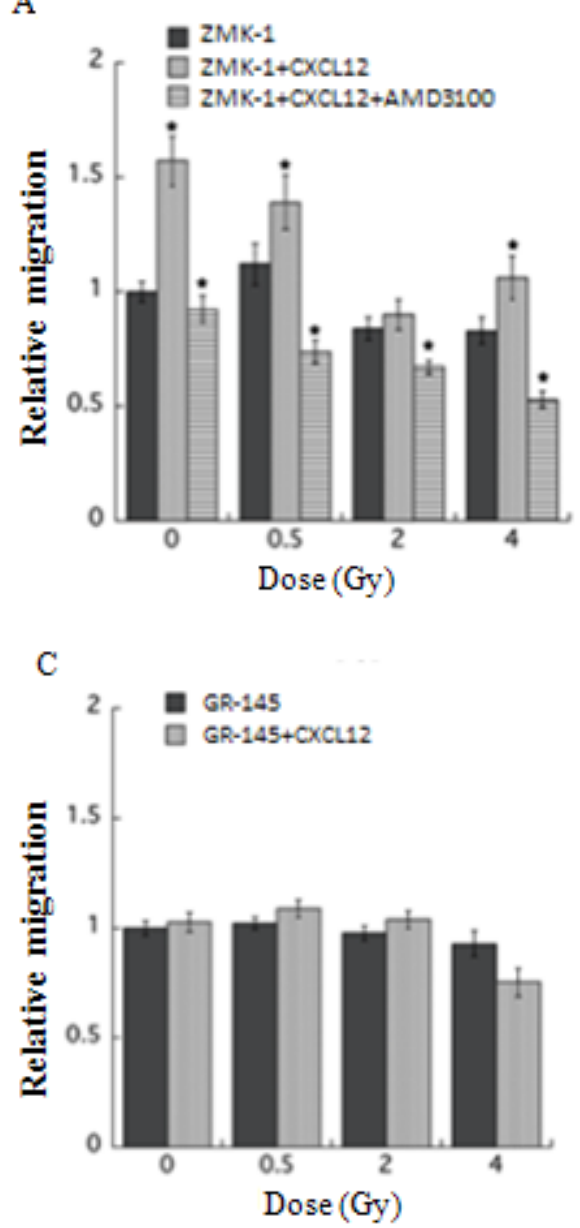
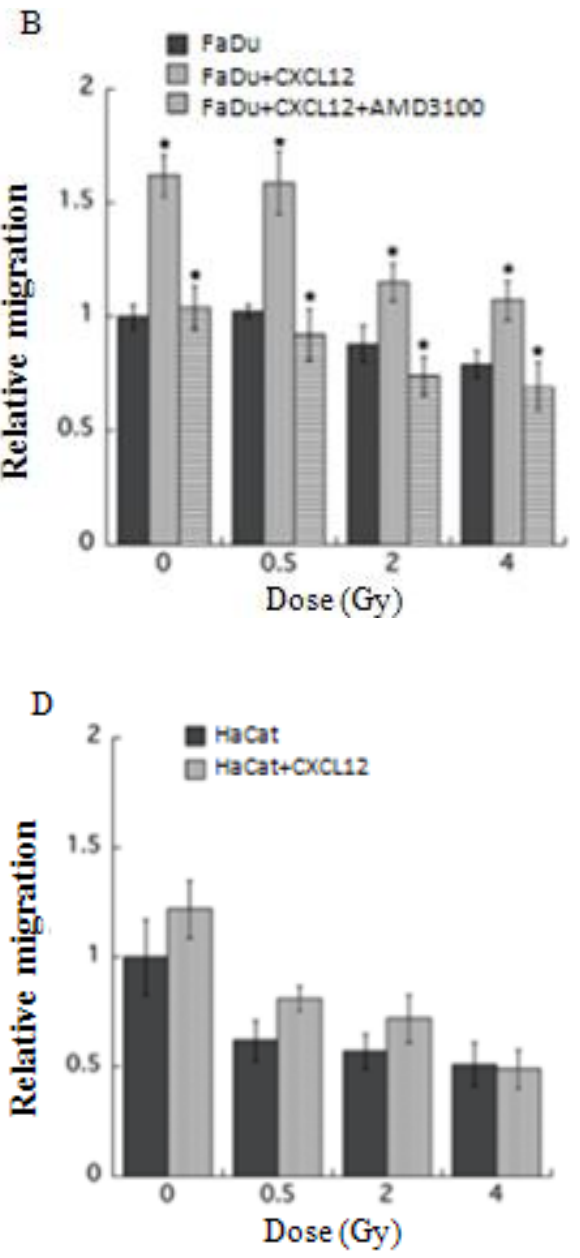

$\mathrm{E}$

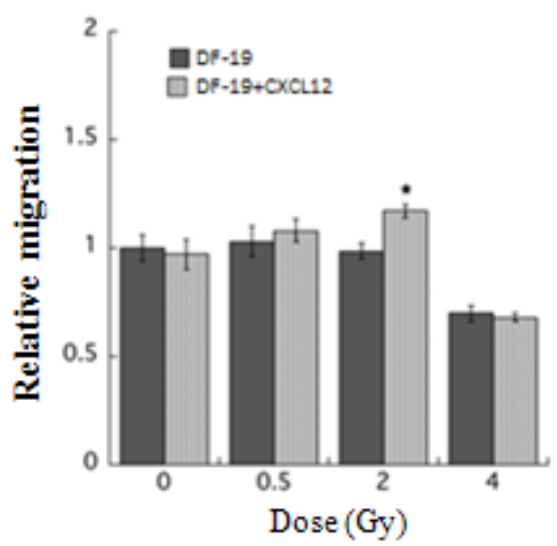

Figure 3.21: Effect of irradiation, CXCL12 and AMD3100 on the migration of three HNSCC tumour and two control cell lines. CXCL12 was present in the lower well and migration of cells was induced by $100 \mathrm{ng} / \mathrm{ml} \mathrm{CXCL12}$. The migration assay showed that the CXCR4-positive cell lines, FaDu (A) and ZMK-1 (B) migrated to CXL12 through the membrane in a dose-dependent manner. No CXCL12-induced migration enhancement was observed for GR-145 and HaCat, which are CXCR4negative cell lines (C, D). After combined CXCL12+AMD3100 treatment, the CXCL12-mediated migration of ZMK-1 and FaDu cells was significantly inhibited in a radiation dose-dependent manner at concentration of $5 \mu \mathrm{g} / \mathrm{ml}$ AMD3100. Student's t-test was used for all experiments: $* \mathrm{p}<0.05$. 


\section{Results}
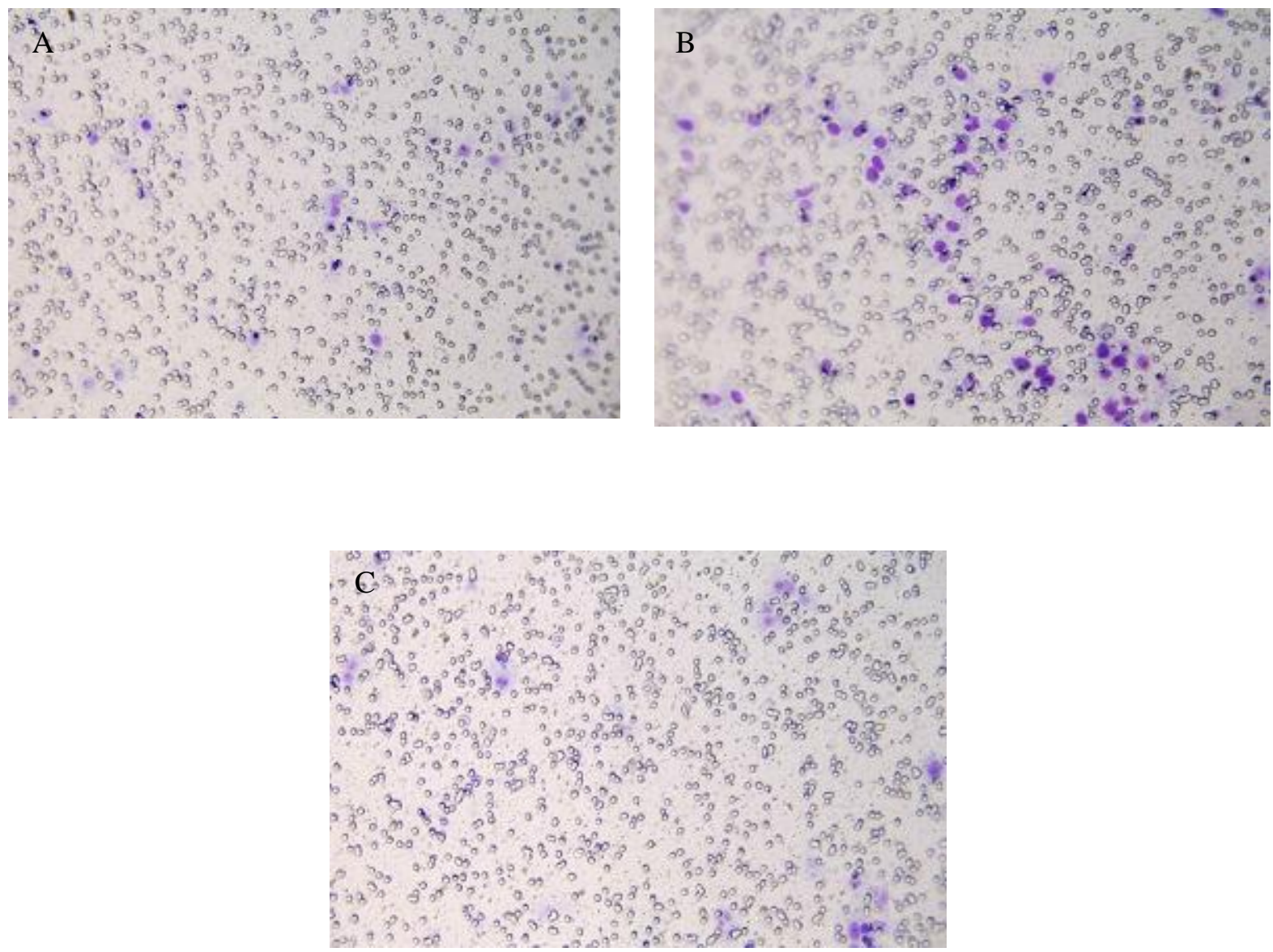

Figure 3.21: Representative membranes of FaDu migrated cells; the blue-stained cells are those cells which migrated through the upper surface to the lower surface of the membrane. The photographs

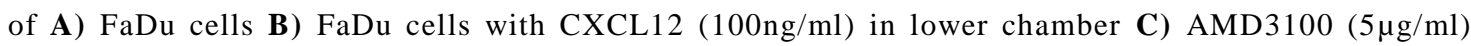
treated FaDu cells with CXCL12 in lower chamber. (20x magnification) 


\section{Discussion}

\section{Discussion}

\subsection{Summary of results}

Besides tobacco and alcohol consumption being primary risk factors for the development of head and neck squamous cell carcinoma (HNSCC), infection with human papillomavirus (HPV) is also etiologically associated with a subgroup of cancers in head and neck regions (Gillison et al. 2000, Argiris et al. 2008). In the present retrospective study, the prevalence of HPV DNA was screened in tissue samples that had been taken from patients with HNSCC before therapy was started. Nested-PCR was used as a direct screening method to detect HPV DNA in 233 HNSCC pre-treatment formalin-fixed paraffin embedded (FFPE)-biopsies. Even though FFPE samples were comparably old, we were able to detect HPV DNA in 44 of the 233 samples (19\%). HPV-16, as a known dominant participant in HPV-positive HNSCC patients, was found in $95 \%$ of all HPV-positive samples.

HPV-positive head and neck cancers are characterised by $16^{\mathrm{INK} 4 \mathrm{~A}}$ overexpression, which is a consequence of retinoblastoma protein $(\mathrm{pRb})$ inhibition by $\mathrm{E} 7$, one of the HPV oncogenes ( $\mathrm{Li}$ et al. 1994). p16 ${ }^{\mathrm{INK} 4 \mathrm{~A}}$ expression was detected by immunohistochemistry (IHC) staining in 102 of the 233 samples in this study (44\%).

The correlation between $\mathrm{p} 16^{\mathrm{INK} 4 \mathrm{~A}}$ expression and HPV DNA in tumour cells was highly significant $(\mathrm{p}<0.01) ; 41$ of the $42(98 \%)$ samples positive for HPV-16 also showed p16 ${ }^{\text {INK4A }}$ immunoreactivity. Because of the difficulties in detecting HPV DNA in old FFPE-biopsies and in view of the extremely significant correlation between HPV-positivity and p16 ${ }^{\text {INK4A }}$ overexpression, we used $\mathrm{p} 16^{\mathrm{INK} 4 \mathrm{~A}}$-positivity for further analysis. The clinicopathological analyses showed no statistically significant difference between patients with $\mathrm{p} 16^{\mathrm{INK} 4 \mathrm{~A}}$ expression and those with no expression. However, positive $\mathrm{p} 16^{\mathrm{INK} 4 \mathrm{~A}}$ expression was correlated with better overall survival (OS) of patients $(\mathrm{p}=0.022)$.

Treatment of HNSCC is usually performed using surgery, radiotherapy (RT), and chemotherapy (CT) (Sayed et al. 2011). The combination of radiation and CT may cause acute organ and/or hematotoxicity. In terms of response to therapy, this treatment-related high-grade acute organ toxicity (HGAOT) plays an important role as positive prognostic factor for locally advanced, inoperable HNSCC patients treated with primary (Wolff et al. 2010a) or adjuvant (Wolff et al. 2011b) radio(chemo)therapy $\mathrm{R}(\mathrm{C}) \mathrm{T}$. In the present work, we 


\section{Discussion}

studied the impact of the combination of HGAOT as a potent prognostic marker in HNSCC and $\mathrm{p} 16^{\mathrm{INK} 4 \mathrm{~A}}$ expression as a known surrogate marker for HPV-positive HNSCC on the survival of patients. We were able to demonstrate that both parameters, $\mathrm{p} 16^{\mathrm{INK} 4 \mathrm{~A}}$ expression and the occurrence of HGAOT, are independent positive prognostic factors for the survival of patients with HNSCC treated with primary $\mathrm{R}(\mathrm{C}) \mathrm{T}$.

HNSCC is characterised by a high rate of early recurrence, the development of secondary primary cancers (Azad et al. 2012), and a high mortality rate. The CXCL12/CXCR4 axis has been suggested to play an important role in cancer metastasis (Crump et al. 1997, Kang et al. 2005, Liang et al. 2010). In the present study we analysed the expression and prognostic significance of CXCL12 and its receptor CXCR4 in our cohort of 233 HNSCC patients. We observed that the expression of CXCL12 is directly correlated with tumour localisation $(\mathrm{p}<0.001)$ and the N-status $(\mathrm{p}=0.025)$ of the patients. However, patients with CXCL12 expression had a significantly better chance of survival $(\mathrm{p}=0.036)$. On the other hand, CXCR4 expression had a negative prognostic impact on distant metastasis-free survival (DMFS) $(\mathrm{p}=0.034)$. These results suggest that CXCR4 expression in HNSCC could be used as a biomarker for aggressive HNSCC tumours with high metastatic tendency.

While the basic research and in vitro studies are the first step towards the elucidation of in vivo physiological processes, a one-to-one agreement between in vitro and in vivo results is not usually possible. In this study the importance of the CXCL12/CXCR4 axis in the migration of HNSCC cells was analysed, while taking into account the effects of irradiation. The cells were characterised for their viability, colony-forming ability, radiosensitivity and the degree of CXCL12 and CXCR4 expression. Through these in vitro analyses, we demonstrated a potentially important role of the CXCL12/CXCR4 axis in the promotion of migration of CXCR4-positive HNSCC cell lines even after irradiation, while AMD3100 effectively blocked the CXCL12-induced migratory response in a dose-dependent manner in CXCR4-expressing cell lines (ZMK-1 and FaDu). These observations confirm a possible important role of CXCR4 in the process of metastasis, as do the results of our in vivo analysis. 


\section{Discussion}

4.2 The crucial role of $\mathrm{HPV} / \mathrm{P} 16^{\mathrm{INK} 4 \mathrm{~A}}$ in prognosis and survival of HNSCC patients

\subsubsection{HPV detection}

Analyses of molecular changes in HNSCC development have identified a new prognostic indicator, namely, HPV infection. The presence of HPV, particularly HPV-16, is of significant clinical importance, as these HPV-positive HNSCC tumours are associated with better clinical outcomes than their HPV-negative counterparts (Ragin and Taioli 2007, Fakhry et al. 2008). However, the reports on the incidence of HPV in oral carcinogenesis are contradictory with infection percentages ranging from $8 \%$ to $50 \%$. This may depend on the different sensitivity of the applied methods, different sampling methods, the tissue preservation status, geographical differences or anatomic sites of infection (Miller and White 1996, Sand et al. 2000). Moreover, the time period of analyses as additional factor should be considered. In this study, we found a significant increase of $\mathrm{p} 16^{\mathrm{INK} 4 \mathrm{~A}}$ expression (the surrogate marker of HPV infection) from 1992 to 2011 ( $\mathrm{p}=0.00091$ ). Chaturvedi et al. in their analyses in 271 oropharyngeal squamous cell carcinoma (OPSCC) patients from 1984 to 2004 also found a significant increase of HPV prevalence over calendar time regardless of the HPV detection assay (Chaturvedi et al. 2011).

The choice of a suitably sensitive method for detecting HPV DNA has become increasingly complex. In situ hybridisation, for example, is only able to detect HPV when there are more than 10 copies of viral DNA per cell and this method may lack the sensitivity to detect HPV DNA in oral squamous cell carcinoma (OSCC) tumours with low copy number of HPV (Miller et al. 1994). Southern blot, dot blot or reverse blot hybridisation, on the other hand, can detect even one copy of viral DNA per cell. PCR, a highly sensitive method, is able to detect even lower amounts than one copy of viral DNA per cell (Miller and White 1996). A meta-analysis by Termine et al. reported that the average HPV prevalence in OSCC published between 1988 and 2007 detected by in situ hybridisation was 29.8\%, while PCR analysis resulted in a prevalence of $39.9 \%$ (Termine 2008). In the present study, we used a highly sensitive PCR-based analysis (nested-PCR) of viral DNA to detect HPV DNA. But even with this highly sensitive method (de Roda Husman et al. 1995, Ludyga et al. 2012) we only detected HPV DNA in 44 (19\%) of the 233 FFPE-biopsies. Amplification in the nested-PCR was performed by two sets of primers with the combined sensitivity of the first and second step of the assay theoretically reaching one viral copy per $10^{6}$ to $10^{7}$ cells (de Roda Husman et 


\section{Discussion}

al. 1995). This reduced the risk of missing any HPV-positive cases in our series. In the first step of nested-PCR using the PGMY09/11 primer set, we found no positive fragments, while in the second step using GP5+/6+ primers we did find positive ones. This result indicates that there are low numbers of intact copies of HPV DNA in our samples. Since the amplification efficiency of a genomic fragment is inversely related to the length of the region targeted by PCR, and additionally, in many archival samples, the amount of intact HPV genome is very small, the detection of the HPV DNA was impossible in some samples.

Another important factor that influences detection of HPV DNA is tissue preservation. According to a meta-analysis by Miller and White, HPV DNA can be detected more often in fresh or frozen samples (51.6\%) than in paraffin-embedded tissues (21.1\%) (Miller and White 1996). In this retrospective study we used FFPE blocks, which is a common way to preserve specimens for a longer time period. In spite of the many advantages of using formalin fixation to preserve tissues, it is known that formalin decreases the efficiency of PCR due to protein cross-linking (Karlsen et al. 1994, Williams et al. 1999). In addition, the degradation of nucleic acids increases during storage, in particular due to a time-dependent decrease of $\mathrm{pH}$ (Gilbert et al. 2007). In addition, Ludyga et al. in their study of old FFPE tissue reported that fixation and storage conditions may make FFPE material unsuitable for further analysis because of the strong fragmentation of DNA (Specht et al. 2001, Ludyga et al. 2012).

In 2005, Kreimer et al. published a meta-analysis of 60 eligible studies using PCR detection to study 5046 cases of squamous cell carcinoma (SCC), 2642 oral cancers, 969 oropharyngeal cancers and 1435 laryngeal cancers. They concluded that HPV-16 was the most common subtype in all types of HPV-positive cancers; $86.7 \%$ of oropharyngeal, $68.2 \%$ of oral and $69.2 \%$ of laryngeal cancers (Kreimer et al. 2005). Rietbergen et al. also reported that after DNA and RNA analysis of 24 HPV-positive frozen oropharyngeal samples, HPV-16 was identified in $91.7 \%$ of the HPV-positive samples (Rietbergen et al. 2013). The present study came to results similar to those of the other studies. The sequencing analysis detected HPV-16 as the clearly dominant (95\%) subtype in the $44 \mathrm{HPV}$-positive HNSCC samples.

In HPV-positive HNSCC, the production of the oncoprotein E7 induces the degradation of $\mathrm{pRb}$, which in turn leads to p16 ${ }^{\mathrm{INK} 4 \mathrm{~A}}$ overexpression (Wiest et al. 2002, Marur et al. 2010). Furthermore, immunohistochemistry (IHC) positivity for $\mathrm{p} 16^{\mathrm{INK} 4 \mathrm{~A}}$ expression is considered to be one of the major molecular hallmarks of HPV-positive HNSCC (Hafkamp et al. 2008, Dayyani et al. 2010, Langendijk and Psyrri 2010, Marur et al. 2010). Many studies used cut- 


\section{Discussion}

off values to define positive $\mathrm{p} 16^{\mathrm{INK} 4 \mathrm{~A}}$ staining, but undisputed criteria do not exist (Deng et al. 2014). For instance, in their study on FFPE tumour samples from HNSCC patients, Deng et al. evaluated the expression of $\mathrm{p} 16^{\mathrm{INK} 4 \mathrm{~A}}$ using a score of zero to four based on the percentage of p16 ${ }^{\mathrm{INK} 4 \mathrm{~A}}$-positive cells (Deng et al. 2014). In a study by Reimers et al., a strong nuclear or cytoplasmic staining was considered positive for $\mathrm{p} 16^{\mathrm{INK} 4 \mathrm{~A}}$ expression (Reimers et al. 2007). In this study, we assigned a weighted score to each case by multiplying the percentage of p $16^{\mathrm{INK} 4 \mathrm{~A}}$ positive cells $(0-100 \%)$ by the staining intensity $(0-3)$ and used the score values as a continuous variable in the Cox regression model. We detected a positive $\mathrm{p} 16^{\mathrm{INK} 4 \mathrm{~A}}$ expression in $102(44 \%)$ of the samples. We also found 30 samples with strong and diffuse p16 ${ }^{\text {INK4A }}$ expression with undetectable HPV DNA. These results must be interpreted within the context of the study's limitations. The source of high levels of $\mathrm{p} 16^{\mathrm{INK} 4 \mathrm{~A}}$ expression in some HPVnegative tumours has not been clarified yet; mutations leading to $\mathrm{p} 16^{\mathrm{INK} 4 \mathrm{~A}}$ overexpression, other mechanisms of inactivation of retinoblastoma pathways or other viral infections are plausible alternatives. In this study, HPV DNA was amplified with the L1 consensus HPV PGMY09/11 and GP5+/6+ primer sets. The probability of a false negative HPV-L1-ORF due to the loss or disruption during integration of the HPV genome is another explanation for HPV DNA-negative, but p16 ${ }^{\mathrm{INK} 4 \mathrm{~A}}$ expression-positive cells (Duray et al. 2011). However, such a discrepancy between positivity of HPV and p16 ${ }^{\mathrm{INK} 4 \mathrm{~A}}$ expression is not uncommon (Blitzer et al. 2014). In this study, eighteen of the thirty $\mathrm{p} 16^{\mathrm{INK} 4 \mathrm{~A}}$ expression-positive/HPV DNA-negative samples $(60 \%)$ revealed either poor quality or small quantity $(<20 \mathrm{ng} / \mu \mathrm{l})$ of extracted DNA, which did not reach the threshold of 1.8 (OD 260/280) as a measure of DNA quality.

On the other hand, 95\% (42 of 44) of HPV-positive HNSCC tumours were found to overexpress $\mathrm{p} 16^{\mathrm{INK} 4 \mathrm{~A}}$. Of this set, only one high-risk HPV-positive tumour was negative for p16 ${ }^{\text {INK4A }}$ expression. We also had one sample that was infected with low-risk HPV-6 and did not show $16^{\mathrm{INK} 4 \mathrm{~A}}$ expression. It could be argued that viral oncoprotein of low-risk HPV such as HPV-6 have no effect on $16^{\text {INK4A }}$ expression because the affinity of HPV-6 E7 protein for cellular $\mathrm{pRb}$ is 10-fold lower than that of E7 oncoprotein of HPV-16 as high-risk HPV subtype for $\mathrm{pRb}$ (Gage et al. 1990).

Because of the low number of patients, in whom HPV DNA was detected and the significant correlation between HPV positivity and $\mathrm{p} 16^{\mathrm{INK} 4 \mathrm{~A}}$ overexpression, we used $\mathrm{p} 16^{\mathrm{INK} 4 \mathrm{~A}}$ positivity for the further statistical analysis. This seems acceptable because the p16 ${ }^{\mathrm{INK} 4 \mathrm{~A}}$ expression 


\section{Discussion}

status kept its prognostic significance even in the absence of concomitant HPV DNA detection in several studies (Weinberger et al. 2006, Lassen et al. 2009, Shah et al. 2009, Harris et al. 2011). Kawakami et al. in their study on Japanese patients with OPSCC even reported that the survival of patients with HPV DNA-positive/p16 ${ }^{\mathrm{INK} 4 \mathrm{~A}}$-negative tumours was not as high as that of those with HPV DNA-positive/p16 ${ }^{\text {INK4A }}$-positive tumours (Kawakami et al. 2013). In this study, we found a significant correlation between the p16 ${ }^{\text {INK4A }}$-positive tumours and OS, which indicated that the probability of survival increases with increasing percentage of $\mathrm{p} 16^{\mathrm{INK} 4 \mathrm{~A}}$-positive cells.

\subsection{2 $\mathrm{HPV} / \mathrm{p} 16^{\mathrm{INK} 4 \mathrm{~A}}$-associated HNSCC and prognosis of patients}

In HPV-associated malignancies, particularly in OSCC and OPSCC, most studies revealed a more favourable prognosis in terms of recurrence-free survival and OS in patients with a HPV-positive tumour compared to those whose tumours were HPV-negative (Lindel et al. 2001, Li et al. 2003, Lindquist et al. 2007). In agreement with three previous studies, Young and colleagues in their study of 131 pre-treatment FFPE OPSCC tissue samples showed that p16 ${ }^{\text {INK4A }}$-positive patients had a significantly improved failure-free survival (FFS) and OS compared to $\mathrm{p} 16^{\mathrm{INK} 4 \mathrm{~A}}$-negative patients (Young et al. 2011). Recent analysis of clinical data revealed that using $\mathrm{p} 16^{\mathrm{INK} 4 \mathrm{~A}}$ expression as a surrogate biomarker in HPV-positive HNSCC patients has a significant impact on treatment response and survival in HNSCC patients and also has a stronger prognostic value than the HPV status (Weinberger et al. 2006, Zhao et al. 2012, Dok et al. 2014). In another study, Lassen et al. indicated that HNSCC patients with p16 ${ }^{\mathrm{INK} 4 \mathrm{~A}}$ expression showed a better response to RT and also an improved locoregional control rate than patients without $\mathrm{p} 16^{\mathrm{INK} 4 \mathrm{~A}}$ expression (Lassen et al. 2009). We also found a close association between $\mathrm{p} 16^{\mathrm{INK} 4 \mathrm{~A}}$ expression in HNSCC tumours and better OS $(\mathrm{p}=0.0022)$. However, the improvement of local recurrence-free survival (LRFS) in patients with $\mathrm{p} 16^{\mathrm{INK} 4 \mathrm{~A}}$ expression was not statistically significant $(\mathrm{p}=0.069$, Figure 3.10). Because patients with oropharyngeal tumours benefit most from $\mathrm{p} 16^{\mathrm{INK} 4 \mathrm{~A}}$-positivity and have better three-year recurrence-free survival (Deng et al. 2014), the combined analysis of tumours located in the oropharynx, hypopharynx, oral cavity, and larynx may explain the lack of a significant correlation of $\mathrm{p} 16^{\mathrm{INK} 4 \mathrm{~A}}$-positivity with LRFS in the present study.

The reason for the improved survival of HNSCC patients positive for $\mathrm{p} 16^{\mathrm{INK} 4 \mathrm{~A}}$ expression has not been definitely explained. Clinically it may be that the patients are younger at disease 


\section{Discussion}

onset, or have a lower exposure to established risk factors such as tobacco and alcohol consumption (Lassen et al. 2009). In addition, improved responsiveness to RT, enhanced immune surveillance and the absence of field cancerisation in the patients who tend to be nonsmokers, have been reported (Lindel et al. 2001, Mellin Dahlstrand et al. 2005, Fakhry and Gillison 2006). McGovern et al. also stated that they had not observed a field cancerisation effect in HPV-positive tumours, where HPV viral DNA integration is solely restricted to the neoplastic and dysplastic tissue (McGovern et al. 2010).

Radiation-induced DNA damage prompts apoptosis in tumour cells (Lima et al. 2012). A possible explanation for tumour radio-resistance may be a failure in DNA damage repair pathways, cell cycle checkpoints, as well as mechanisms of apoptosis ( $\mathrm{Xu}$ et al. 2008). Increased radiation sensitivity of $\mathrm{p} 16^{\mathrm{INK} 4 \mathrm{~A}}$-positive tumours, possibly caused by reduced ability of cells to the normal cellular response to DNA damage, compromised DNA repair capacity or an altered oxygenation status (Kessis et al. 1993, Kong et al. 2009, Rieckmann et al. 2013, Dok et al. 2014) may account for the greater survival rate of patients with $\mathrm{p} 16^{\mathrm{INK} 4 \mathrm{~A}}$ positive tumours. Recently, Kimple and colleagues observed an increased level of apoptosis and low levels of intact p53 after irradiation in HPV/ p16 ${ }^{\mathrm{INK} 4 \mathrm{~A}}$-positive HNSCC cells, which could be activated by RT (Kimple et al. 2013). They also verified that HPV-positive cells in head and neck cancer show increased radiosensitivity. Their results from in vitro and in vivo studies explained this effect with prolonged activation of markers of DNA damage, E6/E7mediated radiation-induced $\mathrm{G}_{2}$ arrest, and a strong apoptotic response and enhanced cell death (Kimple et al. 2013). However, existing data so far are questionable and at times contradictory (Bol and Gregoire 2014). It seems to be a complex interaction between basic mechanisms of radioresponse and the microenvironment of the tumour such as cells of the immune system (Bol and Gregoire 2014). In HPV-positive HNSCC tumour infiltration seems to play a significant role, leading to some studies suggesting that TR promotes immunogenic cell death led by T-cells in HPV-positive HNSCC (Kong et al. 2009, Bol and Gregoire 2014).

\subsubsection{Combined effect of $\mathrm{p} 16^{\mathrm{INK} 4 \mathrm{~A}}$ expression and the occurrence of HGAOT on patients' survival}

In a previous clinical study, HPV-positivity in HNSCC patients was associated with a superior response to RT and RCT and modality-independent survival benefits (Boscolo-Rizzo et al. 2013). Treatment selection in HPV-positive HNSCC is becoming a critical topic and 


\section{Discussion}

HPV-related HNSCC have already led to clinical studies that investigate de-intensified treatment schedules (Psyrri et al. 2014). Based on some studies, which consider that intensive RCT in HPV-positive patients may represent over-treatment (Forastiere 2008, Mannarini et al. 2009), and in view of the fact that HPV-positive patients are often younger and have a better prognosis (Kofler et al. 2014), the question of aggressive combined treatment, which is associated with high rates of acute or late toxicity of the therapy, has become an important issue (Boscolo-Rizzo et al. 2013).

Generally, HNSCC patients undergoing radiation therapy may suffer from a number of sideeffects, above all from organ toxicity. Nevertheless the severity of organ toxicity may vary between patients, as does the course and outcome of the disease. In this respect Bonner et al. showed that in patients with locally advanced HNSCC who were treated with RT and CT, acute rash and skin toxicity were correlated with a significantly better OS (Bonner et al. 2005). In another study on HNSCC patients, Wolff et al. suggested that normal tissue and tumour tissue might behave similarly with reference to treatment response (Wolff et al. 2010a, Wolff et al. 2011b). Their investigation on the association between HGAOT during definite primary and adjuvant radiation and chemotherapy and the treatment outcomes in patients with locally advanced HNSCC showed that occurrence of HGAOT during or after therapy was associated with better outcomes, i.e. a better five-year OS and locoregional control rate of patients (Wolff et al. 2010a, Wolff et al. 2011b). This association of HGAOT and improved OS for patients, suffering from HGAOT, is mentionable.

Much too little is known about the detailed molecular biological mechanisms and causes for the significant correlation between HGAOT and the OS improvement (Wolff et al. 2010a, Wolff et al. 2011b). This behavioural similarity between normal and tumour tissues with regard to treatment response might be explained by inter-individual differences in inherent, genetically determined sensitivity (Wolff et al. 2010a). An association between the appearance and maintenance of inflammatory mediator proteins that can cause acute organ toxicity, and an improved patient outcome has already been defined in the course of other studies (Galon et al. 2013) in contrast to other studies which showed that chronic inflammation promoted tumour progression (Trinchieri 2012). Moreover, the induction of a cytokine cascade in the acute reaction in normal and tumour tissues as a local factor might also be involved (Wolff et al. 2010a, Wolff et al. 2011b). The correlation between HGAOT and better treatment outcomes is not only limited to HNSCC patients. In breast cancer, Kuhnt et al. observed that patients with a pronounced acute reaction of normal tissue, e. g. - 


\section{Discussion}

erythema, dysphagia, or pneumonitis, and who were treated with post-mastectomy RT, showed a trend towards better local control rates (Kuhnt et al. 1998). In anal carcinoma, patients with HGAOT treated with primary radiation and chemotherapy also showed better OS (Wolff et al. 2010c). In another study in patients with locally advanced rectal cancer, a statistically significant association was reported between HGAOT during preoperative radiation and chemotherapy and a complete histopathological tumour regression after total mesorectal excision in multimodal treatment (Wolff et al. 2010b).

In the present study, we retrospectively investigated the correlation between $\mathrm{p} 16^{\mathrm{INK} 4 \mathrm{~A}}$ expression and the occurrence of HGAOT in patients, who were treated with definite $\mathrm{R}(\mathrm{C}) \mathrm{T}$. The univariate analyses showed an association between HGAOT and $\mathrm{p} 16^{\mathrm{INK} 4 \mathrm{~A}}$ expression ( $\mathrm{p}=0.011$, Figure 3.6-F). Patients with $\mathrm{p} 16^{\mathrm{INK} 4 \mathrm{~A}}$-positive tumours demonstrated significantly more HGAOT than patients with $\mathrm{p} 16^{\mathrm{INK} 4 \mathrm{~A}}$-negative tumours. Mucositis and dysphagia are the observable manifestations of acute organ toxicity as side-effects of the $\mathrm{R}(\mathrm{C}) \mathrm{T}$.

Since the present study confirmed the well-known association of $\mathrm{p} 16^{\mathrm{INK} 4 \mathrm{~A}}$-expressing tumours with an improved OS of patients (Weinberger et al. 2006, Lassen et al. 2009, Shah et al. 2009, Blitzer et al. 2014), and also the formerly described correlation of OS with occurrence of HGAOT in patients with HNSCC (Wolff et al. 2010a, Wolff et al. 2011b), we investigated the impact of a combination of these two factors on the survival of patients. However, since multivariate analysis revealed no significant interaction between $\mathrm{p} 16^{\mathrm{INK} 4 \mathrm{~A}}$-expressing tumours and the occurrence of HGAOT, which could suggest additive effects of these two parameters, they were identified as independent prognostic factors. Such combined impact of two parameters is reflected by the five-year OS rates of $47 \%$, for patients with $16^{\mathrm{INK} 4 \mathrm{~A}}$ expression and HGAOT, compared with $42 \%, 20 \%$, and $10 \%$ for patients with HGAOT only, patients with $\mathrm{p} 16^{\mathrm{INK} 4 \mathrm{~A}}$ expression only, and patients without either $\mathrm{p} 16^{\mathrm{INK} 4 \mathrm{~A}}$ expression or HGAOT, respectively (Figure 3.10). Interestingly, the dominant survival effect of $\mathrm{p} 16^{\mathrm{INK} 4 \mathrm{~A}}$ expression was more evident in patients without any or with only mild acute organ toxicity $\leq$ grade 2 CTC. Based on these results, we believe that the analysis of HGAOT of patients during therapy is valuable because it can predict the course of therapy in patients. 


\section{Discussion}

\subsection{Analysis of the prognostic roles of CXCL12 and CXCR4}

Technological advance and scientific research provided valuable information on the cellular and molecular mechanisms that underlie tumour progression and treatment response. The chemokine CXCL12 and its receptor CXCR4 play a role in several types of tumours and promote tumour progression, angiogenesis and metastasis (Popple et al. 2012). An association between CXCL12 expression and better treatment outcomes and improved OS has also been reported in carcinomas of the breast (Kang et al. 2005), the ovaries (Jiang et al. 2006), the oesophagus (Sasaki et al. 2008), the stomach (Ishigami et al. 2007), as well as gliomas (Salmaggi et al. 2005). In addition, increased expression of CXCR4, the main receptor of CXCL12, was reported to a have a prognostic value for patients with renal, colorectal, and breast carcinoma (D'Alterio et al. 2010, Hiller et al. 2011, Parker et al. 2012, Yopp et al. 2012). Since a high expression of CXCL12 and CXCR4 in various types of cancer predicts poor patient outcomes, the analysis of their expression levels may have an important prognostic value (Maréchal et al. 2009, Bennani-Baiti et al. 2010, Wu et al. 2010, Jung et al. 2011, Ramos et al. 2011, Wang et al. 2011, Popple et al. 2012, Zhang et al. 2013). In the present study, we investigated expression of CXCL12 and CXCR4 as novel prognostic factors for HNSCC patients treated with definite $\mathrm{R}(\mathrm{C}) \mathrm{T}$. The levels of the two proteins were independently related to clinicopathological characteristics and survival data of the patients. One significant advantage of this retrospective study was the long follow-up times of up to 217 months (median 83 months), which provided reliable survival data. Using IHC, we detected expression of CXCL12 in $41.6 \%$ and of CXCR4 in $66.1 \%$ of the 233 biopsies taken from HNSCC patients before the beginning of the treatment. In a similar analysis by Almofti et al., the expression of CXCL12 and CXCR4 in biopsy specimens from 61 patients with OSCC assessed by IHC was $11.4 \%$ and $57.3 \%$, respectively (Almofti et al. 2004). In another study by Ishikawa et al., expression of CXCR4 was detected by IHC in $30 \%$ of the 90 OSCC tissue samples (Ishikawa et al. 2006). Although we were unable to find a significant association between the expression of CXCR4 and any clinicopathological features, we did find a statistically significant correlation between the expression of CXCL12 and N-staging $(\mathrm{p}=0.025$, Table 3.2). Despite this association, we found that these patients had significantly better OS, which confirms the results of Clatot et al., who also found a significant association between the CXCL12 expression level and metastatic evolution and OS in a series of 71 OSCC patients (Clatot et al. 2011). Moreover, in a gene expression study conducted by these authors with a focus on the CXCL12/CXCR4 pathway (Clatot et al. 2014), the patient group 


\section{Discussion}

with the better prognosis showed higher expression levels of genes involved in the CXCL12 pathway. It should be noted that observations from experimental studies also support the clinical evidence of improved prognosis in patients with a high level of CXCL12 expression. Roy et al. in in vitro and in vivo studies on pancreatic cancer cell lines and tumour tissues also observed that autocrine CXCL12 expression reduced the growth and migration potential in vitro, and also reduced growth and metastasis rate of pancreatic ductal adenocarcinoma cells in vivo (Roy et al. 2014).

The superior OS of patients, whose tumours expressed CXCL12, may be explained by the experimental findings from other studies that described the suppression of tumour cell migration, reduced tumour growth potential, modified radio- and chemosensitivity, or an enhanced immune response (Williams et al. 2010, Albert et al. 2013, Clatot et al. 2014, Roy et al. 2014). Granot et al. and Williams et al. demonstrated that the activation of functional $\mathrm{CD}^{+} \mathrm{T}$ cells or neutrophils may modulate the immune response, which leads to the inhibition of metastasis and tumour progression (Williams et al. 2010, Granot et al. 2011). However, CXCL12 is able to induce different anti-tumour responses depending on the tumour type (Williams et al. 2010). For instance, Fushimi et al. demonstrated that $\mathrm{CD}^{+} \mathrm{T}$ cells play an important role in the inhibition of the CXCL12-mediated growth of melanoma and lung carcinoma (Fushimi et al. 2006). However, in an in vivo mice model of leukaemia, CD $4^{+}$but not $\mathrm{CD} 8^{+} \mathrm{T}$ cells were required. In this study, all of the $\mathrm{CD} 4^{+}$-depleted animals developed lethal tumours, while this occurred in only $20 \%$ of the $\mathrm{CD}^{+}$-depleted animals (DunussiJoannopoulos et al. 2002). In HNSCC patients treated with definite RCT, Balermpas et al. reported a positive association between a high number of tumour infiltrating $\mathrm{CD}^{+}$and $\mathrm{CD} 8^{+}$ lymphocytes and improved OS and DMFS (Balermpas et al. 2014). Taken together, CXCL12 is a chemokine with a wide spectrum of immunoregulatory properties and tissue specific CXCL12/CXCR4 interactions, and further studies of these mechanisms may lead to novel therapeutic strategies.

The expression of CXCR4 is reported in diverse tumour entities. Moreover, many studies have shown an association between CXCR4 expression and a worsening of the OS because of a rapid tumour recurrence and metastasis (Iwakiri et al. 2009, Wagner et al. 2009, Otsuka et al. 2011). In this study, multivariate analysis showed a significant correlation between high CXCR4 expression and a reduced DMFS. Katayama et al. analysed 56 Japanese patients with HNSCC and found that CXCR4 positivity was correlated with lymph node and distant 


\section{Discussion}

metastases as well as a poor prognosis and poor survival rate (Katayama et al. 2005). In another study in OSCC patients by Lee et al., the association between CXCR4 expression and poor survival rate was also reported (Lee et al. 2009). The causes for an increased CXCR4 expression in HNSCC and the relation to increased metastasis and reduced metastasis-free survival of patients are ascribed to various factors. CXCR4 expression is enhanced in cells that exhibit biological and morphological modifications associated with an epithelial-tomesenchymal transition (EMT) (Yoon et al. 2007, Taki et al. 2008). Ou et al. also found an association between CXCR4 expression and lymph node metastasis, and the authors suggest that the EMT-related critical transcription factor Twist might regulate expression of CXCR4 especially during lymph node metastasis ( $\mathrm{Ou}$ et al. 2008). In addition, Taki et al. demonstrated that CXCR4 was up-regulated in OSCC by CXCL12 and TGF-beta1 (Taki et al. 2008). They also reported that overexpression of SNAIL, another EMT-promoting transcription factor induced overexpression of CXCL12 (Taki et al. 2008). Hypoxia is another important CXCR4-regulating factor in HNSCC. Certain tumour environmental factors such as hypoxia-inducible factor-1 (HIF-1) may directly induce the enhanced expression of CXCR4 (Ishikawa et al. 2009). HIF-1 as a heterodimeric transcription factor responds to oxygen concentration in tissues and up-regulates CXCR4 expression. However, overexpression of HIF-1 is also known as a good indicator for a poor response to CRT in osteosarcoma or bonemetastases (Huang et al. 1998, Bendinelli et al. 2013).

Clinical and experimental studies revealed an association between CXCR4 expression and tumour cell migration or tumour metastasis. The strategic blocking approach to inhibit the CXCL12/CXCR4 pathway has focused on inhibitors of CXCR4 (CXCR4 antibodies or CXCR4 antagonist) or CXCL12. The anti-CXCR4 antibody, MDX-1338 is a novel drug candidate, which could directly block the interaction between CXCR4 and its ligand CXCL12 and also inhibits CXCL12-induced cell migration (Kuhne et al. 2009, Ramsey and McAlpine 2013). AMD3100, a well-known CXCR4 antagonist, which is currently being investigated in phase I/II trials, binds to CXCR4 and effectively blocks CXCL12 binding (Domanska et al. 2013). Furthermore, AMD3100 is an attractive drug candidate for several cancers in which CXCR4 is critically involved. 


\section{Discussion}

4.4 Migration of HNSCC cell lines along a CXCL12 gradient

\subsubsection{Characterisation of the employed cell lines}

We used an in vitro approach to study the role of CXCL12 and CXCR4 in the migration of HNSCC cell lines. Three HNSCC cell lines from two different anatomical subsites of head and neck regions with different CXCL12 and CXCR4 expression patterns were used. To avoid the impact of unexpected factors on the results of this analysis, we precisely characterised the expression of CXCL12 and CXCR4 at the mRNA and the protein level, the radiosensitivity of each cell line, a possible enhancement or reduction of radiosensitivity by CXCL12 and AMD3100 treatment, and at last the enhancing or inhibiting effect of CXCL12 and AMD3100 on the proliferative capacity of the cell lines.

We analysed the expression of CXCL12 and CXCR4 at the mRNA and protein level in three tumour (ZMK-1, FaDu and GR-145) and two control cell lines (HaCat and DF-19) by realtime PCR, western blot and immunocytochemical staining. Our data showed that ZMK-1 and FaDu cells express CXCR4 and GR-145 and DF-19 cells express CXCL12 at both the mRNA and protein level. These results also confirmed the results of Wolff et al., who analysed the expression of several chemokines and chemokine receptors in HNSCC cell lines at the mRNA level (Wolff et al. 2011a).

To determine the effect of CXCL12 and AMD3100 on HNSCC tumour cell radiosensitivity and clonogenic survival, we treated cells with CXCL12 or AMD3100 during colony-forming assay. In the present study, our experimental data showed an influence of CXCL12 on tumour cell radiosensitivity that was cell line-dependent. We found this CXCL12-related radiosensitisation in the tumour cell line ZMK-1 with the highest CXCR4 expression and no CXCL12 expression. To our knowledge no comparable experiments addressing the influence of CXCL12 on the cellular radiosensitivity have been conducted to date. However, Muller et al. showed that CXCL12 suppressed the rate of cisplatin-induced apoptosis in adenoid cystic carcinoma, a rare malignant epithelial tumour of the salivary glands (Muller et al. 2006). This CXCL12 stimulation resulted in the activation of AKT, ERK1/2, and MAP kinase pathways, which are commonly associated with cell survival and proliferation (Chan et al. 1999, Roux and Blenis 2004). 


\section{Discussion}

We found in all of the tumour cell lines (ZMK-1, FaDu and GR-145) and in one control cell line (HaCat) a reduction in clonogenic cell survival following exposure to increasing radiation doses. The second control cell line (DF-19) was not suitable for the colony-formation assay. Although the colony-forming assay is a broadly used technique, the results may be misleading under certain circumstances, when using primary (non-immortalised) cells. On the one hand, cells may be viable and able to divide very efficiently and still may not form colonies very well. On the other hand, non-immortalised cells are subject to replicative senescence after a number of population doublings (Ulus-Senguloglu 2012). At this point, the cells are metabolically viable but unable to undergo further cell division and are accordingly nonclonogenic. This was confirmed for the DF-19 fibroblasts by viability assay.

Do carmo et al. demonstrated that CXCL12 induced a significant increase in the proliferation of a CXCR4-positive glioma cell line (do Carmo et al. 2010). However, the effect of CXCL12 on induction of glioma cell proliferation in a study by Zhou et al. was in disagreement. Zhou et al. showed that there was no association between treatment with CXCL12 and the proliferative potential of CXCR4 expressing cell lines (Zhou et al. 2002).

Most studies investigating the biological function of CXCR4 and CXCL12 used AMD3100 as an efficient and specific CXCR4 antagonist that inhibits CXCL12-mediated calcium mobilisation, chemotaxis and GTP binding (Rubin et al. 2003, Marchesi et al. 2004, Cabioglu et al. 2005, Ohira et al. 2006, Burge and Peled 2009). Kim et al. reported that AMD3100 in high concentrations stimulates the proliferation of myeloma cells as compared to controls (Kim et al. 2010). They observed an initially enhancing and subsequently inhibiting effect on the survival and proliferation of myeloma cells as compared to controls. They also reported comparable observations in one leukaemia cell line (Kim et al. 2010). To investigate the metabolic activity-enhancing/reducing effect of CXCL12 and AMD3100 and irradiation on HNSCC tumour and control cell lines, we analysed the cell viability of the treated cells after a one-week incubation period. Cells were treated for 30 minutes with CXCL12, AMD3100 or both, before irradiation and one week of incubation. The same experimental set was performed with non-irradiated cells. Although some observations have shown that CXCL12 or AMD3100 alters the proliferation of some cells in culture, our findings showed that treatment with either CXCL12, AMD3100 or both, had no enhancing or inhibiting effect on the cell proliferative capacity of all tumour cell lines (ZMK-1, FaDu, and GR-145) for up to one week. DF-19 was non-responsive as well, while in the second control cell line (HaCat) CXCL12 and AMD3100 treatment was associated with enhanced proliferation. Although 


\section{Discussion}

incubation with CXCL12 or AMD3100 did not considerably decrease the viability of HNSCC tumour cell lines, as expected, irradiation significantly reduced cell viability of the tumour cells.

\subsubsection{Effect of irradiation on the migration behaviour of HNSCC and control cell lines among a CXCL12 gradient}

Migration and invasion of tumour cells are chemokine-dependent. Müller et al. have demonstrated organ-specific metastases of breast cancer cells, which were directly associated with CXCL12 (Müller et al. 2001). They found that primary breast cancer tumours highly expressed CXCR4, whereas the peak level of CXCL12 mRNA expression was in organs that are preferential target organs of breast cancer metastasis (Müller et al. 2001). There is growing evidence supporting the crucial role of CXCR4 in promoting migration and metastasis of primary tumour cells to strongly CXCL12-expressing tissues (Burger et al. 1999, Geminder et al. 2001, Müller et al. 2001, Robledo et al. 2001, Taichman et al. 2002, Ishikawa et al. 2006). In the present study, we investigated whether CXCL12 induced HNSCC cell migration with different CXCL12 and CXCR4 expression profiles. Since, no studies have analysed cell migration along a CXCL12 gradient in irradiated cells, we investigated the effect of irradiation on the migratory capacity on HNSCC cell lines, particularly CXCR4-positive cell lines. For cells responsive to CXCL12, an increased cell migration was observed at all radiation doses tested. As described above, CXCR4 contributes to a more aggressive metastatic phenotype (Albert et al. 2013), which could in part be associated with an enhanced migratory capacity of CXCR4-expressing tumours as we observed in CXCR4-expressing HNSCC tumour cell lines, ZMK-1 and FaDu.

To answer to the question, whether CXCR4 expressed in CXCR4-positive HNSCC tumour cells is functionally active upon CXCL12 binding, we analysed the migration tendency in the presence of AMD3100. The significant reduction of cell migration in the CXCR4-expressing tumours cells, ZMK-1 and FaDu, by treatment with the antagonist AMD3100 was observed in both non-irradiated and irradiated cells in a dose-dependent manner. With regard to these results, it is conceivable that the combination of RT and AMD3100 may significantly reduce the migration potential of CXCR4-positive HNSCC cells. In this study, we showed the crucial role of the CXCL12/CXCR4 axis in HNSCC migration as indicated by the treatment effects 


\section{Discussion}

of the blocking CXCR4 antagonist, AMD3100 on CXCR4-expressing HNSCC tumour cell lines.

\subsection{Future directions}

The incidence of HPV-negative HNSCC will probably continue to decline due to the trend to less smoking during the past decades. However, with the increased incidence of OPSCC with HPV positivity or the combination of tobacco and HPV infection it is conceivable that HPV will eventually become the main aetiology of head and neck cancer (Friedman et al. 2014). Because the two different tumour classes have different prognoses, treatment outcomes and survival rates, it will be important to follow the incidence of both HPV-positive and HPVnegative HNSCC in the future. Moreover, further insights into the molecular alterations underlying HPV-induced carcinogenesis will provide valuable opportunities to recognize more effective selected pathways (Mirghani et al. 2014).

Despite the improved clinical outcome for the majority of patients with HPV-positive HNSCC, the trend to reduce the used intensified treatment is growing and the necessity for less toxic therapies is seriously debated. The question for patients with positive HPV is not how to reduce the intensity of treatment, but how to optimize the treatment to these HNSCC tumours. It should be necessary to study further indicators or biomarkers that are able to distinguish which tumour is sensitive to a specific therapy intervention.

CXCL12 and CXCR4 have been involved in organ-specific metastases of several tumour entities. The association between inferior DMFS and a high CXCR4 expression level may be useful in estimating the prognosis and identifying patients who would profit from intensified surveillance and additional or altered treatment.

Our findings suggest that the inhibition of CXCL12 and CXCR4 by AMD3100 in HNSCC should be confirmed in vivo in order to evaluate the potential of CXCR4 as a therapeutic target in the treatment of HNSCC. Inhibition of the CXCL12/CXCR4 axis may have a positive impact on regulating tumour motility and organ-specific metastasis.

Despite significant advances in the field of both HPV and the CXCL12/CXCR4 axis, we still need more research into HNSCC before individualised patient treatment becomes routine. Moreover, finding other biomarkers or prognostic indicators is very important to predict or improve treatment outcome (Romanitan et al. 2013). We believe and hope that the results of 


\section{Discussion}

this study will provide a rational basis for the further development of HPV, CXCR4 and CXCL12 as prognostic indicators in the management of HNSCC patients. 


\section{Conclusion}

\section{Conclusion}

p16 ${ }^{\text {INK4A }}$ expression is an important, independent prognostic marker in HNSCC patients. We observed a strong correlation between tumour HPV status, particularly HPV-16, and p16 ${ }^{\text {INK4A }}$ expression. Accordingly, our data clearly revealed that $\mathrm{p} 16^{\mathrm{INK} 4 \mathrm{~A}}$ expression may be a more powerful marker for predicting prognosis than HPV DNA detection from archived FFPE tumour tissues (Tehrany et al. 2015). The improved OS seen in HNSCC patients with positive p16 ${ }^{\text {INK4A }}$ expression are thought to be independent of the treatment approach (Fakhry et al. 2008, Worden et al. 2008, Lassen et al. 2009, Posner et al. 2011, Cmelak 2012). However, in this study we found that the combination of $\mathrm{HPV} / \mathrm{p} 16^{\mathrm{INK} 4 \mathrm{~A}}$ positivity and HGAOT as treatment-related toxicities may have an additional effect on improved treatment outcomes and OS of HNSCC patients (Tehrany et al. 2015). Morover, p16 ${ }^{\mathrm{INK} 4 \mathrm{~A}}$ expression is more important for patients without HGAOT. For clinicians, the combined IHC report of p16 ${ }^{\mathrm{INK} 4 \mathrm{~A}}$ expression from the pathology laboratory and the analysis of acute organ toxicity of patients during therapy or even seen after therapy at follow-up appointments could provide important prognostic information for the individual patient and also become the basis of treatment decisions in the future.

In this study, we presented clinical and experimental data, underscoring the prognostic value of CXCL12 and CXCR4 in HNSCC patients treated with $\mathrm{R}(\mathrm{C}) \mathrm{T}$. immunohistochemical analysis of HNSCC biopsies showed that the expression of CXCR4 alone in tumour tissue was a negative predictor for patients, while the expression of CXCL12 was associated with improved OS. We evaluated CXCR4 as a predictive indicator for HNSCC patients with poor prognosis with regard to reduced DMFS and also investigated its biological relevance in the migratory capacity of HNSCC tumour cell lines in a CXCL12 gradient. CXCL12 had a specific effect on migration of HNSCC cells that does not stem to enhanced proliferation. Additionally, we were able to show that CXCL12 also induces irradiated HNSCC cells to migrate, whereas this tendency was significantly reduced in a dose-dependent manner by irradiation. As shown by an experiment in the in vitro study, CXCR4 significantly induces the migration of CXCR4-positive tumour cells and promotes the progression of distant metastases in our in vivo analysis. Accordingly, these results indicate that the CXCL12/CXCR4-pathway is functionally relevant in head and neck cancer cell lines, which in turn supports the clinical data. 


\section{Conclusion}

In conclusion, we have demonstrated that different indicators and biomarkers are of independent prognostic value in HNSCC. These results can also lead us to a new efficient treatment strategy, in which the intensity of CT or extent of the irradiated area can be altered while maintaining good tumour control with the ability to rationally personalise therapy to advance therapeutic outcomes. 


\section{Conclusion}

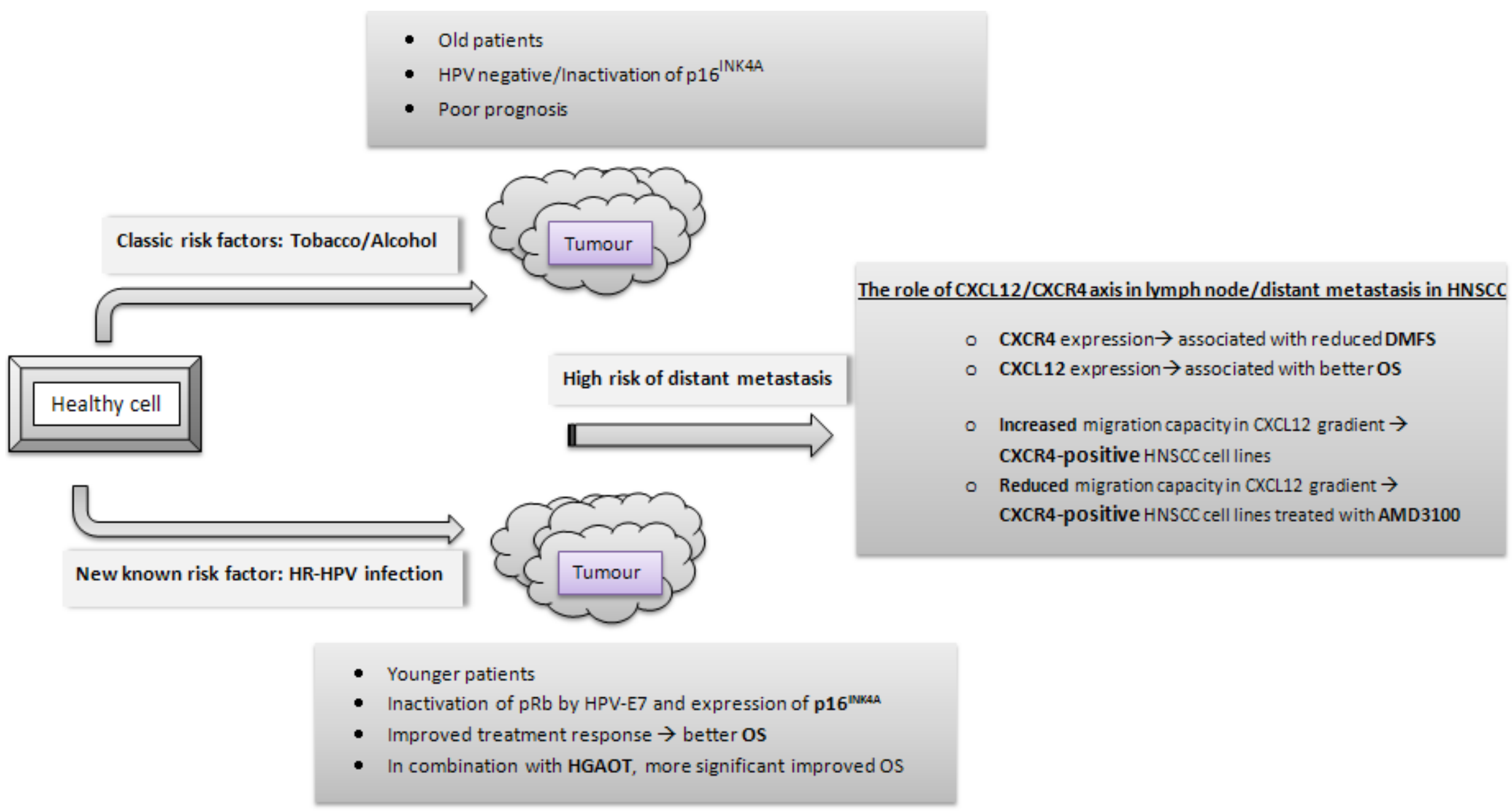

Figure 5.1: Summary of in vivo and in vitro analyses of HNSCC-biopsies and HNSCC cell lines. 
Aebersold, D., Burri, P., Beer, K., Laissue, J., Djonov, V., Greiner, R., Semenza, G., 2001. Expression of hypoxia-inducible factor-1alpha: A novel predictive and prognostic parameter in the radiotherapy of oropharyngeal cancer. Cancer Research 61 (7), 2911-2916.

Aiuti, A., Webb, I., Bleul, C., Springer, T., Gutierrez-Ramos, J., 1997. The chemokine sdf-1 is a chemoattractant for human cd34+ hematopoietic progenitor cells and provides a new mechanism to explain the mobilization of cd34+ progenitors to peripheral blood. The journal of experimental medicine 185, 111-120.

Albert, S., Riveiro, M.E., Halimi, C., Hourseau, M., Couvelard, A., Serova, M., Barry, B., Raymond, E., Faivre, S., 2013. Focus on the role of the cxcl12/cxcr4 chemokine axis in head and neck squamous cell carcinoma. Head Neck 35 (12), 1819-28.

Allen, T., Lewis, J., El-Mofty, S., Haughey, B., Nussenbaum, B., 2010. Human papillomavirus and oropharynx cancer: Biology, detection and clinical implications. Laryngoscope 120, 17561772.

Almofti, A., Uchida, D., Begum, N., 2004. The clinicopathological significance of the expression of cxcr4 protein in oral squamous cell carcinoma. International journal of oncology 25, 65-71.

Anaya-Saavedra, G., Ramirez-Amador, V., Irigoyen-Camacho, M., 2008. High association of human papillomavirus infection with oral cancer: A case-control study. Archives of Medical Research 39, 189-197.

Ang, K., Harris, J., Wheeler, R., 2010. Human papillomavirus and survival of patients with oropharyngeal cancer. The New England Journal of Medicine 363 (1), 24-35.

Argiris, A., Karamouzis, M., Raben, D., Ferris, R., 2008. Head and neck cancer. Lancet 371, $1695-$ 1709.

Askari, A., Unzek, S., Popvic, Z., Goldmann, C., Forudi, F., Kiedrowski, M., Rovner, A., Ellis, S., Thomas, J., Dicorleto, P., Topol, E., Penn, M., 2003. Effect of stromal-cell-derived factor 1 on stem-cell homing and tissue regeneration in ischaemic cardiomyopathy. Lancet 362, 697-703.

Azad, A., Bairati, I., Samson, E., Cheng, D., Cheng, L., Mirshams, M., Savas, S., 2012. Genetic sequence variants and the development of secondary primary cancers in patients with head and neck cancers. Cancer 118 (6), 1554-1565.

Bagri, A., Gurney, T., He, X., Zou, Y., Littman, D., Tessier-Lavigne, M., Pleasure, S., 2002. The chomokine sdf-1 regulates migration and dentate granule cells. Development 129, 4249-4260.

Baker, T., Newcomb, W., Olson, N., Cowsert, L., Olson, C., Brown, J., 1991. Structures of bovine and human papillomaviruses. Analysis by cryoelectron microscopy and three-dimensional image reconstruction. Biophysical Journal 60 (6), 1445-1456. 
Balermpas, P., Michel, Y., Wagenblast, J., Seitz, O., Weiss, C., Rodel, F., Rodel, C., Fokas, E., 2014. Tumour-infiltrating lymphocytes predict response to definitive chemoradiotherapy in head and neck cancer. British journal of cancer 110 (2), 501-9.

Balz, V., Scheckenbach, K., Götte, K., Bockmühl, U., Petersen, I., Bier, H., 2003. Is the p53 inactivation frequency in squamous cell carcinomas of the head and neck underestimated? Analysis of p53 exons 2-11 and human papillomavirus 16/18 e6 transcripts in 123 unselected tumor specimens. Cancer research 63 (6), 1188-1191.

Beasley, N., Prevo, R., Banerji, S., Leek, R., Moore, J., Van Trappen, P., Cox, G., Harris, A., Jackson, D., 2002. Intratumoral lymphangiogenesis and lymph node metastasis in head and neck cancer. Cancer Research 62, 1315-1320.

Bendinelli, P., Maroni, P., Matteucci, E., Luzzati, A., Perrucchini, G., Desiderio, M.A., 2013. Hypoxia inducible factor- 1 is activated by transcriptional co-activator with pdz-binding motif (taz) versus wwdomain-containing oxidoreductase (wwox) in hypoxic microenvironment of bone metastasis from breast cancer. European Journal of Cancer 49 (11), 2608-2618.

Bennani-Baiti, I., Cooper, A., Lawlor, E., Kauer, M., Ban, J., Aryee, D., Kovar, H., 2010. Intercohort gene expression co-analysis reveals chemokine receptors as prognostic indicators in ewing's sarcoma. Clinical Cancer Research 16 (14), 3769-3778.

Bernard, H.U., 2010. Classification of papillomaviruses (pvs) based on 189 pv types and proposal of taxonomic amendments. Virology 401 (1), 70-79.

Bhowmick, N., Moses, H., 2005. Tumor-stroma interactions. Current Opinion in Genetics \& Development 15, 97-101.

Bissell, M., Hines, W., 2011. Why don't we get more cancer? A proposed role of the microenvironment in restraining cancer progression. Nature Medice 17 (3), 320-329.

Bissell, M., Radisky, D., Rizki, A., Weaver, V., Petersen, O., 2002. The organizing principle: Microenvironmental influences in the normal and malignant breast. Differentiation 70, 537546.

Bleul, C., Farzan, M., Choe, H., Parolin, C., Clark-Lewis, I., Sodroski, J., Springer, T., 1996b. The lymphocyte chemoattractant sdf-1 is a ligand for lestr/fusin and blocks hiv-1 entry. Nature 383, 829-833.

Blitzer, G.C., Smith, M.A., Harris, S.L., Kimple, R.J., 2014. Review of the clinical and biologic aspects of human papillomavirus-positive squamous cell carcinomas of the head and neck. International journal of radiation oncology, biology, physics 88 (4), 761-70.

Böcker, H., Denk, P., Heitz, H., 2004. Pathologie Urban \& Fischer Verlag, München.

Bogenrieder, T., Herlyn, M., 2003. Axis of evil: Molecular mechanisms of cancer metastasis. Oncogene 22, 6524-6536.

Bol, V., Gregoire, V., 2014. Biological basis for increased sensitivity to radiation therapy in hpvpositive head and neck cancers. BioMed research international 2014, 696028. 
Bonner, J., Harari, P., Giralt, J., Cohen, R., Baselga, J., Raben, D., Shin, D., Ove, R., Jassem, J., Amellal, N., Azarnia, N., Ang, K., 2005. The relationship of cetuximab-induced rash and survival in patients with head and neck cancer treated with radiotherapy and cetuximab. International Journal of Radiation Oncology Biology Physics 63 (suppl 1), S73.

Bosch, F., Ritter, D., Enders, C., 2004. Head and neck tumor sites differ in prevalence and spectrum of p53 alterations but these have limited prognostic value. International Journal of Cancer 111 (4), 530-538.

Boscolo-Rizzo, P., Del Mistro, A., Bussu, F., Lupato, V., Baboci, L., 2013. New insights into human papillomavirus-associated head and neck squamous cell carcinoma. ACTA 33 (2), 77-87.

Bose, P., Brockton, N., Dort, J., 2013. Head and neck cancer: From anatomy to biology. International Journal of Cancer 133 (9), 2013-2023.

Boukamp, P., Petressevska, R., Breitkreutz, D., Hornung, J., Markham, A., Fusenig, N., 1988. Normal keratinization in a spontaneously immortalized aneuploid human keratinocyte cel line. The Journal of Cell Biology 106 (3), 761-771.

Boyle, P., Levin, B., 2008. World cancer report 2008 Lyon: IARC Press, International Agency for Research on Cancer.

Braakhuis, B., Snijders, P., Keune, W., 2004. Genetic patterns in head and neck cancers that contain or lack transcriptionally active human papillomavirus. Journal of the National Cancer Institute 96 (13), 998-1006.

Bradford, M., 1976. A rapid and sensitive method for the quantitation of microgram quantities of protein utilizing the principle of protein-dye binding. Analytical Biochemistry 72, 248-254.

Brandwein-Gensler, M., Smith, R., 2010. Prognostic indicators in head and neck oncology including the new 7th edition of the ajcc staging system. Head Neck Pathology 4, 53-61.

Brennan, J., Boyle, J., Koch, W., Goodman, S., Hruban, R., Eby, Y., Couch, M., Forastiere Aa, Sidransky, D., 1995. Association between cigarette smoking and mutation of the p53 gene in squamous-cell carcinoma of the head and neck. New England Journal of Medicine 332 (11), 712.

Burge, J., Peled, A., 2009. Cxcr4 antagonists: Targeting the microenvironment in leukemia and other cancers. Leukemia 23, 43-52.

Burger, J., Burger, M., Kipps, T., 1999. Chronic lymphocytic leukemia b cells express functional cxcr4 chemokine receptors that mediate spontaneous migration beneath bone marrow stromal cells. Blood 94 (11), 3658-3667.

Burns, J., Summers, B., Wang, Y., Melikian, A., Berahovich, R., Miao, Z., Penfold, M., Sunshine, M., Littman, D., Kuo, C., Wei, K., Mcmaster, B., Wright, K., Howard, M., Schall, T., 2006. A novel chemokine receptor for sdf-1 and i-tac involved in cell survival, cell adhesion, and tumor development. The journal of experimental medicine 203, 2201-2213. 
Burusapat, C., Jarungroongruangchai, W., Charoenpitakchai, M., 2015. Prognostic factors of cervical node status in head and neck squamous cell carcinoma. World Journal of Surgical Oncology, DOI: 10.1186/s12957-015-0460-6.

Cabioglu, N., Summy, J., Miller, C., Parikh, N., Sahin, A., Tuzlali, S., 2005. Cxcl12/stromal cellderived factor-1alpha transactivates her2-neu in breast cancer cells by a novel pathway involving src kinase activation. Cancer Research 65, 6493-6497.

Calderon, T., Eugenin, E., Lopez, L., Kumar, S., Hesselgesser, J., Raine, C., Berman, J., 2006. A role for cxcl12 (sdf-1 $\alpha$ ) in the pathogenesis of multiple sclerosis: Regulation of cxcl12 expression in astrocytes by soluble myelin basic protein. Journal of Neuroimmunology 177, 27-39.

Calhoun, K., Fulmer, P., Weiss, R., Hokanson, J., 1994. Distant metastases from head and neck squamous cell carcinomas. Laryngoscope 104, 1199-1205.

Ceradini, D., Kulkarni, A., Callagham, M., Tepper, O., Bastidas, N., Kleinman, M., Capla, J., Galiano, R., Levine, J., Gurtner, G., 2004. Progenitor cell trafficking is regulated by hypoxic gradients through hif-1 induction of sdf-1. Nature medicine 10, 858-864.

Chambers, A., 2001. Critical steps in hematogenous metastasis: An overview. Surgical Oncology Clinics of North America 10, 243-255.

Chan, T., Rittenhouse, S., Tsichlis, P., 1999. Akt/pkb and other d3 phosphoinositide-regulated kinases: Kinase activation by phosphoinositidedependent phosphorylation. Annual Review of Biochemistry 68, 965-1014.

Chaturvedi, A., Engels, E., Pfeiffer, R., Hernandez, B., Xiao, W., Kim, E., Jiang, B., Goodman, M., Sibug-Saber, M., Cozen, W., 2011. Human papillomavirus and rising oropharyngeal cancer incidence in the united states. Journal of clinical oncology 29, 4294-4301.

Chin, D., Boyle, G.M., Porceddu, S., Theile, D.R., Parsons, P.G., Coman, W.B., 2006. Head and neck cancer: Past, present and future. Expert Review of Anticancer Therapy 6, 1111-1118.

Chow, L.T., Broker, T.R., Steinberg, B.M., 2010. The natural history of human papillomavirus infections of the mucosal epithelia. APMIS 118 (6-7), 422-449.

Clark, J., Li, W., Smith, G., 2005. Outcome of treatment for advanced cervical metastatic squamous cell carcinoma. Head Neck 27, 87-94.

Clatot, F., Gouerant, S., Mareschal, S., Cornic, M., Berghian, A., Choussy, O., El Ouakif, F., Francois, A., Benard, M., Ruminy, P., Picquenot, J.M., Jardin, F., 2014. The gene expression profile of inflammatory, hypoxic and metabolic genes predicts the metastatic spread of human head and neck squamous cell carcinoma. Oral Oncol 50 (3), 200-7.

Clatot, F., Picquenot, J.M., Choussy, O., Gouerant, S., Moldovan, C., Schultheis, D., Cornic, M., Francois, A., Blot, E., Laberge-Le-Couteulx, S., 2011. Intratumoural level of sdf-1 correlates with survival in head and neck squamous cell carcinoma. Oral Oncol 47 (11), 1062-8.

Clifford, G., Smith, J., Plummer, M., Munoz, N., Franceschi, S., 2003. Human papillomavirus types in invasive cervical cancer worldwide: A meta-analysis. British Journal of Cancer 88 (1), 63-73. 
Cmelak, A., 2012. Current issues in combined modality therapy in locally advanced head and neck cancer. Critical reviews in oncology/hematology 84 (2), 261-273.

Corvo, R., 2007. Evidence-based radiation oncology in head and neck squamous cell carcinoma. Radiotherapy and Oncology 85, 156-170.

Cox, J., Stetz, J., Pajak, T., 1995. Toxicity criteria of the radiation therapy oncology group (rtog) and the european organization for research and treatment of cancer (eortc). International Journal of Radiation Oncology Biology Physics 31 (5), 1341 - 1346.

Crump, M., Gong, J., Loetscher, P., Rajarathnam, K., Amara, A., Arenzana-Seisdedos, F., Virelizier, J., Baggiolini, M., Sykes, B., Clark-Lewis, I., 1997. Solution structure and basis for functional activity of stromal cell-derived factor-1; dissociation of cxcr4 activation from binding and inhibition of hiv-1. European Molecular Biology Organization 16 (23), 6996-7007.

D'alterio, C., Consales, C., Polimeno, M., Franco, R., Cindolo, L., Portella, L., Cioffi, M., Calemma, R., Marra, L., Claudio, L., Perdonà, S., Pignata, S., Facchini, G., Cartenì, G., Longo, N., Pucci, L., Ottaiano, A., Costantini, S., Castello, G., Scala, S., 2010. Concomitant cxcr4 and cxcr7 expression predicts poor prognosis in renal cancer. Current Cancer Drug Targets 10 (7), $772-781$.

D'souza, G., Kreimer, A., Viscidi, R., 2007. Case-control study of human papillomavirus and oropharyngeal cancer. The New England Journal of Medicine 356, 1944-1956.

Dai, Q., Ling, Y., Lia, M., 2005. Enhanced sensitivity to the her1/epidermal growth factor receptor tyrosine kinase inhibitor erlotinib hydrochloride in chemotherapy-resistant tumor cell lines. Clinical Cancer Research 11, 1572-1578.

Dayyani, F., Etzel, C., Liu, M., Ho, C., Lippman, S., Tsao, A., 2010. Meta-analysis of the impact of human papillomavirus (hpv) on cancer risk and overall survival in head and neck squamous cell carcinomas (hnscc). Head \& Neck Oncology 2 (15).

De Roda Husman, A., Walboomers, J., Van Den Brule, A., Meijer, C., Snijders, P., 1995. The use of general primers gp5 and gp6 elongated at their 39 ends with adjacent highly conserved sequences improves human papillomavirus detection by pcr. Journal of General Virology 76, $1057-1062$.

Deng, Z., Hasegawa, M., Aoki, K., Matayoshi, S., Kiyuna, A., Yamashita, Y., Uehara, T., Agena, S., Maeda, H., Xie, M., Suzuki, M., 2014. A comprehensive evaluation of human papillomavirus positive status and p16ink4a overexpression as a prognostic biomarker in head and neck squamous cell carcinoma. International journal of oncology 45 (1), 67-76.

Do Carmo, A., Patricio, I., Cruz, M.T., Carvalheiro, H., Oliveira, C.R., Lopes, M.C., 2010. Cxcl12/cxcr4 promotes motility and proliferation of glioma cells. Cancer Biology and Therapy $9,56-65$.

Doitsidou, M., Reichman-Fried, M., Stebler, J., Köprummer, M., Dörries, J., Meyer, D., Esguerra, C., Leung, T., Raz, E., 2002. Guidance of primordial germ cell migration by the chemokine sdf-1. Cell 111, 647-659. 
Dok, R., Kalev, P., Van Limbergen, E., Asbagh, L., Vázquez, I., Hauben, E., Sablina, A., Nuyts, S., 2014. P16ink4a impairs homologous recombination-mediated DNA repair in human papillomavirus-positive head and neck tumors. Cancer Research 74 (6), 1739-1751.

Domanska, U.M., Kruizinga, R.C., Nagengast, W.B., Timmer-Bosscha, H., Huls, G., De Vries, E.G., Walenkamp, A.M., 2013. A review on cxcr4/cxcl12 axis in oncology: No place to hide. European journal of cancer 49 (1), 219-30.

Donzella, G., Schols, D., Lin, S., Esté, J., Nagashima, K., Maddon, P., Allaway, G., Sakmar, T., Henson, G., Declercq, E., Moore, J., 1998. Amd3100, a small molecule inhibitor of hiv-1 entry via the cxcr4 co-receptor. Nature medicine 4, 72-77.

Dranoff, G., 2004. Cytokines in cancer pathogenesis and cancer therapy. Nature Reviews Cancer 4 (1), $11-22$.

Dunussi-Joannopoulos, K., Zuberek, K., Runyon, K., Hawley, R., Wong, A., Erickson, J., Herrmann, S., Leonard, J., 2002. Efficacious immunomodulatory activity of the chemokine stromal cellderived factor 1 (sdf-1): Local secretion of sdf-1 at the tumor site serves as t-cell chemoattractant and mediates t-cell-dependent antitumor responses. Blood 100 (5), 15511558.

Duray, A., Descamps, G., Arafa, M., Decaestecker, C., Remmelink, M., Sirtaine, N., ErnouxNeufcoeur, P., Mutijima, E., Somja, J., Depuydt, C., Delvenne, P., Saussez, S., 2011. High incidence of high-risk hpv in benign and malignant lesions of the larynx. International Journal of Oncology 39 (1), 51-59.

Dyson, N., Howley, P., Munger, K., Harlow, E., 1989. The human papilloma virus-16 e7 oncoprotein is able to bind to the retinoblastoma gene product. Science 243, 934-937.

Epstein, J., Haveman, C., Huber, M., Peterson, D., Plemons, J., Redding, S., Sanfilippo, N., Schubert, M., Sonis, S., 2008. Oral health in cancer therapy.

Fakhry, C., Gillison, M., 2006. Clinical implications of human papillomavirus in head and neck cancers. Journal of clinical oncology 24, 2606-2611.

Fakhry, C., Westra, W., Li, S., 2008. Improved survival of patients with human papillomaviruspositive head and neck squamous cell carcinoma in a prospective clinical trial. Journal of the National Cancer Institute 100, 261-269.

Fallai, C., Perrone, F., Licitra, L., 2009. Oropharyngeal squamous cell carcinoma treated with radiotherapy or radiochemotherapy: Prognostic role of tp53 and hpv status. International journal of radiation oncology, biology, physics 75 (4), 1053-1059.

Feng, Y., Broder, C., Kennedy, P., 1996. Hiv-1 entry cofactor: Functional cdna cloning of a seventransmembrane, g protein-coupled receptor. Science 272, 872-877.

Ferlay, J., Shin, H., Bray, F., Forman, D., Mathers, C., Parkin, D., 2008. Cancer incidence and mortality worldwide IARC CancerBase No. 10 v1.2. 
Ferlito, A., Rinaldo, A., Buckley, J., Mondin, V., 2001. General considerations on distant metastases from head and neck cancer. ORL:Otorhino-laryngology - Head \& Neck Surgery 63 (4), 189191.

Forastiere, A., 2008. Chemotherapy in the treatment of locally advanced head and neck cancer. Journal of Surgical Oncology 97, 701-707.

Forastiere, A., Koch, W., Trotti, A., Sidransky, D., 2001. Head and neck cancer. The New England Journal of Medicine 345, 1890-1900.

Fregonesi, P., Teresa, D., Duarte, R., Neto, C., Brancini De Oliveira, M., Soares, C., 2003. P16ink4a immunohistochemical overexpression in premalignant and malignant oral lesions infected with human papillomavirus. The Journal of Histochemistry \& Cytochemistry 51 (10), 12911297.

Friedman, J., Stavas, M., Cmelak, A., 2014. Clinical and scientific impact of human papillomavirus on head and neck cancer World Journal of Clinical Oncology 5 (4), 781-791.

Fukumura, D., Jain, R., 2007. Tumor microenvironment abnormalities: Causes, consequences, and strategies to normalize. Journal of Cellular Biochemistry 101, 937-949.

Fushimi, T., O'connor, T., Crystal, R., 2006. Adenoviral gene transfer of stromal cell-derived factor-1 to murine tumors induces the accumulation of dendritic cells and suppresses tumor growth. Cancer Research 66, 3513-3522.

Gage, J., Meyers, C., Wettstein, F., 1990. The e7 proteins of the nononcogenic human papillomavirus type $6 \mathrm{~b}$ (hpv-6b), and of the oncogenic hpv-16 differ in retinoblastoma protein binding, and other properties. Journal of Virology 46, 723-730.

Galon, J., Angell, H.K., Bedognetti, D., Marincola, F.M., 2013. The continuum of cancer immunosurveillance: Prognostic, predictive, and mechanistic signatures. Immunity 39 (1), 11 26.

Geminder, H., Sagi-Assif, O., Goldberg, L., Meshel, T., Rechavi, G., Witz, I., Ben-Baruch, A., 2001. A possible role for cxcr4 and its ligand, the cxc chemokine stromal cell-derived factor-1, in the development of bone marrow metastases in neuroblastoma. The Journal of Immunology 167 (8), 4747-4757.

Gilbert, M., Haselkorn, T., Bunce, M., Sanchez, J., 2007. The isolation of nucleic acids from fixed, paraffin-embedded tissues - which methods are useful when? . PLoS One 2, e537.

Gillison, M., 2004. Human papillomavirus-associated head and neck cancer is a distinct epidemiologic, clinical, and molecular entity. Seminars in Oncology 31, 744-754.

Gillison, M., 2007. Current topics in the epidemiology of oral cavity and oropharyngeal cancers. Head Neck 29, 779-792.

Gillison, M., D'souza, G., Westra, W., Sugar, E., Xiao, W., Begum, S., Viscidi, R., 2008. Distinct risk factor profiles for human papillomavirus type 16-positive and human papillomavirus type 16negative head and neck cancers. Journal of the National Cancer Institute 100, 407-420. 
Gillison, M., Koch, W., Capone, R., Spafford, M., Westra, W., Wu, L., Zahurak, M., Daniel, R., Viglione, M., Symer, D., Shah, K., Sidransky, D., 2000. Evidence for a causal association between human papillomavirus and a subset of head and neck cancers. Journal of the National Cancer Institute 92 (9), 709-720.

Goia, C., Iancu, I., Socolov, D., Botezatu, A., Lazaroiu, A., Huica, I., Plesa, A., Anton, G., 2010. The expression of cell cycle regulators in hpv - induced cervical carcinogenesis. Romanian Biotechnological Letters 15 (4), 5376-5383.

Granot, Z., Henke, E., Comen, E., King, T., Norton, L., Benezra, R., 2011. Tumor entrained neutrophils inhibit seeding in the premetastatic lung. Cancer Cell 20, 300-314.

Gravitt, P., Peyton, C., Alessi, T., Wheeler, C., Coutlee, F., Hildesheim, A., Schiffman, M., Scott, D., Apple, R., 2000. Improved amplification of genital human papillomavirus. Journal of Clinical Microbiology 38 (1), 357-361.

Guha, N., Boffetta, P., Wünsch Filho, V., Eluf Neto, J., Shangina, O., Zaridze, D., Curado, M., Koifman, S., Matos, E., Menezes, A., Szeszenia-Dabrowska, N., Fernandez, L., Mates, D., Daudt, A., Lissowska, J., Dikshit, R., Brennan, P., 2007. Oral health and risk of squamous cell carcinoma of the head and neck and esophagus: Results of two multicentric case-control studies. American Journal of Epidemiology 166 (10), 1159-1173.

Gupta, S., Lysko, P., Pillarisetti, K., Ohlstein, E., Stadel, J., 1998. Chemokine receptors in human endothelial cells: Functional expression of cxcr4 and its transcriptional regulation by inflammatory cytokines. The Journal of Biochemical Chemistry 273, 4282-4287.

Haddad, R., Wirth, L., Posner, M., 2006. Emerging drugs for head and neck cancer. Expert Opinion on Emerging Drugs 11 (3), 461-467.

Hafkamp, H., Manni, J., Haesevoets, A., Voogd, A., 2008. Marked differences in survival rate between smokers and nonsmokers with hpv 16-associated tonsillar carcinomas. International Journal of Cancer 122 (12), 2656-2664.

Harris, S.L., Thorne, L.B., Seaman, W.T., Hayes, D.N., Couch, M.E., Kimple, R.J., 2011. Association of p16(ink4a) overexpression with improved outcomes in young patients with squamous cell cancers of the oral tongue. Head \& neck 33 (11), 1622-7.

Hartmann, T., Burger, J., Glodek, A., Fujii, N., Burger, M., 2005. Cxcr4 chemokine receptor and integrin signaling co-operate in mediating adhesion and chemoresistance in small cell lung cancer (sclc) cells. Oncogene 24, 4462-4471.

Hatse, S., Princen, K., Bridger, G., De Clercq, E., Schols, D., 2002. Chemokine receptor inhibition by amd3100 is strictly confined to cxcr4. FEBS Letters 527, 255-262.

Hedley, B., Chambers, A., 2009. Tumor dormancy and metastasis. Advances in cancer research 102, 67-101.

Hendry, J., Jeremić, B., Zubizarreta, E., 2006. Normal tissue complications after radiation therapy. Revista Panamericana de Salud Pública 20 (2-3), 151 - 160. 
Hiller, D., Meschonat, C., Kim, R., Li, B., Chu, Q., 2011. Chemokine receptor cxcr4 level in primary tumors independently predicts outcome for patients with locally advanced breast cancer. Surgery $150(3), 459-465$.

Holmes, W., Lee, J., Kuang, W., Rice, G., Wood, W., 1991. Structure and functional expression of a human interleukin-8 receptor. Science 253 (5025), 1278-1280.

Homey, B., Muller, A., Zlotnik, A., 2002. Chemokines: Agents for the immunotherapy of cancer? Nature Reviews Immunology 2, 175-184.

Hopkins, J., Cescon, D., Tse, D., Bradbury, P., Xu, W., Ma, C., Wheatley-Price, P., Waldron, J., Goldstein, D., Meyer, F., 2008. Genetic polymorphisms and head and neck cancer outcomes: A review. Cancer epidemiology, biomarkers \& prevention 17, 490-499.

Horner, M., Krapcho, L., 2009. Seer cancer statistics review (1975-2006). http://seer.cancer.gov/csr/1975_2006/,.

Horuk, R., 2001. Chemokine receptors. Cytokine and Growth Factor Reviews 12, 313-335.

Howell, G., Grandis, J.R., 2005. Molecular mediators of metastasis in head and neck squamous cell carcinoma. Head Neck 27, 710-717.

Huang, L., Gu, J., Schau, M., Bunn, H., 1998. Regulation of hypoxia-inducible factor 1alpha is mediated by an o2-dependent degradation domain via the ubiquitin-proteasome pathway. Proceedings of the National Academy of Sciences USA 95 (14), 7987-7992.

Hummel, M., Hudson, J., 1992. Differentiation-induced and constitutive transcription of human papillomavirus type $31 \mathrm{~b}$ in cell lines containing viral episomes. Journal of Virology 66 (10), 6070-6080.

Iarc, 2011. Iarc, human papillomaviruses, in iarc monographs on the evaluation of carcinogenic risk to humans. A review of human carcinogens. B. Biological agents WHO (Lyon, France), 261301.

Imai, K., Kobayashi, M., Wang, J., Shinobu, N., Yoshida, H., Hamada, J., Shindo, M., 1999. Selective secretion of chemoattractants for hemopoietic progenitor cells by bone marrow endothelial cells: A possible role in homing of hemopoietic progenitor cells to bone marrow. British Journal of Haematology 106, 905-911.

Ishigami, S., Natsugoe, S., Okumura, H., Matsumoto, M., Nakajo, A., Uenosono, Y., Arigami, T., Uchikado, Y., Setoyama, T., Arima, H., Hokita, S., Aikou, T., 2007. Clinical implication of cxcl12 expression in gastric cancer. Annals of Surgical Oncology 14 (11), 3154-3158.

Ishikawa, T., Nakashiro, K., Hara, S., Klosek, S.K., Li, C., Shintani, S., Hamakawa, H., 2006. Cxcr4 expression is associated with lymph-node metastasis of oral squamous cell carcinoma. International journal of oncology 28 (1), 61-6.

Ishikawa, T., Nakashiro, K., Klosek, S.K., Goda, H., Hara, S., Uchida, D., Hamakawa, H., 2009. Hypoxia enhances cxcr4 expression by activating hif-1 in oral squamous cell carcinoma. Oncology reports $21(3), 707-12$. 
Itano, N., Zhuo, L., Kimata, K., 2008. Impact of the hyaluronan-rich tumor microenvironment on cancer initiation and progression. Cancer Science 99 (9), 1720-1725.

Iwakiri, S., Mino, N., Takahashi, T., Sonobe, M., Nagai, S., Okubo, K., Wada, H., Date, H., Miyahara, R., 2009. Higher expression of chemokine receptor cxcr7 is linked to early and metastatic recurrence in pathological stage i nonsmall cell lung cancer. Cancer 115 (11), 2580-2593.

Jemal, A., Siegel, R., Xu, J., Ward, E., 2010. Cancer statistics. CA - A Cancer Journal for Clinicians $60(5), 277-300$.

Jiang, Y., Wu, X., Shi, B., Wu, W., Yin, G., 2006. Expression of chemokine cxcl12 and its receptor cxcr4 in human epithelial ovarian cancer: An independent prognostic factor for tumor progression. Gynecologic Oncology 103 (1), 226-233.

Joiner, M., Kogel, V.D., 2009. Basic clinical radiobiology Hodder Arnold, London, Great Britain.

Jung, S., Kim, C., Park, C., Chang, H., Kim, B., Choi, M., Jung, H., 2011. Correlation between chemokine receptor cxcr4 expression and prognostic factors in patients with prostate cancer. Korean Journal of Urology 52 (9), 607-611.

Kang, H., Watkins, G., Douglas-Jones, A., Mansel, R., Jiang, W., 2005. The elevated level of cxcr4 is correlated with nodal metastasis of human breast cancer. The breast 14 (5), 360-367.

Karlsen, F., Kalantari, M., Chitemerere, M., Johansson, B., Hagmar, B., 1994. Modifications of human and viral deoxyribonucleic acid by formaldehyde fixation. Laboratory Investigation 71 (4), 604-611.

Katayama, A., Ogino, T., Bandoh, N., Nonaka, S., Harabuchi, Y., 2005. Expression of cxcr4 and its down-regulation by ifn-gamma in head and neck squamous cell carcinoma. Clin Cancer Res $11(8), 2937-46$.

Kawakami, H., Okamoto, I., Terao, K., Sakai, K., Suzuki, M., Ueda, S., Tanaka, K., Kuwata, K., 2013. Human papillomavirus DNA and p16 expression in japanese patients with oropharyngeal squamous cell carcinoma. Cancer Medicine 2 (6), 933-941.

Keeley, E., Mehrad, B., Strieter, R., 2010. Cxc chemokines in cancer angiogenesis and metastases. Advances in cancer research 106, 91-111.

Kessis, T., Slebos, R., Nelson, W., Kastan, M., Plunkett, B., Han, S., Lorincz, A., Hedrick, L., Cho, K., 1993. Human papilomavirus $16 \mathrm{e} 6$ expression disrupts the p53-mediated cellular response to DNA damage. Proceedings of the National Academy of Sciences USA 90, 3988-3992.

Kim, C., Broxmeyer, H., 1998. In vitro behavior of hematopoietic progenitor cells under the influence of chemoattractants: Stromal cell-derived factor-1, steel factor, and the bone marrow environment. Blood 91, 100-110.

Kim, H.-Y., Hwang, J.-Y., Kim, S.-W., Lee, H.-J., Yun, H.-J., Kim, S., Jo, D.-Y., 2010. The cxcr4 antagonist amd3100 has dual effects on survival and prolifration of myeloma cell in vitro. Cancer Research and Treatment 42 (4), 225-234. 
Kim, J., Takeuchi, H., Lam, S., Turner, R., Wang, H., Kuo, C., Foshag, L., Bilchik, A., Hoon, D., 2005. Chemokine receptor cxcr4 expression in colorectal cancer patients increases the risk for recurrence and for poor survival Journal of clinical oncology 23 (12), 2744-2753.

Kimple, R.J., Smith, M.A., Blitzer, G.C., Torres, A.D., Martin, J.A., Yang, R.Z., Peet, C.R., Lorenz, L.D., Nickel, K.P., Klingelhutz, A.J., Lambert, P.F., Harari, P.M., 2013. Enhanced radiation sensitivity in hpv-positive head and neck cancer. Cancer Res 73 (15), 4791-800.

Kioi, M., Vogel, H., Schultz, G., Hoffman, R., Harsh, G., Brown, J., 2010. Inhibition of vasculogenesis, but not angiogenesis, prevents the recurrence of glioblastoma after irradiation in mice. The Journal of Clinical Investigation 120, 694-705.

Klussmann, J., Weissenborn, S., Wieland, U., 2003. Human papillomavirus-positive tonsillar carcinomas: A different tumor entity? Medical Microbiology and Immunology 192 (3), 129132.

Knupfer, H., Preiss, R., 2007. Significance of interleukin-6 (il-6) in breast cancer (review). Breast Cancer Research and Treatment 102 (2), 129-135.

Kofler, B., Laban, S., Busch, C., Lörincz, B., Knecht, R., 2014. New treatment strategies for hpvpositive head and neck cancer. European Archives of Oto-Rhino-Laryngology 271 (7), 18611867.

Kong, C.S., Narasimhan, B., Cao, H., Kwok, S., Erickson, J.P., Koong, A., Pourmand, N., Le, Q.T., 2009. The relationship between human papillomavirus status and other molecular prognostic markers in head and neck squamous cell carcinomas. International journal of radiation oncology, biology, physics 74 (2), 553-61.

Kowalska, M., Ratajczak, J., Hoxie, J., Brass, L., Gewirtz, A., Poncz, M., Ratajczak, M., 1999. Megakaryocyte precursors, megakaryocytes and platelets express the hiv co-receptor cxcr4 on their surface: Determination of response to stromal-derived factor-1 by megakaryocytes and platelets. British Journal of Haematology 104, 220-229.

Kowalski, L., Carvalho, A., 2001. Influence of time delay and clinical upstaging in the prognosis of head and neck cancer. oral oncology 37 (1), 94-98.

Kreimer, A., Clifford, G., Boyle, P., Franceschi, S., 2005. Human papillomavirus types in head and neck squamous cell carcinomas worldwide: A systematic review. Cancer Epidemiology Biomarkers Prevention 14, 467-475.

Kucia, M., 2005. Trafficking of normal stem cells and metastasis of cancer stem cells involve similar mechanisms: Pivotal role of the sdf-1-cxcr4 axis. Stem Cell 23 (7), 879-894.

Kucia, M., Jankowski, K., Reca, R., Wysoczynski, M., Bandura, L., Allendorf, D., Zhang, J., Ratajczak, J., Ratajczak, M., 2004. Cxcr4-sdf-1 signalling, locomotion, chemotaxis and adhesion. Journal of molecular Histology 35, 233-245.

Kuhne, M., Mulvey, T., Belanger, B., Chen, S., Pan, C., Chong, C., Niekro, W., Kempe, T., Henning, K., Cohen, L., Korman, A., Cardarelli, P., 2009. A fully human anti-cxcr4 antibody induces apoptosis in vitro and shows anti tumor activity in vivo. 100th AACR Annual Meeting Apr 18-22, Abstract LB. 
Kuhnt, T., Richter, C., Enke, H., Dunst, J., 1998. Acute radiation reaction and local control in breast cancer patients treated with postmastectomy radiotherapy. Strahlenther Onkol 174 (5), 257-61.

Kyzas, P., Cunha, I., Ioannidis, J., 2005. Prognostic significance of vascular endothelial growth factor immunohistochemical expression in head and neck squamous cell carcinoma: A metaanalysis. Clinical Cancer Research 11 (4), 1434-1440.

Langendijk, J., Psyrri, A., 2010. The prognostic significance of p16 overexpression in oropharyngeal squamous cell carcinoma: Implications for treatment strategies and future clinical studies. Annals of Oncology 21, 1931-1934.

Lassen, P., Eriksen, J.G., Hamilton-Dutoit, S., Tramm, T., Alsner, J., Overgaard, J., 2009. Effect of $\mathrm{hpv}$-associated p16ink4a expression on response to radiotherapy and survival in squamous cell carcinoma of the head and neck. Journal of clinical oncology : official journal of the American Society of Clinical Oncology 27 (12), 1992-8.

Lee, J., Jin, B., Kim, M., Yoon, H., Hong, S., Hong, S., 2009. Prognostic significance of cxcr-4 expression in oral squamous cell carcinoma. Oral Surgery, Oral Medicine, Oral Pathology, Oral Radiology and Endodontics 107, 678-684.

Leon, X., Quer, M., Orus, C., Del Prado Venegas, M., Lopez, M., 2000. Distant metastases in head and neck cancer patients who achieved loco-regional control. Head Neck 22 (7), 680-686.

Letian, T., Tianyu, Z., 2010. Cellular receptor binding and entry of human papillomavirus. Virology Journal 7, 1-7.

Li, H., Fan, X., Houghton, J., 2007. Tumor microenvironment: The role of the tumor stroma in cancer. Journal of Cellular Biochemistry 101, 805-815.

Li, W., Thompson, C., O'brien, C., 2003. Human papillomavirus positivity predicts favourable outcome for squamous carcinoma of the tonsil. International Journal of Cancer 106, 553-558.

Li, Y., Nichols, M., Shay, J., Xiong, Y., 1994. Transcriptional repression of the d-type cyclindependent kinase inhibitor p16 by the retinoblastoma susceptibility gene product prb. cancer Research 54 (23), 6078-6082.

Liang, J., Zhu, S., Bruggeman, R., Zaino, R., Evans, D., Fleming, J., Gomez, H., Zander, D., Wang, H., 2010. High levels of expression of human stromal cell-derived factor-1 are associated with worse prognosis in patients with stage ii pancreatic ductal adenocarcinoma. Cancer Epidemiology, Biomarkers \& Prevention 19 (10), 2598-2604.

Liang, Z., Brooks, J., Willard, M., Liang, K., Yoon, Y., Kang, S., Shim, H., 2007. Cxcr4/cxc112 axis promotes vegf-mediated tumor angiogenesis through akt signaling pathway. Biochemical and Biophysical Research Communications 359, 716-722.

Libura, J., Drukala, J., Majka, M., Tomescu, O., Navenot, J., Kucia, M., Marquez, L., Peiper, S., Barr, F., Janowska-Wieczorek, A., Ratajczak, M., 2002. Cxcr4-sdf-1 signaling is active in rhabdomyosarcoma cells and regulates locomotion, chemotaxis, and adhesion. Blood 100, 2597-2606. 
Lima, L., De Souza, L., Da Silva, T., Pereira, C., Guimarães, A., De Paula, A., De Andrade Carvalho, H., 2012. DNA repair gene excision repair cross complementing-group 1 (ercc1) in head and neck squamous cell carcinoma: Analysis of methylation and polymorphism (g19007a), protein expression and association with epidemiological and clinicopathological factors. Histopathology 60, 489-496.

Lindel, K., Beer, K., Laissue, J., Greiner, R., 2001. Human papillomavirus positive squamous cell carcinoma of the oropharynx: A radiosensitive subgroup of head and neck carcinoma. Cancer $92,805-813$.

Lindquist, D., Romanitan, M., Hammarstedt, L., 2007. Human papillomavirus is a favourable prognostic factor in tonsillar cancer and its oncogenic role is supported by the expression of e6 and e7. Molecular Oncology 1, 350-355.

Liotta, L., 2001. An attractive force in metastasis. Nature 410 (6824), 24-25.

Loetscher, M., Geiser, T., O'reilly, T., Zwahlen, R., Baggiolini, M., Moser, B., 1994. Cloning of a human seven-transmembrane domain receptor, lestr, that is highly expressed in leukocytes. The Journal of Biochemical Chemistry 269, 232-237.

Ludyga, N., Grunwald, B., Azimzadeh, O., Englert, S., Hofler, H., Tapio, S., Aubele, M., 2012. Nucleic acids from long-term preserved ffpe tissues are suitable for downstream analyses. Virchows Arch 460 (2), 131-40.

Ma, Q., Jones, D., Borghesani, P., Segal, R., Nagasawa, T., Kishimoto, T., Bronson, R., Springer, T., 1998. Impaired b-lymphopoiesis, myelopoiesis, and derailed cerebellar neuron migration in cxcr4- and sdf-1-deficient mice. Proceedings of the National Academy of Sciences USA 95, 9448-9453.

Mannarini, L., Kratochvil, V., Calabrese, L., Gomes Silva, L., Morbini, P., Betka, J., Benazzo, M., 2009. Human papilloma virus (hpv) in head and neck region: Review of literature. Acta otorhinolaryngologica Italica 29 (3), 119-126.

Marchesi, F., Monti, P., Leone, B., Zerbi, A., Vecchi, A., 2004. Increased survival, proliferation and migration in metastatic human pancreatic tumor cells expressing functional cxcr4. Cancer Research 64, 8420-8427.

Maréchal, R., Demetter, P., Nagy, N., Berton, A., Decaestecker, C., Polus, M., Closset, J., Devière, J., Salmon, I., Van Laethem, J., 2009. High expression of cxcr4 may predict poor survival in resected pancreatic adenocarcinoma. British Journal of Cancer 100 (9), 1444-1451.

Marur, S., D'souza, G., Westra, W., Forastiere, A., 2010. Hpv-associated head and neck cancer: A virus-related cancer epidemic. Lancet Oncology 11 (8), 781-789.

Matsuo, Y., Ochi1, N., Sawai, H., Yasuda, A., Takahashi, H., Funahashi, H., Takeyama, H., Tong, Z., Guha, S., 2009. Cxc18/il-8 and cxcl12/sdf-1 $\alpha$ co-operatively promote invasiveness and angiogenesis in pancreatic cancer. International Journal of Cancer 124, 853-861.

Mcgovern, S., Williams, M., Weber, R., 2010. Three synchronous hpv-associated squamous cell carcinomas of waldeyer's ring:Case report and comparison with slaughter's model of field cancerization. Head Neck 32, 1118-1124. 
Mehta, V., Yu, G., Schantz, S., 2010. Population-based analysis of oral and oropharyngeal carcinoma: Changing trends of histopathologic differentiation, survival and patient demographics. Laryngoscope 120 (11), 2203-2212.

Mellin Dahlstrand, H., Lindquist, D., Björnestål, L., Ohlsson, A., Dalianis, T., Munck-Wikland, E., Elmberger, G., 2005. P16(ink4a) correlates to human papillomavirus presence, response to radiotherapy and clinical outcome in tonsillar carcinoma. Anticancer Research 25 (6C), 43754383.

Miller, C., White, D., 1996. Human papillomavirus expression in oral mucosa, premalignant conditions, and squamous cell carcinoma: A retrospective review of the literature. Oral Surgery, Oral Medicine, Oral Pathology, Oral Radiology, Endodontics 82, 57-68.

Miller, C., Zeuss, M., Dk, W., 1994. Detection of hpv DNA in oral carcinoma using polymerase chain reaction together with in situ hybridization. Oral Surgery, Oral Medicine, Oral Pathology, Oral Radiology and Endodontics 77 (5), 480-486.

Mirghani, H., Amen, F., Blanchard, P., Moreau, F., Guigay, J., Hartl, D.M., Lacau St Guily, J., 2014. Treatment de-escalation in hpv-positive oropharyngeal carcinoma: Ongoing trials, critical issues and perspectives. International Journal of Cancer 136 (7), 1494-1503.

Motoyama, S., Ladines-Llave, C.A., 2004. The role of human papilloma virus in the molecular biology of cervical carcinogenesis. Kobe Journal of Medical Science 50 (1-2), 9-19.

Mueller, M., Fusenig, N., 2004. Friends or foes - bipolar effects of the tumour stroma in cancer. Nature Reviews Cancer 4 (11), 839-849.

Müller, A., Homey, B., Soto, H., Ge, N., Catron, D., E. Buchanan, M., Mcclanahan, T., Murphy, E., Yuan, W., N. Wagner, S., Barrera, J., Mohar, A., Verástegui, E., Zlotnik, A., 2001. Involvement of chemokine receptors in breast cancer metastasis. Nature 410, 50-56.

Muller, A., Sonkoly, E., Eulert, C., Gerber, P.A., Kubitza, R., Schirlau, K., Franken-Kunkel, P., Poremba, C., Snyderman, C., Klotz, L.O., Ruzicka, T., Bier, H., Zlotnik, A., Whiteside, T.L., Homey, B., Hoffmann, T.K., 2006. Chemokine receptors in head and neck cancer: Association with metastatic spread and regulation during chemotherapy. Int J Cancer 118 (9), 2147-57.

Murdoch, C., Monk, P., Finn, A., 1999a. Cxc chemokine receptor expression on human endothelial cells. Cytokine 11, 704-712.

Murdoch, C., Monk, P., Finn, A., 1999b. Functional expression of chemokine receptor cxcr4 on human epithelial cells. Immunology 98, 36-41.

Murphy, P., 2002. International union of pharmacology. Xxx. Update on chemokine receptor nomenclature. Pharmacological Reviews 54, 227-229.

Nagasawa, T., 2001. Role of chemokine sdf-1/pbsf and its receptor cxcr4 in blood vessel development. Annals of the New York Academy of Sciences 947, 112-115. 
Nagasawa, T., Hirota, S., Tachibana, K., Takakura, N., Nishikawa, S., Kitamura, Y., Yoshida, N., Kikutani, H., Kishimoto, T., 1996. Defects of b-cell lymphopoiesis and bone-marrow myelopoiesis in mice lacking the cxc chemokine pbsf/sdf-1. Nature 382, 635-638.

Nagasawa, T., Kikutani, H., Kishimoto, T., 1994. Molecular cloning and structure of a pre-b-cell growth-stimulating factor. Proceedings of the National Academy of Sciences USA 91, 23052309.

O’Harye, M., Salanga, C., Handel, T., Allen, S., 2008. Chemokines and cancer, migration, intracellular signaling and intercellular communication in the microenvironment. Biochemical Journal 409, 635-649.

O'regan, E., Toner, M., Sp, F., 2008. P16(ink4a) genetic and epigenetic profiles differ in relation to age and site in head and neck squamous cell carcinomas. Human Pathology 39, 452-458.

Ohira, S., Sasaki, M., Harada, K., Sato, Y., Zen, Y., Isse, K., 2006. Possible regulation of migration of intrahepatic cholangiocarcinoma cells by interaction of cxcr4 expressed in carcinoma cells with tumor necrosis factoralpha and stromal-derived factor-1 released in stroma. American Journal of Pathology 168, 1155-1168.

Oppegard, S., Blake, A., Williams, J., Eddington, D., 2010. Precise control over the oxygen conditions within the boyden chamber using a microfabricated insert. Lab on a Chip 10, 2366-2373.

Otsuka, S., Klimowicz, A., Kopciuk, K., Petrillo, S., Konno, M., Hao, D., Muzik, H., Stolte, E., Boland, W., Morris, D., Magliocco, A., Bebb, D., 2011. Cxcr4 overexpression is associated with poor outcome in females diagnosed with stage iv non-small cell lung cancer. Journal of Thoracic Oncology 6 (7), 1169-1178.

Ottaiano, A., Franco, R., Aiello Talamanca, A., Liguori, G., Tatangelo, F., Delrio, P., Nasti, G., Barletta, E., Facchini, G., Daniele, B., Di Blasi, A., Napolitano, M., Ieranò, C., Calemma, R., Leonardi, E., Albino, V., De Angelis, V., Falanga, M., Boccia, V., Capuozzo, M., Parisi, V., Botti, G., Castello, G., Vincenzo Iaffaioli, R., Scala, S., 2006. Overexpression of both cxc chemokine receptor 4 and vascular endothelial growth factor proteins predicts early distant relapse in stage ii-iii colorectal cancer patients. Clinical Cancer Research 12 (9), 2795-2803.

Ou, D.L., Chien, H.F., Chen, C.L., Lin, T.C., Lin, L.I., 2008. Role of twist in head and neck carcinoma with lymph node metastasis. Anticancer Res 28 (2B), 1355-9.

Paget, S., 1989. The distribution of secondary growths in cancer of the breast. Cancer and Metastasis Reviews 8 (2), 98-101.

Pai, S., Westra, W., 2009. Molecular pathology of head and neck cancer: Implications for diagnosis, prognosis, and treatment. Annual Review of Pathology 4, 49-70.

Parker, C., Kim, R., Li, B., Chu, Q., 2012. The chemokine receptor cxcr4 as a novel independent prognostic marker for node-positive breast cancer patients. Journal of Surgical Oncology 106 (4), 393-398.

Percherancier, Y., 2005. Bioluminescence resonance energy transfer reveals ligandinduced conformational changes in cxcr4 homo- and heterodimers. The Journal of Biological Chemistry 280 (11), 9895-9903. 
Perez-Ordonez, B., Beauchemin, M., Jordan, R., 2006. Molecular biology of squamous cell carcinoma of the head and neck. Journal of clinical pathology 59, 445-453.

Poeta, M., Manola, J., Goldwasser, M., Forastiere, A., Benoit, N., Califano, J., Ridge, J., Goodwin, J., Kenady, D., Saunders, J., Westra, W., Sidransky, D., Koch, W., 2007. Tp53 mutations and survival in squamous-cell carcinoma of the head and neck. The New England journal of medicine 357 (25), 2552-2561.

Polyak, K., Haviv, I., Campbell, I., 2009. Co-evolution of tumor cells and their microenvironment. Trends in Genetics 25 (1), 30-38.

Ponomaryov, T., Peled, A., Petit, I., Taichman, R., Habler, L., Sandbank, J., Arenzana-Seisdedos, F., Magerus, A., Caruz, A., 2000. Induction of the chemokine stromal-derived factor-i following DNA damage improves human stem cell function. The Journal of Clinical Investigation 106, 1331-1339.

Popple, A., Durrant, L., Spendlove, I., Rolland, P., Scott, I., Deen, S., Ramage, J., 2012. The chemokine, cxcl12, is an independent predictor of poor survival in ovarian cancer. British Journal of Cancer 106 (7), 1306-1313.

Posner, M., Lorch, J., Goloubeva, O., Tan, M., Schumaker, L., Sarlis, N., Haddad, R., Cullen, K., 2011. Survival and human papillomavirus in oropharynx cancer in tax 324: A subset analysis from an international phase iii trial. Annals of Oncology 22 (5), 1071-77.

Psyrri, A., Rampias, T., Vermorken, J.B., 2014. The current and future impact of human papillomavirus on treatment of squamous cell carcinoma of the head and neck. Ann Oncol.

Qian, F., Hanahan, D., Weissman, I., 2001. L-selectin can facilitate metastasis to lymph nodes in a transgenic mouse model of carcinogenesis. Proceedings of the National Academy of Sciences USA 98, 3976-3981.

Ragin, C., Taioli, E., 2007. Survival of squamous cell carcinoma of the head and neck in relation to human papillomavirus infection: Review and meta-analysis. International Journal of Cancer $121,1813-1820$.

Ramos, E., Grochoski, M., Braun-Prado, K., Seniski, G., Cavalli, I., Ribeiro, E., Camargo, A., Costa, F., Klassen, G., 2011. Epigenetic changes of cxcr4 and its ligand cxcl12 as prognostic factors for sporadic breast cancer. PLoS One 6 (12), e29461.

Ramsey, D.M., Mcalpine, S.R., 2013. Halting metastasis through cxcr4 inhibition. Bioorganic \& Medicinal Chemistry Letters 23 (1), 20-25.

Rangans, S., 1972. A new human cell line (fadu) from a hypopharyngeal carcinoma. Cancer 29 (1), $117-121$.

Rave-Frank, M., Virsik-Peuckert, P., Bertram, K., Schmidberger, M., 1996. Chromosome analysis in $\mathrm{x}$-irradiated primary cells of a human squamous cell carcinoma by fluorescence in situ hybridization. International Journal of Radiation Biology 69 (6), 695-700. 
Reimers, N., Kasper, H., Weissenborn, S., 2007. Combined analysis of hpv-DNA, p16 and egfr expression to predict prognosis in oropharyngeal cancer. International Journal of Cancer 120, $1731-1738$.

Rieckmann, T., Tribius, S., Grob, T.J., Meyer, F., Busch, C.J., Petersen, C., Dikomey, E., Kriegs, M., 2013. Hnscc cell lines positive for hpv and p16 possess higher cellular radiosensitivity due to an impaired dsb repair capacity. Radiotherapy and oncology : journal of the European Society for Therapeutic Radiology and Oncology 107 (2), 242-6.

Rietbergen, M., Leemans, C.R., Bloemena, E., Heideman, D., Braakhuis, B., 2013. Increasing prevalence rates of hpv attributable oropharyngeal squamous cell carcinomas in the netherlands as assessed by a validated test algorithm. International Journal of Cancer 132 (7), $1565-1571$.

Ringstrom, E., Peters, E., Hasegawa, M., Posner, M., Liu, M., Kelsey, K., 2002. Human papillomavirus type 16 and squamous cell carcinoma of the head and neck. Clinical Cancer Research 8 (10), 3187-3192.

Robledo, M., Bartolome, R., Longo, N., Rodríguez-Frade, J., Mellado, M., Longo, I., Van Muijen, G., Sánchez-Mateos, P., Teixidó, J., 2001. Expression of functional chemokine receptors cxcr3 and cxcr4 on human melanoma cells. The Journal of Biological Chemistry 276 (48), 4509845105 .

Romanitan, M., Näsman, A., Munck-Wikland, E., Dalianis, T., Ramqvist, T., 2013. Egfr and phosphorylated egfr in relation to hpv and clinical outcome in tonsillar cancer. Anticancer Research 33, 1575-1584.

Roux, P., Blenis, J., 2004. Erk and p38 mapk-activated protein kinases: A family of protein kinases with diverse biological functions. Microbiology and Molecular Biology Reviews 68, 320-344.

Roy, I., Zimmerman, N.P., Mackinnon, A.C., Tsai, S., Evans, D.B., Dwinell, M.B., 2014. Cxcl12 chemokine expression suppresses human pancreatic cancer growth and metastasis. PLoS One 9 (3), e90400.

Rubin, J., Kung, A., Klein, R., Chan, J., Sun, Y., Schmidt, K., 2003. A small-molecule antagonist of cxcr4 inhibits intracranial growth of primary brain tumors. PNAS 100, 13513-13518.

Rubin, P., Constine, L.R., Fajardo, L., Phillips, T., Wasserman, T., 1995. Eortc late effects working group. Overview of late effects normal tissues (lent) scoring system. Radiotherapy and Oncology 35 (1), $9-10$.

Salcedo, R., Oppenheim, J., 2003. Role of chemokines in angiogenesis: Cxcl12/sdf-1 and cxcr4 interaction, a key regulator of endothelial cell responses. Microcirculation 10, 359-370.

Salcedo, R., Wasserman, K., Young, H., 1999. Vascular endothelial growth factor and basic fibroblast growth factor induce expression of cxcr4 on human endothelial cells: In vivo neovascularization induced by stromal-derived factor-1alpha The American journal of pathology $154,1125-1135$.

Salmaggi, A., Gelati, M., Pollo, B., Marras, C., Silvani, A., Balestrini, M., Eoli, M., Fariselli, L., Broggi, G., Boiardi, A., 2005. Cxcl12 expression is predictive of a shorter time to tumor 
progression in low-grade glioma: A single-institution study in 50 patients. Journal of NeuroOncology 74 (3), 287-293.

Sambrook, J., Fritsch, E.F., Maniatis, T., 1989. Molecular cloning-a laboratory manual. 2nd ed. Cold Spring Habour Laboratory Press.

Sand, L., Jalouli, J., Larsson, P., Hirsch, J., 2000. Human papillomaviruses in oral lesions. Anticancer Research 20, 1183-1188.

Sanderson, R., Ironside, J., 2002. Squamous cell carcinomas of the head and neck. British Medical Journal 325, 822-827.

Sano, T., Oyama T, Kashiwabara, K., 1998. Expression status of p16 protein is associated with human papillomavirus oncogenic potential in cervical and genital lesions. American Journal of Pathology 153, 1741-1748.

Sasaki, K., Natsugoe, S., Ishigami, S., Matsumoto, M., Okumura, H., Setoyama, T., Uchikado, Y., Kita, Y., Tamotsu, K., Sakurai, T., Owaki, T., Aikou, T., 2008. Expression of cxcl12 and its receptor cxcr4 correlates with lymph node metastasis in submucosal esophageal cancer. Journal of Surgical Oncology 97, 433-438.

Sayed, S., Dwivedi, R., Katna, R., Garg, A., Pathak, K., 2011. Implications of understanding cancer stem cell (csc) biology in head and neck squamous cell cancer. Oral oncology 47, 237-243.

Schier, A., 2003. Chemokine signaling: Rules of attraction. Current Biology 13, R192-R194.

Schiffman, M., Castle, P., Jeronimo, J., Rodriguez, A., Wacholder, S., 2007. Human papillomavirus and cervical cancer. Lancet 370, 890-907.

Schols, D., Struyf, S., Van Damme, J., Esté, J., Henson, G., De Clercq, E., 1997. Inhibition of t-tropic hiv strains by selective antagonization of the chemokine receptor cxcr4. The journal of experimental medicine $186(8), 1383-1388$.

Schrader, A., Lechner, O., Templin, M., Dittmar, K., Machtens, S., Mengel, M., 2002. Cxcr4/cxc112 expression and signalling in kidney cancer. British Journal of Cancer 86, 1250-1256.

Shah, N.G., Trivedi, T.I., Tankshali, R.A., Goswami, J.V., Jetly, D.H., Shukla, S.N., Shah, P.M., Verma, R.J., 2009. Prognostic significance of molecular markers in oral squamous cell carcinoma: A multivariate analysis. Head \& neck 31 (12), 1544-56.

Shirozu, M., Nakano, T., Inazawa, J., Tashiro, K., Tada, H., Shinohara, T., Honjo, T., 1995. Structure and chromosomal localization of the human stromal cell-derived factor 1(sdf-1) gene. Genomics 28, 495-500.

Silva, P., Homer, J., Slevin, N., Musgrove, B., Sloan, P., Price, P., West, C., 2007. Clinical and biological factors affecting response to radiotherapy in patients with head and neck cancer: A review. official journal of ENT-UK ; official journal of Netherlands Society for Oto-RhinoLaryngology \& Cervico-Facial Surgery 32, 337-345. 
Singh, S., Sadanandam, A., Singh, P., 2007. Chemokine in tumor angiogenesis and metastasis. Cancer Metastasis Reviews 26, 453-467.

Smith, E., Hoffman, H., Summersgill, K., 1998. Human papillomavirus and risk of oral cancer. Laryngoscope 108, 1098-1103.

Smith, M., Luker, K., Garbow, J., Prior, J., Jackson, E., Piwnica-Worms, D., Luker, G., 2004. Cxcr4 regulates growth of both primary and metastatic breast cancer. Cancer Research 64, 86048612 .

Sobin, L., Compton, C., 2010. Tnm seventh edition: What's new, what's changed: Communication from the international union against cancer and the american joint committee on cancer. Cancer 116, 5336-5339.

Specht, K., Richter, T., Muller, U., Walch, A., Werner, M., Hofler, H., 2001. Quantitative gene expression analysis in microdissected archival formalin-fixed and paraffin-embedded tumor tissue. American Journal of Pathology 158, 419-429.

Sporn, M., 1996. The war on cancer. Lancet 347, 1377-1381.

Strati, K., Lambert, P., 2007. Role of rb-dependent and rb-independent functions of papillomavirus e7 oncogene in head and neck cancer. Cancer Research 67, 11585-11593.

Szlosarek, P., Charles, K., Balkwill, F., 2006. Tumour necrosis factor-alpha as a tumour promoter. European Journal of Cancer 42 (6), 745-750.

Tachibana, K., Hirota, S., Iitasa, H., Yoshida, H., Kawabata, K., Kataoka, Y., Kitamura, Y., 1998. The chemokine receptors cxcr4 is essential for vascularization of the gastrointestinal tract. Nature 393, 591-604.

Taichman, R., Cooper, C., Keller, E., Pienta, K., Taichman, N., Mccauley, L., 2002. Use of the stromal cell-derived factor-1/cxcr4 pathway in prostate cancer metastasis to bone. Cancer Research 62 (6), 1832-1837.

Taki, M., Higashikawa, K., Yoneda, S., Ono, S., Shigeishi, H., Nagayama, M., Kamata, N., 2008. Upregulation of stromal cell-derived factor-1alpha and its receptor cxcr4 expression accompanied with epithelial-mesenchymal transition in human oral squamous cell carcinoma. Oncol Rep 19 (4), 993-8.

Tashiro, K., Tada, H., Heilker, R., Shirozu, M., Nakano, T., Honjo, T., 1993. Signal sequence trap: A cloning strategy for secreted proteins and type i membrane proteins. Science 261, 600-603.

Tehrany, N., Kitz, J., Rave-Fränk, M., Lorenzen, S., Li, L., Küffer, S., Hess, C., Burfeind, P., Reichardt, H., Canis, M., Beißbarth, T., Wolff, H., 2015. High-grade acute organ toxicity and p16(ink4a) expression as positive prognostic factors in primary radio(chemo)therapy for patients with head and neck squamous cell carcinoma. Strahlentherapie und Onkologie DOI:10.1007/s00066-014-0801-3.

Termine, N., 2008. Hpv in oral squamous cell carcinoma vs. Head and neck squamous cell carcinoma biopsies: A meta-analysis (1988-2007). Annals of Oncology 19 (10), 1681-1690. 
Todd, R., Hinds, P., Munger, K., 2002. Cell cycle dysregulation in oral cancer. Oral Biology \& Medicine 13 (1), 51-61.

Trinchieri, G., 2012. Cancer and inflammation: An old intuition with rapidly evolving new concepts. Annual review of immunology 30, 677-706.

Trotti, A., Byhardt, R., Stetz, J., 2000. Common toxicity criteria: Version 2.0. An improved reference for grading the acute effects of cancer treatment: Impact on radiotherapy. International Journal of Radiation Oncology Biology Physics 47 (1), 13 - 47.

Trotti, A., Colevas, A., Setser, A., Rusch, V., Jaques, D., Budach, V., Langer, C., Murphy, B., Cumberlin, R., Coleman, C., Rubin, P., 2003. Ctcae v3.0: Development of a comprehensive grading system for the adverse effects of cancer treatment. Seminars in Radiation Oncology $13(3), 176-181$.

Tse, J., Kalluri, R., 2007. Mechanisms of metastasis: Epithelial-to-mesenchymal transition and contribution of tumor microenvironment. Journal of Cellular Biochemistry 101 (4), 816-829.

Uchida, D., Onoue, T., Kuribayashi, N., 2010. Blockade of cxcr4 in oral squamous cell carcinoma inhibits lymph node metastases. European Journal of Cancer 47 (3), 452-459.

Uchida, D., Onoue, T., Tomizuka, Y., 2007. Involvement of an autocrine stromal cell derived factor$1 /$ cxcr4 system on the distant metastasis of human oral squamous cell carcinoma. Molecular cancer research 5, 685-694.

Ueda, M., Shimada, T., Goto, Y., Tei, K., Nakai, S., Hisa, Y., Kannagi, R., 2010. Expression of ccchemokine receptor 7 (ccr7) and cxc-chemokine receptor 4 (cxcr4) in head and neck squamous cell carcinoma. Auris Nasus Larynx 37 (4), 488-95.

Ulus-Senguloglu, G., 2012. Artemis over-expression and radiosensitivity in human cell lines. PhD thesis.

Valastyan, S., Weinberg, R., 2011. Tumor metastasis: Molecular insights and evolving paradigms. Cell 147, 275-292.

Van Houten, V., Tabor, M., Van Den Brekel, M., Kummer, J., Denkers, F., Dijkstra, J., Leemans, R., Van Der Waal, I., Snow, G., Brakenhoff, R., 2002. Mutated p53 as a molecular marker for the diagnosis of head and neck cancer. The Journal of Pathology 198, 476-486.

Villa, L., 2006. Chapter 1: Biology of genital human papillomaviruses. International Journal of Gynecology \& Obstetrics 94 (1), 3-7.

Volin, M., Joseph, L., Shockley, M., Davies, P., 1998. Chemokine receptor cxcr4 expression in endothelium. Biochemical and Biophysical Research Communications 242, 46-53.

Wagner, P., Hyjek, E., Vazquez, M., Meherally, D., Liu, Y., Chadwick, P., Rengifo, T., Sica, G., Port, J., Lee, P., Paul, S., Altorki, N., Saqi, A., 2009. Cxcl12 and cxcr4 in adenocarcinoma of the lung: Association with metastasis and survival. The Journal of Thoracic and Cardiovascular Surgery 137 (3), 615-621. 
Wang, J., Liu, Z., Groopman, J., 1998. The alpha-chemokine receptor cxcr4 is expressed on the megakaryocytic lineage from progenitor to platelets and modulates migration and adhesion. Blood 72, 756-764.

Wang, M., Chen, G., Song, H., Hong, X., Yang, Z., Sui, G., 2011. Significance of cxcr4, phosphorylated stat3 and vegf-a expression in resected non-small cell lung cancer. Experimental and Therapeutic Medicine 2 (3), 517-522.

Weinberger, P.M., Yu, Z., Haffty, B.G., Kowalski, D., Harigopal, M., Brandsma, J., Sasaki, C., Joe, J., Camp, R.L., Rimm, D.L., Psyrri, A., 2006. Molecular classification identifies a subset of human papillomavirus--associated oropharyngeal cancers with favorable prognosis. Journal of clinical oncology : official journal of the American Society of Clinical Oncology 24 (5), 736 47.

Wiest, T., Schwarz, E., Enders, C., Flechtenmacher, C., Bosch, F., 2002. Involvement of intact hpv16 e6/e7 gene expression in head and neck cancer with unaltered p53 status and perturbed prb cell cycle control. Oncogene 21, 1510-1517.

Williams, C., Ponte'N, F., Moberg, C., Söderkvist, P., Uhlen, M., Ponten, J., Sitbon, G., Lundeberg, J., 1999. A high frequency of sequence alterations is due to formalin fixation of archival specimens. American Journal of Pathology 155 (5), 1467-1471.

Williams, S.A., Harata-Lee, Y., Comerford, I., Anderson, R.L., Smyth, M.J., Mccoll, S.R., 2010. Multiple functions of cxcl12 in a syngeneic model of breast cancer. Molecular cancer 9, 250.

Wilson, V.G., West, M., Woytek, K., Rangasamy, D., 2002. Papillomavirus e1 proteins: Form, function, and features. Virus Genes 24 (3), 275-290.

Wolff, H., Bosch, J., Jung, K., Overbeck, T., Hennies, S., Mattias, C., Hess, C., Roedel, R., Christiansen, H., 2010a. High-grade acute organ toxicity as positive prognostic factor in primary radio(chemo)therapy for locally advanced, inoperable head and neck cancer. Strahlentherapie und Onkologie 186, 262-268.

Wolff, H., Rolke, D., Rave-Frank, M., Schirmer, M., Eicheler, W., Doerfler, A., Hille, A., Hess, C., Matthias, C., Rödel, R., Cristiansen, H., 2011a. Analysis of chemokine and chemokine receptor expression in squamous cell carcinoma of the head and neck (scchn) cell lines. Radiation and Environmental Biophysics 50 (1), 145-154.

Wolff, H.A., Daldrup, B., Jung, K., Overbeck, T., Hennies, S., Matthias, C., Hess, C.F., Roedel, R.M., Christiansen, H., 2011b. High-grade acute organ toxicity as positive prognostic factor in adjuvant radiation and chemotherapy for locally advanced head and neck cancer. Radiology 258 (3), 864-71.

Wolff, H.A., Gaedcke, J., Jung, K., Hermann, R.M., Rothe, H., Schirmer, M., Liersch, T., Herrmann, M.K., Hennies, S., Rave-Frank, M., Hess, C.F., Christiansen, H., 2010b. High-grade acute organ toxicity during preoperative radiochemotherapy as positive predictor for complete histopathologic tumor regression in multimodal treatment of locally advanced rectal cancer. Strahlenther Onkol 186 (1), 30-5.

Wolff, H.A., Raus, I., Jung, K., Schuler, P., Herrmann, M.K., Hennies, S., Vorwerk, H., Hille, A., Hess, C.F., Christiansen, H., 2010c. High-grade acute organ toxicity as a positive prognostic 
factor in primary radiochemotherapy for anal carcinoma. Int J Radiat Oncol Biol Phys 79 (5), 1467-78.

Wong, R., Bodart, V., Metz, M., Labrecque, J., Bridger, G., Fricker, S., 2008. Comparison of the potential multiple binding modes of bicyclam, monocylam, and noncyclam small-molecule cxc chemokine receptor 4 inhibitors. Molecular Pharmacology 74 (6), 1485-1495.

Wong, S., Hynes, R., 2006. Lymphatic or hematogenous dissemination: How does a metastatic tumor cell decide? Cell Cycle 5 (8), 812-817.

Worden, F., Kumar, B., Lee, J., Wolf, G., Cordell, K., Taylor, J., Urba, S., Eisbruch, A., Teknos, T., Chepeha, D., Prince, M., Tsien, C., D'silva, N., Yang, K., Kurnit, D., Mason, H., Miller, T., Wallace, N., Bradford, C., Carey, T., 2008. Chemoselection as a strategy for organ preservation in advanced oropharynx cancer: Response and survival positively associated with hpv16 copy number. Journal of Clinical Oncology 26 (19), 3138-3146.

Wu, Y., Jin, M., Xu, H., Shimin, Z., He, S., Wang, L., Zhang, Y., 2010. Clinicopathologic significance of hif- $1 \alpha$, cxcr4, and vegf expression in colon cancer. Clinical and Developmental Immunology 2010, pii: 537531.

Xia, J., Chen, N., Hong, Y., Chen, X., Tao, X., Cheng, B., Huang, Y., 2011. Expressions of cxcl12/cxcr4 in oral premalignant and malignant lesions. Mediators of Inflammation 2012.

Xu, Q., Gao, Y., Liu, Y., Yang, W., Xu, X., 2008. Identification of differential gene expression profiles of radioresistant lung cancer cell line established by fractionated ionizing radiation in vitro. Chinese medical journal 121 (18), 1830-1837.

Yeo, E., Chun, Y., Park, J., 2004. New anticancer strategies targeting hif-1. Biochemical Pharmacology 68 (6), 1061-1069.

Yoon, Y., Liang, Z., Zhang, X., 2007. Cxc chemokine receptor-4 antagonist blocks both growth of primary tumor and metastasis of head and neck cancer in xenograft mouse models. Cancer Research 67, 7518-7524.

Yopp, A., Shia, J., Butte, J., Allen, P., Fong, Y., Jarnagin, W., Dematteo, R., D'angelica, M., 2012. Cxcr4 expression predicts patient outcome and recurrence patterns after hepatic resection for colorectal liver metastases. Annals of Surgical Oncology 19 (suppl 3), 339-346.

Yoshitake, N., Fukui, H., Yamagishi, H., Sekikawa, A., Fujii, S., Tomita, S., Ichikawa, K., Imura, J., Hiraishi, H., Fujimori, T., 2008. Expression of sdf-1 alpha and nuclear cxcr4 predicts lymph node metastasis in colorectal cancer. British Journal of Cancer 98 (10), 1682-1689.

Young, R., Rischin, D., Fisher, R., Mcarthur, G., Fox, S., Peters, L., Corry, J., Lim, A., Waldeck, K., Solomon, B., 2011. Relationship between epidermal growth factor receptor status, p16ink4a, and outcome in head and neck squamous cell carcinoma. Cancer Epidemiology, Biomarkers \& Prevention 20 (6), 1230-1237.

Yu, L., Cecil, J., Peng, S., Schrementi, J., Kovacevic, S., Paul, D., Su, E., Wang, J., 2006. Identification and expression of novel isoforms of human stromal cell-derived factor 1 . Gene 374, 174-179. 
Bibliography

Zernecke, A., Schober, A., Bot, I., Von Hundelshausen, P., Liehn, E., Mopps, B., Mericskay, M., Gierschik, P., Biessen, E., Weber, C., 2005. Sdf-1 $\alpha /$ cxcr4 axis is instrumental in neointimal hyperplasia and recruitment of smooth muscle progenitor cells. Circulation Research 96, 784791.

Zhang, L., Ye, S., Ma, G., Tang, X., Chen, S., He, J., Liu, W., Xie, D., Zeng, Y., Li, J., 2013. The expressions of mif and cxcr4 protein in tumor microenvironment are adverse prognostic factors in patients with esophageal squamous cell carcinoma. Journal of Translational Medicine 11, 60.

Zhang, W., Navenot, J., Haribabu, B., Tamamura, H., Hiramatu, K., Omagari, A., 2002. A point mutation that confers constitutive activity to cxcr4 reveals that 1140 is an inverse agonist and that amd 3100 and alx40-4c are weak partial agonists. The Journal of Biological Chemistry $277,24515-24521$.

Zhao, N., Ang, M., Yin, X., Patel, M., Fritchie, K., Thorne, L., 2012. Different cellular p16(ink4a) localisation may signal different survival outcomes in head and neck cancer. British Journal of Cancer 107, 482-490.

Zhou, Y., Larsen, P., Hao, C., Yong, V., 2002. Cxcr4 is a major chemokine receptor on glioma cells and mediates their survival. The Journal of Biological Chemistry 277, 49481-49487.

Zigrino, P., Löffek, S., Mauch, C., 2005. Tumor-stroma interactions: Their role in the control of tumor cell invasion. Biochimie 87, 321-328.

Zlotnik, A., 2004. Chemokines in neoplastic progression. Seminars in Cancer Biology 14 (3), 181-185.

Zlotnik, A., 2008. New insights on the role of cxcr4 in cancer metastasis. The journal of pathology 215, 211-213.

Zlotnik, A., Yoshie, O., 2000. Chemokines: A new classification system and their role in immunity. Immunity 2, 121-127.

Zou, Y., Kottmann, A., Koruda, M., Taniuchi, I., Littman, D., 1998. Function of the chemokine receptor cxcr4 in haematopoiesis and in cerebellar development. Nature 393, 595-599.

Zur Hausen, H., 2006. Papillomavirus infections: A major cause of human cancer, in infections causing human cancer Wiley-VCH, p145-243, Weinheim. 


\section{Personal Information}

Name: $\quad$ Narges Tehrany

Address: $\quad$ Schlözerweg 9, 37085 Göttingen

Date of birth: $\quad 22$ January 1982 (Teheran, Iran)

Nationality: $\quad$ Iranian

\section{Education}

March 2013-August 2015 PhD Student of “molecular medicine program”, University Medical Centre Göttingen, Germany

January 2012-March 2013 employed in the department of Radiotherapy and Radiation Oncology. University Medical Centre Göttingen, Germany

2007-2011

Diplom in Microbiology, Georg-August University of Göttingen, Germany

$1999-2004$

BSc in Microbiology, Azad University of Teheran, Iran

1999-2002

associated degree in Laboratory Science, Paramedical Faculty Tehran University, Iran

\section{Publication}

Narges Tehrany, Julia Kitz, Margret Rave-Fränk, Stephan Lorenzen, Li Li, Stefan Küffer, Clemens F. Hess, Peter Burfeind, Holger M. Reichardt, Martin Canis, Tim Beißbarth, Hendrik A. Wolff. "High-grade acute organ toxicity and $\mathrm{p} 16^{\mathrm{INK} 4 \mathrm{~A}}$ expression as positive prognostic factors in primary radio(chemo)therapy for patients with head and neck squamous cell carcinoma”. Strahlentherapie und Onkologie, 2015; DOI 10.1007/s00066-014-0801-3 